\title{
Universiteit
}

Leiden

The Netherlands

\section{Conflict and cooperation within an organization: a case study of the metropolitan water district of Southern California}

Zetland, D.J.

\section{Citation}

Zetland, D. J. (2008, April 24). Conflict and cooperation within an organization: a case study of the metropolitan water district of Southern California. Retrieved from

https://hdl.handle.net/1887/3213779

Version: $\quad$ Not Applicable (or Unknown)

License: $\quad$ Licence agreement concerning inclusion of doctoral thesis in the

Institutional Repository of the University of Leiden

Downloaded from: https://hdl.handle.net/1887/3213779

Note: To cite this publication please use the final published version (if applicable). 


\section{DAVID JASON ZETLAND}

B.A. (University of California, Los Angeles) 1991

M.S. (University of California, Davis) 2003

\section{DISSERTATION}

Submitted in partial satisfaction of the requirements for the degree of

\section{DOCTOR OF PHILOSOPHY}

in

Agricultural and Resource Economics

in the

OFFICE OF GRADUATE STUDIES

of the

\section{UNIVERSITY OF CALIFORNIA}

\section{DAVIS}
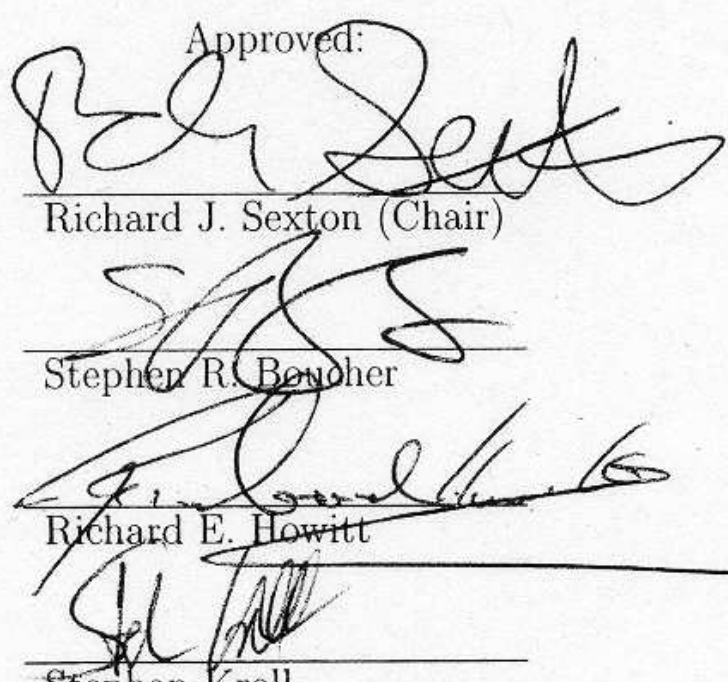

Stephan Kroll

Committee in Charge 



\section{Abstract}

Back in 1995, one member of a water cooperative announced it was going to buy water from an "outside" source. Other members of the cooperative did not like this idea, and a dispute broke out. After lawsuits, lobbying and lopsided votes, peace of a sort was bought with 235 million dollars of taxpayer money and intense political pressure. Why did this dispute happen? Was it exceptional or typical? Is it possible that cooperative members are not cooperative? These questions are intrinsically interesting to students of collective action, but they are more significant with this cooperative: The Metropolitan Water District of Southern California (MET) is one of the world's largest water utilities, supplying water to 18 million people.

In this dissertation, a case study of MET, I answer these questions and explain how the 1995 dispute had roots in deeper problems. The story has three analytical threads: The first traces MET as a case-history; the second models institutional structure and incentives within a public corporation; the third bridges the two: linking empirical history and actions at MET to theoretical predictions of models.

The story goes as follows: MET's cooperative structure worked well when water was abundant and costs were subsidized for most members. When supply fell and demand rose, water grew scarce. Since the rules governing the management of water did not change to reflect this scarcity, water continued to be treated as a club good when it should have been treated as a private good. Because MET did not change its policies for allocating water (take as much as you need, at a fixed price, no matter where it is delivered), inefficiency increased. Arguments over the policies increased inefficiency even further.

According to Hart and Moore (1996), cooperatives are efficient (relative to firms) when members have reasonably homogenous preferences. Taking the high correlation between characteristics and preferences for granted, I quantify heterogeneity among members through their dependency on MET for water, and their heterogeneous dependencies imply that they will also have heterogeneous preferences on policies, e.g., how much storage to build.

The dependency result violates Hart and Moore's necessary and sufficient condition of "reasonable homogeneity," but they had assumed self-interested members were managing scarce goods (i.e., goods with excess demand at a price of zero). Relaxing these assumptions allows for the possibility that social preferences, (i.e., treating others as yourself or maximizing group welfare) or abundance (i.e., having so much water that the use of one member is not rival to another) might result in MET being an efficient cooperative - even with members that have heterogeneous preferences.

Social preferences are tested using eco- 
nomic experiments in which water managers and comparison groups of undergraduate students play public goods games. Although the experimental results indicate that managers are relatively more cooperative than students, they do not achieve an absolute level of cooperation consistent with social preferences. This result - in combination with the historical fact that MET water stopped being abundant after the 1960sleads us to dismiss the possibility that cooperation or abundance could overcome heterogeneous preferences. MET may have been efficient in the 1960s, but it is not today.

So, how is MET inefficient? MET's pricing policies are inefficient in multiple ways: MET fixes prices in the year before they take effect; charges the same price for delivery anywhere (postage stamp prices); and mixes fixed and variable costs into one price. Put differently, MET's prices are inefficient because they are based on average costnot marginal cost. MET is also inefficient because its cooperative structure is not conducive to settling disputes among members; conflicts over policies are decided by median vote, which dissipates the surplus.

Can we measure inefficiency? Perhaps some member agencies get more value from water than others? Perhaps MET water is more valuable than local water? The presence of these effects (or similar effects) would violate a basic definition of economic efficiency - equality of marginal benefit. I use 60 years of panel data to measure the impact of water supply on assessed land values. The results support inefficiency:
MET water is more or equally valuable; dependency of MET lowers property values for cities; and member-agencies post-1994 (post-drought) land values change by different amounts.

How can MET improve efficiency? I outline how MET can use internal auctions to allocate water and conveyance among member agencies - reducing conflict over allocation, increasing efficiency and generating useful price signals. Even better, auctions can complement equity by allocating marginal water and conveyance left after inframarginal water and conveyance are allocated on a per capita ("lifeline") basis. I also describe results from experimental auctions with water managers and students that show how managers suffer from stronger endowment effects in a buy-sell auction but are more competitive in a bidonly auction.

This dissertation is intrinsically important as a case study of one of the world's largest water utilities, but it also contains "interesting features" that can be expanded upon or used elsewhere. Dependency can be used to quantify bargaining power among (or within) other organizations; the experimental quantification of cooperation among MET's member agency managers can guide other attempts to understand bureaucrats; the estimate of the impact of water on urban land values appears to be the first of its kind; and - finally - the combination of percapita allocation of inframarginal water and auction for marginal water seems to deliver a nice compromise between equity and efficiency that could be used in many settings. 


\section{Contents}

List of Tables $\quad$ vii

List of Figures $\quad$ ix

Glossary xii

Acknowledgements $\quad$ xiii

1 Introduction 1

1.1 Themes in Water . . . . . . . . . . . . . . . . . 2

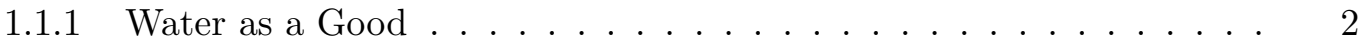

1.1.2 Water as a Human Right . . . . . . . . . . . . . . . 2

1.1.3 Water as a Tool for Growth . . . . . . . . . . . . . . . . 3

1.1.4 Water as a Public Service . . . . . . . . . . . . . . 3

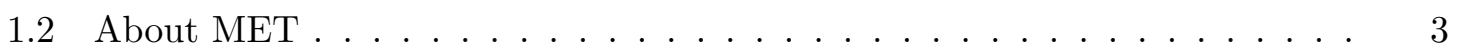

1.3 The Wheeling Dispute . . . . . . . . . . . . . . . 4

1.3.1 MET Rejects an Offer . . . . . . . . . . . . . . . . 4

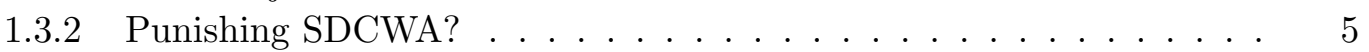

1.3.3 Resolution ...................... 6

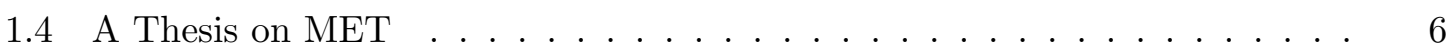

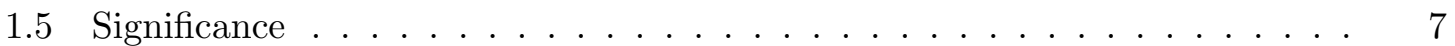

1.6 Dissertation Overview . . . . . . . . . . . . . . . 8

2 MET Today $\quad 11$

2.1 Cooperative Structure . . . . . . . . . . . . . . . . . . 11

2.1.1 Governance and Oversight . . . . . . . . . . . . . . 11

2.1 .2 What Is MET's Mission? . . . . . . . . . . . . . . . . 13

2.2 Water Supplies . . . . . . . . . . . . . . . . . . . . . . 14

2.2.1 Costs of MET Water . . . . . . . . . . . . . . . . . . . 14

2.3 Revenue Structure . . . . . . . . . . . . . . . . . . . 15

2.3 .1 Rate Classes . . . . . . . . . . . . . . . . 17

2.3.2 Prices and Equilibrium . . . . . . . . . . . . . . 18

2.3.3 Efficient Pricing . . . . . . . . . . . . . . . . . . . . 20

2.4 Demand Management . . . . . . . . . . . . . . . . . 20

2.4 .1 Elasticity . . . . . . . . . . . . . . . . . 21 
2.4.2 Preferential Rights . . . . . . . . . . . . . . . . . . . 21

2.4 .3 Purchase Orders . . . . . . . . . . . . . . . . . 23

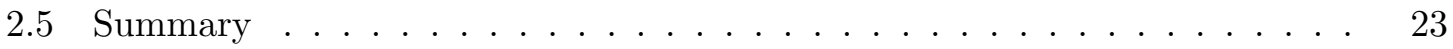

3 MET's History $\quad 25$

3.1 LA Sets the Stage . . . . . . . . . . . . . . . . 25

3.2 From Power to MET . . . . . . . . . . . . . . . . . 26

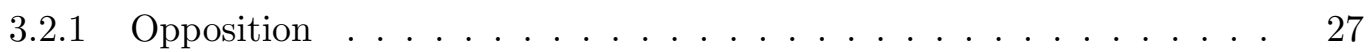

3.2 .2 Add Water . . . . . . . . . . . . . . . 27

3.2 .3 Bids for Hoover Power . . . . . . . . . . . . . . . . . . . . . . . . . . . . . . . . . 28

3.2.4 Colorado River Aqueduct . . . . . . . . . . . . . . . . . . 28

3.3 Dumping Water . . . . . . . . . . . . . . . . 28

3.3.1 Miscalculating Demand . . . . . . . . . . . . . . . . . . . . . . . . . . . . . 30

3.3 .2 Cross-Subsidies . . . . . . . . . . . . . . . . . . . . . . . . . . . . .

3.3.3 Free Riding and Expansion . . . . . . . . . . . . . . . 31

3.3.4 SDCWA to the Rescue? . . . . . . . . . . . . . . . . . 31

3.4 Glory Years . . . . . . . . . . . . . . . . . . . . . . 32

3.5 Irrational Los Angeles? . . . . . . . . . . . . . . . . . . . . . . . . . . . 34

3.6 The End of Abundance . . . . . . . . . . . . . . . . 36

3.7 Changes in Supplies . . . . . . . . . . . . . . . . . . . . . . . . . . . . . . .

3.7.1 The Colorado River . . . . . . . . . . . . . . . . . . . 36

3.7 .2 The State Water Project . . . . . . . . . . . . . . . . . 37

3.8 Changes in Demand . . . . . . . . . . . . . . . . . . . . . 39

3.9 Changes in Votes . . . . . . . . . . . . . . . . . . . . . . . . . 40

3.10 Changes in Culture . . . . . . . . . . . . . . . . . 41

3.11 Changes in Cost . . . . . . . . . . . . . . . . . . . 42

3.12 The Big Drought . . . . . . . . . . . . . . . . . 43

3.13 SDCWA Defects . . . . . . . . . . . . . . . . . 45

3.14 Barriers to Change . . . . . . . . . . . . . . . . . . . . . 45

3.14 .1 Monopoly Power . . . . . . . . . . . . . . . . . 47

3.14 .2 Principal-Agent Problems . . . . . . . . . . . . . . . 47

3.14 .3 Agricultural Water . . . . . . . . . . . . . . . . . . . . . . . . 47

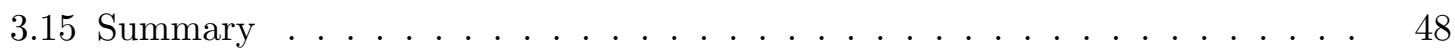

4 Analysis of Efficiency at MET $\quad 49$

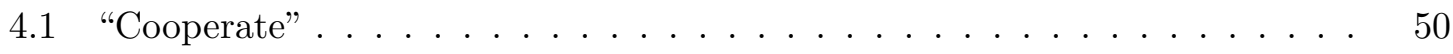

4.1 .1 Type, Preference \& Action . . . . . . . . . . . . . . . 50

4.1.2 Organization, Game \& Outcome . . . . . . . . . . . . . . 51

4.2 Efficient Form . . . . . . . . . . . . . . . . . . . . . 52

4.2.1 Efficient Cooperatives . . . . . . . . . . . . . . . . . 52

4.2 .2 Social or Selfish . . . . . . . . . . . . . . . . . 54

4.2 .3 Abundant or Scarce . . . . . . . . . . . . . . . . . 55

4.2.4 Homo- or Heterogeneous . . . . . . . . . . . . . . . . 55

4.2 .5 Forms of Inefficiency . . . . . . . . . . . . . . . . . 56

4.3 Making Decisions . . . . . . . . . . . . . . . 57 
4.3.1 Causes of Conflict . . . . . . . . . . . . . . 58

4.3 .2 Examples of Conflict . . . . . . . . . . . . . . . 58

4.4 Inefficient Allocation . . . . . . . . . . . . . . . . . . . 59

4.4 .1 Ramsey and Tier Prices . . . . . . . . . . . . . . . . 59

4.4 .2 Postage Stamp Pricing . . . . . . . . . . . . . . . . 60

4.4 .3 Setting Prices for Next Year . . . . . . . . . . . . . . . . . 62

4.4 Total Cost Control . . . . . . . . . . . . . . . . . . . 62

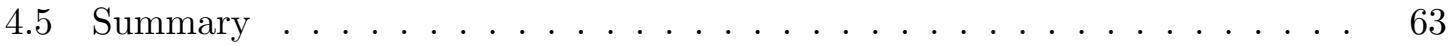

5 Experiments in Cooperation $\quad \mathbf{6 5}$

5.1 How Experiments Work . . . . . . . . . . . . . . . 66

5.1 .1 Cooperation Games . . . . . . . . . . . . . 66

5.1 .2 Experimental Validity . . . . . . . . . . . . . . . . . . . 67

5.1 .3 Internal Validity . . . . . . . . . . . . . . . . . . . 68

5.1 .4 External Validity . . . . . . . . . . . . . . . . . . 68

$5.2 \quad$ Experimental Design . . . . . . . . . . . . . . . . . . . . . 69

5.2 .1 Determining Type . . . . . . . . . . . . . . . . . 71

5.2 .2 Group Cooperation . . . . . . . . . . . . . . . . . . . . . . 72

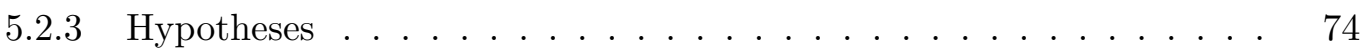

5.2 .4 Session Details . . . . . . . . . . . . . . . . 74

5.3 Results . . . . . . . . . . . . . . . . . . . 74

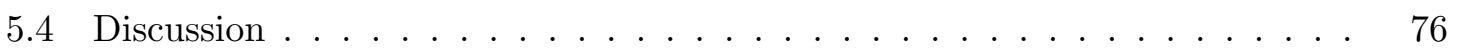

5.4 .1 Statistical Significance . . . . . . . . . . . . . . . . . 76

5.4 .2 Quadratic Form . . . . . . . . . . . . . . . . . . 78

5.4 .3 Tobit Model . . . . . . . . . . . . . . . . . . . 79

5.4 .4 Application to MET . . . . . . . . . . . . . . . . 79

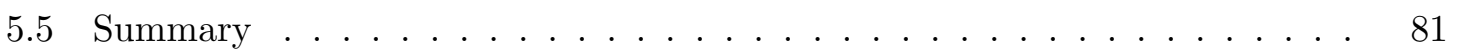

6 Testing for Impacts of Water Misallocation $\quad \mathbf{8 3}$

6.1 Theoretical Model . . . . . . . . . . . . . . . . 83

6.2 Potential Problems . . . . . . . . . . . . . . . . . 85

6.3 Data . . . . . . . . . . . . . . . . 86

6.3 .1 Assessed Value . . . . . . . . . . . . . . . . 86

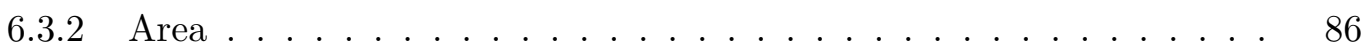

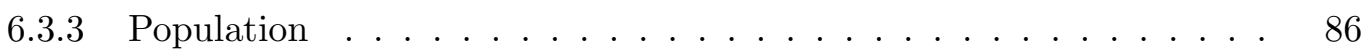

6.3.4 Water ....................... 87

6.3 .5 Land Use . . . . . . . . . . . . . . . . . . . . . . 87

6.4 Econometric Model . . . . . . . . . . . . . . . . . . . 88

6.5 Results . . . . . . . . . . . . . . . . . . . . . . . . . . . . . . . . . 89

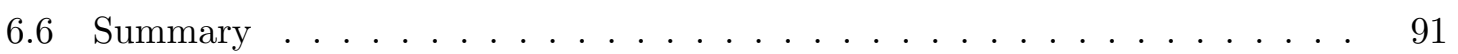

7 Experiments with Auctions $\quad 95$

7.1 Markets and Auctions . . . . . . . . . . . . . . . . . . 95

7.1 .1 Auctions . . . . . . . . . . . . . . . . 96

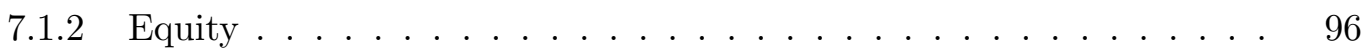




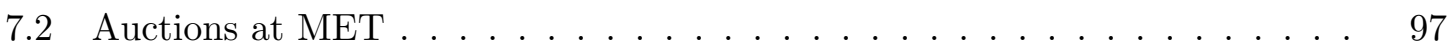

$7.2 .1 \quad$ Price Volatility . . . . . . . . . . . . . . . . . 98

7.2.2 Profits from Auctions . . . . . . . . . . . . . . . . 99

7.3 Experimental Design . . . . . . . . . . . . . . . . . . 100

7.3.1 G2-Buy-Sell Auction . . . . . . . . . . . . . . . . . . . 101

7.3.2 G3-Bid-Only Auction . . . . . . . . . . . . . . . 101

7.3.3 Hypotheses . . . . . . . . . . . . . . . . . . . . . . 101

7.3 .4 Session Details . . . . . . . . . . . . . . . . . 104

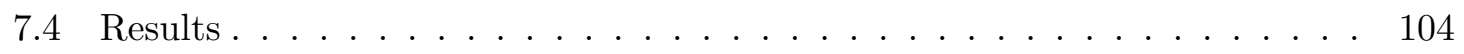

7.5 Discussion . . . . . . . . . . . . . . . . . . . . . . . . . . . . . . . . . . . . . . . .

7.6 Summary . . . . . . . . . . . . . . . . . . . . . 109

8 Conclusion $\quad 111$

$\begin{array}{ll}\text { Appendices } & 115\end{array}$

$\begin{array}{ll}\text { A Instructions for Cooperation Game } & 117\end{array}$

A.1 Experimenter Procedures . . . . . . . . . . . . . . . . . 117

A.2 Instructions for Session . . . . . . . . . . . . . . . . 118

A.3 Instructions for G1 . . . . . . . . . . . . . . . . . . . . . . 119

A.4 Questionnaire . . . . . . . . . . . . . . . 120

$\begin{array}{ll}\text { B Regression Output } & 121\end{array}$

C Instructions for Auction Games $\quad \mathbf{1 2 5}$

C.1 Experimenter Procedure . . . . . . . . . . . . . . . . . . . . 125

C.2 Instructions for $\mathrm{G} 2 / \mathrm{G} 3 \ldots \ldots \ldots \ldots \ldots \ldots \ldots \ldots$

C.3 Instructions for $\mathrm{G} 2 \ldots \ldots \ldots \ldots \ldots \ldots \ldots$

C.4 Instructions for G3 . . . . . . . . . . . . . . . . . 127

D Notes on Data Sources 129

D.1 Final Data-Tables . . . . . . . . . . . . . . . . . . . . . . 129

D.2 Final Data-Figures . . . . . . . . . . . . . . . . . . . 130

D.3 Processed Data Files . . . . . . . . . . . . . . . . . . . 131

$\begin{array}{ll}\text { References } & 135\end{array}$

$\begin{array}{ll}\text { Author and Subject Indices } & 151\end{array}$ 


\section{List of Tables}

2.1 Characteristics of MET's 26 member agencies . . . . . . . . . . . . . . . . 12

2.2 Sources, costs and quantities of MET's water supplies $\ldots \ldots \ldots \ldots$

2.3 MET's water rates . . . . . . . . . . . . . . . . . . 18

3.1 Contracts for power from the Hoover Dam . . . . . . . . . . . . . . . 29

3.2 MET's initial sales were below projections . . . . . . . . . . . . . . . 31

3.3 MET's Chairmen of the Board . . . . . . . . . . . . . . . . 33

3.4 MET's general managers change from engineers to lawyers . . . . . . . . . . 42

3.5 Water deliveries in the drought years . . . . . . . . . . . . . . 44

4.1 Member agency dependency . . . . . . . . . . . . . . . . . 57

5.1 Details of water manager sessions . . . . . . . . . . . . . . 75

5.2 Descriptive statistics of experimental subjects _ . . . . . . . . . 75

5.3 Subject types and group efficiency . . . . . . . . . . . . . . . . 77

5.4 Average Trust Index values . . . . . . . . . . . . . . . . . . . 77

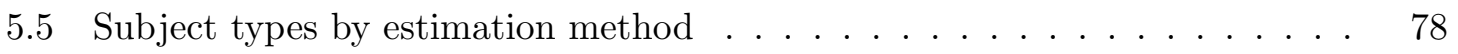

6.1 Correcting MET's accounting for groundwater delivery . . . . . . . . . . 88

6.2 Comparing econometric models for goodness-of-fit . . . . . . . . . . 89

6.3 The effects of water supply on assessed value . . . . . . . . . . . . . 91

6.4 Post-drought shifts in AV for cities . . . . . . . . . . . . . . . . 92

6.5 Post-drought shifts in AV for MWDs . . . . . . . . . . . . . . . . 92

7.1 Descriptive statistics of participants . . . . . . . . . . . . . 105

7.2 Player counts, induced demands and unit supplies . . . . . . . . . . . 105

7.3 Auction efficiency improved with experience . . . . . . . . . . . . 106

B.1 Cross-sectional time-series FGLS regression results for Cities . . . . . . . . 122

B.2 Cross-sectional time-series FGLS regression results for MWDs . . . . . . 123

Table data sources are in Appendix D.1 . . . . . . . . . . . . . . 129 



\section{List of Figures}

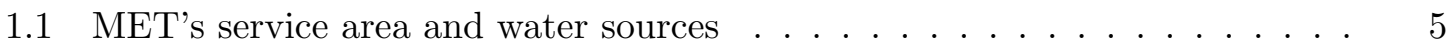

2.1 MET supplies a rising share of regional water . . . . . . . . . . . . . . 15

2.2 Stylized supply curves for MET . . . . . . . . . . . . . . . 16

2.3 MET estimates supply and demand, sets prices and hopes for $E$. . . . . 19

2.4 Water prices rise steeply after the $87-91$ drought $\ldots \ldots \ldots$. . . . . . . 22

3.1 MET did not use all its Hoover power rights until 1960 . . . . . . . . . . 29

3.2 New member agencies are responsible for MET's increase in area . . . . . . 33

3.3 Historical supply to MET from CRA and SWP . . . . . . . . . . . . 37

3.4 MET's CRA entitlement rises and falls . . . . . . . . . . . . . . 38

3.5 MET's SWP rights are stable but deliveries vary . . . . . . . . . . . . . . 39

3.6 Per capita water use rises and falls . . . . . . . . . . . . . . . . 40

3.7 Los Angeles' share of assessed value falls over time . . . . . . . . . . . . . . 41

3.8 MET's revenue mix changed over the years . . . . . . . . . . . . . . 44

3.9 LADWP buys much more water in the $87-91$ drought . . . . . . . . . . 46

3.10 SDCWA only buys a little more water in the $87-91$ drought . . . . . . . . 46

5.1 Screenshot from cooperation game . . . . . . . . . . . . . . . 71

5.2 Sample panels for subjects typed as cooperators and free-riders . . . . . . 73

5.3 Sample panels for subjects typed as reciprocators . . . . . . . . . . . . 73

5.4 Only MAM cooperation was higher than average student cooperation . . . 76

5.5 Average types from linear characterization of students. . . . . . . . . . . 77

5.6 Average types from quadratic characterization of subjects . . . . . . . 79

6.1 Assessed values broke from their trends in $1994 \ldots \ldots$. . . . . . . . . 90

7.1 Induced value demand curve for a ten-person auction . . . . . . . . . . . . 102

7.2 Screenshot from G2 (buy-sell auction) . . . . . . . . . . . . . . . 102

7.3 Screenshot from G3 (bid-only auction) . . . . . . . . . . . . . . 103

7.4 Water manager and student auction efficiencies . . . . . . . . . . . 106

7.5 Students sometimes overbid . . . . . . . . . . . . . . . 108

7.6 Most students (and all water managers) did not overbid . . . . . . . . . 108

Figure data sources are in Appendix D.2 f . . . . . . . . . . . . . . . 130 



\section{Glossary}

AAC All-American Canal. Runs from Imperial Dam to IID.

AF acre-foot. The volume of water sufficient to cover one acre (approximately 0.4 ha) of area to one foot deep $(0.3 \mathrm{~m})$. One AF of water contains 325,851 gallons $\left(1,234 \mathrm{~m}^{3}\right)$. In California, 4 or 5 people might use one AF per year.

AR annual report. AR60 means MET's annual report for FYE60.

AV assessed value. The value of land used to determine property taxes.

BCP Boulder Canyon Project. A group of water projects approved and funded in the 1930s.

CEO Chief Executive Officer.

CFO Chief Financial Officer.

cfs cubic feet per second. A measure of volumetric flow rate equivalent to a volume of one cubic foot of water flowing past a point every second.

CRA Colorado River Aqueduct. Runs from Parker Dam to MET's service area.

CWA California Water Agencies. Organization representing investor-owned (private) utilities. "CWAs" are people from CWA who participated in experiments in Chapters 5 and 7.

DWR Department of Water Resources. California's DWR manages the SWP.

FYE fiscal year ended. MET's fiscal year begins on July 1 and ends on June 30, e.g., FYE78 ends June 301978.

GM General Manager. Both MET and member agencies have GMs - see also MAM.

IID Imperial Irrigation District.

KH Kurzban and Houser (2005). Inspired the experiment in Chapter 5.

$\mathrm{kWh}$ kilowatt hour. Hairdryers and microwaves use about one $\mathrm{kW}$ per hour.

LA City of Los Angeles. Also used in place of LADWP. 
LADWP Los Angeles Department of Water and Power. LADWP is a city member agency of MET.

$\operatorname{MAF}(\mathrm{Y})$ millions of AF (per year).

MAM Member Agency Manager. The GM of a member agency. "MAMs" are GMs who participated in experiments in Chapters 5 and 7.

MET Metropolitan Water District of Southern California. MET is usually called "MWD," but "MET" is used to avoid confusion with "Municipal Water Districts." "METs" are MET executives who participated in experiments in Chapters 5 and 7.

MWD Municipal Water District. A regional water entity that wholesales water to other water entities. MET has two types of member agency-MWDs and (retail) cities.

MWDOC MWD of Orange County. MWDOC is a MWD member agency of MET.

PGG public goods game. The cooperation game played in Chapter 5 is a PGG.

PRs preferential rights.

PSP postage stamp pricing. MET's pricing method (same price for delivery everywhere) described in Chapter 2.

PtB Price to Beat. The minimum accepted price in the bid-only auction (Game 3) in Chapter 7 .

RHS right-hand side. RHS variables are on the right side of the equal sign in an equation.

SCE Southern California Edison. SCE is an investor-owned power company.

SDCWA San Diego County Water Authority. SDCWA is a MWD member agency of MET.

SWP State Water Project. SWP infrastructure moves water from the Sacramento/San Joaquin Delta to Southern California and is managed by DWR. (Central Valley Project infrastructure is run by the Bureau of Reclamation and does not supply water to MET.)

TAF $(Y)$ thousands of AF (per year).

UG Undergraduates. Students at UC Davis who participated in experiments in Chapters 5 and 7 . 


\section{Acknowledgements}

It took a village to bring this dissertation to a conclusion, and I want to thank as many villagers as possible.

My advisors were amazing. Richard (Howitt) inspired me to look deeper into water issues. (He told me about the Wheeling dispute.) In the five-plus years that we have worked together, Richard has been consistently enthusiastic and helpful - even while trying to rein in my tendencies to spin off in too many directions, offend with my ranting and be my own worst enemy. I am lucky to get so much time from a man who can't say no to yet another project. Rich Sexton was truly the chair of this committee, and he lived up to and beyond my expectations of what a chair, adviser and friend would be capable of. Not only did I learn the nuances of many tedious details from Rich (Sentence fragments!), but I also got a lot of big-picture advice that helped me grow as an economist and researcher. Rich's focus kept me on track; his patience with my goals and ideas got me to where I wanted to go. Steve has been amazing throughout. He persisted with relevant advice in the face of my inability to deal with first-order conditions, made original points on material outside his field and was there when I needed him. (Well, his office is right next to the coffee room, so maybe that was involuntary ().) He better get tenure, dammit! Stephan came late to the game, but he has been really great to work with, given a lot of attention to the material and helped me when
I was stuck. Now that I write these words, I realize how difficult it is for words words words to capture my regard for these guys. The bottom line is that I am even more glad to be working with them now than when I began.

I also want to acknowledge the amazing help and cooperation that I got from all the "water buffaloes" I worked with - and I say WB with good intentions! First in line comes Tim Quinn, who gave me an early start with his enthusiasm and introductions. Next come Kevin Hunt, Gil Ivey, and Jeff Kightlinger - who not only made the experiments happen (getting on the agenda is important!), but also gave me valuable support. Brian Thomas was an excellent source of fast and clear information. I also want to thank Steve Arakawa, Kathy Cole, Steve Erie, Jack Hawk, Gordon Hess, Tim O'Halloran, Sara Jacobs, David Pettijohn, Chris Scheuring, Karl Seckel, Deven Upadhyay, Margie Wheeler, and many members of the MET staff for their conversations, insights, gossip and data files. Half of this dissertation (at least) is due to your efforts and support.

Moving back to the academics, I want to thank Michael Hanemann for his enthusiastic support, instant and amazing feedback and helpful conversations on water in California. I am really looking forward to working with him next year. Also at Cal, I want to thank Linda Vida and the WRCA staff for their helpful support (in- 
cluding travel money!) and interest in this research. Thank god for librarians!

My experiments reflect the help of many: Rob Kurzban and Dan Houser's cooperation game (and their advice on how to use it) was invaluable. Kristi Hansen and Stephan Kroll gave me a leg up on the auctions design in zTree. I also want to thank the experimental community: Urs Fischbacker for writing zTree; the folks at CalTech for CASSEL; the X-Lab for lending me laptops (thanks Bob, Lawrence and Brenda!); the ztree and ESA mailing list participants who were patient with my newbie questions; and Jim Murphy, Charlie Plott, Robin Pope, and Bart Wilson for coming through at critical moments. Aslıhan and Carlo provided excellent research support (Carlo was so good, he designed himself out of a job!) I also want to acknowledge critical funding through the A. P. Giannini Foundation and Jastro Shields Research Award.

I also thank all of my experimental participants: 162 UC Davis students, 13 people at the CWA, 15 water managers at MET and 14 MET executives and staff. Again, you made a big part of this dissertation (well, Chapters 5 and 7) possible.

Ranging a bit further afield, I want to acknowledge the advocates of craft: Edward Tufte on design, Deidre McKlosky on communication, and very, very important: Donald Knuth - the creator of TEX. This dissertation was typeset in $\mathrm{AT}_{\mathrm{E}} \mathrm{X}$ using Jabref, MikTeX and WinEdt. It would have taken far more work and been far uglier if not for the craftspeople who wrote these programs.

At UC Davis, I want to thank Aaron Smith and Jeffrey Williams for reading and commenting on my prospectus, Mark
Lubbell and Richard Green for attending my orals, Jay Lund for insights into the engineering side of water.

I want to thank and acknowledge many grad students at Davis. Those who stand out are Carlo, Tar, Gorm, Henry, Chris, Matthew, and Kristi for their helpful discussions. Special thanks to the "last minute shock crew" for last minute flash-proofing: Aslıhan, Duncan M., Lisa B., Antoine (I'll get to those comments one day), Ricardo, Teddy and Chris. I also want to thank my officemates over the years for putting up with my noise (I get a commission from headphone manufacturers, you know...)

And, finally, we move to the personal thanks to those who kept me going over the years: Sandra (you are wonderful), Sue (my best friend), DPG (my alterhippie), D'Arcy and Cleide (bon vivants), Henry (great roomie even for a Canadian!), and - finally-Aslıhan. Aslihanthanks for being such a great person in my life, continuing to surprise me with your thoughtfulness, shame me with your consideration, and favor me with your love.

To my father, I thank you for being a wonderful refuge when times were tough (and were they ever!), telling me stories and listening to me rant and rave about optimal water allocation. You are a good block to chip off of!

I dedicate this work to my mother, who died just over 20 years ago. She is responsible for who I am today (good and bad-she wouldn't have minded), and the source of my passion for life. She taught me the most important lesson: "People do the best they can." 
The reformer has all those who benefit from the old order as enemies, and he has lukewarm defenders in all those who might benefit from the new orders.

- Machiavelli (1532) 



\section{Chapter 1}

\section{Introduction}

"Water is a gift from God." - Argentine State's Attorney

"Yes, but he forgot to lay the pipes." - Olivier Barbaroux of Vivendi ${ }^{1}$

This dissertation is about a public cooperative, the Metropolitan Water District of Southern California (MET), and it began with a story of rent-seeking inside the organization. In the short version of the story, one member of MET (San Diego County Water Authority, or SDCWA) wanted to move water it bought from farmers using MET's pipes. The other members thought that SDCWA should pay a lot to move (wheel) the water. SDCWA disagreed, and they ended up in court. Why were cooperative members not being so cooperative?

The quick economic answer is that selfinterested parties fight over spoils, but quick is not quite satisfying. Why were these members in a cooperative? Had they always fought? Was SDCWA getting robbed? Don't public servants just work these things out?

This dissertation shows that water managers are mostly selfish; organizations can be inefficient for decades; SDCWA has benefitted from membership in MET; and mismanagement creates many of California's water supply problems. In all cases, these answers match or contradict economic theory in interesting ways. These results are augmented by qualitative discussions of bigger themes: conflict and cooperation inside organizations; the benefits of utilities; the influence of professional culture on ideas and decisions; and the irrelevance of market forces within a bureaucracy.

The central question is whether MET is efficient, and the robust answer is no. MET is inefficient because its structure as a cooperative (rather than as a firm) makes it harder for member agencies with different interests to agree on a single set of goals. The explanation for these answers begins in Chapter 2-a description of MET - and moves to Chapter 3, which gives MET's history. Chapter 4 links MET's current form and history into an analysis of MET's efficiency as a cooperative and how MET's policies and conflict over those policies increase inefficiency at MET. When policies started to matter, the differences among MET's member agencies grew more relevant, and inefficiency - from conflict among members and misallocation of water and costs - increased. Chapters 5 and 6 contribute empirical support to this analysis. Although MET is inefficient, it does not need to be privatized or shut down-

\footnotetext{
${ }^{1}$ Quotation taken from Tagliabue (2002).
} 
Chapter 7 describes how MET could use internal auctions to allocate water among its member agencies in a way that is both efficient and equitable.

The sections ahead give a brief description of MET (previewing Chapter 2) and a detailed description of SDCWA's wheeling dispute. Sections 1.4 and 1.5 state the thesis and significance of this dissertation, and Section 1.6 previews other chapters. But first, let's take a quick glance at the many ways that people (economists and non-economists) see water.

\subsection{Themes in Water}

Economists have been interested in water ever since Adam Smith puzzled over the "diamond-water paradox" in 1776: Why, he wondered, is (precious) water cheap while (unimportant) diamonds are expensive? It was only with the arrival of the Marginal Revolution nearly a century later that economists could explain how the first unit of water is valuable but the last unit (of many) is not. For non-economists, water is more than a commodity: It is a human right, a tool for growth and prosperity, a public asset that should be managed by public organizations. Note that some definitions clash, e.g., human right versus commodity; any water management scheme must consider these conflicts.

\subsubsection{Water as a Good}

Managing water as if it is abundant, when it is scarce, leads to shortage, misallocation and inefficiency. The key part of this observation is "as if," which suggests that water can be one type of good or another. The literature on natural resources (e.g., Ostrom et al. (1994) and Dietz et al. (2003)) defines a good by its properties and property rights, i.e., a rival good diminishes with use; access to an excludable is restricted. These two characteristics combine to determine the mechanism for efficiently managing the good. Private goods are both rival and excludable; public goods are neither. A rival but non-excludable good is a common-pool good, e.g., an aquifer that many farmers tap, but none control. Club goods are non-rival but excludable, e.g., an uncrowded swimming pool available only to club members.

Water can be any one of these goods - a private good when consumed, a public good when different qualities mix in pipes, a club good when abundant but guarded, and a common-pool good when access is open but quantity is limited.

Note that a club good is similar to a private good with excess supply, i.e., supply greater than demand at a zero price. ${ }^{2}$ In both cases, non-rivalry or excess supply can end: Club goods become rival with congestion; excess supply ends when supply is less than demand at a price of zero. Although there is no need to manage demand with abundance, the end of abundance can lead to problems if institutions of abundance do not change to ration demand when there is congestion or excess demand at zero prices (Ciriacy-Wantrup and Bishop, 1975).

\subsubsection{Water as a Human Right}

For some, treating water as a commodity to be bought and sold is scandalous (Polanyi, 1944). Denying someone water because they have no money would be unethical. While this point is true - and all economists would agree that water should be free in those circumstances - not all water should be free. If it is, demand will exceed supply for both high and low-value uses. If non-price rationing is used, and water will not be allocated to highest and best

\footnotetext{
${ }^{2}$ Club goods can have a positive price, but the cost of their provision is often covered by membership fees, i.e., the price of overcoming exclusion.
} 
uses. A compromise would give everyone some water and allocate the rest with price, (i.e., the inframarginal and marginal allocation described in Chapter 7).

Unfortunately, the conventional means of allocating water is to set price equal to average cost so that everyone pays the same price, and revenues just cover costs. Because this method makes water cheap at the margin, it encourages cheap-water lifestyles (pools, landscaping, etc.) that "harden" demand at levels that are hard to reduce in shortage, when price increases do not reduce quantity demanded.

\subsubsection{Water as a Tool for Growth}

When new service areas (e.g., housing developments) join existing water distribution systems, they pay for meters and connection fees, but these costs rarely reflect the marginal cost of water and infrastructure.

Older areas pay more and get lower reliability, and the resulting overdevelopment is inefficient. ${ }^{3}$ Inefficient does not mean unpopular: Mayors and water managers say that restrictions on water supply would stop growth, and the end of growth is the end of prosperity (Rake, 2006), and many voters agree (Folz, 1965; Czech, 2000). Those who question cheap-water-driven growth (Hirshleifer and Milliman, 1967; Graff, 1985; Gottlieb and FitzSimmons, 1991) are ignored.

\subsubsection{Water as a Public Service}

There is no clear consensus in the theoretical economic literature favoring public over private utilities: Vining and Boardman (1992) argue in favor of public ownership while Shleifer (1998) argues against it. Wilson (1989), Gleick et al. (2002) and
Chakravorty et al. (2004) claim that oversight, governance and competition are more important than ownership. The empirical literature on utilities is similarly divided: Kwoka (2005) finds that private electricity utilities are more efficient at power generation, and public companies are better at customer service. (This advantage disappears with size.) Economist Staff (2003) report that state water utilities are relatively costly and inefficient in the UK. Wallsten and Kosec (2005) find that competition is more important than ownership in water system efficiency.

Most of this discussion is moot: Public organizations supply over 80 percent of California's residential water, and MET never would have existed as a private organization (see Section 3.2.2).

\subsection{About MET}

The California Legislature authorized MET as a public corporation, but its backers were water utilities that would buy MET's water. Given that MET and these utilities would make big fixed investments in each other, MET was configured as a cooperative: MET would be unable to use its market power to extract rents from its consumers, and they - as members of the cooperative - would not support competition to MET or hesitate to make big investments.

Today, MET is a cooperative of 26 member agencies. Fourteen are municipallyowned, retail water utilities; twelve are Municipal Water Districts (MWDs) that wholesale water to about 230 retail agencies within their service areas. Member agencies serve a total population of over eighteen million Southern Californians. According to

\footnotetext{
${ }^{3}$ Although expansion may allow increasing economies of scale from central waterworks, it brings diseconomies for expanding infrastructure. Even if net economies of scale are positive, they always turn negative at some point (in water), and politicians, developers and engineers are unlikely to stop development before the inflection point - making overexpansion likely.
} 
Brian Thomas (MET's CFO), MET is the largest water utility in the United States by population served and treated water delivery (Thomas, 2007a).

Most of MET's water comes from the Colorado River (via the Colorado River Aqueduct, or CRA) and Sacramento-San Joaquin Delta (via the California Aqueduct of the State Water Project, or SWP). Figure 1.1 shows the physical location of MET and these sources. For most of its member agencies, MET is the sole supplier of imported water. ${ }^{4}$

\subsection{The Wheeling Dispute}

One of MET's member agencies, the San Diego County Water Authority (SDCWA), decided to circumvent MET's "monopoly" on imported water by purchasing water from the Imperial Irrigation District (IID). Since SDCWA had no pipeline to IID, it needed to use the CRA to wheel (move) the water from IID. MET's other member agencies wanted SDCWA to pay more for wheeling that SDCWA offered. This section describes their fight over that price (the wheeling dispute) - a fight that almost tore MET apart.

SDCWA, MET's biggest member agency by sales, suffered during the 1987-91 drought. In response, SDCWA started negotiating to buy water from IID to the east of San Diego county (see Figure 1.1). Their 1995 deal specified that SDCWA would pay about $\$ 250$ per acre-foot (AF) for IID's water. Deliveries would start at 10,000 acrefeet per year (TAFY) and rise over a 20 year phase-in to 300 TAFY. ${ }^{5}$ SDCWA needed to take delivery of IID water and hoped to pay $\$ 97 / \mathrm{AF}$ - the marginal cost of using the CRA. In support of this price, SDCWA cited Section 1812 of the State Water Act, which "prevents public agencies from denying bona fide transferors of water access to a water conveyance facility, which in fact has unused capacity, during the time such capacity is unused, so long as 'fair compensation' is paid by the transferor" (Sofaer, 1997, p. 18).

\subsubsection{MET Rejects an Offer}

SDCWA's \$97/AF offer did not seem like "fair compensation" to MET's other member agencies. They wanted $\$ 250 / \mathrm{AF}$. Why so much? Although SDCWA's purchase from IID would increase supply in the region (benefitting all agencies), members were worried that SDCWA's action was a "water grab," would circumvent MET's Board of Directors, and drive up their costs.

After a 1984 ruling that IID was wasting water, MET and IID made a deal in 1988: MET would fund conservation in exchange for 100 TAFY of saved water (State Water Resources Control Board, 1984). ${ }^{6}$ Since IID's waste was estimated to be 300 TAFY, this deal left "water on the table" that - according to someMET claimed (Colorado River Board of CA, 1992). When IID wanted to sell more water after the 87-91 drought, MET was not interested, but SDCWA was. Some saw SDCWA's deal with IID as a water grab - an intrusion into MET's territory. SDCWA went around MET to approach legislators in Sacramento in an effort to secure an "artificially low" wheeling charge of $\$ 97 / \mathrm{AF}$. According to Tim Quinn (MET's VP of State Water Project Resources until 2007), SDCWA only agreed to pay IID $\$ 250 / \mathrm{AF}$ for the water because IID promised the $\$ 97 / \mathrm{AF}$ wheeling rate (2006c). Because MET recovers the fixed costs of its facilities in the price

\footnotetext{
${ }^{4}$ The important exception to this monopoly is the Los Angeles Aqueduct, which has brought water to Los Angeles since 1913.

${ }^{5}$ In the five years to 2004, MET delivered an average of 630 TAFY to SDCWA.

${ }^{6}$ DeHaven and Hirshleifer (1957) suggested that IID should sell water to cities.
} 


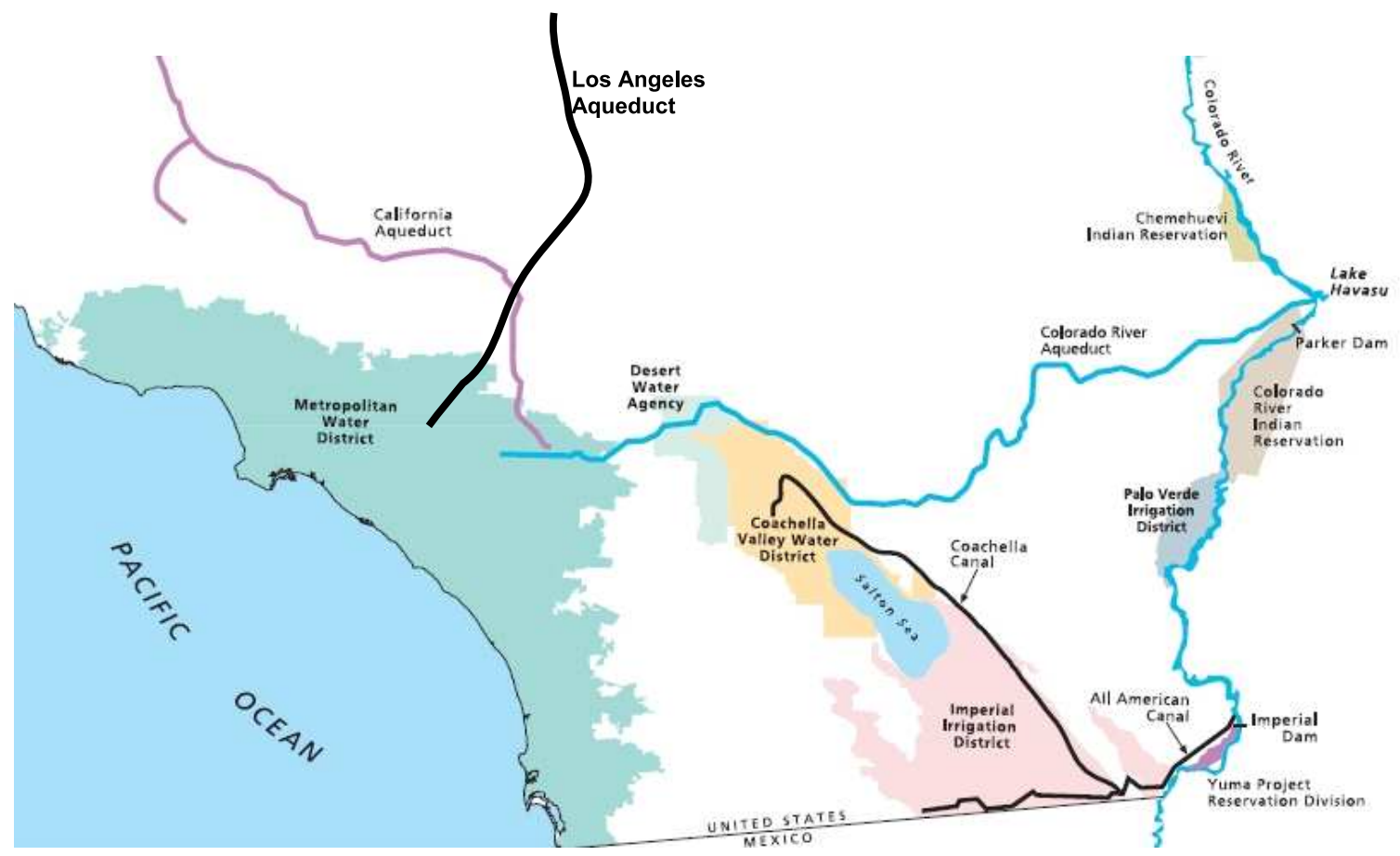

Figure 1.1: MET's service area and water sources

of its water, SDCWA's use of MET's facilities to move IID water threatened to shift some fixed costs to other member agencies (MET, 2004a).

MET and other member agencies reacted to SDCWA's triple affront by invoking MET's long-standing tradition of postage stamp pricing (PSP), i.e., charging SDCWA a pro-rata share of MET's entire system costs: ${ }^{7}$

The proposed rates would recover Metropolitan's reasonable costs for the use of its transportation system, including all committed, unavoidable costs in order to avoid financial harm to other Metropolitan member agencies... The proposed rate for firm wheeling is $\$ 262$ per acre foot.

$$
\text { -MET (1997b, p. 2) }
$$

\subsubsection{Punishing SDCWA?}

Member agencies voted 25-1 to impose PSP on SDCWA in 1997. If the IID deal increased marginal costs by less than PSP, those member agencies were voting to be subsidized by SDCWA (MET, 1997a). ${ }^{8}$ Why?

\footnotetext{
${ }^{7}$ Note that PSP does not mean the average cost of moving water but the average cost of MET's system, i.e., total cost (debt, power, overhead, etc) divided by total AF wheeled in the year.

${ }^{8}$ Say MET has total costs of $T C$ (including $V C$ as the variable cost of wheeling water) and moves $X$ units of water at a price equal to average cost $(p=a=T C / X)$. If SDCWA brings one more unit into the system, and the marginal cost of moving that unit is $m<a$, charging $p$ to move that unit results in revenue of $p(X+1)$ that exceeds total costs of $T C+m . \quad(m<a$ when surplus conveyance capacity exists, and it did.) To maintain the zero-profit constraint requires a lower $p$, which benefits all member agencies. (In the long-run, cooperatives have zero-profits, but they are non-profit - retaining profits for investment without distributing profits - in the short run.)
} 
First, they rejected the figure of $\$ 97 / \mathrm{AF}$ : According to MET (1997b), the marginal cost of using the CRA was $\$ 116 / \mathrm{AF}$. Second, even at $\$ 116 / \mathrm{AF}$, other members worried that SDCWA's IID purchases would result in "cost shifting," i.e, if SDCWA reduced its purchases, MET's fixed costs would be allocated across a smaller quantity of water, increasing the average cost of MET water by $\$ 9 / \mathrm{AF}$ to all members. (This argument assumes that no member agency buys MET water "displaced" by IID water.) Third (and most important), even if $\$ 116 / \mathrm{AF}$ did not shift costs, SDCWA was using the cheap part of MET's system without paying for the more expensive parts. MET's PSP prices are based on average cost; if members could choose to use the cheap parts of MET's systemavoiding the expensive parts-MET's financial model could collapse. $\$ 262 / \mathrm{AF}$ would cover MET's fixed costs and send a signal: Members share MET's expenses - no matter what those expenses cover.

\subsubsection{Resolution}

SDCWA sued MET, claiming abuse of market-power and won a judgement that rejected MET's postage stamp pricing (USWNO Staff, 1998). ${ }^{9}$ MET was ready to appeal when the State Legislature offered a deal: Accept the lower wheeling rate and get $\$ 235$ million to line the All American Canal (AAC) with cement and "save" 67 TAFY of water (Erie, 2000). MET accepted, but complications kept the case open until a grand bargain - the multiparty, multi-state Quantification Settlement Agreement (QSA) — was reached in 2003 (IID et al., 2003). According to Quinn, the
QSA capped SDCWA's purchases from IID at 200 TAFY (from 300 TAFY), transferred the AAC money and water from MET to SDCWA, certified that SDCWA would pay MET's \$262/AF wheeling charge, and established a truce on the QSA that would last until October 10, 2008 (2006c).

\subsection{A Thesis on MET}

These facts indicate that neither SDCWA nor MET were victims in the wheeling dispute, but the dispute is perhaps a sign of deeper issues at MET, i.e., troubles among member agencies that have different goals. Because MET has a cooperative governance structure, its member agencies have to agree on policies, and MET's inefficiency falls when members fight over policies and/or adopt policies that misallocate resources.

This was not always the case: MET was efficient for many years because it had "too much," "too cheap" water that it managed as a club good, i.e., join the club and use as much as you like. Abundance allowed MET to grow for many years, and Southern California prospered. When abundance ended in the 1960s, costs went up and water grew scarce-becoming a private good.

The effect of water as a private good (given MET's structure as a cooperative) depended on member agency preferences: If members had homogenous preferences, they could agree on a single policy. If they had social preferences (seeing others as an extension of oneself), they could negotiate differences to maximize group welfare. ${ }^{10}$ If they had neither (i.e., selfish, heterogeneous preferences), then their common ground or

\footnotetext{
${ }^{9}$ The Lerner Index of market power is calculated by dividing price less marginal cost by price. It ranges from 0 (no market power) to 1.00 (perfect market power). If price is the $\$ 262 / \mathrm{AF}$ wheeling charge and marginal cost is the $\$ 116 / \mathrm{AF}$ incremental charge, MET's Lerner Index is 0.56.

${ }^{10}$ This assumption appears to anthropomorphize organizations, but it is not hard to imagine that the manager (or director) of an agency serving a compact urban area will have different goals from his equivalent in a sprawling farming area.
} 
core would perhaps be too small for a consensus on policy. ${ }^{11}$ As it is, MET's members have neither homogenous nor social preferences, and the onset of scarcity weakened MET through conflict among members and inefficient policies. (SDCWA's decision to buy water from IID was simultaneously the result and cause of those conflicts and policies.)

Although MET's status as a public corporation guarantees its continued existence, its inefficiency as a cooperative (versus firm) weakens the ongoing effort to supply water to one of the most water-stressed regions in the world. My goal in explaining MET's inefficiency is not to criticize the hard-working, smart people who work there but to suggest how policies and incentives impede their work and how those policies and incentives could change to strengthen MET and its mission to serve Southern California.

\subsection{Significance}

By this point, readers will have asked themselves at least two "so what?" questions: Assuming the analysis of today's MET is accurate, does it apply to the MET of the future, i.e., do we need to change MET before things get worse? Second, does MET share fundamental similarities with other organizations managing wateror other goods - in other parts of the world? Can we (should we?) apply these lessons to those organizations?

Yes. The forces that led to the wheeling dispute (and other problems) are only growing stronger: As demand grows and supply shrinks, conflict among member agencies over MET's water will also grow, and policies for water allocation will be increasingly inadequate.
MET's supplies are shrinking and becoming more volatile under the triple-threat of changing climate, environmental restrictions, and increasing demand from competitors: The Colorado River is suffering its worst drought in a century, and the Sierra Nevada mountains (the source of SWP water) only had 40 percent of their average snowpack in 2007 (Boxall, 2007). Global warming is putting more pressure on the system (Union of Concerned Scientists, 2006): By 2050, scientists project a loss of at least 25 percent of the Sierra snowpack, with greater volatility in precipitation (CA Dept. of Water Resources, 2007). According to Barnett and Pierce (2008), Lake Meadone of the biggest reservoirs on the Colorado River - has a fifty percent chance of having zero storage capacity by 2021 . MET can see the challenges coming: Tim Brick, MET's current Chairman, says that "drought is going to be a permanent condition by 2040" (Herdt, 2007). In December 2007, Judge Wanger ruled that SWP supplies have to be cut by 30 percent to save an endangered fish (Weiser and Ellis, 2007). Demand on Colorado River supplies (from Arizona, Las Vegas, etc.) is growing. Although MET has "rights" to Colorado water, the probability of getting more than those rights is falling.

In the face of these threats, Chairman Brick claims that MET is "a model of adaptability" that will meet future challengesapparently with the same methods used in the 1987-1991 drought, i.e., an intensive public education campaign to persuade customers of the importance of conserving water, and-failing that - shortage allocation formulas (Schoch, 2008b). ${ }^{12}$ Although Brick says "We're not in the business of inflicting pain on people," member agency managers already know that voluntary conservation

\footnotetext{
${ }^{11}$ As a heuristic definition, "core" means a stable arrangement that members have no incentive to change.

${ }^{12}$ According to the current allocation plan, e.g., members get credits for low-flush toilets but not for xeriscaping, which is "too hard" to count in a formula.
} 
has little impact. Everything that MET has said and done in the past few years points to a repeat of what happened in 1987-1991: Water supplies reach a critical point, MET imposes emergency surcharges on members that buy more than their "base allocation," and people feel pain. So, yes, the analysis of this dissertation still applies to MET and will apply to MET if MET continues with business as usual.

Can we apply these lessons elsewhere? MET is the largest water utility in the United States, but it is also a typical utility applying typical policies (average cost pricing, rationing in shortage based on past use) and facing typical problems (supply falling, demand growing, everyone claiming an exemption to shortage allocations). The analyses and conclusions here will apply to many water utilities.

Although the main purpose of this dissertation is to provide an instructive case study of one of the largest water utilities in the world, it has several innovations, techniques or results that may be used elsewhere, i.e., a quantification of heterogeneity among water agencies that can be used to quantify bargaining power in conditions where some market power exists (Section 4.2.4); a measurement of cooperation among water managers in public goods games showing that their preferences are more selfish than social (Chapter $5)$; a measurement of the impact of water on urban land values (Chapter 6); and a way to allocate "essential goods" that supports equity - by allocating an inframarginal portion on a per-capita basis - and efficiencyby auctioning the marginal, remaining portion (Chapter 7).

\subsection{Dissertation Overview}

MET is a cooperative of member agencies buying water to augment their supplies, but they do not always agree on their rights and obligations as members. In one example, SDCWA's desire to use MET's infrastructure to move water was opposed by other members unless SDCWA paid a high price. The dispute only ended when the State of California convinced them to stop with a $\$ 235$ million payment. This dispute motivated this dissertation, but the issues that emerge from this study apply elsewhere: Efficient management within monopolistic organizations requires that the goods (water, electricity, roads, etc.) have some form of price rationing - selling at fixed prices can result in excess demand; non-price rationing leads to inefficiency and distortions that weakens these organizations. This case study is a cautionary tale of how even an ongoing and "successful" public organization can suffer from conflict and misallocation under institutions designed for earlier era.

The next chapter describes MET's current structure and policies. Chapter 3 tells how MET's world moved from abundance to scarcity, but MET did not. After this history, Chapter 4 shows how the end of abundance revealed MET's inefficiency, and how that inefficiency manifests in conflict and misallocation. Chapter 5 gives details on an experiment that shows member agencies are unlikely to "cooperate their way to efficiency." Chapter 6 has an estimation of the effect of water on land values using 60 years of panel data; results reject the hypothesis that the 1987-1991 drought did not have different effects on member agencies - a necessary (but not sufficient) outcome if MET is misallocating water. Chapter 7 describes how MET could use internal auctions to allocate water and conveyance among member agencies and gives results from auction experiments that test allocation efficiency. The last chapter summarizes. 
Note to Readers: All data sources are documented and cross-referenced in Appendix D. Readers who want to find the data sources and analysis behind Table 3.1, Figure 2.3, etc., should look in that Appendix. Words in bold define terms; these definitions may change from chapter to chapter, e.g., "efficiency". Most key concepts are cross-referenced in the Subject Index. 


\section{Chapter 2}

\section{MET Today}

A public business philosophy draws from the very different worlds of public administration and private business. What comes out of the mix is a model of government efficiency that assertively protects the public trust. Imagine the joining of Wal-Mart with the Nature Conservancy. You get the picture - a conglomerate with a conscience. At MET, we are working towards the same type of business model that embraces efficiency, but not at the sake of core social values like economic and environmental responsibility.

-Phil Pace, Chairman of the Board (2003, p. 13)

This chapter describes MET's features as an organization: its cooperative structure (characteristics of member agencies, governance and mission), water supplies (sources, storage and local supplies), revenue structure (prices and classes of water service) and demand management tools (elasticity, preferential rights and purchase orders). This description will be useful in Chapter 3 (MET's history) and Chapter 4 (an analysis of MET's efficiency).

\subsection{Cooperative Structure}

In 1928, the California Legislature authorized MET's foundation as a selfregulating consumer cooperative managed by its member agencies. MET's mission was to build an aqueduct from the Colorado River to Southern California and then sell the water brought by that aqueduct to its member agencies. Although legally defined as a public corporation, MET combines the legal status, monopoly rights and taxing powers of a government agency, the autonomy and professional management of a corporation, and the governance and nonprofit constraint of a cooperative. ${ }^{1}$

Today, MET's member agencies vary widely in area, population, water use and local water supply; see Table 2.1. Fourteen are the municipal utilities of cities, selling water at retail; 12 are Municipal Water Districts (MWDs) that wholesale water to over 230 downstream water agencies.

\subsubsection{Governance and Oversight}

MET's formation as a cooperative, with joint obligation to pay for the aqueduct and joint access to the water it would bring, overcame the collective action problem that a profit-motivated company would en-

\footnotetext{
${ }^{1}$ The cooperative cannot distribute profits, but it can retain profits to pay for future cooperative activities.
} 


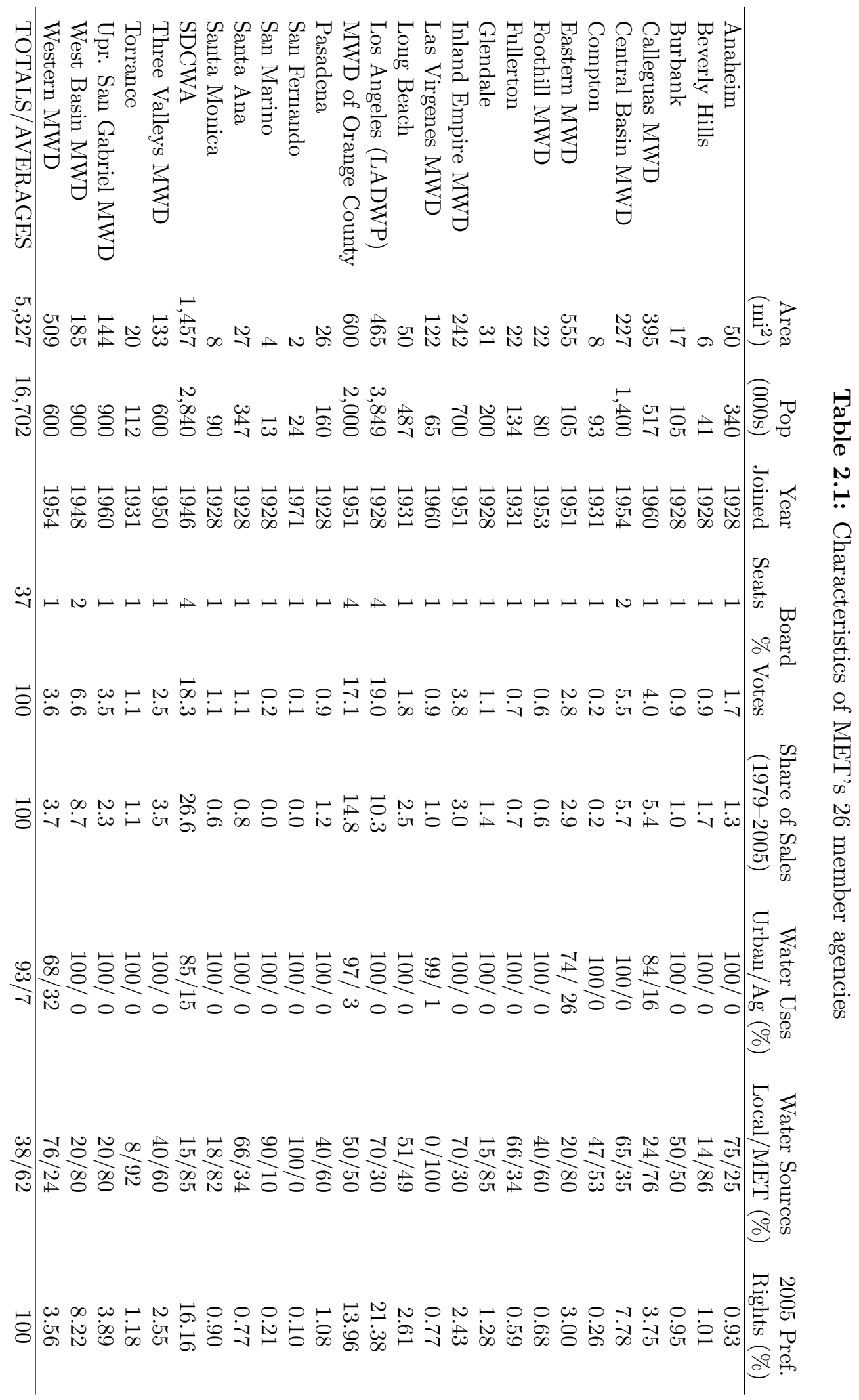


counter if it tried to build the aqueduct and then find consumers for the water, a particularly acute problem with water infrastructure (Hanemann, 2005). ${ }^{2}$

Because MET is a cooperative, it regulates itself in making decisions on pricing, hiring, capital expenditures, etc. ${ }^{3}$ The problem with this system - as Olson (1971) notes - is its one-size-fits-all nature. Polices that apply to all members are approved by a majority vote, and these votes will be more contentious when members' characteristics diverge. (This problem dominates the analysis of MET.)

Today, each of MET's 26 member agencies receives one seat on MET's 37-seat Board of Directors; those with larger assessed property values share the remaining eleven seats. (Directors are appointed by their member agencies.) Votes on the Board depend on each member agency's share of assessed property values within the MET service area - they are not in direct proportion to the number of directors or purchases from MET.

The Board of Directors appoints MET's General Manager (GM) to implement Board policies and manage MET's staff of 2,000 people. Member agencies have a similar GM position. For this dissertation, I ignore principal-agent issues and assume that MET's GM implements Board decisions, member agency GMs work for their employers, and directors work for their agencies. ${ }^{4}$ Thus, the decisions units-MET's 26 mem- ber agencies - jointly decide MET's policies as a cooperative. ${ }^{5}$

Although MET is self-regulating, the Legislature that created it is capable of intervention and has done so twice: In 1950, the Legislature forced MET to annex Pomona MWD; in 1998 , it paid $\$ 235$ million to end the MET-SDCWA wheeling dispute; see, respectively, Sections 3.4 and $1.3 .^{6}$

\subsubsection{What Is MET's Mission?}

In 1928, MET's mission was to make water "available to all areas within the District in accordance with their requirements, domestic use being the dominant use" (O'Connor, 1998a, p. 30). In 1939, "adequate and reliable supplies" are to be provided in an "economically responsible" way (MET, 1939); much later, MET pledges that supplies will be provided in a "environmentally responsible" way (MET, 2004b, Table 14). Contrast these goals with the California Constitution of 1879 :

The general welfare requires that the water resources of the State be put to beneficial use to the fullest extent of which they are capable... in the interest of the people and for the public welfare.

$$
\text { -Art. } 10 \text { Sec. } 2 \text { ("Water") }
$$

"Requirements" at MET imply no rationing, but "beneficial use to the fullest extent" in the California Constitution implies optimization. MET's mission gives no

\footnotetext{
${ }^{2}$ If a company paid the fixed cost of building the aqueduct and then tried to sell the water, consumers would only offer the marginal cost of conveyance (plus $\epsilon$ ) for water, and the company would go bankrupt.

${ }^{3}$ The State Water Resources Control Board regulates water quality. The California Public Utilities Commission regulates investor-owned, private utilities.

${ }^{4}$ Directors supposedly represent the region, but O'Connor (1998b) reports that they put their agencies first. See Section 3.14.2 for principal-agent issues.

${ }^{5}$ Recall the assumed merger of individual and organizational identity and preferences from Footnote 10 on page 6 .

${ }^{6}$ According to McCubbins et al. (1989), Philip (2003) and insiders, oversight of MET is costly and produces few results. MET has ignored critical reports from the CA State Auditor (1996, 2004) and the Legislature (O'Connor, 1998a,b).
} 
hint of how it would allocate a water supply falling short of "requirements" - unlike the Constitution's endorsement of highest and best use. Section 2.4 describes MET's difficulty in rationing demand when supply is inadequate.

\subsection{Water Supplies}

Most of MET's water supply comes from the Colorado River (via the Colorado River Aqueduct, or CRA) and Sacramento-San Joaquin Delta (via the California Aqueduct of the State Water Project, or SWP). These annual surface supplies have different qualities (CRA water is saltier), quantities and costs. MET's CRA and SWP water accounts for about 60 percent of the water that member agencies use. The rest comes from local water. Member agencies value local water because it gives them more flexibility in management decisions and relaxes the impact of changes in MET policies. ${ }^{7}$

Table 2.1 shows members' current mix of local/MET supplies - the result of a long trend in which MET has increased its share of total supply. In the 1950s, MET supplied an average of 25 percent of total regional water. This share rose to $43-44$ percent in the $60 \mathrm{~s}$ and $70 \mathrm{~s}, 47$ percent in the $80 \mathrm{~s}, 52$ percent in the 90 s and 57 percent in 20002004 (reaching 62 percent in 2004); see Figure 2.1 .

For member agencies, MET water has moved from complement to substitute to somewhere in-between: The correlation between local and MET supplies is 0.74 (19511970), 0.01 (1971-1990) and -0.48 (19902004). Because members use MET as their marginal source of water, MET's sales tend to be unstable: The correlation between MET's deliveries from one year and the next is 0.86 for $1980-2004$.

Member agencies get local water from the ground (approx 1.2 MAFY) and recycling (300 TAFY). LADWP's Los Angeles Aqueduct (LAA) is good for 250-325 TAFY; ${ }^{8}$ SDCWA buys water from IID (80 TAFY now and rising to 200 TAFY) and takes delivery of the water saved by lining the earthen All-American Canal with cement (77 TAFY). Member agencies have no operating desalination plants, but a 56 TAFY plant is going through the approval process in SDCWA's area.

Most of MET's water from the CRA and SWP is immediately delivered to members, but high variation in these flows (see Figure 3.3 on page 37 ) requires that MET (and members) use storage and local supplies to smooth variation and meet demand. MET opened a 800 TAF reservoir (Diamond Valley Lake, or DVL) in 2002. DVL cost $\$ 2$ billion and doubled MET's surface water storage to 1.6 MAF - or about eighty percent of annual deliveries (MET, 2005, 2006). MET stores much less water underground: Its 350 TAF in the Arvin-Edison Water Storage District has an annual maximum withdrawal is 75 TAFY - about five percent of MET's average SWP supply (MET, 2007a).

\subsubsection{Costs of MET Water}

MET pays nothing for water at the source -its costs come from the infrastructure and power it needs to receive and redistribute the water. ${ }^{9}$ Infrastructure/operations/power are, respectively, $50 / 30 / 20$ percent of the cost of SWP water, and average cost per unit varies from $\$ 135$ -

\footnotetext{
${ }^{7}$ According to Atwater and Blomquist (2002), member agencies were not happy that MET included local supplies in its 1996 Integrated Water Resources Plan for the region.

${ }^{8}$ The LAA gives LADWP considerable leverage. In 2006, it announced it would "tie" the LAA to SWP contractors - bypassing MET and wheeling charges (LADWP, 2006).

${ }^{9} \mathrm{MET}$ pays $\$ 0.25 / \mathrm{AF}$ for CRA water, a figure loosely based on the cost of storing water at the Hoover Dam (Milliman, 1956a). SWP water is free.
} 


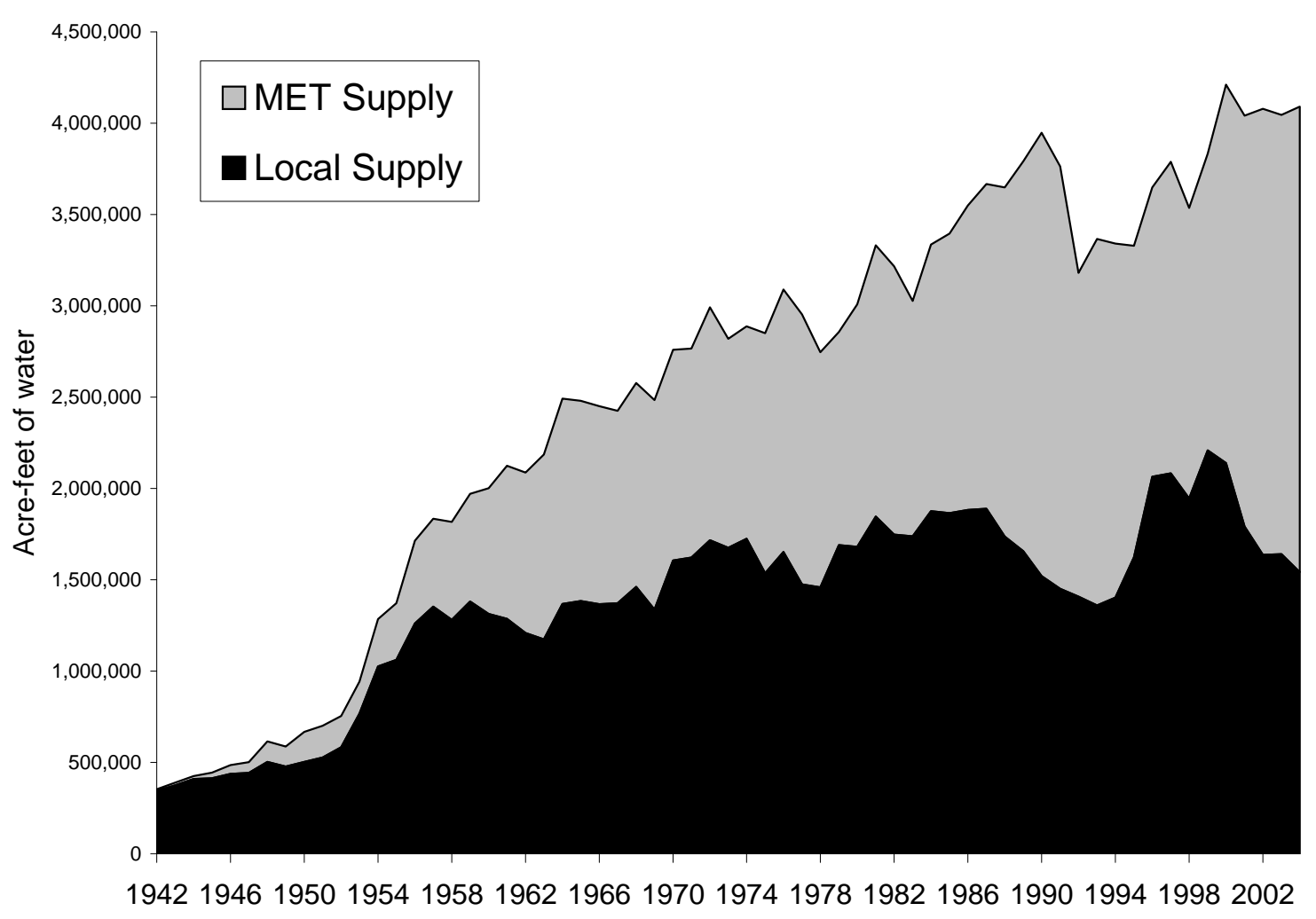

Figure 2.1: MET supplies a rising share of regional water

294/AF because of wide variation in deliveries. CRA uses fully-paid infrastructure and cheaper power, so it is much cheaperabout $\$ 70-100 / \mathrm{AF} .{ }^{10} \mathrm{MET}$ also buys water from irrigation districts (IID and PVID; see Section 3.7.1). Table 2.2 compares MET's water supplies.

These figures are combined to give two stepwise versions (min cost, $\max$ cost) of MET's supply curve in Figure 2.2. ${ }^{11}$ Note that the flat spots in these curves reflect MET's average cost accounting.

\subsection{Revenue Structure}

This section describes how MET targets its prices to earn zero profits. Section 2.3.1 defines MET's rate classes and gives their prices. Section 2.3.2 describes how MET targets its weighted average price at average cost. Before we get to those details, a few comments are useful:

First, MET's costs are 20 percent variable (for pumping water) and 80 percent fixed (infrastructure, overhead, etc.). Until the 1960s, most of MET's revenue came from property taxes (see Section 3.11); today, 80 percent of MET's revenue comes from water sales, and the remainder comes

\footnotetext{
${ }^{10}$ According to Brian Thomas (MET's CFO), the first 800 TAF of CRA water uses cheap Hoover power (Thomas, 2007b). If MET moves move, it must buy power on the open market at substantially higher prices.

${ }^{11}$ The curves reflect an SWP price of $\$ 220 / \mathrm{AF}$. MET claims that $\$ 450 / \mathrm{AF}$ (the price of full service untreated water in Table 2.3) represents its cost of additional supplies, i.e., MET's backstop price.
} 
Table 2.2: Sources, costs and quantities of MET's water supplies

\begin{tabular}{lrc} 
Source & Cost/AF & Median/Max. TAFY \\
\hline CRA & $\$ 98-102$ & $1,200 / 1,300(1975-2004)$ \\
SWP & $\$ 135-294$ & $700 / 2,250(1975-2004)$ \\
IID & $\$ 112-125$ & $100 / 110(1998+)$ \\
PVID & $\$ 200$ & $100 / 115(2005+)$ \\
\hline
\end{tabular}

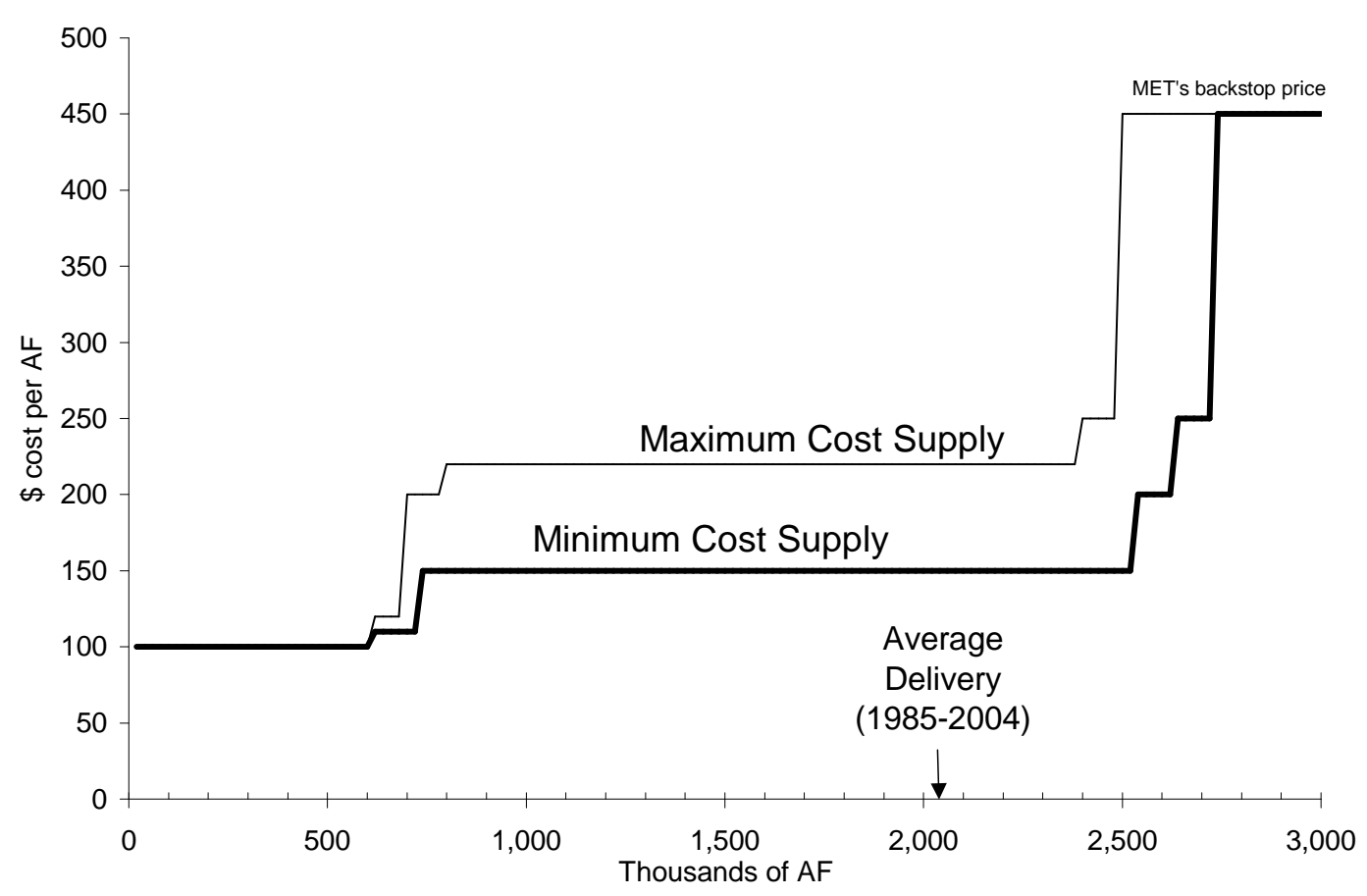

Figure 2.2: Stylized supply curves for MET

from taxes and capacity charges (MET, 2004a). Note the mismatch-80 percent of costs are fixed, and 80 percent of revenues are variable.

Second, Section 134 of MET's Administrative Code states that "prices shall be uniform for like classes of service." MET defines class as a function of inputs (e.g., treatment), consumer identity (e.g., agricultural), purpose (e.g., replenishment) and/or contract (i.e., purchase order). What class does not include is location, i.e., the price of "Treated Tier 1" water is the samewhether it is delivered one mile or 100 miles from the treatment plant. This policy is known as postage stamp pricing (PSP), i.e., same price to all delivery points (see Section 4.4.2 for the economics of PSP).

\footnotetext{
${ }^{12}$ CFO Thomas described these steps at the November 17, 2006 MAM meeting. This method has been used for over thirty years-Flaxman (1976) mentions it.
} 
Dec 2006 Member agency managers discuss proposed rate increases.

Jan 2007 Board of Directors Finance Committee reviews proposed increases.

Feb Public comments taken.

Mar Board of Directors takes action.

Jan 2008 Rates take effect for 2008 .

\subsubsection{Rate Classes}

Table 2.3 has prices for different classes of water. Class definitions come from MET (2007b) unless noted.

Tier 1 rates recover the cost of maintaining a reliable supply. According to SDCWA (2006b), it "recovers MET's supply costs that are not recovered by sales at the Tier 2 Supply Rate and a portion of the long-term storage [replenishment] and agricultural water sales."

Tier 2 rates equal MET's cost of developing additional supply to encourage efficient use of local resources.

System Access charges "recover a portion of the costs associated with the conveyance and distribution system, including capital, operating and maintenance costs" (SDCWA, 2006b).

System Power charges are the costs of power for pumping.

Water Stewardship charges are the cost of MET's financial commitment to conservation, water recycling, groundwater clean-up and other local resource management programs. These charges subsidize alternative sources of water, e.g., desalination, recycling. etc.

Treatment Surcharges recover the cost of treating imported water "including capital and operating costs" (SDCWA, 2006b).

Replenishment is a discounted rate for surplus system supplies available for the purpose of replenishing local storage. This water is not for use in the current year; see Section 6.3.4 for a discussion of MET's interesting replenishment accounting.

Interim Agricultural rates are discounted and available for surplus system supplies that are used for growing agricultural, horticultural, or floricultural products. MET sells an average of 100 TAFY of water (5-6 percent of its total) at this rate. Although MET's founders promised water would not be used for agriculture, others broaden the interpretation of "municipal uses" in Section 5(10) of the MET Act to include irrigation (Milliman, 1956a). These sales absorb excess supply in the early years, but their continuation - at discounted prices - is hard to justify today. According to Oshio (1992), member agencies with large agricultural demand (SDCWA, Western and Eastern MWDs) oppose seasonal pricing (for all water) because they want cheap agricultural water in high demand summer months.

Readiness-to-Serve Charges "recover costs associated with standby and peak conveyance capacity and system emergency storage capacity. The Readinessto-Serve Charge is to be allocated among MET member agencies on the basis of each agency's ten-year rolling average of firm demands (including water transfers and exchanges conveyed through system capacity)" (SDCWA, 2006b). Since these charges depend on average use over ten years, they are not really fixed.

Capacity charges "recover the cost of providing peak capacity within the distribution system. Peak-day deliveries in excess of the requested amount of capacity chosen by the member agency will be assessed a Peaking Surcharge" (SDCWA, 2006b). 
Table 2.3: MET's water rates

\begin{tabular}{|c|c|c|c|}
\hline & 2006 & 2007 & 2008 \\
\hline \multicolumn{4}{|c|}{ a là carte $(\$ / \mathrm{AF})$} \\
\hline (1) Tier 1 & 73 & 73 & 73 \\
\hline (2) Tier 2 & 169 & 169 & 171 \\
\hline (3) System Access ${ }^{\dagger}$ & 152 & 143 & 143 \\
\hline (3) System Power ${ }^{\dagger}$ & 81 & 81 & 90 \\
\hline (3) Water Stewardship ${ }^{\dagger}$ & 25 & 25 & 25 \\
\hline (4) Treatment Surcharge & 122 & 147 & 157 \\
\hline \multicolumn{4}{|c|}{ Full Service Untreated $(\$ / \mathrm{AF})$} \\
\hline Tier $1(1+3)$ & 331 & 331 & 351 \\
\hline Tier $2(2+3)$ & 427 & 427 & 449 \\
\hline Replenishment & 238 & 238 & 258 \\
\hline Interim Agricultural & 241 & 241 & 261 \\
\hline \multicolumn{4}{|c|}{ Full Service Treated $(\$ / A F)$} \\
\hline Tier $1(1+3+4)$ & 453 & 478 & 508 \\
\hline Tier $2(2+3+4)$ & 549 & 574 & 606 \\
\hline Replenishment & 335 & 360 & 390 \\
\hline Interim Agricultural & 339 & 364 & 394 \\
\hline \multicolumn{4}{|c|}{ Fixed Charges } \\
\hline Readiness-to-Serve (\$ million) & & 80 & \\
\hline Capacity (\$/cubic-feet-second) & & 6,800 & \\
\hline
\end{tabular}

\subsubsection{Prices and Equilibrium}

MET targets the equilibrium in Figure 2.3 by estimating demand and supply and setting prices to generate revenue equal to MET's costs at the expected equilibrium $(E)$. If MET's projections are correct, actual demand matches MET's actual supply. In shortage, MET rations (see Section 2.4); in surplus (e.g., the winter of 2005-2006), MET approves a lower price.

Here is the step-by-step procedure that MET uses to set prices for the firm water (Tier 1 and Tier 2) that represents 70-80 percent of its delivery volume. ${ }^{13}$

1. Early in year $t-1$, MET forecasts year $t$ demand (dashed line in Figure 2.3) as a function of population, the mix of residential, industrial \& agricultural sectors of the economy, climate, expected price, etc. (Thompson et al., 1993). According to Tim Quinn (MET's VP of State Water Project Resources), MET forecasts demand within a large range $( \pm 25 \%)$, i.e.,

At the beginning of every year, we do a risk assessment of the likely variation in demands we will

\footnotetext{
${ }^{13}$ Firm water is meant to be reliable, i.e., available on demand at the predetermined price. Nonfirm water (e.g., interim agricultural and replenishment) is inframarginal, i.e., MET declares that a certain quantity exists and sells it at a lower price. Nonfirm water cannot be used for current municipal consumption (MET, 2004a).
} 


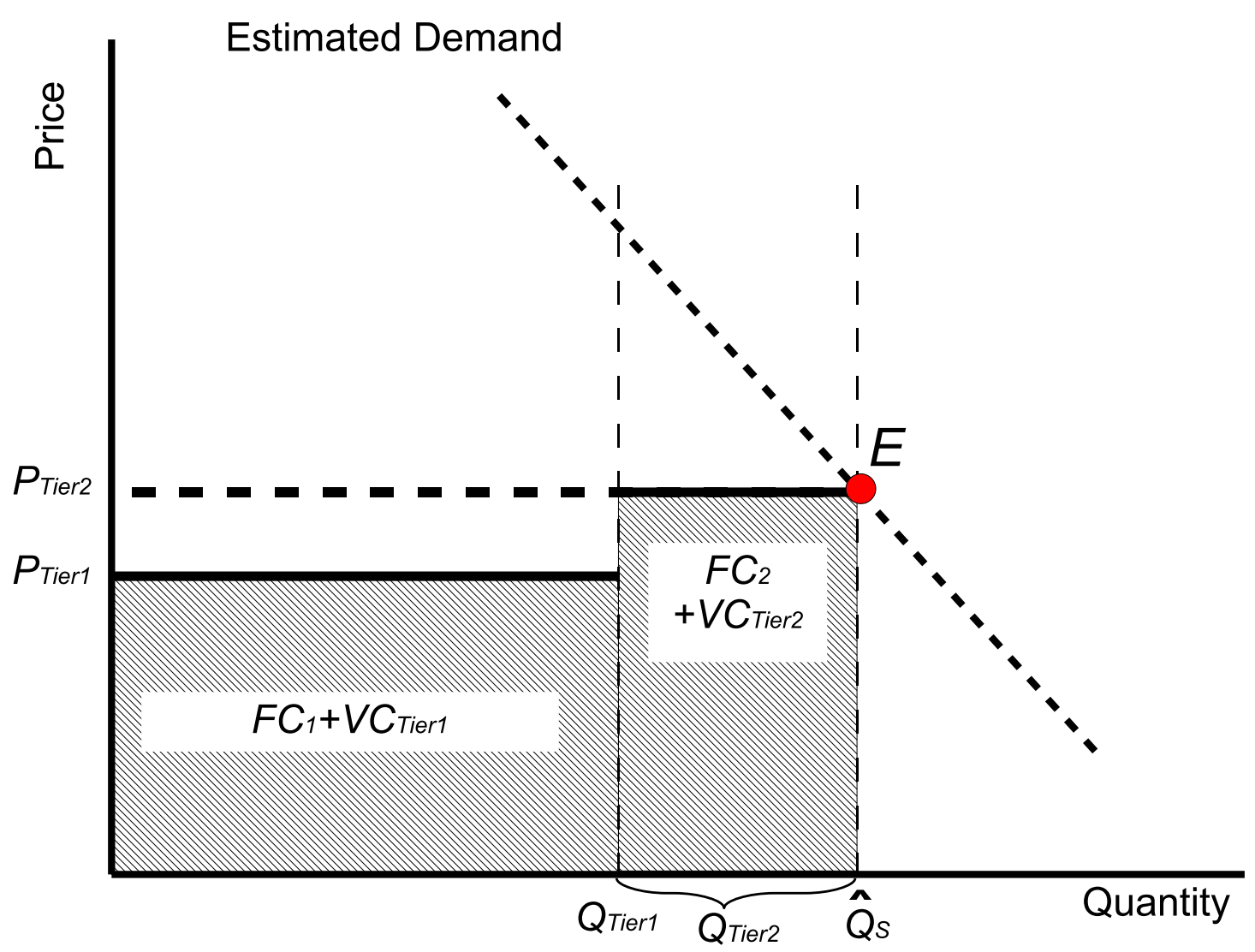

Figure 2.3: MET estimates supply and demand, sets prices and hopes for $E$

have to meet. Under current circumstances, wholesale demands are typically bounded by 1.5 MAF on the low side and perhaps $2.6+$ MAF on the high side.

$$
\text { —Quinn (2006b) }
$$

Most of MET's water will be sold at Tier 1 prices, which are lower than Tier 2 prices. Member agencies must have purchase orders (POs) to buy Tier 1 water (see Section 2.4.3). If they do not have POs or want to buy more than allocated in their POs, they pay the Tier 2 price.

2. $P_{\text {Tier } 2 \text {-representing the marginal }}$ cost of new water-intercepts the estimated demand function, indicating the quantity of supply MET will target $\left(\hat{Q}_{S}\right) \cdot{ }^{14}$

3. MET estimates total costs as a function of estimated supply, $T C=$ $V C\left(\hat{Q}_{S}\right)+F C$. Fixed costs depend on service standards and MET's over-

\footnotetext{
${ }^{14}$ Before February of year $t$, the actual supply of water for year $t$ is risky, i.e., the probabilistic distribution of supply is known but the draw from that distribution is not yet known. Between February and May, the Department of Water Resources releases four editions of "Water Conditions in California" (Bulletin 120, at http://cdec.water.ca.gov/snow/bulletin120/), which give an increasingly-accurate estimate of expected water supply.
} 
head, e.g., engineering, maintenance, etc.

4. In March of year $t-1$, MET's Board sets water prices for year $t$ (MET, 2004a). MET sets $P_{\text {Tier } 1}$ to "recover MET's supply costs that are not recovered by sales at the Tier 2 Supply Rate and a portion of the long-term storage and agricultural water sales" (SDCWA, 2006b).

5. In year $t$, actual demand and actual supply are realized. If MET's projections are accurate, equilibrium is at point $E$, MET actually sells $Q_{\text {Tier } 1}$ at $P_{\text {Tier } 1}$ and $Q_{\text {Tier } 2}$ at $P_{\text {Tier } 2}$, and makes no profit.

\subsubsection{Efficient Pricing}

Chapter 4 has the economic analysis of these prices but keep the following in mind: In an economically efficient world, price would be set according to marginal cost, and fixed costs would be allocated in proportion to infrastructure burden/surplus. Given 26 members, two goods (water and conveyance) and two costs (fixed and variable), this world would have 104 different prices.

What MET has instead are four prices (Tier $1 / 2$, agricultural and surplus) that bundle water and conveyance, include most fixed costs, and do not vary by distance or member. ${ }^{15}$ Because MET sets Tier 2 prices at marginal cost and targets zero-profits, Tier 1 prices are targeted below MET's average cost, i.e., Tier 2 sales subsidize Tier 1 sales. Even worse, prices that are fixed almost a year in advance will have little to do with actual supply and demand. The bottom line is that MET's pricing system is unlikely to facilitate equilibrium, and these implications are discussed in Section 4.4.3.

\subsection{Demand Management}

MET affects demand through prices (elasticity) and quantity controls (POs and preferential rights). Demand can be stated as a desire for reliability, i.e., "given a price, quantity supplied equals or exceeds quantity demanded." The traditional way for water managers to get reliability is by increasing supply faster than the increase in demand, or, as MET's CFO puts it: ${ }^{16}$

Metropolitan will make deliveries of all water demanded except when we cannot. While this seems like a trite answer, it really reflects how we approach this problem. We plan ahead, we build supplies and we store water to be sure that we can meet demands.

$$
\text { -Brian Thomas (2006a) }
$$

The economic way to get reliability (especially when supply is constrained) is to increase prices such that quantity demanded equals supply. MET (and water managers in general) are not accustomed to equalizing supply and demand through prices. They prefer to estimate the quantity demanded, find the same supply, and charge the average cost as price. (A common assumption of zero elasticity often underpins this method. ${ }^{17}$ )

MET now recognizes elasticity but does not use prices to control demand; prices are for cost recovery. If those prices are too low

\footnotetext{
${ }^{15}$ Twenty percent of MET revenue comes from capacity charges and property taxes, which more closely match fixed costs.

${ }^{16}$ Water managers (and consumers) tend to think of reliability as the probability of physical supply, e.g., having water available at the reservoir (the kitchen sink). This definition ignores the notion that water should cost (or be worth) anything more than the effort of wanting it.

${ }^{17}$ For many years, the demand elasticity of water was assumed to be zero; see Hildebrand (1984) - a report MET commissioned.
} 
to choke off demand in the event of shortage, MET must have some way to limit the quantity of water demanded. Nominally, MET has a system of preferential rights to a share of water (Section 2.4.2), but these are not viable. In recent years, MET has adopted a system of POs, but these only serve to ration access to a quantity of cheaper (Tier 1) water; see Section 2.4.3. When MET has to deal with a shortage, it gives members access to a cheaper base allocation (similar but different from the PO allocation) that depends on historical purchases (and contentious adjustments) and allows unlimited purchases at penalty rates that are typically double the base price. ${ }^{18}$ MET's technique is common - it used this method during the 1977, 1987-91 and current (2007-8) droughts (see Section 3.12).

SDCWA (2006a, Appendix B) asked its water managers their opinions on prices: The first question asks "What is the most important issue in a drought management plan?" The most popular answer is an "equitable allocation of cutbacks" while the least popular is "wholesale pricing signals." The next question asks "Is it appropriate to use wholesale pricing signals to encourage conservation?" 14 managers say yes; 8 say no. The next question affirms (22-0) that water managers are willing to use water transfers to avoid rationing, but only a minority (6-15) favor paying more to avoid mandatory conservation. The next question asks "Should agencies be able to sell their unused allocation for profit?" 6 managers say yes; 14 say no. When asked to "rank the most important issue regarding shortage allocation methodology," the top choice is equity of water allocations; "financing penalties and pricing signals" has less than half the support, tying with "communications strategy" for second place.

\subsubsection{Elasticity}

According to MET (1990), single-family residences have price elasticities of -0.16 in winter and -0.36 in summer. Using data from cities in the western United States, Mansur and Olmstead (2007) estimated an overall elasticity of -0.36 . Within this number, they estimate demand elasticity near zero for indoor water use; for outdoor water use, elasticity varies from -0.48 for rich people with large lots and -0.87 for poor people with small lots.

One reason for low elasticity is that water is so cheap. From Table 2.3, we see MET's 2007 wholesale cost for Tier 1 water is $\$ 478 / \mathrm{AF}$; this works out to less than $\$ 1.50 / 1,000$ gallons. If retail prices are three times this number, $\$ 4.50 / 1,000$ gallons is still cheap. Keep in mind that these prices are much higher than they were 20 years ago: Figure 2.4 shows that MET's prices (in 2004 dollars) rose sharply after the 19871991 drought. Even so, water managers do not raise prices in drought - they ask people to use less water (Harris, 1990).

\subsubsection{Preferential Rights}

Under Section 135 of the MET Act, member agencies have preferential rights (PRs) to MET water in proportion to their historic, cumulative payments of taxes (77 percent, as of 2005) and capacity charges (23 percent); see Table 2.1 for current shares of PRs. These rights determine each member agency's share of a fixed quantity of water if MET has a shortage. PRs have three important features: They have never been used; they are not legally valid; and member agencies will not renounce them.

Because LADWP paid high property taxes for so long during MET's early years, it had accrued the most PRs. As of 2006, LADWP has the largest share of PRs-

\footnotetext{
${ }^{18}$ The Water Surplus and Drought Management plan of April 1999, for example, does not specify the details of allocation under drought (Atwater and Blomquist, 2002).
} 


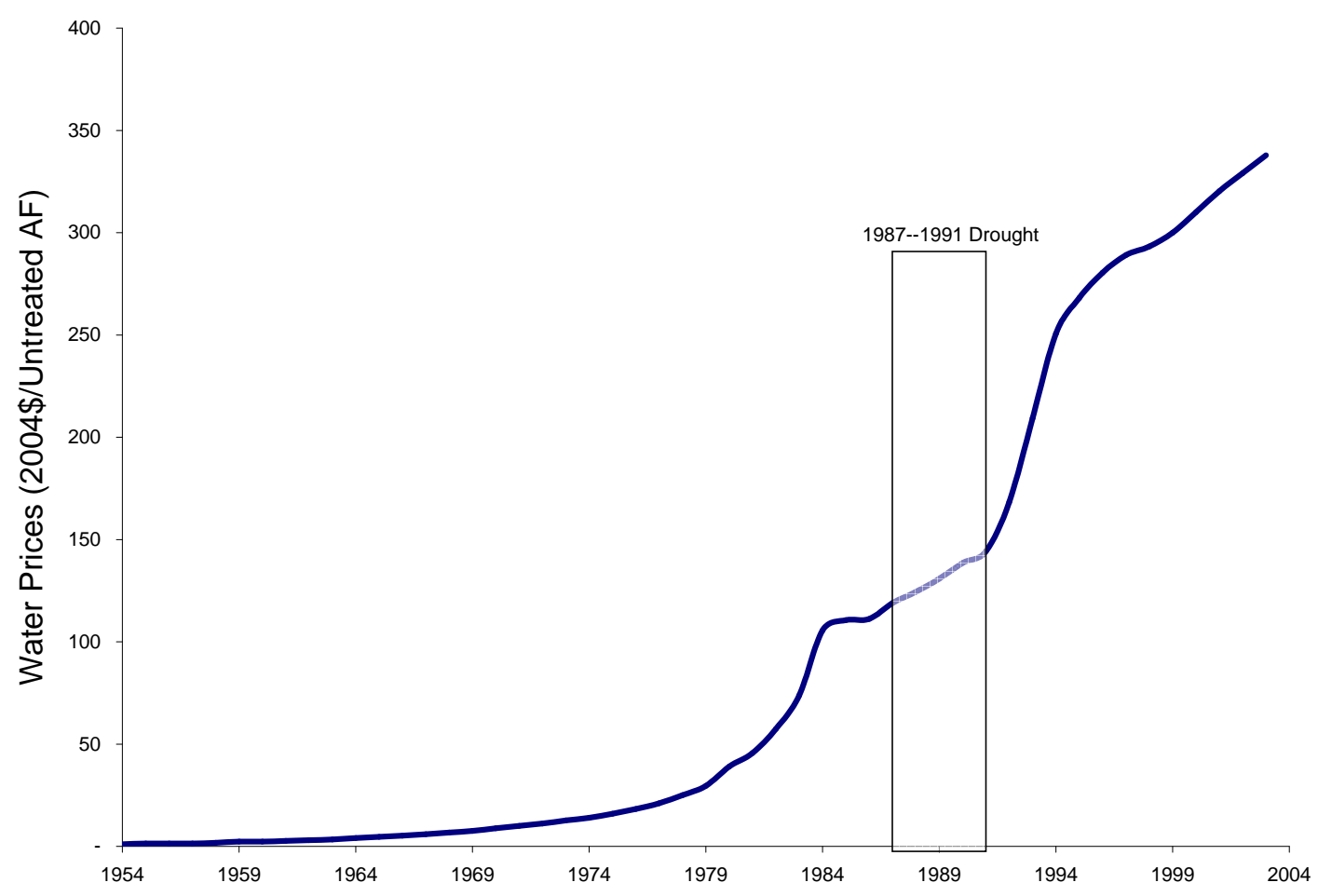

Figure 2.4: Water prices rise steeply after the 87-91 drought

equivalent to 208 percent of its average 1979-2005 deliveries, and SDCWA has the second-highest PRs-but these only cover 61 percent of its average deliveries.

After MET started earning more money from selling water (see Section 3.11), the formula for PRs shares did not change. Heavy buyers complained that they were paying MET's fixed costs without getting proportionate PRs (Blue Ribbon Task Force, 1994). The correlation between 2005 PRs and 1979-2005 water purchases is 85 percent.

Although PRs loom large in member agencies' consciousness, they have never been used: MET allocated water in proportion to historic deliveries during the 1977 and 1987-91 droughts. Further, MET's lawyers have said they are invalid, and they can be overruled in the event of a "water emergency." 19

Despite doubts and drawbacks, member agencies are unwilling to relinquish PRs when they may be all they have to show for their past payments (Flaxman, 1976). Both LADWP and SDCWA have rejected changes in the PRs formula (Erie, 2006). PRs constitute a "moral property right" and focal point that influences bargaining and anchors expectations (Gächter and Riedl, 2002). LADWP uses PRs to estimate its firm supply-because it has so many PRs, it does not have to build expensive storage. SDCWA uses the same assumption to get the opposite result: It limits supply to PRs in simulations and projects significant shortages (SDCWA, 2002), and the subsequent results justify SDCWA's aggressive spend-

\footnotetext{
${ }^{19}$ Under California State Water Code Sections 350-358, MET's Board can declare a "water shortage emergency and distribute water according to need" (Flaxman, 1976, p. 22).
} 
ing to secure "drought-proof" supplies.

\subsubsection{Purchase Orders}

In 2003, MET signed ten-year purchase order contracts (POs) with member agencies. POs require member agencies to buy at least 60 percent of their Base Demandwhether they take delivery or not-and allow member agencies to buy as much as 90 percent of their Base Demand. ${ }^{20}$ POs execute at (lower) Tier 1 prices, but they do not guarantee supply-MET only needs to "make an effort" to deliver water (MET, 2003).

In a comparison of 1990-2004 deliveries (390 member agency-year pairs) to average deliveries in a base period of 1980-1989, 7 percent of deliveries are below the 60 percent minimum and 76 percent of deliveries are above the 90 percent maximum. ${ }^{21}$ Put another way, MET uses POs to ration access to its cheaper water based on past use, not a more efficient measure like per capita use.

\subsection{Summary}

This chapter describes MET's current operations as a self-regulating consumer cooperative that makes decisions through a Board of Directors appointed by member agencies. Member votes depend on their share of MET's total assessed value, but their contributions to MET's finances are mostly in the form of water purchases. This discrepancy leads to disagreements over who benefits from and who pays for MET's policies.

MET gets its water from the Colorado River (via the CRA) and Northern California (via the SWP) as well as some smaller sources. It supplies an average of 60 percent of its member agencies' water; member agencies get 0-100 percent of their water from their local supplies.

MET's most interesting feature is its use of a single price for delivering the same class of water anywhere in the region. These postage stamp prices are easy to understand, but they are based on several types of cost - fixed and variable, water and conveyance - that differ for each agency. The result is a web of cross subsidies andworse - weak signals of scarcity that make it harder for MET to efficiently allocate water and conveyance. When MET has problems with supply (e.g., the 1987-1991 drought), it rations supply based on past purchasesinstead of raising prices.

The next chapter discusses the history behind MET's current policies, and Chapter 4 has a detailed economic analysis of how these policies affect incentives. It is useful to preview one major result: Because MET sells water at postage stamp prices and has no rationing scheme, risk-averse managers support excess storage because, first, PSP subsidizes storage and, second, because MET does not increase prices to equalize demand and supply. The resulting over-building of storage is not only expensive but fails to deliver reliability. ${ }^{22}$

\footnotetext{
${ }^{20}$ Base Demand starts out as the highest annual purchase of firm water between FY89-90 and FY01-02 and increases if the ten-year moving average of purchases rises above this number (MET, 2003).

${ }^{21}$ SDCWA complains that the 60/90 formula serves LADWP (since LADWP demand often drops below 60 percent but does not rise above 90 percent) and harms SDCWA, which often buys more than 90 percent of Base (Erie, 2006).

${ }^{22}$ Reliability does not increase if there is no water to fill the extra storage space or demand is greater than supply at MET's prices.
} 


\section{Chapter 3}

\section{MET's History}

$[\mathrm{G}]$ oods that are produced at decreasing costs, even if their consumption is purely private, may be shown to require some sharing arrangement in an equilibrium or optimal organization.

$$
\text { -Buchanan (1965, pp. 8) }
$$

This chapter covers MET's history from the period before its foundation in 1928, to its explosive growth in the early 50 s, to the contraction in supply in the 60s and paradigm-changing drought of 1987-1991. The history of MET helps us understand many of MET's policies, its character as an expansionist organization, and Los Angeles' critical role in MET's formation and growth. The material is divided into two eras: the pre-1960 growth era and the post-1960 era of scarcity. These eras did not result from exogenous factors: MET policies created excess supply in the early years; MET's solutions to those problems created excess demand that continues to affect MET today. Although this chapter is about history, the economic impact of forces unleashed by MET policies are significant - and discussed in Chapter 4.

In Sections 3.2-3.4, we learn why Los Angeles sponsored MET's creation, how Los Angeles' objective (more electricity) resulted in too much water, and how MET expanded to dump that water. Section 3.5 explores the rationality of Los Angeles' decision to underwrite MET's vast cost over- runs. Sections 3.6-3.11 describe how many factors combined with (and were changed by) MET's expansionist-era policies to produce problems of shortage and misallocation. Section 3.12 describes how the 19871991 drought broke MET's long-standing guarantee of reliability. If the drought was bad, the reaction was worse: Section 3.13 describes how SDCWA's 1995 deal to buy water from IID not only circumvented MET's informal monopoly on imported water but set off a conflict over inefficient policies that further weakened MET. Despite the damage from that incident and those policies, MET has made little effort at reform, and Section 3.14 why reforming MET is difficult. By the end of the chapter, the reader will understand why some question MET's future. Chapter 4 explains why: MET's cooperative form is inefficient.

\subsection{LA Sets the Stage}

In 1902, the City of Los Angeles bought the private Los Angeles City Water Company and acquired the services of William Mulholland. After appointment as Chief Engineer of the City's Bureau of Water 
Works \& Supply, Mulholland oversaw construction of the Los Angeles Aqueduct (LAA) from the Owens Valley to Los Angeles (Milliman, 1956a). ${ }^{1}$

The LAA was a gravity-fed aqueduct that generated power from water flow. After the LAA opened in 1913, Los Angeles ran it at full capacity to generate as much power as possible. Los Angeles used the resulting excess water to grow. In 1915, Los Angeles annexed the San Fernando Valleydoubling the city's size (Milliman, 1956a). ${ }^{2}$ Although some areas chose to annex to Los Angeles, others joined reluctantly-needing the water - or refused outright. Local cities (e.g., Beverly Hills, Burbank, Santa Monica and Pasadena) that valued their independence complained that Los Angeles was a "water imperialist," and this backlash weakened Los Angeles politically.

Two elements from this story reappear in the story of MET: the combination of economically-valuable electricity and politically-valuable water and growth driven by cheap water supplies. Even more interesting, perhaps, is how the independent cities threatened by Los Angeles' aggressive tactics joined Los Angeles in founding MET and then benefited from Los Angeles' generous subsidies of MET's operations.

\subsection{From Power to MET}

This section describes how Los Angeles joined with agricultural interests to get a bigger power supply, allied itself with thirsty cities, and founded MET in a three- way deal. It ends with some interesting details of the struggle over power supplies and the dubious (but successful) campaign to raise money to construct the Colorado River Aqueduct (CRA). When water began flowing through the CRA in 1942, the doubters were proven right (too much water for too much money), and Section 3.3 describes MET's attempts to cope.

In 1902, farmers in the Imperial Valley (just north of the Mexican border) received their first deliveries of water from the Colorado River. Unfortunately, this water came north from Mexico, and Mexican farmers were taking "too much." In 1911, Imperial farmers formed the Imperial Irrigation District (IID) with the intention of capturing water before it got to Mexico (Milliman, 1956a). Their plan consisted of an Imperial Dam and All-American Canal (AAC) connecting the Dam to IID; see Figure 1.1 for a map.

Meanwhile, the Los Angeles Bureau of Power \& Light (LABPL) wanted to supplement LAA-generated electricity. ${ }^{3}$ In 1920 , LABPL Chief Scattergood proposed construction of a high dam at Boulder Canyon (present-day Hoover Dam) to generate electricity (Ostrom, 1953; LADWP, nd). ${ }^{4}$

In a deal of mutual benefit, Los Angeles threw its support behind the IID plan in exchange for IID's support for Hoover Dam. The three projects (Hoover Dam, AAC and Imperial Dam) were bundled into one package - the Boulder Canyon Project (BCP).

\footnotetext{
${ }^{1}$ This project removed water from Owens Valley and-according to Reisner (1993) but not Libecap (2004) - devastated the area. Activists often protest water transfers with "Remember Owens Valley" signs.

${ }^{2}$ The San Fernando Valley added $170 \mathrm{mi}^{2}$ to Los Angeles' existing area. Between 1910 and 1932, Los Angeles grew from 90 to $450 \mathrm{mi}^{2}$.

${ }^{3}$ Los Angeles had separate organizations for water and power until 1937, when it merged its Bureaux of Power \& Light and Water Works \& Supply into the Los Angeles Department of Water \& Power (LADWP). Under Ezra F. Scattergood's 31-year leadership (1909-1940), the Bureau of Power \& Light became the biggest municipally-owned power company in the United States (LADWP, nd).

${ }^{4}$ The dam was supposed to be in Boulder Canyon, but when the project moved to Black Creek Canyon, the name did not change. Congress renamed Boulder Dam to Hoover Dam in 1931.
} 


\subsubsection{Opposition}

Southern California Edison (SCE), an investor-owned utility that sold one-quarter to one-third of its output to LABPL, opposed the BCP because it did not want to lose LABPL as a consumer. LABPL, which bought 30 percent of its power from SCE, supported the BCP because it wanted to replace SCE's expensive power (1.05cents/kWh) with cheaper hydropower - LAA power only cost LABPL 0.45cents/kWh (Milliman, 1956a). Even ignoring cost, Scattergood wanted the BCP because it would put LABPL closer to his goal of 100 percent publicly-owned generation and distribution (Ely, 1995). ${ }^{5}$ Despite strong support for public power, the BCP was blocked by an alliance of private-power companies (e.g., SCE), anti-Socialists and fiscal conservatives (Hundley Jr., 1992).

\subsubsection{Add Water}

In 1923-one year after proclaiming Los Angeles had four times its water requirements - Mulholland proposed that a Colorado River Aqueduct (CRA) bring water from the Colorado River to "parched" Southern California (Milliman, 1956a). ${ }^{6}$ Mulholland's announcement was misleading but not totally unfounded: Although Los Angeles had plenty of water, other communities that relied on groundwater were running short. Instead of selling excess LAA water or allowing them to solve their own problems, Mulholland instead proposed a regional water organization that would share the water and the costs of bringing the water. That organization was MET.

Los Angeles's decision to go for water was politically astute. If LA wanted to get power, it needed a dam. Although money was not available for dams, it was available for water. MET joined the interests of Los Angeles and neighboring cities: Los Angeles got political support for a high dam (and power generation) in exchange for helping cities pay for the CRA (Parsons, 1990). As it turned out, the CRA ended up costing Los Angeles a lot more than expected - as discussed in Section 3.3.1.

The plan was that MET would build the CRA and use power from Hoover Dam to pump water from the Colorado River, via the CRA, to Southern California. Although MET expected to use 30 percent of Hoover power, the fact that MET did not yet legally exist (and its major project - the CRAhad not been planned, let alone built) cast doubt on the BCP's financial viability. SCE stepped in with financial guarantees - in exchange for the right to buy Hoover power (Milliman, 1956a; Ely, 1995).

With something for everyone, the intertwined $\mathrm{BCP}$ and CRA projects attracted support from cities, IID, SCE and MET (Ostrom, 1953). After a political tussle that limited Los Angeles' voting power to 50 percent and prohibited MET from seizing local water supplies, the California Legislature approved the MET Act (CA Legislature, 1927; Milliman, 1956a). In 1928, Los Angeles and twelve other cities joined MET as founding member agencies.

At the federal level, MET's plan to use Hoover power to bring water to the people dramatically increased the BCP's popularity. In 1928, the Congress passed the BCP Act - authorizing construction of

\footnotetext{
${ }^{5}$ Scattergood bought SCE's distribution system in 1922 and reached his goal in 1938 (LADWP, nd).

${ }^{6}$ Surplus water dumped from the LAA was already damaging crop roots in the San Fernando Valley. Milliman (1956a) says that Mulholland either lied or exaggerated when arguing for the CRA. Mulholland did not announce an extension of the LAA to Mono Lake (a cheaper source of additional water) until 1930-after the BCP was approved.

${ }^{7}$ A 1931 amendment added the Parker Dam to give the CRA a higher starting point. greater headwater pressure would reduce the power required to pump water through the CRA.
} 
Hoover Dam, Imperial Dam and the AAC. ${ }^{7}$ With the BCP approved, MET wanted to begin construction of the CRA. Before it could do so, it needed to secure contracts for Hoover power that SCE and Los Angeles also wanted.

\subsubsection{Bids for Hoover Power}

When the power contracts were put out to tender, Interior Secretary Wilbur said that "major emphasis should be placed on adequate security for the repayment of the funds advanced to the [Hoover Dam] project" (Milliman, 1956a, p. 156). These words did not seem to affect the award of contracts, a plurality of which went to MET; see Table 3.1. MET's status as a public organization ended up being more important than its financial strength: The 50-year contracts were signed over a year before MET received voter approval on the CRA (i.e., the project that would use the power) in the early years of the Depression. Voters approved MET's strategic coup by voting to pay for the CRA in September 1931 (Milliman, 1956a).

It turned out that MET signed too many contracts. When power deliveries began in 1938, the CRA was not complete, and MET could not use the power. Unfortunately, contracts for Hoover power restricted reselling power rights: Between 1938 to 1942, MET paid nearly $\$ 72$ million (in 2004 dollars) for power it could not use. Even after 1942, low demand for MET water left the CRA running below capacity. By then, contracts allowed resale of surplus power, and MET sold surplus until 1960; see Figure 3.1. LADWP and SCE were the beneficiaries of MET's “mistake" - buying MET's surplus. Today, the Hoover Dam (capacity 2,080 MW) sells power to Arizona and Nevada (44.1\%), MET (28.5\%), LADWP (15.4\%), SCE (5.5\%), and other cities (6.5\%).

\subsubsection{Colorado River Aqueduct}

With the Hoover Dam underway and power contracts signed, MET needed $\$ 220$ million to build the CRA. Member agencies distributed over 500,000 pamphlets in voters' utility bills, and these pamphlets gave four reasons to vote for the largest bond issue in Southern California's history. Milliman (1956a) argues that three of these reasons were untrue:

1. "A water shortage is imminent." False: The District had surplus water when LAA supplies are included.

2. "The project can be financed with a small increase in property taxes." False: Property taxes were not 0.10 percent (as promised) but ranged from 0.25 to 0.50 percent between 1937 and 1954.

3. "The CRA will provide jobs for District citizens." True: 10,000 (1.2 percent of all workers in the area) were employed for six years.

4. "The CRA will 'perfect' Southern California's water-rights on the Colorado River." False: See below.

Voters approved the Bond in September 1931, and MET built the CRA with a capacity of 1.3 MAFY. This capacity choice reflected several factors: Under the 1931 Seven Party Agreement among California water users, MET had an entitlement of 1.1 MAFY out of a total of 5.2 MAFY allocated to California, but 1.1 MAFY was well above MET's 550 TAFY share of California's 4.4 MAFY authorized by the 1928 BCP Act. These conflicting numbers were reconciled to MET's disadvantage in 1963, when the Supreme Court upheld the BCP; see Section 3.7.1.

\subsection{Dumping Water}

Although the CRA came in on budget and water began flowing in 1941, wildly- 
Table 3.1: Contracts for power from the Hoover Dam

\begin{tabular}{lrr} 
Entity & Bid (Oct '29) & Final (Apr '30) \\
\hline LADWP & $100 \%$ & $19 \%$ \\
SCE & $100 \%$ & $9 \%$ \\
MET & $50 \%$ & $36 \%$ \\
AZ/NV & $33 \%$ & $36 \%$ \\
Others & $17 \%$ & $0 \%$ \\
\hline Total & $300 \%$ & $100 \%$
\end{tabular}

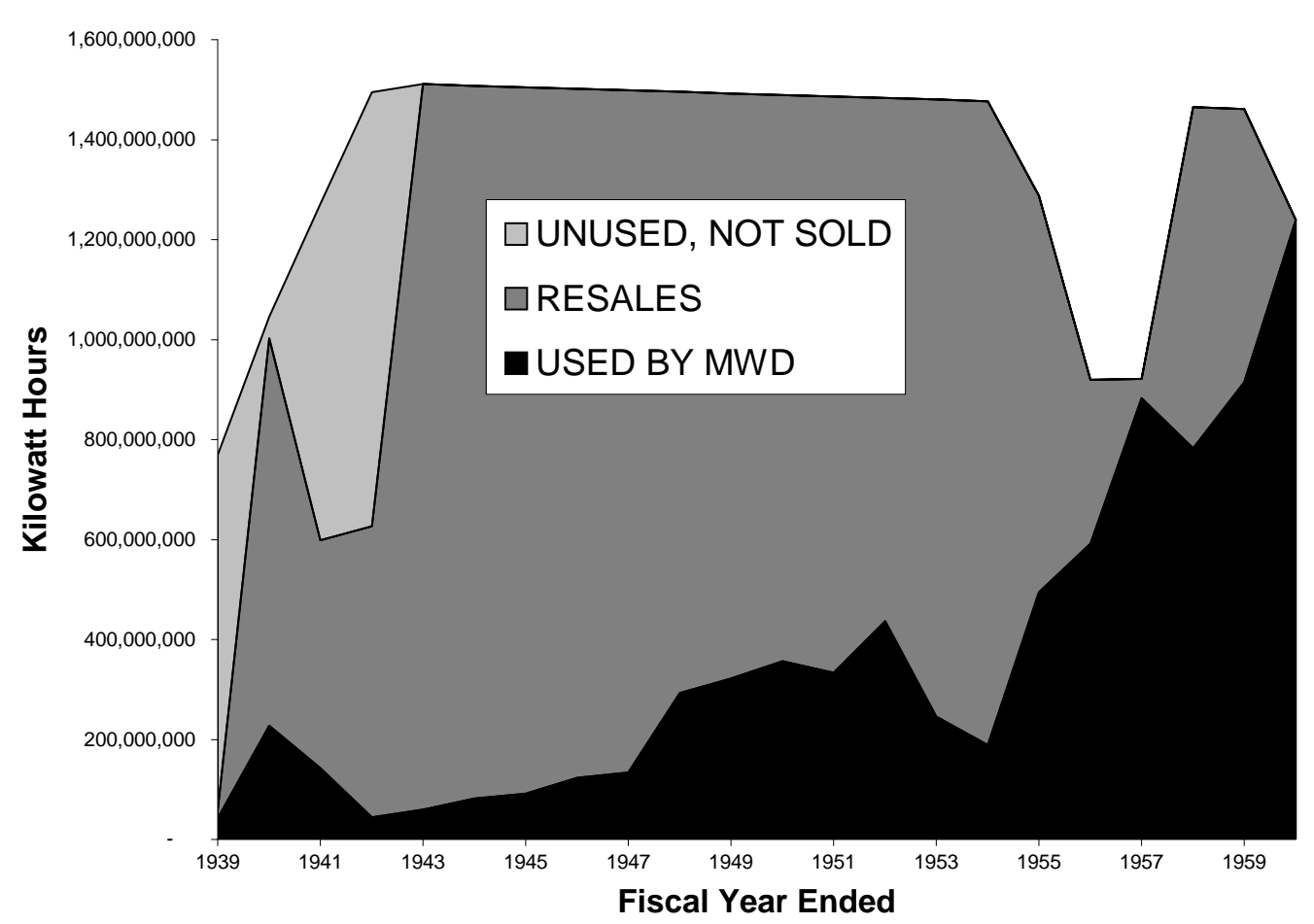

Figure 3.1: MET did not use all its Hoover power rights until 1960

inaccurate demand projections meant that MET could not sell water at projected prices. MET, in fact, had to drop its prices below the cost of member agencies' local supplies to increase sales (Milliman, 1956a). ${ }^{8}$ With subsidies on every unit sold, MET's operating losses added to the fixed costs of bond debt. MET increased property taxes to cover the losses, and Los Angeleswith most of the assessed value - paid the most (Milliman, 1957). Member agencies (including LADWP) decided that the solution was growth: If MET could sell enough water to make an operating profit (presumably through a combination of lower unit costs and increased prices from greater demand), it could lower taxes. Although this strategy worked, it was hard to remove subsidies from MET's policies when that era ended; see Section 3.6.

\footnotetext{
${ }^{8}$ Most local water was groundwater, but most of Los Angeles' local water came from the LAA.
} 


\subsubsection{Miscalculating Demand}

MET based its demand calculation on the "habitable [not inhabited] area of the South Coastal Basin" and made no provision for the effect of prices (Milliman, 1956a, p. 243; Milliman, 1957). ${ }^{9}$ Milliman (1956a) claims that MET engineers started with a CRA capacity of 1,500 cfs (cubic feet per second) and projected a demand that would require that much water. After building the CRA, MET set prices to cover the cost of building and operating the CRA but ignored the possibility that demand would not exist at those prices. Given "the average cost of Colorado River water, even on the basis of full capacity operation, is roughly three to five times the cost of existing water supplies" and a reduction in demand due to high rainfall, actual sales missed projected sales by an order of magnitude - see Table 3.2 (Milliman 1957, p. 43; Kahrl, 1979).

\subsubsection{Cross-Subsidies}

Facing the prospect of a flood of unsold water, MET lowered its prices below the price of local water to increase sales. It covered operating losses by increasing property taxes. This financing structure transferred wealth - via water - from high-tax areas to high demand areas (Ostrom, 1953). The justification for high taxes required creative thinking. In 1931, MET said that "cost would be allocated in a 'just' way to encourage 'full use' of the CRA" (Milliman, 1956a, p. 206), and this was interpreted to mean that property taxes would subsidize variable costs. The duration and magnitude of these subsidies ended up being quite large: By 1954, Los Angeles (with nearly 70 percent of MET's tax base) had paid 61 percent of
MET's costs in exchange for 8 percent of its water (Milliman, 1956a).

Another subsidy came from price discrimination: MET's retail price was $\$ 50$ $60 / \mathrm{AF}$, but irrigators and industrial users paid $\$ 8 / \mathrm{AF}$ and $\$ 25 / \mathrm{AF}$, respectively (Milliman, 1956a). Although this practice may have been economically sound - agriculture users have a higher elasticity, use lowerquality water, and bought one-third to onehalf of MET's water - it appeared to contradict the MET Act, which said CRA water would be for urban use (Milliman, 1956a).

A third subsidy came at annexation. Although MET "penalized" later annexation with penalty fees and back taxes, those fees were calculated in the most generous way possible: First, they were the lower of a per acre charge or back tax assessment. Second, city member agencies paid no annexation charges. ${ }^{10}$ Third, fees based on per acre charges used book value of paid assets, a number smaller than (allowed but unused) valuations based on replacement cost or market valuation (MET, 1992). Alternatively, fees based on back taxes used the share of new member assessed value in total assessed value. Since this calculation compares pre-annexation values to post-annexation values, it understates the real share a new area represents. ${ }^{11}$

MET also received subsidies from outsiders: In the 1931 bond prospectus, MET claimed that debt would be paid by service charges, not taxes. Despite this, MET collected taxes - claiming that property taxes were "ownership charges" that gave potential access to MET water. When MET qualified as a "self-liquidating project without resort to taxation" in 1932, it could

\footnotetext{
${ }^{9}$ The first mention of prices in MET's CRA plans was in April 1931 (Milliman, 1956a).

${ }^{10}$ This policy dates from MET's foundation, when cities worried that MET would try to control their growth (MET, 2004a).

${ }^{11}$ Put differently, the base is measured before annexation and payments occur after annexation-when property values reflect a post-annexation jump in value from access to water.
} 
Table 3.2: MET's initial sales were below projections

\begin{tabular}{lrr} 
Fiscal Year & Actual & Projected \\
\hline $1941-2$ & $12.9 \mathrm{cfs}(9.3 \mathrm{TAF})$ & $400 \mathrm{cfs}$ \\
$1942-3$ & $20 \mathrm{cfs}(14.5 \mathrm{TAF})$ & $400 \mathrm{cfs}$ \\
$\vdots$ & & \\
1953 & $340 \mathrm{cfs}$ & $400 \mathrm{cfs}$ \\
\hline
\end{tabular}

swap bonds issued in 1931 for cheap loans from the Federal Reconstruction Finance Corporation - bringing another federal subsidy (the first came from Hoover power) to Southern California (Milliman, 1956a, 1957).

\subsubsection{Free Riding and Expansion}

Although MET's price was below the marginal cost of delivery, and MET covered losses with property taxes, existing MET members favored expansion. They may have reasoned that new members would increase revenue and broaden the tax base: Short-run losses would increase, but the absorption of excess capacity would support higher prices - reducing the burden in the long run (Milliman, 1956a; Erie, 2006). Robert Skinner (MET's GM from 196267) said that MET's "effort of the early $40 \mathrm{~s}$ is to actually encourage annexations to expand the tax base as an ameliorating measure on the economic side" (Oshio, 1992, p. 109). Although operating costs exceeded sales revenue until 1954, expansion accelerated the arrival of break even by absorbing capacity - facilitating higher prices - and lowering marginal costs. SDCWA's annexation was the biggest and most important expansion.

\subsubsection{SDCWA to the Rescue?}

MET had surplus supply, and San Diego county had big demand, but the county's "natural" annexation to MET was hindered by the City of San Diego's historic rivalry with Los Angeles, location outside the South Coast Basin (MET's service area), and agricultural sector (Erie, 2006). ${ }^{12}$

Before joining MET, San Diego county depended on seasonal supplies - only onethird of its supply came from groundwater. ${ }^{13}$ Although the City of San Diego had rights to 112 TAFY of Colorado River water, it had no aqueduct. MET had water and the CRA, but San Diego resisted joining.

WWII broke the impasse: The Federal government ordered San Diego to join MET in 1944 after Navy operations and an exploding population lowered San Diego's supplies to "negligible" (Milliman, 1956a). Since San Diego county's numerous cities and irrigation districts would have complicated annexation, local citizens voted in June 1944 to create a municipal water district (MWD) and named it the San Diego County Water Authority (SDCWA). ${ }^{14}$ SDCWA resembled MET: It had 20 member agencies (30 today), and the City of San

\footnotetext{
${ }^{12}$ MET's 1931 vision did not include San Diego county, i.e., "Those portions of the Coastal Plain to which the aqueduct system can economically deliver water are regarded as the ultimate area that should be included within the Metropolitan Water District" (O'Connor, 1998a, p. 30).

${ }^{13}$ The South Coast Basin got three-quarters of its water from underground.

${ }^{14}$ At the same time as he promoted the SDCWA Act, State Senator Fletcher tried to amend the MET Act to allow any district to use the CRA to carry water (Ostrom, 1953). Had that amendment succeeded, SDCWA would have faced fewer problems in trying to take delivery of IID water in 1995; see Section 1.3.
} 
Diego dominated it as Los Angeles dominated MET.

SDCWA was still resisting joining MET when the end of the war ended federal pressure to annex. Suddenly, SDCWA decided that it did want to join MET, and local leaders lobbied Washington DC to force MET to accept SDCWA (Oshio, 1992; Erie, 2006). The battle within MET was no easier: Many members opposed the annexation, but LADWP Director Rossetti's arguments that SDCWA would reduce MET's debt won the day (Oshio, 1992).

When SDCWA joined, it traded its entitlement to 112 TAFY of Colorado River water for more time to pay back taxes (30 instead of 20 years) and cost sharing on the 70 mile aqueduct connecting SDCWA to MET's distribution network (Milliman, 1956a). ${ }^{15}$ SDCWA joined MET in December 1946 and received its first deliveries in November 1947 (SDCWA, 2004). By 1949, SDCWA was buying half of MET's water.

\subsection{Glory Years}

SDCWA's annexation heralded a new era in which MET-pushed by scarce revenues and abundant water and pulled by local drought - expanded more, and on more favorable terms than predicted in the 1930s (Oshio, 1992). Between 1946 and 1955, the eight member agencies that annexed with SDCWA were big and vacant: MET's area increased by over 200 percent (see Figure 3.2), but its population only increased by 75 percent. ${ }^{16}$

Nobody embodied expansionary spirit like Joseph Jensen (former oilman and chair of the Los Angeles Chamber of Commerce committee on water), who was elected
Chairman of MET's Board of Directors in 1949. (Table 3.3 lists all of MET's Chairmen.) He and others vowed to "maintain the momentum of the boom in Southern California" (Oshio, 1992, p. 109). Opposed to these boosters were those who worried that overexpansion would strain Colorado River supplies without lowering taxes.

In 1948, the slow-growth group (led by Los Angeles but not Jensen) blocked the annexation of thirsty, poor Pomona MWD (later Three Valleys MWD). Politicians in the California Legislature retaliated with a motion to replace block voting with individual director voting, which threatened Los Angeles' cohesion (Oshio, 1992). In a compromise, Pomona agreed to pay higher annexation charges, the reform disappeared, and Pomona annexed to MET (Oshio, 1992). Pomona's annexation rebalanced MET's financing enough to allow for rapid growth.

With a new growth path (out of the Basin to SDCWA, to non-urban areas like Pomona), MET's Colorado River rights suddenly looked inadequate. Chairman Jensen believed that MET could buy enough water to maintain reliability while growing (Ostrom, 1953). On December 16 1952, Jensen issued the Laguna Declaration in which MET guaranteed Southern California's water supply: ${ }^{17}$

The District is prepared, with its existing governmental powers and its present and projected distribution facilities, to provide its service area with adequate supplies of water to meet expanding and increasing needs in the years ahead. When and

\footnotetext{
${ }^{15}$ The CRA is 242 miles long, with a larger diameter and bigger pumping units.

${ }^{16} \mathrm{MET}$ had a population density of 4,000 people $/ \mathrm{mi}^{2}$ before the nine (population density of 1,420 people $/ \mathrm{mi}^{2}$ ) joined.

${ }^{17}$ Bold text was added to the original Declaration, which is now Section 4202 of MET's Administrative Code.
} 


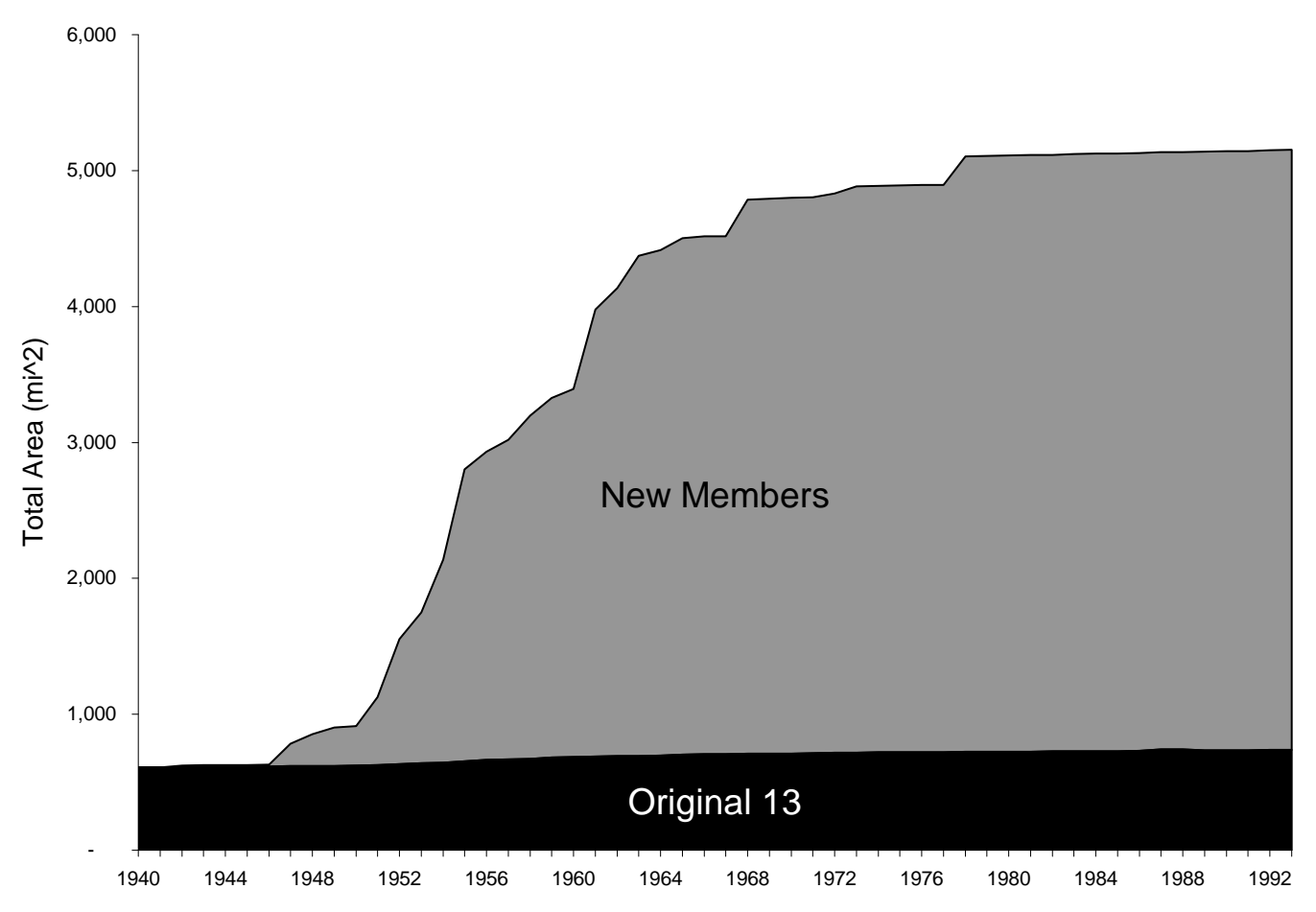

Figure 3.2: New member agencies are responsible for MET's increase in area

Table 3.3: MET's Chairmen of the Board

\begin{tabular}{lll} 
Name & Representing & Term \\
\hline W. P. Whitsett & LADWP & $1929-47$ \\
Victor H. Rossetti & LADWP & 1947 \\
John H. Ramboz & San Marino & $1948-49$ \\
Joseph Jensen & LADWP & $1949-74$ \\
Warren W. Butler & Compton & $1974-75$ \\
Howard H. Hawkins & Upr. San Gabriel MWD & $1975-79$ \\
Earle C. Blais & Burbank & $1979-83$ \\
E. Thornton Ibbetson & Central Basin MWD & $1983-87$ \\
E. L. Balmer & West Basin MWD & $1987-89$ \\
Lois B. Krieger & Western MWD & $1989-93$ \\
Michael J. Gage & LADWP & 1993 \\
Patrick H. Miller & Calleguas MWD & 1993 \\
John V. Foley & MWDOC & $1993-98$ \\
Phillip J. Pace & Central Basin MWD & $1999-2005$ \\
Wesley M. Bannister & MWDOC & $2005-06$ \\
Timothy F. Brick & Pasadena & $2006-$ now \\
\hline
\end{tabular}


as additional water resources are required to meet increasing needs for domestic, industrial and municipal water, the District will be prepared to deliver such supplies.

Taxpayers and water users residing within the District already have obligated themselves for the construction of an aqueduct supply and distribution system. This system has been designed and constructed in a manner that permits orderly and economic extensions and enlargements to deliver the District's full share of Colorado River water and State Project water as well as water from other sources as required in the years ahead. Establishment of overlapping and paralleling governmental authorities and water distribution facilities to service Southern California areas would place a wasteful and unnecessary financial burden upon all of the people of California, and particularly the residents of Southern California.

According to Ostrom (1953), the Laguna Declaration gave others notice that MET intended to control the Feather River Project (later renamed as the State Water Project) - extending its self-proclaimed monopoly on imports to the region.

\subsection{Irrational Los Angeles?}

Under Jensen's leadership (1949-74), MET's service area grew from 900 to 4,900 $\mathrm{mi}^{2}$, and much of the cost of that expansion fell on Los Angeles. By 1954-the first year in which revenues covered operating costs-Los Angeles had paid 61 percent of MET's costs for 8 percent of its water (Milliman, 1956a). It was not until 1973 that water sales provided more revenue than property taxes.

Although LADWP had 50 percent of the vote until 1953 and a substantial plurality until the 1970 s, it did not veto expansion. ${ }^{18}$ Why not? Looking more deeply, why did Los Angeles even support MET's formation if it was pretty clear that it would subsidize everyone else?

One logical answer is that Los Angeles decided the benefit of electricity from Hoover Dam was worth the cost of subsidizing MET (see Section 3.2.2). Using numbers Los Angeles could have known at the time, we can estimate the total net present value of Los Angeles' benefit from access to Hoover power as $\$ 1.33$ billion (in 2004 dollars). ${ }^{19}$ These calculations ignore the value of MET water and (perhaps) unanticipated purchases of MET's surplus power in early years; recall Figure 3.1.

LADWP's planned cost (ignoring the cost as well as benefit of water) would come from property taxes of 0.10 percent of Los Angeles' assessed value. Even if taxes were higher, they were worth somethingpreferential rights that would give LADWP valuable option rights to water if there was a shortage (Erie and Joassart-Marcelli, 2000; Berkman and David, 2000). In any event,

\footnotetext{
${ }^{18}$ The MET Act of 1928 limited Los Angeles' votes to 50 percent of the total. In 1947, Los Angeles had 69 percent of total assessed value; see also Figure 3.7.

${ }^{19}$ Multiply $1.05-0.45=0.60$ cents $/ \mathrm{kWh}$ (savings from buying Hoover Dam power instead of SCE power; see Section 3.2.1) by 19 percent of Hoover Dam contracts (Section 3.2.3) by Hoover Dam's annual average output of 4.4 billion kilowatt-hours (1947-2005 from http://www.usbr.gov/lc/hooverdam/faqs/powerfaq. html).
} 
property taxes varied between 0.25 and 0.50 percent of $\mathrm{AV}$, and preferential rights turned out to be invalid (see Sections 3.2.4 and 2.4.2, respectively). Between 1942 and 2004, Los Angeles' cumulative property tax payments were $\$ 2.98$ billion (ignoring sizable pre-1942 payments). In hindsight, the MET-Hoover deal was not an obvious winner for LADWP, but it was certainly not a loser: If taxes had been 0.10 percent or even half the level they turned out to be (2.5 to 5 times higher than 0.10), Los Angeles' net benefit from MET (ignoring the value of water) would have been positive.

Putting aside the cost-benefit analysis, Los Angeles may have subsidized MET for other reasons. First, Los Angeles may have wanted MET water for its own growth or as an insurance policy against failure of LAA supplies (Erie, 2006).

Second, LADWP managers may have been empire builders who understated supply and overstated demand to expand at the expense of ratepayers and taxpayers. ${ }^{20}$ If not LADWP, then perhaps Los Angeles' leaders wanted expansion because they were regional boosters and/or direct beneficiaries of regional growth (Parsons, 1990; Gottlieb and FitzSimmons, 1991; Hundley Jr., 1992; Erie, 2006)..$^{21}$

Third, Los Angeles may have wanted to contribute to social welfare - acting out of Progressive ideals, as Brick (2003) supposes. Ostrom (1953, p. 144) quotes Chairman Whitsett (1929-1947), who said "whatever is done should be done for the benefit of the whole and whatever is done for the benefit of the whole should be shared by all the parts." Whitsett led the Los Angeles dele- gation, which kept the peace, sought unanimous decisions, never opposed a united opposition, and voted last to either support the consensus or ask for reconsideration if consensus is not clear.

Fourth is the possibility that "the small" exploited Los Angeles. ${ }^{22}$ When MET was founded by 13 cities in 1928, Los Angeles represented 82 percent of assessed land value but was politically weak from the fallout over its aggressive management of LAA water. In later years, less powerful entities (e.g., SDCWA and Pomona) used political pressure to force their way into MET.

While these other reasons contributed to Los Angeles' support of MET (and subsidies to other member agencies), the most obvious conclusion is that Los Angeles had supported MET to get access to Hoover Dam power. That decision did not look so smart when MET's sales fell short of expectations and property taxes increased, but Los Angeles may have ignored the possibility that MET's water would be too expensive. By the time Los Angeles realized its mistake the CRA was a sunk cost, and the optimal action of LADWP (and MET) was to expand. (MET's haphazard expansion path (e.g., SDCWA and Pomona) indicates that MET had not planned for expansion in the 1930s.)

Regardless of intention, MET expanded, and it used subsidies to do so. Although MET's use of average cost pricing meant that some subsidies were inevitable, these subsidies turned out to be much greater when expansion led to the annexation of distant, poor, thirsty and thinly-populated areas. Subsidies to these areas put MET on

\footnotetext{
${ }^{20}$ LADWP claimed its operations placed "no burden on Los Angeles taxpayers" in the 1950s, but general tax assessments funded LADWP projects -including MET (Milliman, 1956a).

${ }^{21}$ With increasing returns to scale technology (e.g., the CRA), first movers can change payoffs such that other actors join (Oliver et al., 1985).

${ }^{22}$ Skaperdas (2003) demonstrates how the poorer (less productive) opponent has a comparative advantage in grabbing from a common-pool - a concept resembling the exploitation of LADWP by poorer member agencies.
} 
an unsustainable path that continued well past the supply contractions and the end of subsidies described next.

\subsection{The End of Abundance}

With hindsight, we can see that MET started down an unsustainable path in the 1940s and discovered it was on that path in the 1960s. Policies that may have been efficient in the years of abundance became inefficient when conditions changed.

\subsection{Changes in Supplies}

MET's founders estimated that CRA water would support demand growing at 1920s rates until 1980 (Milliman, 1957). ${ }^{23}$ The 1952 Laguna Declaration that MET would provide "adequate" supplies seemed reasonable at the time - MET was only selling one-third of its supply by 1956 .

Unfortunately, MET's plans did not consider competing demands: Soon after the Declaration, Arizona decided to contest California's allocation of Colorado River water (Ostrom, 1953). Since MET held junior rights in California's allocation, this attack (which ended in the US Supreme Court) pushed MET to look for other supplies. By 1960, MET had become the biggest contractor of the (unbuilt) State Water Project (SWP), but SWP supplies also turned out to be vulnerable: Ten years after SWP deliveries began in 1972, voters limited the SWP's total size - and thus reduced MET's contracts. The two sections that follow review these changes in more detail.

These artificial shocks to MET's supplies occurred against a background of natural variation, and MET worked hard to maintain service reliability. Figure 3.3 shows MET's supplies from both sources.

\subsubsection{The Colorado River}

The 1922 Colorado River Compact allocated 7.5 MAF to the Lower Colorado Basin (Arizona, California and Nevada) without dividing that water among those states (Bureau of Reclamation, 2004). ${ }^{24}$ In June 1929, six of seven states bordering the Colorado River approved the BCP Act, but Arizona refused-it wanted the Gila River excluded from its allocation (Milliman, 1956a). The BCP Act-besides authorizing construction of the Hoover Dam and related infrastructure - divided the Lower Basin's 7.5 MAF among California (4.4 MAF), Arizona (2.8 MAF) and Nevada (0.3 MAF).

As long as Arizona used less than 2.8 MAFY, its claim to Gila River water did not matter-Arizona even approved the BCP Act in 1944. When Arizona decided to build the Central Arizona [irrigation] Project, its claim on the Gila River became relevant, and the state went to court. In the 1963 Arizona vs. California decision, the US Supreme Court ruled in favor of Arizona, and California's allocation was confirmed at 4.4 MAF (Rossman, 2005). This decision also divided surplus water among California $(50 \%)$, Arizona (46\%) and Nevada (4\%).

With California held to a $4.4 \mathrm{MAF}$ ceiling, the intrastate allocation of water became relevant. California's 1931 Seven Party Agreement allocated 5.2 MAF among California water users -in violation of the BCP. Agricultural interests (IID et al.) held 3.85 MAF of senior rights, and MET had

\footnotetext{
${ }^{23}$ Although CA Dept. of Water Resources (1930) and Commonwealth Club of CA (1931) discuss moving water from Northern California to the San Joaquin Valley via the SWP, they pay almost no attention to the idea of pumping water over the Tehachapi mountains to MET's service area.

${ }^{24}$ Because water flow in the years prior to 1922 were higher than normal, and the Colorado River Compact specified acre-foot entitlements to states, the River was overallocated on paper. When actual flows fall below paper rights, states re-negotiate allocations. The most recent negotiation concluded in 2008.

${ }^{25}$ MET began with rights to 1.1 MAFY and added 0.112 MAFY when SDCWA annexed in 1946.
} 


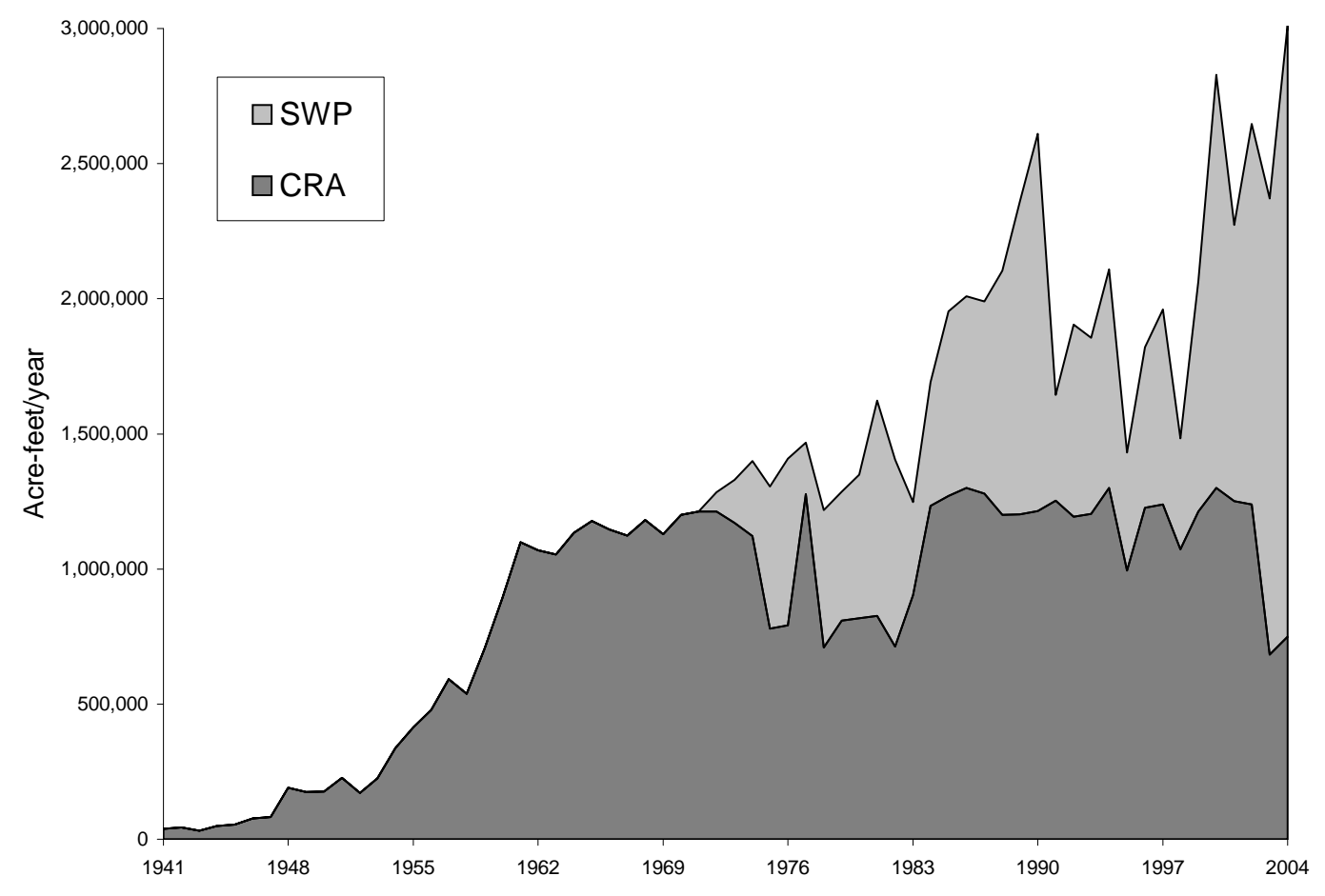

Figure 3.3: Historical supply to MET from CRA and SWP

the next 1.212 MAFY in rights. ${ }^{25}$ With a 4.4 MAF limit, MET's allocation was cut to 0.55 MAF (SDCWA, 2002).

The bottom line is that MET lost access to firm rights to Colorado River water (from 1.212 to $0.55 \mathrm{MAF}$ ) and the surplus was smaller (since Arizona kept Gila River water, its 2.8 MAFY extraction left less water). Although MET would get the next $0.662 \mathrm{MAF}$ of the surplus that went to California (50 percent of total surplus), the decision reduced MET's supply from the Colorado.

MET's paper supply from the Colorado River did not change until 1988, when six years of negotiation culminated in an agreement with IID. In exchange for financing IID's conservation programs, MET would receive 100-110 TAFY of saved water (MET, 2004c), and deliveries began in 1998 (MET, 2004a). In 2005, MET signed a land-fallowing agreement with Palo Verde
Irrigation District (PVID) - another agricultural area with rights to part of the 3.85MAF. MET pays PVID farmers to fallow as much as 30 percent of their acreage for two years and takes delivery of up to 115 TAF of unused PVID water at the Colorado River. (MET recently activated this program Bowles (2008).)

Figure 3.4 shows the fluctuations in MET's entitlements to and supply of water from the Colorado River. Today, MET gets about 30-40 percent of its water from the CRA - often in excess of its rights.

\subsubsection{The State Water Project}

In 1960, California's Department of Water Resources (DWR) began signing contracts for a State Water Project (SWP) to bring water from the Sacramento Delta to Southern California. MET was DWR's first and biggest contractor but hesitated to sign too many contracts for fear that a new, se- 


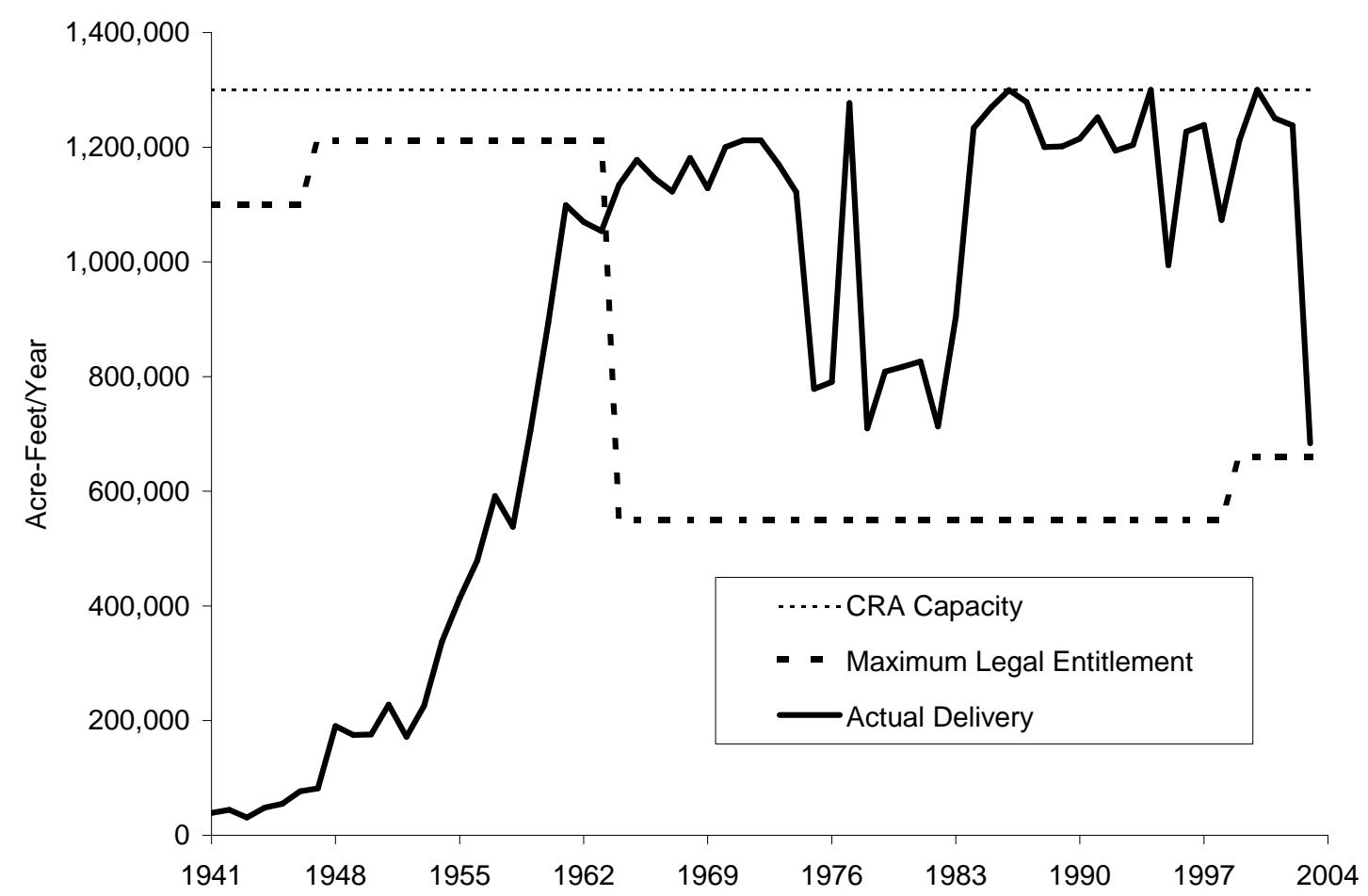

Figure 3.4: MET's CRA entitlement rises and falls

cure supply would affect Arizona v. California (Milliman, 1957; Hundley Jr., 1992). When California lost that case, MET signed enough additional contracts to increase its entitlement to 2.0115 MAFY - 48 percent of the SWP's planned capacity (Hundley Jr., 1992; SDCWA, 2002).

After SWP deliveries began in 1972, MET's increased its deliveries (as high as 800 TAFY) until 1982, when voters rejected a Peripheral Canal project in the Sacramento Delta that would have "completed" the SWP (Rossman, 2005). The Peripheral Canal defeat signalled a shift in power from water agencies to environmentalists that would only grow stronger (McDermott, 1998; Erie, 2006): More recent rulings have limited exports of water from the Delta to protect endangered fish (Weiser, 2007).

MET's SWP supplies were limited by other factors: During the 1987-1991 drought, agricultural contractors lost almost all their SWP water. Their protests led to the 1994 Monterey Agreement, which ended urban contractors' priority access to SWP water. As a final blow, the California Court of Appeals ruled, in the 2003 Planning and Conservation League vs. DWR decision, that "contractors surely cannot be entitled to water nature refuses to provide or the body politic refuses to harvest, store and deliver" (Rossman, 2005, pp. 4-5).

In the 20 years to 2004, MET's median SWP purchase was 700 TAF. Today, MET estimates its SWP supply to be 0.6 MAF in a dry year and 1.35 MAF in an average year (SDCWA, 2002). Present SWP deliveries to MET are approximately 1.35-1.5 MAFYor 60-70 percent of its total supply (MET, 2004c). Figure 3.5 shows MET's rights and deliveries over the years. 


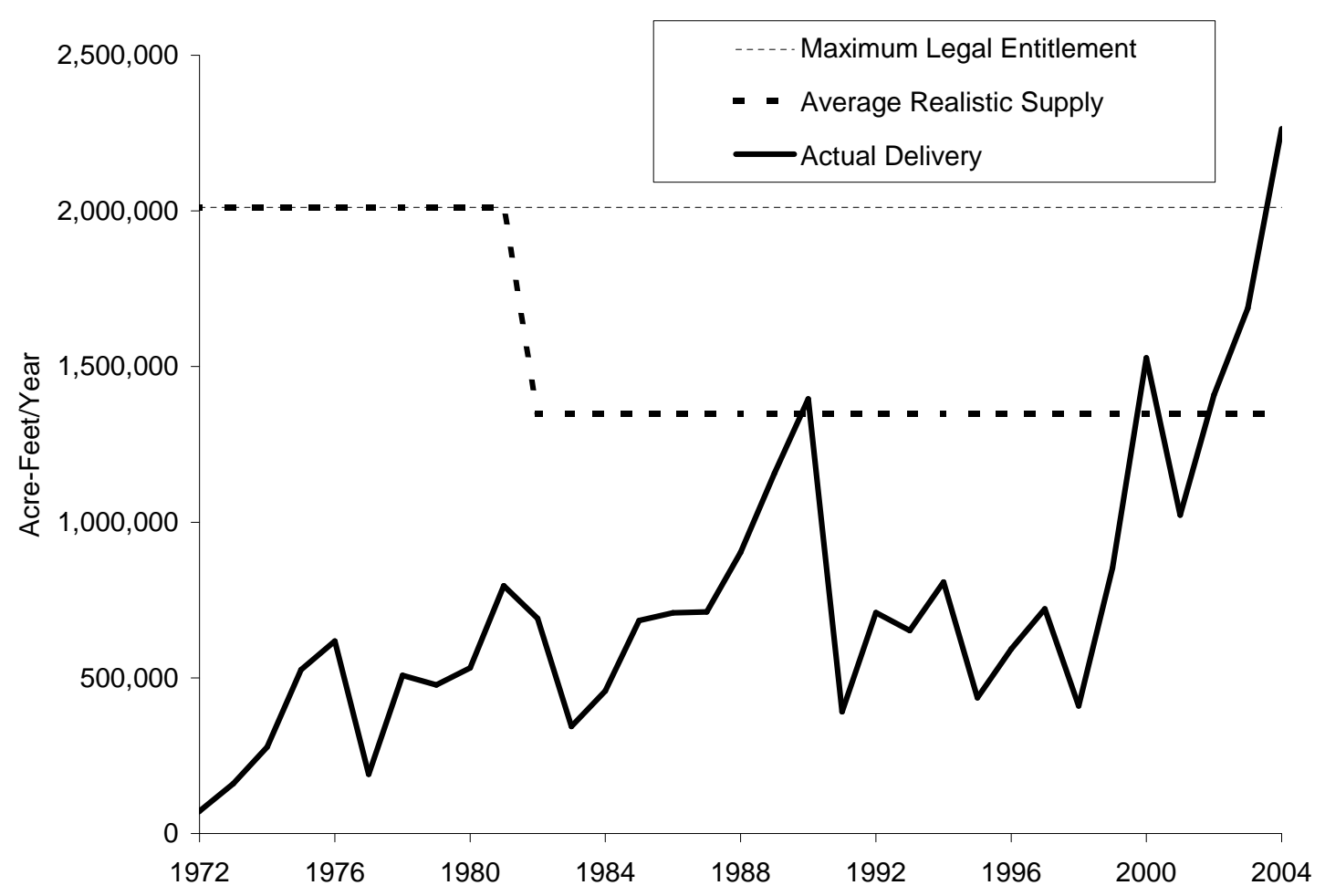

Figure 3.5: MET's SWP rights are stable but deliveries vary

\subsection{Changes in Demand}

In the 1950s, MET's low prices encouraged existing consumers to replace groundwater with MET water and new consumers to annex to MWD - increasing intensive and extensive demand, respectively. New members were responsible for 97 percent of the increase in MET's service area in the fifty years to 1993; see Figure 3.2. Although area (and population) increase over all these years, per capita use peaked in the 1960s; see Figure 3.6.

Active attempts to limit demand (with the exception of voluntary cutbacks in the 1977 drought) did not begin until 1988, when LADWP began a voluntary water conservation program based on water-efficient fixtures. ${ }^{26}$ Conservation pricing has only taken the form of increasing block rates and/or penalty rates during drought (see Section 3.12).

Other conservation efforts have centered on limiting growth: In 1978, MET's changed its annexation policy to require upfront payment of fees. ${ }^{27}$ This change nearly halted growth in MET's service area: Between 1978 and 2005, MET grew by less

\footnotetext{
${ }^{26}$ According to Quinn (2006c), MET's rationing during the 1977 drought was a response to political pressure - not actual shortage. The Board of Directors wanted demand to fall by ten percent and imposed 100 percent surcharges on deliveries exceeding 90 percent of 1976 deliveries; members that took less than 90 percent got rebates (Wahl and Davis, 1986; Oshio, 1992). Total demand fell by 14 percent (MET, 1990); MET deliveries for FYE 1978 are 91 percent of the average for the three prior years.

${ }^{27}$ This rule change coincided with Proposition 13 (also passed in 1978), a law that restricted property tax increases. Without the option of increasing property taxes, new areas had to use special assessments or cash flow to pay fees. Section 3.3.2 describes how cheap annexation fees encouraged growth.
} 


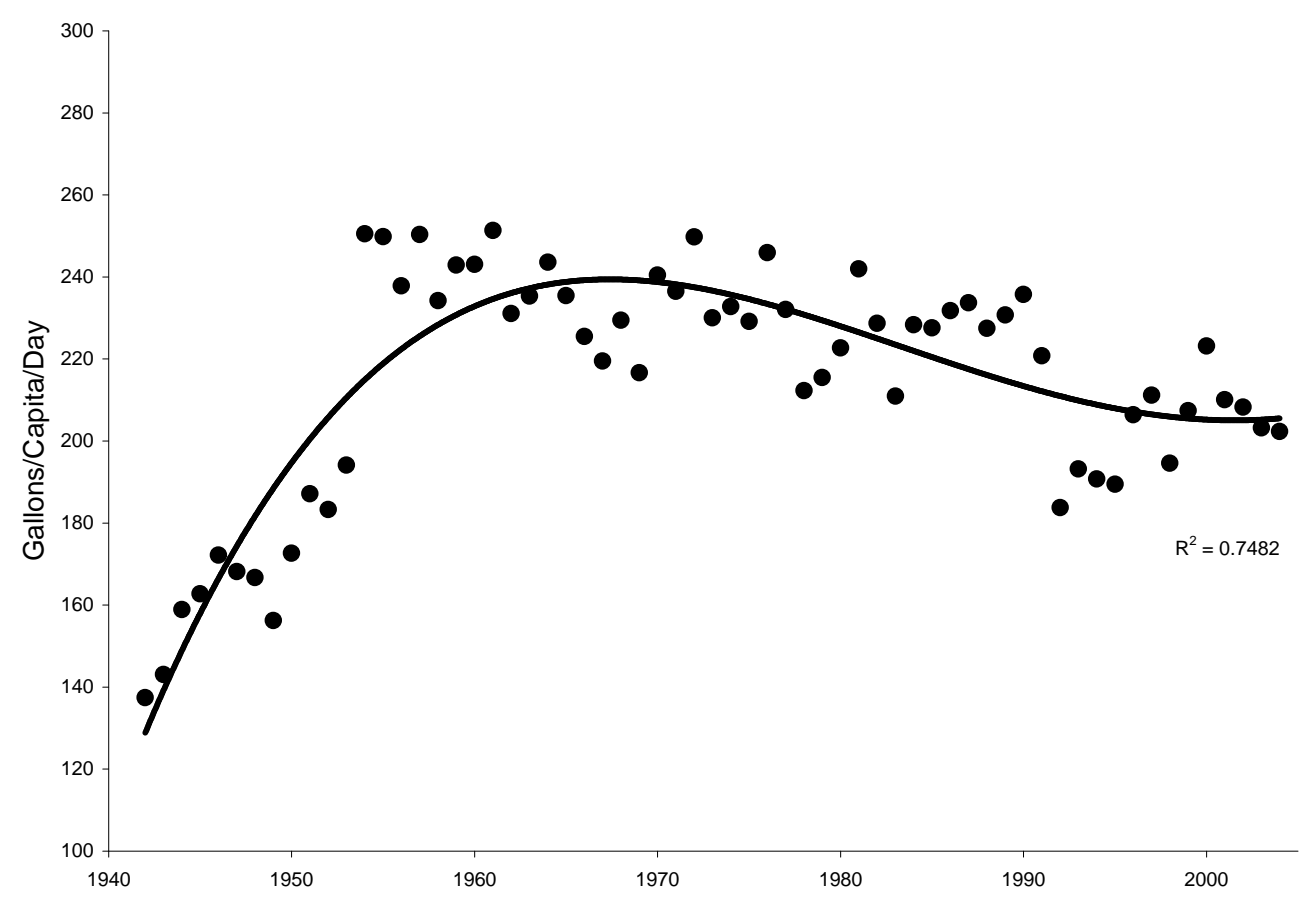

Figure 3.6: Per capita water use rises and falls

than $2 \mathrm{mi}^{2} /$ year, or 1.4 percent in total (MET, 1992). (Recall from Section 3.3.4 that SDCWA had 30 years to pay its annexation fees.) California law SB610 (2002) limits growth of demand from infill projects: It requires that large commercial, industrial and residential projects secure a 20year supply of water before receiving construction approval (Rossman, 2005). For the future, MET (2001) projects a final and total service area increase of $104 \mathrm{mi}^{2}$ - two percent larger than MET's area today.

\subsection{Changes in Votes}

From MET's beginning, Los Angeleswith the largest share of MET's total assessed value (AV) and thus votes on MET's Board of Directors - held the most political power. Los Angeles' veto over MET policies ended in 1949 when its share of AV dropped below 50 percent, but it was not until 1973 that the shares of the second and third-largest members agencies (SDCWA and MWDOC) passed that of LADWP; see Figure 3.7. In 2005, LADWP had 23 percent of the votes with 18 percent for MWD of Orange County (MWDOC) and 15 percent for SDCWA. As Los Angeles' relative power declined, Board decisions became more democratic - and unpredictable.

The power shift from Los Angeles to other agencies was accompanied by a parallel shift from the Board of Directors to MET's Staff: After Jensen died in 1974, director terms were limited, and staff grew in relative authority (McDermott, 1998).

Also because of term limits, directors were less likely to be retired "water buffaloes" and more likely to be aspiring politicians on their way to higher office. Because they see their districts - not the regionas their clients, Board decisions have become more contentious. Jeff Kightlinger's 2006 election as GM-against the wishes 


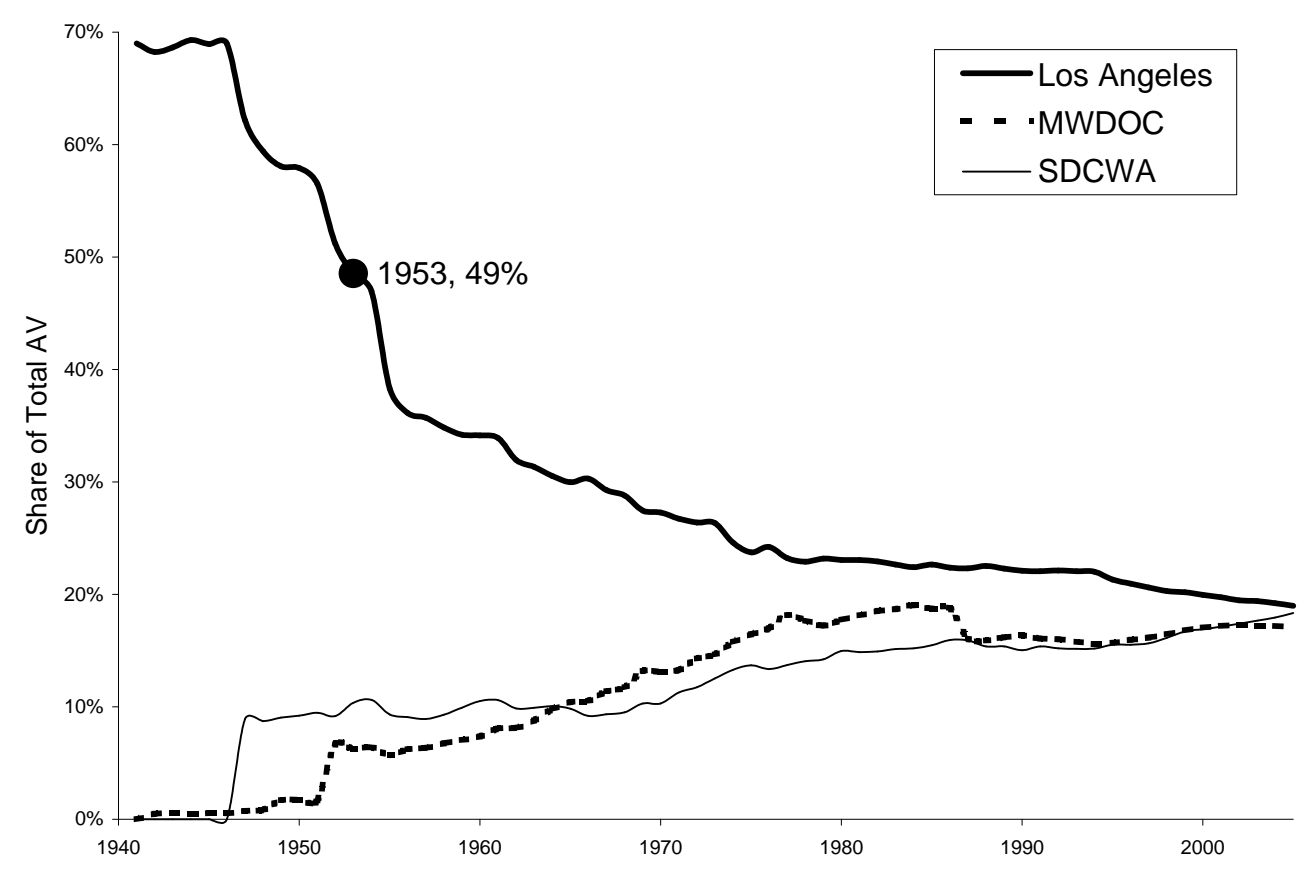

Figure 3.7: Los Angeles' share of assessed value falls over time

of LADWP and SDCWA - set an historic precedent.

\subsection{Changes in Culture}

Along with these changes in political power (or perhaps because of them), the culture of MET changed over the years. As Ostrom et al. (1994, p. 45) point out, culture is a function of "generally accepted norms of behavior, the level of common understanding about action areas, the extent to which the preferences are homogenous, and distribution of resources among members."

MET's first General Manager (GM) was F.E. Weymouth, an engineer from the $\mathrm{Bu}-$ reau of Reclamation who held a joint appointment as Engineer of Dams at the Los Angeles Bureau of Water Works \& Supply (Milliman, 1956a). Weymouth hired many employees from the Bureau and established a culture of engineering at MET that would last deep into the 1970s; see Table 3.4.

At risk of overgeneralization, engineering culture rewards problem solving and treats costs as an outcome rather than a constraint. When engineers face a shortage, they ration with a formula (see, e.g., pro-rata rationing in SDCWA (2006a)). As MET's situation changed, and shortages and costs became more important, the reallocation of existing rights and renegotiation of policies gave lawyers a comparative advantage, and most recent GMs have been lawyers. ${ }^{28}$ Note that Wodraska (the exception to the lawyer trend) spent most of his five years "trying to regain control of the staff" McDermott (1998). Insiders say that conflict among member agencies (e.g., the Wheeling Dispute) led him to resign in frustration.

\footnotetext{
${ }^{28}$ The value of negotiation is demonstrated in the non-uniformity of "uniform cuts" implemented during the 1987-91 drought; see Section 3.12.
} 
Table 3.4: MET's general managers change from engineers to lawyers

\begin{tabular}{|c|c|c|c|}
\hline Name & Title & Term & Notes \\
\hline F. E. Weymouth & GM \& CE & $1929-41$ & Engineer, planned CRA \\
\hline Julian Hinds & GM \& CE & $1941-51$ & Engineer, worked on CRA \\
\hline Robert B. Diemer & GM \& CE & $1952-61$ & Engineer, worked on CRA \\
\hline Robert A. Skinner & GM & $1962-67$ & Assistant CE since 1952 \\
\hline Henry J. Mills & GM & $1967-71$ & Former CE \\
\hline Frank M. Clinton & GM & $1971-74$ & Engineer \\
\hline John H. Lauten & GM & $1974-77$ & Lawyer \\
\hline Evan L. Griffith & GM & $1977-84$ & Engineer \\
\hline Carl Boronkay & GM & $1984-93$ & Lawyer \\
\hline John R. Wodraska & GM & $1993-98$ & Business Manager \\
\hline Ronald R. Gastelum & $\mathrm{CEO}$ & 1999-2004 & Lawyer \\
\hline Dennis B. Underwood & $\mathrm{CEO} / \mathrm{GM}$ & 2005 & Lawyer \\
\hline Jeffrey Kightlinger & GM & 2006-now & Lawyer \\
\hline
\end{tabular}

Until the 1980s, executives at MET and member agencies came from a homogenous group of water buffaloes: male engineers who worked together for years (Milliman, 1956a; McDermott, 1998). More recently, leaders' gender, training, tenure and prior experience have diversified. Although diversity improves community representation, cooperation is more difficult when common knowledge, language and goals diverge (Wilson, 1989; Ostrom et al., 1994). It has become more difficult to agree how to solve problems at MET. ${ }^{29}$

\subsection{Changes in Cost}

At its inception, MET covered costs with property tax revenues, and this policy shifted costs to low-demand, wealthier areas from high-demand, poorer areas. Milliman (1956a), for example, calculates that SDCWA paid 6 percent of taxes in exchange for 34 percent of MET's water between 1948 and 1955. Los Angeles, in contrast, paid
62 percent of taxes for 9 percent of the water. On an acre-foot basis, this works out to $\$ 38 / \mathrm{AF}$ for SDCWA and $\$ 1,246 / \mathrm{AF}$ for LA. Flaxman (1976) does the same calculations twenty years later and finds that SDCWA's average cost is $\$ 69 / \mathrm{AF}$ and Los Angeles' cost is $\$ 532 / \mathrm{AF}$. Ostrom (1953) also pointed out the imbalance between cost and benefit at MET.

Since Los Angeles was probably not interested in long-term charity (see Section 3.5), it fought to shift costs from taxes to water sales (via higher prices). In July 1960, the MET Board approved Resolution 5748, which mandated that MET would pay capital costs and operating expenses "from water revenues as soon as practicable." In September of the same year, Resolution 5821 mandated that half of capital expenses and all operating expenses would be paid through water sales (Flaxman, 1976).

MET's Board interpreted "as soon as practicable" to mean "later." Besides the

\footnotetext{
${ }^{29}$ With caveats about sampling error, 73 percent of the 15 member agency managers who participated in the experiment in Chapter 5 were engineers but only 14 percent of the 14 MET executives were engineers; see Table 5.2 .
} 
obvious inference that the Board wanted to subsidize water prices, the Board probably also preferred steady tax payments to unpredictable water revenues. ${ }^{30}$

Los Angles kept pushing, and sales revenue exceeded taxes by 1973; see Figure 3.8. Unfortunately, this change created a different problem: Since voting power remained a function of assessed land values, water buyers were paying a larger share of MET's expenses without gaining more control over how that revenue was spent, i.e., taxation without representation (SDCWA, 2001; Atwater and Blomquist, 2002). ${ }^{31}$ Today, MET receives about 80 percent of its operating revenue from water sales; the rest comesin equal shares - from taxes and capacity charges (MET, 2004a).

\subsection{The Big Drought}

Over the years, MET adapted to falling supply, growing demand, realignment of political power, changes in culture and the way it paid for its operations. From an outside perspective, everything seemed fine: Water was reasonably cheap and nearly always available. It was only when the 1987-1991 drought hit that outsiders discovered everything was not fine: MET's excess supply was gone, and it had no policies for managing demand or rationing supply. In the resulting conflict over ad hoc solutions MET adopted, relations among member agencies grew so strained that analysts actively considered options for a postMET world (MET-RAND, 1998; O'Connor, 1998b). This section describes those ad hoc solutions.

In the early years of the 87-91 drought, MET maintained or increased deliveries to member agencies with falling local supplies. Local supplies in 1990-92 were about 80 percent of their pre-drought, five-year average. MET's 1990-91 deliveries were 160 percent of the five-year base; see Table 3.5. In 1992, they fell to 120 percent of the base because MET could not get enough water. ${ }^{32}$ The drought just lasted too long. MET's 1952 Laguna Declaration, a pledge to provide "adequate supplies", was no longer credible.

MET also tried to reduce demand. Since it had no demand-reduction policy, it created one: In November 1990, MET's Board approved an "Incremental Interruption and Conservation Plan" (IICP) and implemented Stage 1 (voluntary reductions) immediately. Stage 2 was implemented in February 1991. Just one month later, the IICP jumped to Stage 5, which aimed to cut urban deliveries by twenty percent and agricultural deliveries by fifty percent. MET stayed in Stage 5 until April 1992.

MET used prices to reduce demand toward targeted "rights," which varied by member agency and depended on their base year allocation (Base), which was calculated using a formula that depended on historical use, conservation programs, and local supplies. Base did not determine who got water but how much water would cost: Members buying more than Base paid a penalty rate of $\$ 394 / \mathrm{AF}$ (double the normal price of $\$ 197 / \mathrm{AF}$ ); those that bought

\footnotetext{
${ }^{30}$ MET's Deputy General Counsel Donald Whitlock explained that the Board did not want prices that might "cause some hardship upon the water user" (Flaxman, 1976, pp. 11-13).

${ }^{31}$ preferential rights (a function of past contributions to fixed costs) are also distorted, but they are not used; see Section 2.4.2.

${ }^{32} \mathrm{CRA}$ deliveries averaged close to 1.2MAFY (MET's entitlement) during the drought. SWP deliveries averaged 1.04 MAFY in the first four years, but then dropped to 391 TAF in 1991. This figure would have been lower (it represented 69 percent of total SWP deliveries, more than MET's share of SWP contracts), if urban contractors had not had priority (SDCWA, 2002). The 1994 Monterey Agreement ended that priority for future shortages; see Section 3.7.2.
} 


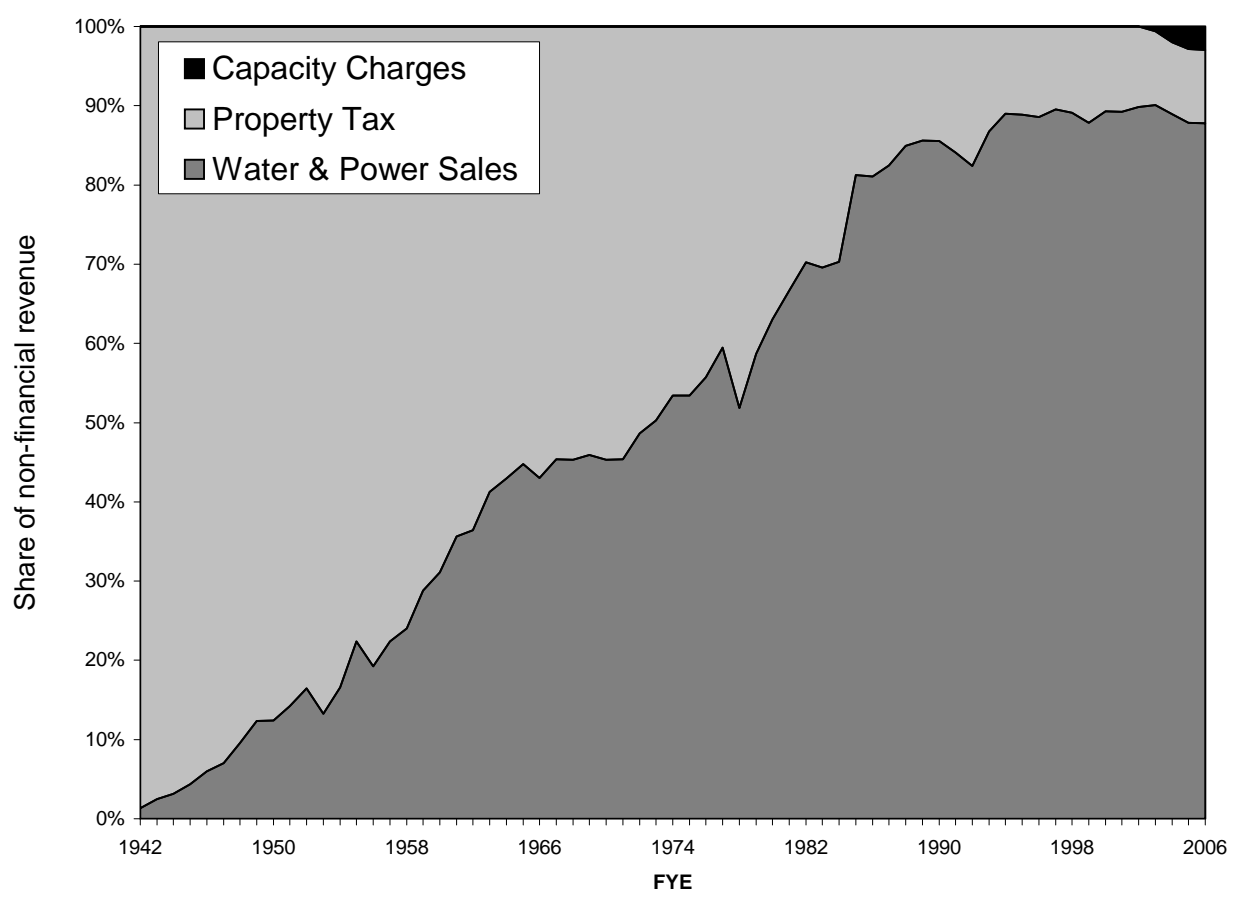

Figure 3.8: MET's revenue mix changed over the years

Table 3.5: Water deliveries in the drought years (MAF)

\begin{tabular}{lcccc} 
& Local & Local Share $(\%)$ & MET & Total \\
\hline $1982-86$ (avg) & 1.82 & 55 & 1.48 & 3.30 \\
1987 & 1.89 & 52 & 1.78 & 3.67 \\
1988 & 1.74 & 48 & 1.91 & 3.65 \\
1989 & 1.66 & 44 & 2.14 & 3.79 \\
1990 & 1.52 & 38 & 2.43 & 3.95 \\
1991 & 1.45 & 39 & 2.31 & 3.76 \\
1992 & 1.41 & 44 & 1.77 & 3.18 \\
1993 & 1.36 & 40 & 2.01 & 3.37 \\
\hline
\end{tabular}

less than 95 percent of Base received $\$ 99$ for each AF they did not buy (Boronkay, 1990).

The IICP appeared to favor some member agencies over others and had unintended effects, ${ }^{33}$ but it worked: MET's FYE 1992 deliveries were 77 percent of the 1989-1991 average, which was 155 percent of MET's pre-drought average.

Although any formula (especially a negotiated formula) is going to give different results to different subjects, the experiences of LADWP and SDCWA were very different. Because LADWP lost "local sup-

\footnotetext{
${ }^{33}$ First, agencies that overdrafted groundwater (and bought less MET water) received conservation payments. Because overdrafting reduced local supply, Base increased - allowing them to buy more MET water at normal prices. Second, some agencies lost money when customers cut demand (reducing revenue) faster than conservation payments increased (Young, 1998).
} 
plies" from the LAA, it got a higher Base and could increase its purchases without surcharges (Hundley Jr., 1992). LADWP's 1992 delivery was 350 percent of its 1986 delivery; see Figure 3.9. SDCWA got no such adjustment, and its 1992 delivery was 92 percent of its 1986 delivery; see Figure 3.10. On the other hand, SDCWA was able to cut demand by enough to receive $\$ 5.7$ million of conservation payments; LADWP got $\$ 6.9$ million (Young, 1998).

\subsection{SDCWA Defects}

The drought hit all member agencies, but SDCWA was particularly vulnerable. Not only was SDCWA MET's biggest customer (buying 26 percent of MET's total water), but MET supplied 83 percent of SDCWA's supply. SDCWA was more dependent on MET than any other agency, and MET's supply woes became SDCWA's woes. ${ }^{34}$ According to SDCWA (2004, p. 4), the "region's economy suffers loss of millions of dollars in economic activity and thousands of jobs are imperiled. Economic development in the region suffers major blow." 35

SDCWA took steps to reduce its dependency - breaking many taboos in the process. First, SDCWA circumvented MET's informal monopoly on imported supplies: In 1995, SDCWA signed an agreement to buy water from IID. That agreement led to eight years of negotiation and lawsuits between MET and SDCWA; see Section 1.3. Second, SDCWA sued MET, MET's Board of Directors and LADWP, asking that the Laguna Declaration be confirmed (i.e., that MET guarantee supplies to SDCWA) and
LADWP's preferential rights be revoked as a threat to SDCWA's supply (SDCWA, 2001). ${ }^{36}$ Third, SDCWA (and its member agencies) began building substitute infrastructure to reduce dependence on MET: In 2004, a few of SDCWA's member agencies signed contracts to buy water from a $\$ 270$ million, 56 TAFY seawater desalination plant (now in the permitting process). In 2006, SDCWA approved a $\$ 4.3$ billion capital improvement budget "to guarantee that the region would have a reliable water supply" (Conaughton, 2006). To observers inside and outside of MET, SDCWA's actions signalled that MET's function as an organization of collective action was imperiled.

\subsection{Barriers to Change}

MET's troubles during the drought and SDCWA's reaction were not surprising to outside observers. MET's weaknesses have been known to economists for over fifty years (Ostrom, 1953; Milliman, 1956b, 1957), but suggestions for improvement or reform have rarely been implemented. This section reviews the barriers to change at MET. First, MET - as a government bureaucracy - can resist outside pressure for change. Second, the web of principals and agents scattered throughout MET, member agencies and other bureaucratic agencies makes it hard to monitor for effort or even measure performance outcomes. Third, MET may believe it can "overcome" problems by purchasing agricultural water. Put differently, MET can resist reform, cannot be told where to reform, and

\footnotetext{
${ }^{34}$ See Section 4.2.4 for more discussion of dependency.

${ }^{35}$ According to Erie (2006, p. 108), SDCWA dramatized the drought's impact by cutting "supplies by 31 percent across-the-board, not by a weighted average of 31 percent [ 20 percent cuts to urban users and 50 percent cuts to agricultural users]. This protected agriculture in San Diego county at the expense of urban customers and bolstered SDCWA's claim to urban customers that they were vulnerable to MET."

${ }^{36}$ SDCWA argued that Los Angeles' tax payments and SDCWA's water purchases both count towards preferential rights and claimed that uncertainty over preferential rights harmed SDCWA. SDCWA lost that case in 2004.
} 


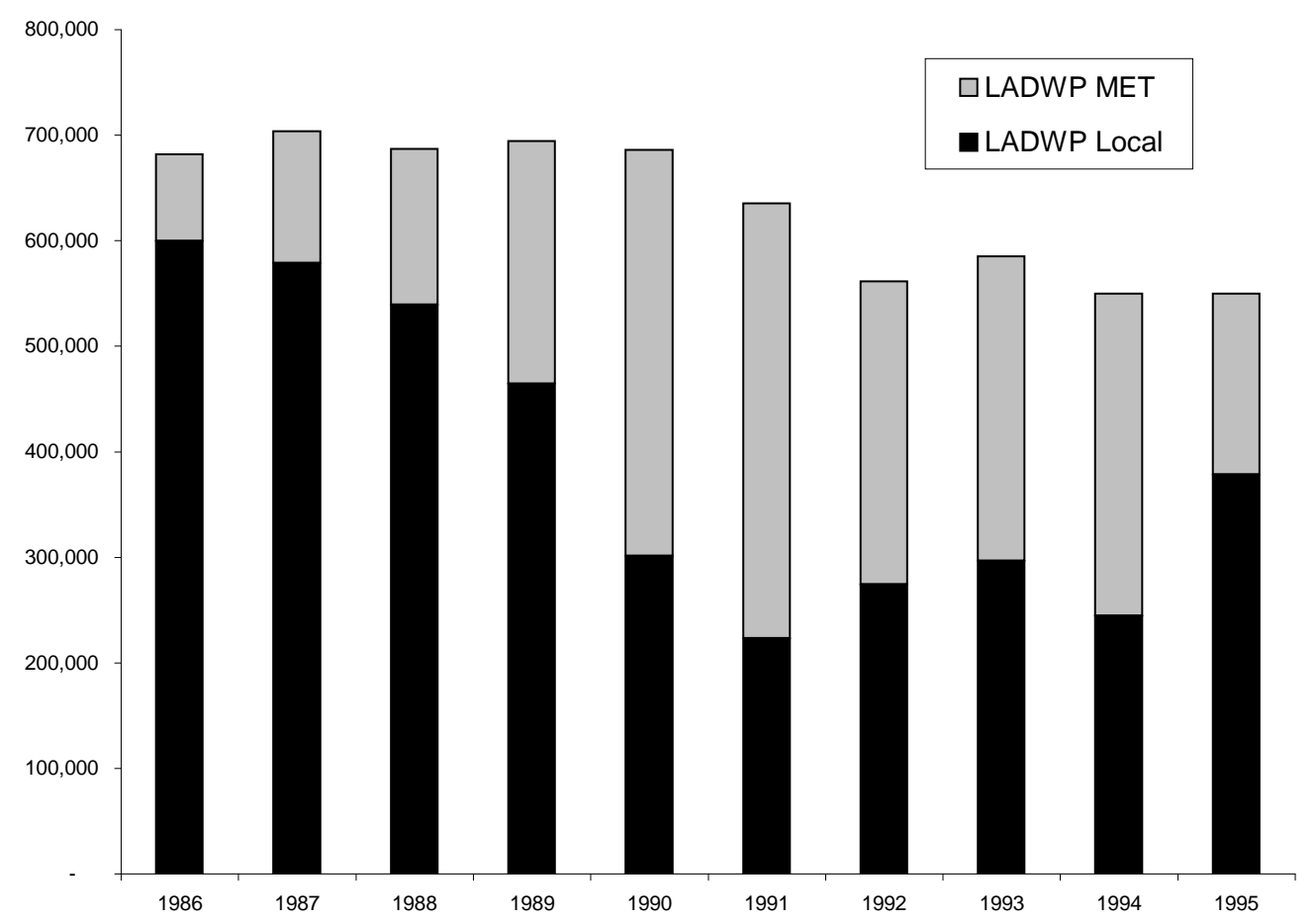

Figure 3.9: LADWP buys much more water in the $87-91$ drought

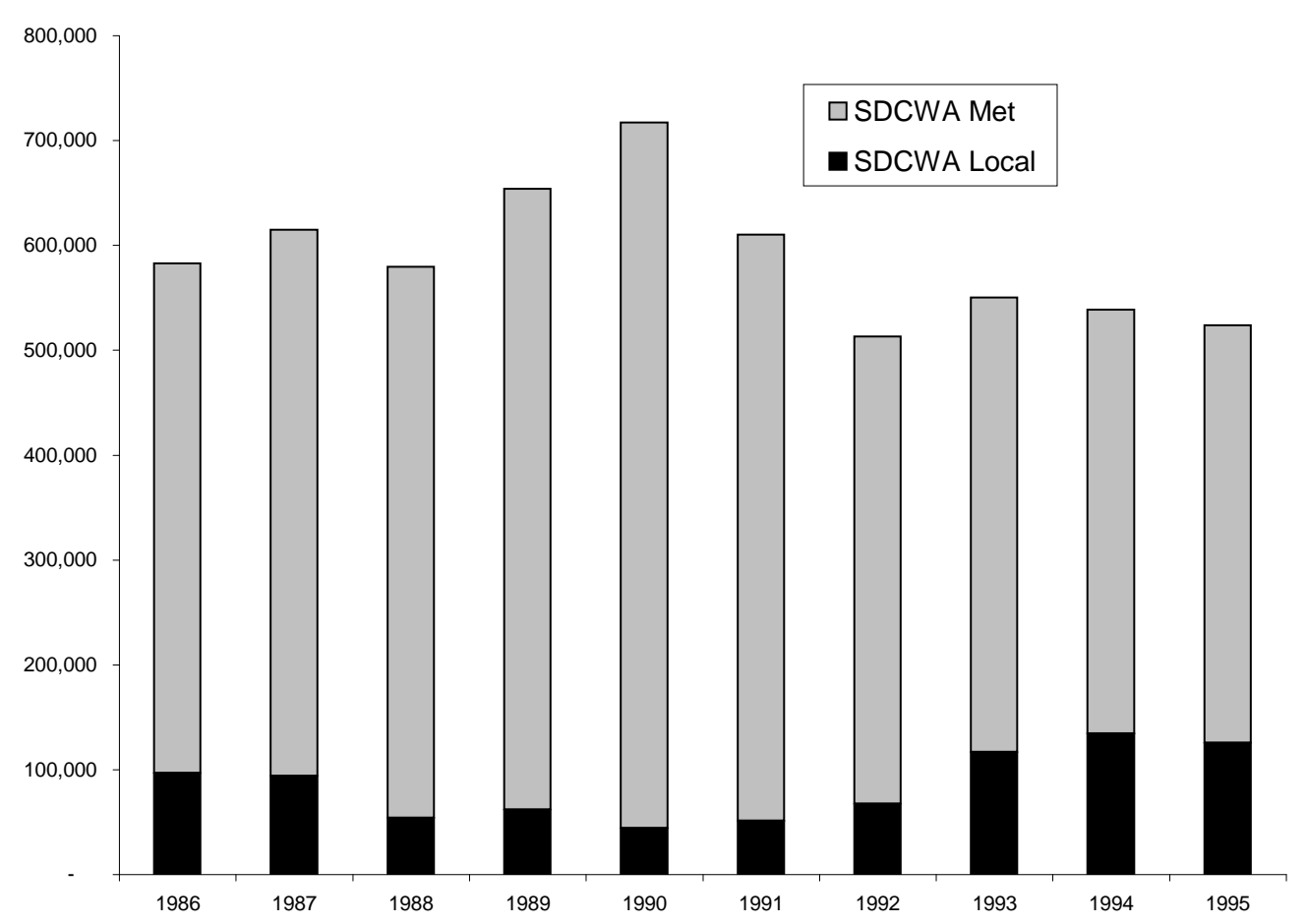

Figure 3.10: SDCWA only buys a little more water in the 87-91 drought 
does not feel it needs to reform.

\subsubsection{Monopoly Power}

Public sector organizations are rarely subject to market competition, which means that they can ignore pressure to improve quality, efficiency, etc. (Moe, 1984). As Lach et al. (2005a) note, water managers divert tricky problems to committees, blue ribbon panels, consultants, et al. in the hope that studying the problem will be interpreted as solving the problem.

After the 87-91 drought and SDCWAIID wheeling dispute, Assemblyman Bruce Thompson asked for reports to explain what went wrong at MET and what to do about it. Those reports (O'Connor, 1998a,b) and MET's own reports (Blue Ribbon Task Force, 1994; Dixon et al., 1998; PriceWaterhouseCoopers, 1998) suggest many reforms. What did MET do? In 1999, MET announced it would "act as a regional provider with contracting and shareholding characteristics," i.e., to do what it has always done (Atwater and Blomquist, 2002, p. 1197). ${ }^{37}$

\subsubsection{Principal-Agent Problems}

Throughout this work, it is assumed that customers, managers, staff and directors from each member agency share a single, common interest (see Section 2.1). A second assumption ignores the interests of MET's executives and 2,000 staff-implying that they faithfully implement Board policies. If we relax these assumptions, we must deal with innumerable principalagent-beneficiary relationships and severe asymmetric information. Consider these factors: First, MET is embedded in a web of bureaucracies - buying water from the Bureau of Reclamation and California's Department of Water Resources and selling water to monopolistic member agencies (some of which sell to other monopolies). Few of these agents can be punished for moral hazard. Second, information flows up, but costs flow down. MET could incur the cost of monitoring member agencies, but gains accrue to customers (as residual claimants), so MET has no incentive to monitor. If MET does nothing, customers pay more to their water sellers, and MET faces little negative feedback. Third, customers face their own collective action dilemma: If some customers work to improve efficiency, all customers benefit. $\mathrm{Mu}-$ nicipal employees may work to represent customer interests, but they are also agents. Finally, customers cannot distinguish between expenses that enhance reliability or reflect inefficiency. Additional risk and uncertainty from cutting spending is likely to outweigh potential savings. ${ }^{38}$

\subsubsection{Agricultural Water}

MET need not reform itself if it can buy agricultural water, and restore the conditions of abundance it enjoyed until the 1960s. IID and two other Southern California agricultural areas control 3.85 MAF of California's allocation from the Colorado River - nearly double MET's total supply of water. Given the relatively low value of water used for agriculture in these areas, potential gains from trade are large. ${ }^{39}$ Newlin

\footnotetext{
${ }^{37}$ Electricity deregulation and privatization created pressure to reform the water industry (Dixon et al., 1998), but the 2001 energy crisis resulting from California's botched deregulation removed that pressure - say insiders - for at least a decade.

${ }^{38}$ Southern Californians pay $\$ 450-550$ per year for water-less than one percent of their median income (Public Policy Institute of California, 2006).

${ }^{39}$ According to Wahl and Davis (1986), IID farmers added $\$ 35 / \mathrm{AF}$ of value to water they bought for $\$ 13 / \mathrm{AF}$. (IID farmers pay $\$ 16.50 / \mathrm{AF}$ today.) Given that MET was paying $\$ 221 / \mathrm{AF}$ for SWP water at the time, gains from trade existed. Soon after this study, MET and IID agreed to trade conservation funding for water; see Section 3.7.1.
} 
et al. (2002) estimate that a market-based transfer of 13 percent of Southern California's agricultural water would decrease MET's scarcity costs by 84 percent.

But trade is not that easy. Even after years of study and negotiation, agricultural areas only transfer 300-400 TAFY to MET and SDCWA. Why so little? Farmers want other farmers' "surplus" for themselves; environmentalists want "surplus" to flow down the rivers. Water transfers are politically costly, and it is unlikely that urban areas can buy more water without showing that they are managing their resources efficiently (Quinn, 1983; Harris, 1990). (Replacing PSP with auctions would be a good start.) MET must put its house in order before it can expect others to help.

\subsection{Summary}

MET's history helps us understand its current institutional form, i.e., the policies, norms and behavior that shape its operations. In the beginning, Los Angeles supported (and subsidized) the CRA to get access to Hoover power. When the CRA brought excess, expensive water, MET used Los Angeles' tax payments to lower its water prices below local prices and expandgrowing by 200 percent. MET considered these actions prudent and sustainable: The 1952 Laguna Declaration guaranteed water to member agencies, new and old.

But events conspired to threaten the Laguna Declaration: New members wanted a lot of water, various complications lowered MET's supply, and Los Angeles cut its subsidies. Formerly abundant water became scarce, but MET had no policies to allocate in scarcity. As negotiation replaced expansion in importance, power shifted from engineers to lawyers.

MET was adapting to change, but it was not ready for the 87-91 drought. With supplies stretched to the limit, MET's Board of Directors - with very short notice - imposed dramatic penalties on members that bought "too much" water. All member agencies suffered, but SDCWA - as MET's most dependent member - felt it faced the most "unfair" cutbacks. In the years after the drought, SDCWA took dramatic steps to reduce its dependence, but these steps (including the move to buy water from IID) caused conflict and disruption at MET. Today, MET's function as an organization of collective action is weakened: Water supplies are stressed, cost allocation is controversial, and member agencies have a hard time agreeing on policies to address these problems. The next chapter explains how this situation is the result of MET's structure as a cooperative, i.e., why and how MET is inefficient. 


\section{Chapter 4}

\section{Analysis of Efficiency at MET}

If a creature from outer space dropped in on California and reviewed our water supply allocation, it would report back finding no sign of intelligent life here.

—Carl Boronkay, ex-GM (1984-93) quoted in Erie (2006, p. 176)

The last chapter recounted MET's history, which divides into early years of abundance and expansion and later years of scarcity and congestion. If those early years were characterized by cooperationmost notably by Los Angeles' subsidies to growing regions - then the later years were characterized by conflict - not only when establishing the rationing formula during the 1987-1991 drought but in MET's decision to set a high wheeling charge on the water SDCWA wanted to buy from Imperial Irrigation District (IID). In this chapter, I show how MET's form as a cooperative is inefficient in theory. ${ }^{1}$ This theoretical argument identifies the structural origin of MET's problems - rejecting an alternative explanation that they are random bumps on the road.

According to Hart and Moore (1996), cooperatives whose members have heterogeneous preferences are inefficient because members cannot agree on the cooperative's activities. $^{2}$ This theory could explain why MET is inefficient today, i.e., some members are more dependent than others (leading to different preferences over water reliability, etc.), they disagree on actions, and MET is inefficient.

Accepting that heterogeneity leads to inefficiency, when did this heterogeneity emerge? In fact, heterogeneity has been present ever since MET's foundation, and it did not matter until the 1970s, when problems with water allocation and conflict among members began to emerge. How was it that heterogeneous preferences and efficiency coexisted for so long?

Perhaps member agencies (and managers) ignored their differences and cooperated to make MET efficient? While anecdotal evidence suggests this was true in the distant past (in Los Angeles' role as a team player or Jensen's drive for expansion),

\footnotetext{
${ }^{1}$ Efficiency is defined as the percentage of maximum attainable surplus achieved given a set of choice variables - including organizational form. Section 4.4 defines efficiency in more detail.

${ }^{2}$ Recall from Footnote 10 on page 6 that I merge the preferences of customers, managers, staff at each member agency into one "individualistic" set of preferences. This assumption ignores principal-agent relations (discussed in Section 3.14.2) and intragroup dynamic - mentioned in Footnote 1 on page 65.
} 
there are few stories of "all for one and one for all" today. The experimental results in Chapter 5 show that contemporary member agency managers are not much more cooperative than random groups of undergraduates.

Or maybe members' preferences did not matter? If MET had abundant wateran excess supply of water - then members did not have to decide if MET should supply large quantities of expensive water or smaller quantities of cheaper water. With abundance, MET could treat water as a club good (non-rival-having excess supply at a price of zero), and MET's allocation policies would be efficient because member agencies could get as much as they wanted.

In the 1960s, MET's abundant, cheap water became scarce and expensive (see Sections 3.7 and 3.11), and water became a private good. ${ }^{3}$ Put differently, rivalry over supply (water used by one member left less of other members) and costs (expenses created by one member were borne by other members) required that MET change its institutions for managing water and cost. Because MET's members had heterogeneous preferences over how this change should occur, and MET was a cooperative that made decisions by median vote, changes (or failure to change) were inefficient, and these inefficiencies support Hart and Moore's theoretical prediction that a cooperative whose members have heterogeneous preferences will be inefficient. MET's case is interesting because its peculiar history delayed the emergence of inefficiency. Note also the breadth of this examination: We are not just considering efficiency of allocation under institutional constraints, but the efficiency of the institutions themselves, i.e., is MET's form as a cooperative efficient?

Before we explore the details of these ar- guments in Section 4.2, consider two objections to the "MET is inefficient" hypothesis. First, even if inefficiencies exist, isn't the harm too small to worry about? Second, even if the harm is large, what real solution is there? It is not as if MET can be broken up or privatized. These questions are addressed in Chapter 6, which estimates the permanent reduction in property values from the 1987-1991 drought, and Chapter 7, which discusses how internal auctions for water can improve efficiency while maintaining MET's cooperative form.

Section 4.3 shows how conflict among heterogeneous members dissipates surplus. Section 4.4 describes how price distortions limits surplus. But first we take a small detour to clarify the different uses of "cooperate."

\section{1 "Cooperate"}

"Cooperate" appears over 250 times in this dissertation, and its meaning depends on context: Chapter 3 recounts MET's history as a cooperative organization and how its members are reaching less efficient outcomes. This chapter describes when a cooperative is efficient and how MET members are not cooperative enough to maintain efficiency. Chapter 5 gives results from noncooperative public goods games in which players (free-riders, reciprocators or cooperators) achieve a level of cooperation (efficiency). Chapter 7 describes how noncooperative auction games can channel selfish actions (bidding, buying and selling) into efficient outcomes. The following sections clarify these different uses.

\subsubsection{Type, Preference \& Action}

MET is a cooperative. Do its members have to be cooperative for MET to be efficient? No. A cooperative can reach a

\footnotetext{
${ }^{3}$ During those years, MET's management of water and Los Angeles' subsidies may have been inefficient from a regional perspective, but MET's operations as a cooperative were not.
} 
Pareto-efficient outcome with selfish members if the incentives are right. ${ }^{4}$ If incentives are not right, members may achieve an efficient outcome if they ignore selfish incentives and help each other, i.e., if they are cooperative types.

Individuals have preferences over outcomes, but we can never know them. All we can do is observe stated or revealed preferences (choices) and declare individuals to be certain "types." If someone says she donates to public radio, she is a "cooperator" type via stated preferences; if she does not donate (but listens), she is a "free-rider" type via revealed preferences. Stated and revealed preference can conflict (e.g., Ashley says she donates to public radio but actually does not), in which case I-like many economists - am inclined to type Ashley by her actions, as a free-rider. In general, however, we are inclined to think that preferences (beliefs) drive types (outcomes), so that someone with cooperative preferences (also called social preferences) will take cooperative actions and be typed as cooperator.

Type classifications are vulnerable to observational conditions. In an excellent example of this plasticity, Gächter and Thöni (2005) type individuals as freeriders in a public goods game and then place all the free-riders into the same group. Those players - knowing the group's composition - then play as if they are cooperators. This result does not invalidate the idea that those people were free-riders; instead it validates the idea that they are profit-maximizers who choose a strategy to match the circumstances.
Players who cooperate in public goods games - and life - are not choosing the profit-maximizing strategy: Cooperators are those people who are willing to sacrifice their own interests in the hope that others will follow their example. (Those others are defined as reciprocators - contributing more when others do; free-riders never contribute more.) In the short-run they earn less than free-riders, but if they are able to convince (in various ways) others to cooperate, then everyone is better off in the long run. (Freeriders - by contributing nothing - maximize their own profits but reduce social welfare by setting a bad example for reciprocators.)

\subsubsection{Organization, Game \& Out- come}

In a cooperative organization, members are simultaneously owners and clients. MET, for example, is a consumer cooperative of member agencies that decide how much they will pay for MET's water. The main advantage of cooperatives is that members can use them to solve collective action problems (e.g., building, managing and paying for water infrastructure); their main disadvantage is all members have to live with policies supported by the majority (Olson, 1971). ${ }^{5}$

In a very different use of the word, players in a cooperative games use trust, contracts and/or outside enforcement to ensure that actions promised are taken. In a noncooperative game, there are no enforcement mechanisms, so players may cooperate, but they cannot be bound by their promises, which are cheap talk. A cooperative can emerge as the result of a non-

\footnotetext{
${ }^{4}$ Pareto-efficient in the sense that all gains from voluntary trade are exhausted, which ignores potential gains under hypothetical, Kaldor-Hicks compensation schemes. This use emphasizes the sense of institutional forms and processes over the eventual result, which is called "efficient" to the degree in which actual surplus reaches maximum potential surplus.

${ }^{5}$ When exit is possible, this problem is much smaller - a question of transactions costs versus expected benefits that depend on the credibility of the exit threat. For members of MET, exit threats are not viable because most of them could not easily replace MET's water supply.
} 
cooperative game in which players join together in pursuit of self-interest to create an efficient outcome.

Perhaps the best example of a cooperative outcome is illustrated by Adam Smith's "Invisible Hand." As each individual goes about pursuing his own selfinterest, the outcome (production and consumption of bread, candles, etc.) maximizes social welfare without guidance or intention. This outcome is common to markets but harder to achieve within organizations with limited or non-existent competition. One way to achieve such an outcome is for all members of the organization to have cooperative preferences (as defined above) such that group welfare is maximized. Another is for the organization to establish incentives such that the game is cooperative (e.g., contracts) or a non-cooperative game results in cooperation (e.g., Gächter and Thöni (2005)). Another way is to play a repeated game such that cooperation in one period allows the next period (with positive expected profits) to take place. With infinite periods (or a finite but uncertain number of periods), this structure can support cooperative outcomes. Although these outcomes are now called "efficient" in the sense that surplus is maximized, this discussion is a useful reminder of how people have thought of them in the past and the paradoxical nature of "cooperative" outcomes that often result from uncoordinated pursuit of self-interest.

For MET, a cooperative organizational structure gave members a way to pool political and financial strength in an "all for one, one for all" organization that would take collective action (building an aqueduct) that resulted in a cooperative outcome (more water for everyone). Unfortunately, a cooperative structure does not work so well if members are not cooperative types and decide to free-ride instead. MET suffers from that problem. The solution? Either members become cooperative types, or MET changes the incentive structure to encourage cooperative outcomes.

\subsection{Efficient Form}

This section shows that MET's form as a cooperative is inefficient. In it, we go beyond the traditional analysis of cooperative forms (self-interested members making decisions about scarce goods) to consider cases where members utility functions are interdependent with respect to allocation ("social preferences") and/or allocate abundant goods.

\subsubsection{Efficient Cooperatives}

The theoretical consensus is that cooperatives are more efficient than organizations with outside ownership (profitmaximizing firms) if and only if the members of the cooperative share a single goal or the same ordering of goals, i.e., their preferences are "reasonably" homogenous (Hart and Moore, 1996, 1998; Meade, 2005; Herbst and Prüfer, 2007). ${ }^{6}$

Firms use a simple metric of success (profits) to choose among activities. Because most cooperatives can pursue multiple goals (e.g., lower prices and higher quality), members need to agree on how to rank or balance between them. ${ }^{7}$ Given that cooperative members will have preferences over activities, there will also be a distribution of members' preferences. The skewness

\footnotetext{
${ }^{6}$ A firm can be either non-profit or profit-maximizing and still have profit as its objective. Outside ownership and/or professional management results in different incentives than those of a cooperative in which members (as consumers or vendors) make policies.

${ }^{7}$ Cooperatives that profit maximize are not different from firms, and most profit-maximizing enterprises are not cooperatives. MET, like many cooperatives, does not choose profit maximization but some combination of low price and high reliability—holding quality constant.
} 
of the distribution of preferences (the degree to which the mean (or mass) diverges from the median) indicates the propensity for members to disagree. Put differently, a cooperative whose members disagree on goals cannot pursue all of the goals favored by all of the members. Because of this problem, skewness is a leading indicator of disagreement and misaligned policies - two outcomes that reduce cooperative efficiency relative to that of a firm (Hart and Moore, 1996).

Skewness reflects the divergence of mean and median preference, and it manifests in policy-making. Since cooperatives (and MET) generally use a median voter method of making decisions and the mean may reflect willingness to pay, divergence of these two measures indicates the divergence of political and economic power. The greater this divergence, the greater the potential redistribution of gains and losses from cooperative policies and thus the greater the conflict in making these policies (see Section 4.3). (For firms, the skewness of owners' preferences do not matter because owners are unified by the desire to maximize profits. ${ }^{8}$ )

Hart and Moore say that reasonably homogenous preferences are necessary and sufficient for efficiency in a cooperative. They assume that cooperative members are selfinterested and that the consumer/producer cooperative allocates a scarce good. If we relax their assumptions, homogenous preferences are still sufficient but no longer necessary, and two alternative sufficient conditions for efficiency emerge:

First, members of the cooperative may have social preferences, i.e., including other members in their utility functions. When members with social preferences de- cide cooperative policies, they will put more weight on group welfare - offsetting all or part of their underlying differences - and maximize group surplus. In the early years of CRA construction and during Jensen's reign (1949-1974), MET's Board of Directors acted as if they wanted to maximize surplus in the MET area (Sections 3.4-3.5). Although that earlier era ended, it is possible that today's water managers have social preferences and cooperate to maximize group surplus. Section 4.2.2 argues that member agencies (rather, their managers) do not have social preferences. This argument rests on results from the cooperation experiments in Chapter 5.

Second, the cooperative may produce an abundant good for its consumers, i.e., a good for which one member's consumption does not affect another's. Since the cooperative need make no policy on managing that good (it is not scarce), all members can consume according to their own preferences, and MET is efficient. Until the 1960s, MET had abundant water, and LADWP paid most costs (Section 3.4), leading to de facto efficiency. Section 4.2.3 reviews how abundance went away.

Without social preferences or abundance, the analysis collapses to that of Hart and Moore, and the question returns to homogeneity of preferences. Are they homogeneous enough to deliver efficiency? If we assume preferences follow from characteristics (i.e., the characteristic of "dependency" defined in Section 4.2.4-leads to a preference for reliability ${ }^{9}$ ) and show that member agencies do not have homogenous characteristics, we can conclude that they do not have homogenous preferences.

How is it possible that water man-

\footnotetext{
${ }^{8}$ When firms pursue other objectives (e.g., Corporate Social Responsibility), they also experience conflicting goals.

${ }^{9}$ Reliability is a binary concept that exists when quantity supplied equals or exceeds quantity demanded at a given price- under all states of nature.
} 
agers share a common desire for reliability yet have heterogeneous preferences? Although all water managers have reliability as an argument in their utility functions, the importance of reliability (versus, e.g., low prices) varies in their access to water, i.e., in their probability density functions on expected water supply. Reliability is more important - and low prices are less important - for members that have smaller local supplies, i.e., more dependency on MET. It is in this sense that member agencies can have heterogeneous preferences. And if this is so, MET lacks Hart and Moore's necessary condition, which, thus, is sufficient for MET's form as a cooperative to be inefficient in their model. Let us now explore these conditions for efficiency in more detail.

\subsubsection{Social or Selfish}

When MET was formed, Los Angeles represented 82 percent of assessed value within MET. Despite needing (or taking) little of MET's water and having a veto on MET policies, Los Angeles' property tax payments covered most of MET's costs. These subsidies gave the appearance that LADWP was willing to put aside its own priority (minimizing MET's costs) to address the priorities of water-poor members. ${ }^{10}$

Chapter 3 recounted two possible reasons for the generosity of Los Angeles: ${ }^{11}$ Ei- ther Los Angeles' social preferences led it to ignore its interests, or Los Angeles had selfish preferences. There is more support for the latter: First, Los Angeles' best response to MET's "demand failure" was to subsidize MET until expansion absorbed excess supply and led to higher prices; Second, LADWP's obsession with electricity may have led it to ignore MET's plans or policies for water; and third, LADWP pushed for lower taxes and higher prices from 1960, perhaps the earliest possible date it could have done so.

Assuming those actions were selfinterested does not mean that LADWP and other agencies do not have social preferences today, i.e., that they cannot work together to maximize joint social welfare. If that were to happen - even if they had different priorities (e.g., reliability versus cost) MET could be efficient as a cooperative. One result, for example, might be that some member agencies would subsidize others and thus increase total welfare.

Chapter 5 details how Member Agency Managers (MAMs) played public goods games in lab experiments and the results from the experiments quantified their mix of social and selfish preferences. Although MAMs were slightly more cooperative than undergraduate students, they did not achieve a level of absolute cooperation consistent with predominantly-social preferences.

\footnotetext{
${ }^{10}$ Although Los Angeles was certainly wealthier than other members in 1928, it could not afford to finance the CRA alone. Only MET could have raised $\$ 220$ million in bond financing (over $\$ 3$ billion in 2007 dollars) or received subsidized loans from the Federal government; see Sections 3.2.4 and 3.3.2. As time passed and member agencies grew wealthier, the necessity of using MET to aggregate buying power decreasedweakening MET's hold on members (its core) and thus its viability. Buchanan (1965, p. 12) explains that optimal club size falls in wealth, i.e., goods that exhibit "some publicness at low income levels" tend to become private as income increases. Take the example of desalinated water: Ostrom (1953) mentions that desalinated water costs $\$ 500-1,200 / \mathrm{AF}$ (in 1953 dollars) — versus $\$ 30 / \mathrm{AF}$ for MET water. Today, desalinated water costs about the same (in 2007 dollars) — and MET's water costs about $\$ 600 / \mathrm{AF}$. The relative attraction of desalinated water has risen, and member agencies have enough wealth to build their own projects, e.g., the proposed plant in Section 3.13. MET's core is shrinking.

${ }^{11}$ Rather, the people from LADWP representing the City of Los Angeles on behalf of the citizens of Los Angeles; they are all lumped into one entity, Los Angeles.
} 


\subsubsection{Abundant or Scarce}

Section 3.3 describes how MET had too much supply for too little demand - even after setting its price below the cost of local water. Its member agencies were satiated, but debt on the CRA had to be paid. In the short term, Los Angeles covered operating losses and fixed costs with its property tax payments (see Section 3.5) but that situation was unsustainable.

Given the CRA's status as a sunk cost, the natural step was to increase demand, and MET did this by offering its subsidized water to new members. Nine sparselypopulated, water-thirsty member agencies annexed to MET between 1946 and 1955. Since neither new nor old members faced a tradeoff between reliability and cost, water was abundant - effectively a non-rival club good. ${ }^{12}$

MET's demand-side expansion worked-after 1961, MET ran the CRA near capacity (Figure 3.4), but then MET lost a big chunk of supply (Section 3.7). Suddenly, MET was suffering from congestion - the downfall of clubs (Buchanan, 1965) - and water changed from a club to a private good. At the same time, LADWP cut its subsidies - making scarcer water more expensive (Section 3.11).

As Ciriacy-Wantrup and Bishop (1975, p. 724) note, "ubiquitous resources are resources which, at least up to some stage of economic development, are not scarce. Nobody is excluded from their use... Institutions regulating their use and allocation are not needed before that stage of economic development is reached." For the first twenty years of its operations, MET did not need institutions to manage abun- dant (ubiquitous) water. When abundance ended, MET - as a cooperative - needed to create the institutions for managing a scarce resource, and those institutions will only be efficient if MET's member agencies have relatively homogenous preferences.

\subsubsection{Homo- or Heterogeneous}

Although water managers' most important concern is reliability in water supply (Lach et al., 2005a), managers with stronger risk aversion want more supplies and/or storage. Since MET provides a single level of reliability (and cost), managers' heterogeneous preferences for reliability leads to inefficient conflict over policies and inefficiency from the policies themselves.

I created an index of dependency to quantify and compare heterogeneity. The index combines two factors member agencies do not want: dependency from a lack of alternatives to MET (via MET's share of a member's total water supply, or $M E T S h_{i}$ ) and dependency from being a big customer (via the member's share in MET's total sales, or $\left.S h M E T_{i}\right)$.

Members do not want "big customer" dependency because it means they will have a hard time replacing MET's supplies. Say that the CRA is shut down for some reason. Is it more likely that Beverly Hills (taking one percent of MET's total deliveries, or an average of 13 TAFY since 1990) or SDCWA (taking 26 percent of MET's total - an average of 514 TAFY) will be able to replace that lost water? Beverly Hills could purchase water from another agency (e.g., LADWP), build a desalination plant, or even import water on trucks. SDCWA, in contrast, could not replace 26 percent of MET's supply very easily.

\footnotetext{
${ }^{12}$ Abundance does not require zero prices (price was positive) as much as satiation, i.e., zero demand elasticity when prices drop. Put differently, water is so cheap that its consumption is a residual of other decisions (e.g., taking a shower, filling the pool, watering the lawn). Note that we are not discussing a cup of water (which is rivalrous) but a pool of water so vast as to allow anyone to consume his limit. As such, the pool would be a non-rival club good.
} 
To find a single measure of each agency's dependency, divide each member's share in each of the two dependencies by the largest share in each dependency (normalizing each dependency measure to fit a $0-1$ scale), and divide the average of those two values by the largest value of any member agency (again, to fit a $0-1$ scale), i.e.,

$$
\text { Dependency }_{i}=\frac{\left[\frac{M E T S h_{i}}{\max \left\{M E T S h_{j} \forall 1 \ldots 26\right\}}+\frac{S h M E T_{i}}{\max \left\{S h M E T_{k} \forall 1 \ldots 26\right\}}\right]}{\max \left\{\left[\frac{M E T S h_{h}}{\max \left\{M E T S h_{j} \forall 1 \ldots 26\right\}}+\frac{S h M E T_{h}}{\max \left\{S h M E T_{k} \forall 1 \ldots 26\right\}}\right] \forall 1 \ldots 26\right\}},
$$

where $i$ is the member agency and $\{j, k, h\}$ are the member agencies with the highest dependency shares in one of the two measures and the pre-normalized, raw measure of aggregate dependency, respectively.

Table 4.1 (using 1970-2004 data) shows strong differences in dependency. ${ }^{13}$ The importance of these differences grows larger when we consider the 53 percent correlation between 1970-2004 dependency and 2004 votes on the Board of Directors. Because MET's Board votes to impose one policy on all members, some will pay for too much reliability while others will get less reliability than they want, and the divergence between dependency and votes ensures that agreement will be difficult. It is in this way that these differences - this heterogeneity - enter into preferences and thus into conflict over cooperative policies.

\subsubsection{Forms of Inefficiency}

In the prior section, we saw how MET does not possess two sufficient conditions for efficiency (abundance and social preferences). Without these sufficient conditions, the argument for efficiency reverts to Hart and Moore's theoretical case that homogenous preferences are necessary and sufficient for efficiency. Given that MET's member agencies differ in their dependency on MET for water - and that dependency is a driv- ing force in member agencies preferenceswe can conclude that MET lacks the necessary condition for efficiency - in theory.

If we believe Hart and Moore's conceptual framework - that MET's form as a cooperative is inefficient - we should be able to find examples of inefficiency. In this section, we look for two forms of inefficiency common to collective choice organizations: inefficiency from conflict over making decisions in Section 4.3 and inefficiency from misguided policies in Section 4.4 (Hansmann, 1996). ${ }^{14}$

Note that conflict over policy is not the end of the game. If policies change the balance of power, they can increase conflict related to new policies (Hodgson, 2003). On the other hand, conflict can decrease the efficiency of policies if member agencies bring a hostile interpretation to incomplete contracts. SDCWA, for example, decided the Laguna Declaration's promise of "adequate supplies" meant it could buy as much water as it wanted at MET's scheduled prices (see Section 3.13 on page 45); a more generous interpretation would have allowed prices to rise. If SDCWA wanted less at those prices, its harm from "unavailable" water would have been reduced.

If inefficiency increases inequality, those who gain wealth may suffer if those who lose reduce the scope for cooperation (Car-

\footnotetext{
${ }^{13}$ An examination of annual dependency shows that SDCWA is most dependent in all 35 years (standard deviation $=0.00)$ as well as in calculations over different ranges (1960-2004 or 1980-2004). In those different ranges, the second and third most-dependent member agencies swap places.

${ }^{14}$ Chapter 6 has an empirical test of efficiency in water allocation.
} 
Table 4.1: Member agency dependency

\begin{tabular}{lcccc} 
Member & $\begin{array}{c}\text { MET's share of } \\
\text { Agency }\end{array}$ & $\begin{array}{c}\text { MA's share of } \\
\text { MET sales }\end{array}$ & $\begin{array}{c}\text { Dependency } \\
\text { Index }\end{array}$ & $\begin{array}{c}\text { Std Dev } \\
\text { of DI }\end{array}$ \\
\hline SDCWA & 83 & 26 & 1.00 & 0.00 \\
West Basin MWD & 92 & 11 & 0.73 & 0.10 \\
MWD of Orange County & 63 & 16 & 0.68 & 0.09 \\
Beverly Hills & 93 & 1 & 0.55 & 0.08 \\
Las Virgenes MWD & 91 & 1 & 0.54 & 0.06 \\
Calleguas MWD & 75 & 5 & 0.52 & 0.09 \\
Torrance & 80 & 1 & 0.48 & 0.05 \\
Glendale & 76 & 1 & 0.46 & 0.11 \\
Burbank & 73 & 1 & 0.44 & 0.13 \\
Central Basin MWD & 47 & 7 & 0.41 & 0.11 \\
Long Beach & 62 & 3 & 0.41 & 0.05 \\
Santa Monica & 65 & 1 & 0.38 & 0.11 \\
Foothill MWD & 59 & 1 & 0.35 & 0.03 \\
Pasadena & 55 & 1 & 0.34 & 0.05 \\
Three Valleys MWD & 45 & 3 & 0.31 & 0.08 \\
Los Angeles & 23 & 8 & 0.29 & 0.23 \\
Fullerton & 44 & 1 & 0.27 & 0.10 \\
Eastern MWD & 32 & 3 & 0.24 & 0.04 \\
Compton & 40 & $\sim 0$ & 0.23 & 0.08 \\
Anaheim & 34 & 1 & 0.22 & 0.08 \\
Western MWD & 25 & 3 & 0.21 & 0.06 \\
Santa Ana & 33 & 1 & 0.20 & 0.04 \\
Inland Empire MWD & 23 & 2 & 0.18 & 0.11 \\
Upr. San Gabriel MWD & 18 & 0.14 & 0.09 \\
San Fernando & 10 & 0.06 & 0.06 \\
San Marino & 9 & 0.05 & 0.07 \\
\hline & & & & \\
\hline
\end{tabular}

denas, 2003; Bardhan and Singh, 2004). For example, a reduction in MET suppliesholding local supply and share of joint supply constant - increases wealth for a member like LADWP (with the LAA) and decreases wealth of a dependent member like SDCWA (Berkman and David, 2000; Erie, 2000). If that loss in wealth makes SDCWA more insecure, SDCWA may react by pursuing outside options, e.g., the IID dealweakening MET and LADWP in the pro- cess.

\subsection{Making Decisions}

MET's member agencies decide policy. Ignore the policies themselves for a moment and consider how conflict in the decisionmaking process - delay, vote cycling, changing goals and/or partisan agenda settingcan raise transaction costs and destroy surplus. ${ }^{15}$ Decision-making at MET grew more costly in the 70s for three reasons: Jensen's

\footnotetext{
${ }^{15}$ These losses are over-and-above the basic transactions costs present in all organizations, e.g., internal negotiations, wrong decisions, etc.
} 
domination ended, LADWP lost relative political power as assessed values (and votes) at SDCWA and MWDOC grew, and the mismatch between political power (votes) and economic power (purchases) increased. After discussing these reasons, we will see examples of contentious decisions that reduced MET's surplus (without considering the efficiency of those decisions).

\subsubsection{Causes of Conflict}

In MET's early years, consensus was driven by LADWP's veto (held until 1953) and Jensen's domination as Chairman from 1949 to 1974 . LADWP's consensus-driven style of managing its power (Section 3.5) and MET's culture of engineers (Section 3.10) made it easier for members to work together in making and implementing policies. With few exceptions (LADWP's veto of the Pomona annexation was overruled in 1948; see Section 3.4), LADWP's subsidies of other members and abundant water supply kept the "all for one, one for all" spirit going into the 1960s. The end of this spirit came with the end of easy water (Section 3.7), LADWP's subsidies (Section 3.11), and LADWP's domination of the Board.

An important watershed was passed in 1972, when the combined assessed property values - hence Board of Director votes - of the second- and third-largest member agencies (MWDOC and SDCWA) passed that of LADWP; see Figure 3.7. As Mehlum and Moene (2002) show, equality between contestant parties increases the intensity of competition (when it happens) and thus the dissipation of surplus. Although the three big members have much in common, disagreements - when they happenare more energetic. The most recent example was the surprise victory of a MWDOCcoalition over an alliance of LADWP and SDCWA in the choice of Kightlinger as GM in 2006. Contributing to this effect is the increasing importance of contracts, policies and agreements: As water scarcity has increased so has downside risk and conflict over wording - increasing the dissipation of surplus from negotiation.

Median voting on economic issues is inefficient and grows more inefficient as the skewness of economic mass moves away from the median; see Section 4.2.1. Rosen and Sexton (1993) document the adverse impact of political voting on efficient water management at IID. They conclude that a mismatch between voting power and the benefits from trade reduces efficiency. McCann and Zilberman (2000) draw similar conclusions from a larger study of irrigation districts.

Although MET does not rely on popular vote to allocate economic goods, it suffers from a similar disconnect between voting power and economic power: When MET was founded, both votes and economic contributions (property taxes) were a function of assessed value, but the shift in revenue from property taxes to water sales over the years (Figure 3.8) has decoupled political and economic weight (median and mean values). The correlation between assessed values and average water purchases for 19801999 was 73 percent, with significant outliers in SDCWA (fewer votes than purchases) and LADWP (more votes than purchases). SDCWA (2001) complains that its contributions do not result in proportional power in voting how revenue should be spent. Although the mismatch has fallenthe 2000-2004 correlation is 0.92-SDCWA may already be suffering from inefficient policies.

\subsubsection{Examples of Conflict}

Two contentious issues were decided in 2003 - but not without absorbing enormous resources: Conflict over the wheeling charge 
(see Section 1.3) only ended after eight years and a $\$ 235$ million payoff from the State. ${ }^{16}$ Since the wheeling charge is only a transfer between SDCWA and MET, the $\$ 235$ million was only beneficial if stopping conflict over the charge improves management of water in Southern California. Although the money did stop the conflict, it institutionalized high wheeling charges, which discourages water trades.

After a few years of negotiation, MET signed ten-year purchase order contracts (POs) with member agencies in 2003 (Section 2.4.3). According to Thomas (2006b), MET projects that renegotiating these contracts will start in 2008 and take five years. This renegotiation is expected to take a long time because the definitions in the contracts ("base allocation," etc.) have importantand different-effects on member agencies. Even worse, these definitions will be fixed from 2013 to 2023.

\subsection{Inefficient Allocation}

How efficient are MET's policies? First, define efficiency as the ratio of actual to maximum attainable surplus in an aggregate welfare function in which individuals receive the same weight. ${ }^{17}$ This definition is equivalent to equating marginal benefit and marginal cost, but fixed costs must also be considered. ${ }^{18}$ Fixed costs should be paid out of surplus in proportion to some exogenous factor, e.g., population, assessed value, etc.

Thus, efficient allocation must cover fixed costs and maximize total surplus. MET's policies deviate from this notion by inefficiently price discriminating (Section 4.4.1; bundling the price of water and conveyance into one price, allocating most fixed costs to that price and charging that price - a single price - to deliver water anywhere in MET's service area (Section 4.4.2); fixing that price the year before it takes effect - well before supply and demand are known (Section 4.4.3); and providing incentives to increase total costs (Section 4.4.4).

MET could avoid these inefficiencies with member-specific prices that rose in scarcity and unbundled fixed and variable costs. Although up to 104 prices would deliver efficiency on paper (see Section 2.3.3), they are complicated. A different solution would replace price schedules (based on normative ability to pay) with prices set in competition (based on positive willingness to pay). One way to do this (auctions) is discussed in Chapter 7.

\subsubsection{Ramsey and Tier Prices}

According to economic theory, a seller of a single product can increase overall surplus by pooling consumers with similar elasticities and charging each pool different Ramsey prices, i.e., prices that vary inversely with elasticity of demand (Baumol and Bradford, 1970). If, for example, agricultural demand is more elastic than urban demand, Ramsey pricing suggestions that farmers should pay a lower price than urban users for the same quality and reliability of

\footnotetext{
${ }^{16}$ That $\$ 235$ million is equivalent to the first 18 years of MET's additional revenue from the wheeling charge $(\$ 258-\$ 116 / \mathrm{AF})$.

${ }^{17}$ Assume known quantities of water and conveyance with variable and fixed costs that must be allocated in a single period. Efficiency in a dynamic environment (over multiple time periods via storage, with changes in supply and demand) has the same goal (equate marginal benefit and marginal cost) but more variables and parameters. Additional complexity does not add value, since most decisions at MET are made in a static environment, i.e., fixed-investment decisions that take years to implement do not affect and are not affected by short-term decisions.

${ }^{18}$ Ignore fixed costs and MET loses money; add some portion of fixed costs to price, and smaller sales reduce surplus. Reduce fixed costs to zero and lose capacity in the next period.
} 
water. $^{19}$

But Ramsey pricing does not work when supply is fixed. Say the firm faces two demand curves and sets one price for the first demand curve. A certain quantity will be demanded at that price - leaving the remaining quantity to be sold at whatever price (on the second demand curve) leads to a quantity demanded that equals the remainder. Since the second price does not reflect the elasticity of the second demand curve, it does not maximize surplus in the manner of "proper" Ramsey pricing. If, instead, the firm ignores elasticity and sets two prices such that total quantity demanded is equal to total quantity available, then it is easy to see that the marginal unit sold at a lower price to the more elastic demander will produce a lower total surplus than if that same unit were sold to the less elastic demander - a result that also fails to maximize surplus. Thus, Ramsey pricing is not feasible, and attempted Ramsey pricing would not maximize surplus. A better solution would be to set a single price such that aggregate quantity demanded equals the fixed supply.

Unfortunately, MET implements a form of Ramsey pricing with limited quantities: Its current drought allocation formula allows sales of subsidized water to farmers to continue at the same time urban water deliveries are cut (Saltzgaver, 2008). This notion allows farmers to pay less than lowelasticity urban users.

MET uses another form of price discrimination through its Tier 1 and Tier 2 classes of firm (always available) water. ${ }^{20}$ In this increasing block pricing system, Tier 1 water is cheaper, and each mem- ber agency's right to buy Tier 1 water depends on past purchases; see Section 2.4.3. Members are allowed to buy unlimited Tier 2 water, which is sold at a price reflecting the cost of new water (the backstop price). Tier 2 prices allow MET to discriminate between members who want to buy more reliability and those who can "make do" with their Tier 1 supplies or find more water elsewhere.

Tier prices (in combination with surplus prices) result in a stepped price schedule that improves the efficiency of MET's water allocation, but MET's implementation of the schedule has several flaws: First, access to Tier 1 prices depends on past purchases (not demand per capita - a better way of assuring equity/improving efficiency); second, Tier 2 prices do not ration water in shortage because Tier 2 prices do not rise (to choke demand), and Tier 2 water is limited; and third, MET's non-profit constraint, average cost pricing (PSP), and Tier 2 prices set at marginal cost combine to ensure that Tier 1 prices are below the average cost of supplying water, a result that will encouragerather than dampen - the demand of those members facing Tier 1 prices at the mar$\operatorname{gin} .^{21}$

\subsubsection{Postage Stamp Pricing}

MET's most inefficient policy is postage stamp pricing, i.e., selling each class of water (e.g., Tier 1 or Tier 2) at the same price - no matter where it is delivered. PSP is inefficient in four ways: PSP does not sort member agencies by willingness to pay; PSP bundles water and conveyance; PSP bundles fixed and variable costs; and PSP averages costs across member agencies. Overall, PSP

\footnotetext{
${ }^{19}$ Although farmers generally buy untreated, interruptible water, and urban users buy treated, firm water, they are close substitutes.

${ }^{20}$ See Section 2.3.2 for a description of classes and prices.

${ }^{21}$ Although all members buying water from MET pay Tier 1 prices for a portion of their water (in accordance to their purchase orders), most buy more than allowed under their purchase orders. These members face Tier 2 prices on their marginal purchases.
} 
is inefficient in the typical way that average cost pricing is inefficient. Although some would argue that PSP is useful because it is simple to calculate and understand, the distortions resulting from weak or non-existent forces at the margin means that PSP increases inefficiency. ${ }^{22}$

First, PSP is de facto inefficient: If member agencies' willingness to pay for reliability (i.e., outbid others to buy a certain quantity) differs, they should be allowed to pay for the reliability they want and the accompanying conveyance. Since they cannot, they face the same price, marginal benefit-cost ratios vary, and inefficiency results (Brewer, 1964; Staatz, 1983). ${ }^{23}$ Inefficiency from reduced reliability is very costly to member agencies.

Second, PSP combines different conveyances and waters into one good (e.g., Tier 1 water) - a distortionary practice with a long tradition at MET: In the 1940s, MET averaged the cost of local and CRA water to make CRA water look cheaper (Milliman, 1956a). In the 1960s, it blended the cost of (now cheap) CRA water with SWP water to make SWP water look cheaper (Brooks, 1964). ${ }^{24}$ More recently, the bundled price of different conveyance facilities (e.g., SWP versus CRA) has dampened-if not halted - demand for water trades that would have low marginal conveyance costs. SDCWA's Wheeling Charge of $\$ 258 / \mathrm{AF}$ pays for all of MET's facilities; it would be $\$ 116 / \mathrm{AF}$ if it was only based on the fixed and variable costs of the CRA; see Section 1.3.

Third, PSP mixes fixed and variable costs. ${ }^{25}$ Efficiency requires that the marginal benefit of a unit be greater than or equal to its marginal costs; equity suggests that fixed costs be allocated in proportion to surplus. This match is not straightforward, e.g., allocation in proportion to purchases does not guarantee efficiency (Sexton, 1986).

Because MET's fixed costs are so significant, and PSP pays them, decreased sales volumes require higher prices - and vice versa (Sofaer, 1997). ${ }^{26}$ Although it may make sense that prices should fall when MET has plenty of water (and rise when it does not), member agencies use a combination of local water and MET water to meet demand. If local supplies are scarce and MET supplies are abundant, they can buy more MET water (at ever-cheaper prices) to replace missing local water. ${ }^{27}$ This diversification smoothes supply and dampens price movements, but those effects neutralize or contradict scarcity signals, discouraging conservation and encouraging perceptions of reliability that can lead to a higher baseline of "hardened" demand. If MET benefits from higher sales volume (in prestige, cheaper bond financing, etc.), unreliable member agency supplies also benefit MET - creating perverse incentives to keep them that way.

Finally, PSP do not vary by deliv-

\footnotetext{
${ }^{22}$ Water managers claim that PSP are politically efficient because they are "fair" and easy to understand. While this may be true when thousands or millions of different efficient prices are possible, it is not at MET. Its 26 member agencies are "sophisticated" enough to understand the need for different prices.

${ }^{23}$ Without quantity rationing, ratios vary from MET's perspective-because MET's MC of delivery varies. With quantity rationing, they vary for member agencies and MET because, now, members do not choose how much water to buy.

${ }^{24}$ Average cost makes sense if SWP water raises average quality for all, but it did not.

${ }^{25} 80$ percent of MET's revenues are from sales, and 80 percent of MET's costs are fixed.

26 "Metropolitan increased rates dramatically. . funds had been rapidly depleted in the face of an unexpected, extraordinary drop in water sales during the particularly wet year of 1983-84" (Oshio, 1992, p. 228).

${ }^{27}$ For an earlier discussion on the correlation between MET and local supplies, see Section 2.2 on page 14.
} 
ery distance - often due to an explicit progrowth policy (Tarlock and van de Wetering, 2008). Under PSP, members that use a lot of infrastructure or require new infrastructure do not pay the marginal cost of system expansion (Brewer, 1964; Dixon et al., 1998). ${ }^{28}$ In a multiple-period world, PSP create a subsidy from consistent water buyers to occasional (e.g., drought) buyersregardless of the quantity of infrastructure used. In a classic paper, Faulhaber (1975) argues that organizations with significant fixed costs can avoid cross-subsidies only if consumers pay different prices and generate marginal revenues in excess of marginal costs. Although MET's variable revenue exceeds its variable costs, PSP ensures that member agencies do not contribute marginal revenue in proportion to marginal costs, making cross-subsidies likely.

\subsubsection{Setting Prices for Next Year}

MET estimates demand and supply in March and sets prices for the next calendar year. During that year, members buy as "much water as they want" at those fixed prices - regardless of actual quantity available, says Tim Quinn, MET's VP of State Water Project Resources (2006a). Section 2.3.2 on page 18 describes the details of this process, but we discuss its economic dimension here. The main point is that it is hard to achieve equilibrium with fixed prices and much harder to do so when setting prices based on estimated supply $\left(\hat{Q}_{S}\right)$ and demand $\left(\hat{Q}_{D}\right)$. Besides equilibrium, four different supply/demand imbalances are possible:

High Supply: If $Q_{S}>\hat{Q}_{S}$, MET sells or stores surplus water, and profits are zero. Social surplus is not maximized because additional quantity is not sold at a lower price on the demand curve but as surplus water to inframarginal users.

Low Supply: If $Q_{S}<\hat{Q}_{S}, P_{\text {Tier } 2}$ is too low, member agencies fight over supply, and MET loses money. $\left(Q_{S}<\hat{Q}_{S}\right.$ results in lower variable costs, but unfunded fixed costs are much bigger.) MET fills the gap with stored water and financial reserves.

High Demand: If $Q_{D}>\hat{Q}_{D}, P_{\text {Tier } 2}$ is too low, and member agencies fight over supply-destroying surplus. MET does not lose money because it sells $Q_{S}=\hat{Q}_{S}$.

Low Demand: $P_{\text {Tier } 2}$ is too high, and MET cannot sell enough water at Tier 2 prices. If $Q_{D}<\hat{Q}_{D}$, Because revenues are lower than total costs, MET draws on financial reserves.

Besides these effects, all cases of imbalance involve misallocation of water among users, which reduces efficiency. MET tries to reduce harm from disequilibrium by managing shortages and surpluses on an ad hoc basis with large buffers of water (e.g., the two billion dollar Diamond Valley Lake) and cash-MET keeps an average of $\$ 440$ million in buffer and stabilization reserves. ${ }^{29}$

\subsubsection{Total Cost Control}

Average cost pricing also dulls the incentive to control costs: Increases in marginal and fixed costs are spread among all buyers instead of appearing as sharply higher prices or block transfers, respectively.

Within MET, average cost pricing increases costs in three ways: Spending by MET and member agencies that does not serve downstream water customers; spending by MET that does not serve member

\footnotetext{
${ }^{28}$ Bjornlund and O'Callaghan (2005) show that both water and water infrastructure impact agricultural land values. If they are both subsidized, value is twice-inflated.

${ }^{29}$ This number is the 2000-2004 average of Water [Revenue Remainder/Rate Stabilization/Transfer] funds.
} 
agencies; and spending by some member agencies that does not serve other member agencies.

Water managers - to paraphrase Bertrand and Mullainathan (2003) — want the quiet life. Water shortages make them look incompetent and attract attention from customers, politicians and the press (Lach et al., 2005a; SDCWA, 2006a). The best way to counter those risks is to create overcapacity (or slack) — "overbuilding systems to ensure the right quantity and quality of water was available to all users at all times" (Lach et al., 2005b, p. 4). ${ }^{30}$ Water managers tend to hoard reserves: In a recent working paper, Borenstein et al. (2008) give empirical evidence that electrical utilities do not make valuable trades if those trades might result in shortage and a regulatory inquiry. For MET, the equivalent occurs when water supplies are tight: Should MET sell additional water to meet current demand or hold back in case the shortage gets worse? If somebody else (the customer) is going to pay the cost of avoiding that decision (by having more storage), then water managers will take the action that increases costs. Timmins (2002), in a study of water utilities, calculates that the marginal benefit of the last dollar spent on behalf of customers is worth 45 cents.

MET management and staff have incentives to shirk (Alchian and Demsetz, 1972; Hansmann, 1980) - e.g., not making an effort to optimize water or cost management practices-because MET faces little competition for imported water supply, and prices will rise to cover costs: MET (2004b) projects 3-5 percent annual increases in water prices between 2004 and 2014. As joint residual claimants, member agencies have an incentive to free-ride on monitoring while claiming a share of cost savings, so reducing overall monitoring and cost control will be "too low."

Finally, members pay for MET's programs when they buy water - whether they like it or not (Dixon et al., 1998). In one case, MET paid $\$ 16$ million for two-thirds of the construction cost of the Center for Water Education at the urging of former Chairman Pace, who serves as chairman of the non-profit operating the Center (Fetbrandt, 2007a,b; Lait, 2007). When the non-profit ran out of money, MET canceled the 99-year lease, took over the Center, and voted $24-5$ to spend $\$ 4.67$ million more on the Center. In another example, SDCWA paid 25 percent of $M E T$ 's defense costs (via water purchases) when it sued MET during the wheeling dispute (USWNO Staff, 1998). On the other hand, member agencies may block storage projects with positive returns if those returns are unevenly distributed (Blue Ribbon Task Force, 1994).

\subsection{Summary}

MET's form as a cooperative (versus firm) is inefficient. Under traditional conditions (self-interest and allocation of a scarce good), Hart and Moore (1996) show that members of a cooperative must have relatively homogenous preferences for the cooperative to make decisions that benefit all members. The greater the skewness in preferences, the greater the inefficiency of the cooperative. Section 4.2.4 discusses how member agencies' dependence on MET varies. Given that the characteristic of dependence would lead to a preference for more reliable water supply, this heterogeneity means that members are unlikely to agree on the same level of reliability (via storage). Thus, we can say that MET's lack of a necessary condition (homogeneity) is sufficient for MET to be inefficient based on

\footnotetext{
${ }^{30}$ Cyert and March (1963) define slack as the extra reserves or operational capacity managers use to reduce internal conflict and/or cushion the organization while adjusting to external shocks.
} 
Hart and Moore's model.

The story does not end there, however. If we relax the assumptions of self-interest and scarcity, MET has other sufficient conditions that can lead to efficiency-even with heterogeneous dependency. One sufficient condition is that member agenciesvia their managers - have social preferences, i.e., they put group welfare in their own utility functions. Another sufficient condition is that MET has abundant water, i.e., so much water (and so cheap) that all members take as much water as they like without influencing other members' water supply or costs.

In Chapter 5, we see that water managers do not have social preferences, which implies that they are more likely to represent their agencies than MET as a whole. With this result, we know that MET will not achieve efficiency through cooperation. Chapter 3 documents MET's abundance (and efficiency) in the 1940s and 1950s as well as the end of abundance in the 1960s. With neither social preferences nor abundance, this discussion returns to Hart and Moore's necessary condition for efficiencyrelatively homogeneous preferences. Given heterogeneity in dependency, we can con- clude that MET's form as a cooperative is not efficient.

How is inefficiency manifest? In Section 4.3, we see how member agencies' conflict over policy choices dissipates surplus. Section 4.4 reviews inefficient policies: MET charges the same postage stamp prices (PSP) for water delivered to any location, mixing fixed and variable costs for water and conveyance. Although there is some benefit in the simplicity and predictability of PSP, the use of a single price means that prices create almost no incentives on the margin. MET's practice of fixing prices to equal estimated average cost in the year before they take effect is also inefficient. Because estimates are based on projections of supply and demand, prices are almost certain to be too high or too low.

Because MET's pricing system is rarely in equilibrium, MET and members use pools of cash and water to compensate for imbalances. These costs are further magnified by MET's use of average cost pricing, which encourages marginal (e.g., expensive alternative supplies) and fixed costs (e.g., larger storage facilities). 


\section{Chapter 5}

\section{Experiments in Cooperation}

There is no way to build a model for the interaction of two or more decision units, with the behavior and expectations of those decision units being derived by purely formal deduction. An analyst can deduce the decisions of a single rational mind if he knows the criteria that govern the decisions; but he cannot infer by purely formal analysis what can pass between two centers of consciousness. [...] One cannot, without empirical evidence, deduce what understandings can be perceived in a nonzero sum game of maneuver any more than one can prove, by purely formal deduction, that a particular joke is bound be funny.

—Schelling (1960, pp. 163-4)

This chapter describes experiments in which four different subject populationsMember Agency Managers (MAMs), MET executives (METs), executives from investor-owned water companies (CWAs), and UC Davis undergraduates - played public goods games. These experiments were designed to answer a question from Chapter 4: "Can cooperation among member agencies make MET efficient as a cooperative?"

Although member agencies are unlikely to sacrifice self-interest for the benefit of the whole, and water managers have told me that cooperation and trust are rare at MET, it is possible that member agencies (and their proxies, water managers) have social preferences, i.e., that they value benefits to other member agencies as they would benefits to themselves. ${ }^{1}$

How do we measure social preferences or cooperation? Stated preferences (e.g., "We are public servants who serve the community in partnership.") may be cheap talk, but revealed preferences (e.g., lawsuits, contentious votes) may be normal friction attendant to a surplus-maximizing outcome. Experiments allow us to quantify cooperation that results from social preferences using the measure of efficiency - the fraction of maximum attainable surplus. This quan-

\footnotetext{
${ }^{1}$ Organizations do not take actions or have preferences. People within organizations have preferences, and their preferences are reconciled in some decision model that often results in an action attributed to the organization that may be neither rational not consistent; see, e.g., Allison (1969) and Fehr (2005). For convenience, however, let us assume - following McFadden (1975) - that the people in member agencies act as if they are part of a rational, monolithic entity with a single set of preferences in a single "decisionmaking unit." From this assumption comes statements such as "LADWP decides" or "water managers are cooperative and thus so are their agencies."
} 
tification makes it possible to compare the cooperation levels of different groups.

But how much cooperation is enough? Should we worry about relative or absolute cooperation? How would one define absolute? It turns out that MAMs are relatively more cooperative than all three comparison groups, but their cooperation falls short of the absolute level (defined in Section 5.2.3) that would allow us to label them as cooperative - let alone the confidence to predict cooperation outside the lab.

These results are vulnerable on two points: First, some observers are unwilling to accept that lab results might apply outside the lab. Second, experimental participants were MAMs - not the Directors who formally represent member agencies on MET's Board. These qualms are discussed in Sections 5.1.4 and 5.4.4, respectively.

The rest of the chapter goes as follows: The next section describes how experiments work and why economists use them. Section 5.2 describes the experiment and hypotheses. Section 5.3 has results, and Section 5.4 has the discussion.

\subsection{How Experiments Work}

As Schelling notes at the start of this chapter, models do not reproduce complex interactions very well, limiting their usefulness for studying everyday life. Artificial (or lab or scientific) experiments, on the other hand, sacrifice the control of models in exchange for realistic interactions. Input and outputs are known, but the transformation of inputs into outputs takes place in an unobserved black box. ${ }^{2}$

In economic experiments, subjects- typically undergraduate students - interact in an experimenter-designed setting of limited information, communication, action and timing-usually on computers in a lab. Since lab experiments require simple decisions under conditions of common knowledge - often without uncertaintyand outcomes are easy to measure, it is easy to explore the impact of changes in the environment. Economic experiments need not occur in a lab with students and zero context. Harrison and List (2004) establish four intermediate steps between pure lab and pure field experiments (when subjects do not even know they are under observation). Two are used in this dissertation: An experiment that uses members of a relevant group as subjects (e.g., water managers are relevant if results are meant to apply to water managers) is an artefactual field experiment. An experiment where the experimental commodity has context (e.g., auctions for "water" in Chapter 7) is called a framed field experiment.

\subsubsection{Cooperation Games}

In a one-period social dilemma game, an individual must decide between a selfish action that benefits himself (and harms others) and a cooperative action that harms himself (and benefits others). ${ }^{3}$ Standard utility functions that do not take the welfare of others into account lead to the prediction that individuals in these situations will take the selfish action. What is interesting is that some people take the cooperative action. These two examples highlight two "types" of people: cooperators who take the welfare of others into account, and free-riders who take the selfish ac-

\footnotetext{
${ }^{2}$ I ignore the vast theoretical and experimental literature on group decision making (beginning with Black (1948) and including famous works such as Arrow (1963)).

${ }^{3}$ This decision may be the only one (e.g., a dictator game), one of two in series (e.g., ultimatum or trust games) or one of two simultaneous decisions (e.g., a prisoner's dilemma game).

${ }^{4}$ It is assumed that a player's type (or preference) is the same as her strategy, e.g., a free-rider pursues a strategy of defection or selfishness.
} 
tion. ${ }^{4}$

If the game has more than one period, the prospect of punishment can induce players to cooperate - rather than free-ride - in the first period. The most famous "punishment" strategy is called tit-for-tat, i.e., matching the other player's cooperation or defection move, and players who use this strategy are called reciprocators. ${ }^{5}$ The existence of other types (besides free-riders) challenges the straw-man version of homoeconomicus - a hyper-rational individualist who only exists for transactions but not social relations, etc. See Tooby and Cosmides (1992) and Bergstrom and Stark (1993) on cooperation and Axelrod (1984) on reciprocation.

The social dilemma game used here is a public goods game, or PGG. This game emphasizes the tension between contributing to the public account (helping others at a cost to oneself) or a private account. In each run, each player (in a group of $n$ ) splits his endowment $(e)$ between the group's public account and his private account. Each subject's total earnings is the sum of his private earnings plus a fraction of the public account. This fraction, called the Marginal Contribution Ratio (MCR) is a parameter chosen by the researcher that runs between $\frac{1}{n}$ and 1.00 .

Given that all players benefit from contributions to the public account, the rational strategy is to contribute nothing; in the resulting Nash equilibrium, all subjects contribute nothing and receive $e$ (Ledyard, 1995). The social-welfare maximizing strategy is for all subjects to contribute their total endowment, so each receives $\operatorname{MCR}(n$ * $e)>e$. Therefore, the degree to which contributions to the public account rise above zero is the degree of cooperation (and efficiency). ${ }^{6}$ By observing each player's contributions to the public account, we can also classify him as a cooperator (contributing a lot to the public account, independently of what others do), reciprocator (contributing more when others do) or free-rider (contributing little or nothing).

\subsubsection{Experimental Validity}

We want an experimental design that creates a clean connection between input and output and gives results that can be used outside the experimental setting. It is thus that a good experimental design has internal validity - consistent incentives and clear links between stimulus and response in the lab - and external validity - where lab results apply outside the lab; see, respectively, McDermott (2002) and Levitt and List (2007). While validity is important, Guala (2003) worries that validity problems can lead some people to prematurely dismiss all experimental results. As Falk and Fehr (2003) note, experiments suffer from the same problems of more traditional empirical methodsreplication is not guaranteed, and completeness (description of all terms that affect the

\footnotetext{
${ }^{5}$ Recall the discussion of different uses of "cooperation" in Section 4.1: Social dilemmas are noncooperative games in which reciprocators can take a cooperative action. On the other hand, only cooperators take cooperative actions in non-cooperative games.

${ }^{6}$ In most experiments, efficiency is actual earnings (from public and private accounts) as a percentage of maximum possible earnings. In this chapter, efficiency is a function of surplus from contributions to the public account, i.e., zero tokens in public account means 0 percent efficiency. This definition does not reduce generality, as there is a monotonic relationship between contributions to the public account and total surplus from private and public accounts. If private account contributions are included in efficiency, minimum efficiency would be fifty percent $(n * e / M C R(n * e))$, i.e., the outcomes of total free-riding. Rescaling efficiency as contributions to the public account also emphasizes the link between efficiency and "cooperation." Note that experimental measures of efficiency are continuous; in other chapters, something is discretely efficient or not.
} 
outcome) is impossible - but these methods (e.g., econometrics) are used because they provide more information. Presumably, experiments should be accepted because they provide information unavailable elsewhere.

\subsubsection{Internal Validity}

Internal validity results when subjects take experiments seriously, i.e., they pay attention to incentives and respond to changes in incentives. Incentives are established through payments that depend on outcomes. ${ }^{7}$ More specifically, a subject's earnings are a function of his surplus, and the experimenter sets incentives to test hypotheses. The degree to which actual behavior goes against incentives indicates the strength with which the hypothesis is rejected.

\subsubsection{External Validity}

The most common criticism of experiments is that they are not externally valid, i.e., that subject validity or situational validity is not maintained. Subject validity means that the experimental subjects resemble the population of interest. Situational validity means that the experimental design resembles the external situation of interest.

Experimenters use students as experimental subjects - despite the objection that they do not match the general populationbecause they are convenient (location, schedule), cheap (lower wages) and homogenous. Harrison and List (2004) argue that experiments with students are not appropriate if the population of interest is selfselected (e.g., water managers) or when the characteristics, age, experience or continuing relations of the targeted population are theoretically relevant. The experimental literature has examples that emphasize or deny the differences between students and non-students. While Fehr and List (2004, p. 743) find "that CEOs are considerably more trusting and exhibit more trustworthiness than students," Kovalchika et al. (2005) conclude that students and the very old pursue the same strategic behavior in the lab, and Gächter et al. (2004) find that student and non-student behavior in trust games is explained by socio-economic status - not student status or age. Subject validity does not matter in this dissertation, since the experimental subjects (water managers) are the target population, and students only serve as a comparison group.

Situational validity does not require complete realism. According to McDermott (2002, p. 40), the experiment is realistic enough if it "engages the subject in an authentic way." More realism than that can introduce idiosyncratic bias, create gratuitous complications, or result in loss of control. The goal is that the situation in the lab map to the situation outside the lab. Although it is hard to believe that people will change completely outside the lab, the framing and/or rendering of "reality" inside lab experiments can make results useless outside the lab.

A small literature links lab behavior to everyday life. In Mestelman and Feeny (1988), common property advocates (mostly human ecologists and anthropologists) give more to the public account than students. Cadsby and Maynes (1998) find-using a multiple equilibrium experimental settingthat nurses focus their effort on the socialwelfare maximizing equilibrium while economics and business students focus on the individual-welfare maximizing equilibrium. Cooper et al. (1999) find that managers playing production games in the lab learn

\footnotetext{
${ }^{7}$ Money is used instead of other rewards (e.g., candy, hugs) because subjects are not satiated by more money the way they might be with candy (Smith, 1976). Expected payments are set close to the hourly wage a subject might earn to reduce problems of opportunity cost (Plott, 1982).
} 
faster and are more strategic when context matches their everyday experience. Cardenas (2000) finds that experimental subjects with income from common-pool resources (e.g., wood-cutting or fishing) reach higher levels of cooperation faster than subjects with income from private goods (e.g., farming). In a famous paper on games that anthropologists conducted in many cultures, Henrich et al. (2001, pp. 76-77) conclude that "the degree of cooperation, sharing, and punishment exhibited by experimental subjects closely corresponds to templates for these behaviors in the subjects' daily lives." Alatas et al. (2006) find that Indonesian public servants are less corrupt than students in a lab experiment with context: Public servants - despite experiencing more corruption at work - offered fewer bribes. They passed on the opportunity to earn 20 times their hourly earnings "to reduce corruption and social costs." Students, on the other hand, "made their decisions to maximize their payoffs" [pp. 1718]. Palacios-Huerta and Volij (2008) report that soccer players transfer their skills from penalty kicks to zero-sum games in the lab, earning more than students. ${ }^{8}$ Herrmann et al. (2008) measure anti-social punishment in 16 countries, finding a negative relationship between punishing cooperation and GDP/capita. ${ }^{9}$ They hypothesize that free-riders get revenge by punishing those who want cooperation; in the resulting melee, overall cooperation falls. Although their results are driven by the "culture" of countries, there is no reason why they could not apply to the culture of orga- nizations or industries - explaining how internecine battles can weaken an organization.

A smaller literature examines the impact of outside relationships on PGG results in the lab. Zelmer (2003), in a meta-analysis of PGGs, finds that previous friendship with other players does not affect contributions. This result has exceptions - or perhaps clarifications: Peters et al. (2004) report that people playing with members of their family contribute more than when they are playing with strangers; Haan et al. (2006) report that teens contribute more in groups of friends than in groups of classmates.

In summary, significant evidence supports the relevance of outside conditions (occupation, experience, relationships) to lab results. ${ }^{10}$ This result is important if we are to believe that water manager cooperation in the PGG reflects their cooperation in the office.

\subsection{Experimental Design}

This section describes the PGG design, method of "typing" subjects (cooperator, free-rider or reciprocator) from their game decisions, calculation of group efficiency, hypotheses tested, logistics of experimental sessions, and characteristics of participants.

In most PGGs, subjects play simultaneously, which creates some uncertainty over who or what one is reacting to and who or what others will react to in the next round. If, for example, two players in a group of four change their contribution in equal but opposite ways, the other players will not know if the first two changed their behav-

\footnotetext{
${ }^{8}$ Levitt et al. (2007) report that experienced poker players and US soccer players do not earn more. This example highlights another advantage of experiments - that they can be replicated.

${ }^{9}$ Their analysis also supports a positive correlation between cooperation and GDP per capita, but punishing cooperation - instead of free-riding - is a novel finding.

${ }^{10}$ In an admirable reversal of this idea, Cardenas (2004) returned to play games in communities in which he had conducted cooperation experiments. In new sessions, he observed learning and diffusion-both experienced and amateur players played with the understanding that "both trust and cooperation could be sustained and would be profitable" [p. 27].
} 
ior or did nothing at all. Likewise, players changing their behavior may do so in the hope that others' actions will offset or reinforce their own.

Players will act differently in a sequential setting when they know their actions occur in isolation. From the experimenter's perspective, this sequential isolation is useful because it clarifies what the player saw and did - allowing the experimenter to "type" each player from his behavior. The experiments here use a sequential contribution mechanism PGG inspired by the design of Kurzban and Houser (2005), or KH. ${ }^{11}$

The PGG described below uses the following terminology: A round is an individual decision; a period passes when all players in a group have had one round; a run lasts as long as the maximum number of rounds (the round limit), and every session had five runs. Simultaneous decisions made in period zero did not count toward the round limit, but runs would end in mid-period if the round-limit was not divisible by four. The round limits (from $\mathrm{KH})$ were used in all sessions: The first run took 16 rounds (4 periods), the second was seven rounds (2 periods/mid-period end), then 23 ( 6 periods/mid-period end), 32 and 32 rounds ( 8 periods/each). ${ }^{12}$ The PGG had the following steps: ${ }^{13}$

1. Subjects were randomly placed in groups of four or five at the beginning of each run.

2. In period zero, all subjects had 20 seconds to make a simultaneous, ini- tial contribution to the public account from their 50-token endowments. Participants understood that their remaining tokens were provisionally (and in the final period, permanently) allocated to their private accounts.

Contributions were final only when the run ended. Subjects knew they had at least one opportunity to confirm/change their period zero contribution. Period zero contributions were non-binding cheap talk, but decisions after period zero were payoff relevant because the run could end at any point.

3. After period zero, contributions were sequential, i.e., one participant per group saw his prior contribution, the average contribution of others, and the total in the public account; see Figure 5.1. He changed or confirmed his contribution within the ten second duration of his round while other players waited.

4. Each group's public account was updated, the next round began, and the next member of the group could change/confirm his contribution. Rounds and periods ran without signal or interruption.

5. This updating continued for an unknown, random number of rounds until the run ended, contributions were finalized, and subjects saw their pay-

\footnotetext{
${ }^{11}$ The main difference between this treatment and KH's treatment was that subjects did not see the average contribution of others in KH's treatment. (They saw own contribution, total contribution and groupsize.) This difference is important, because KH assumed that players "knew" that average from the information they saw. Although irrelevant here (all subjects saw the average), the impact of displaying the average is explored in Zetland (2008).

${ }^{12}$ In mixed groups of four and five, four-player groups waited while five-player groups finished, but fifth player decisions did not count towards the round limit. (Because subjects were already waiting for others in their group, additional waiting did not affect the flow of the game.)

${ }^{13}$ See Appendix A for a copy of instructions. These experiments ran on z-Tree (Fischbacher, 2007).

${ }^{14}$ Average contributions were biased upwards by the limited number of rounds and $1 / n$ probability of any
} 


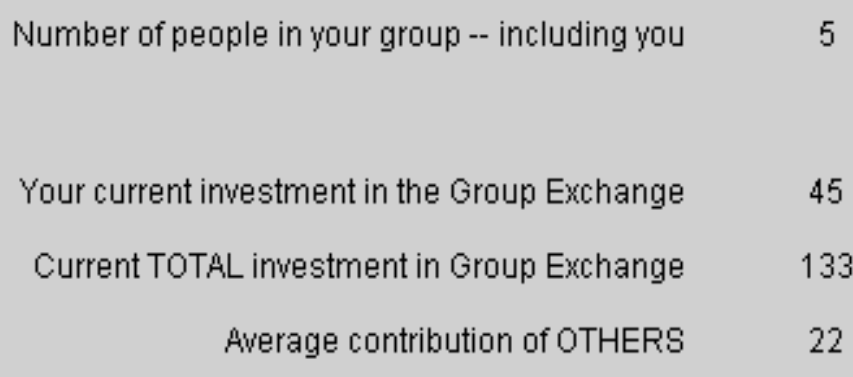

Figure 5.1: Screenshot from cooperation game

offs from public and private contributions. ${ }^{14}$ Each subject received one token for each token in his private account and 0.5 token $(M C R=0.5)$ for each token in the group account.

6. In each session, there were five runs of the game, each ending after the quasirandom number of rounds from $\mathrm{KH}$. Participants were randomly shuffled into groups and randomly ordered at the beginning of each run and played in the same order for that run. They knew they were in new groups, but they did not know the round limit or number of runs in the session.

\subsubsection{Determining Type}

Each subject played the game five times, and made one to eight decisions per runsimultaneous, period zero contributions are ignored - with some players making more decisions than others. ${ }^{15}$ Each player in each session has 26-28 "average contribution of others/own contribution" datapoints. To type players, each player's observations are used to estimate the following equation:

$$
x_{i g t}=\alpha_{i}+\beta_{i} \bar{x}_{i g t}+\epsilon_{i g t}
$$

where $x_{i g t}$ is the contribution of person $i$ in group (run) $g$ in round $t, \bar{x}_{i g t}$ is the average contribution of other group members observed by $i$ in round $t$ of run $g ; \alpha_{i}$ and $\beta_{i}$ are individual-specific parameters to be estimated and $\epsilon_{i g t}$ is a mean-zero disturbance term $\left(\sim N\left(0, \sigma_{i}^{2}\right)\right)$ that controls for group effects $(g)$ and trend effects $(t)$.

Each individual's type depends on $\alpha_{i}$ and $\beta_{i}$ values estimated in an individual OLS regression of Equation (5.1). Given $\hat{\alpha}$ and $\hat{\beta}$, KH's classification rules for type are as follows:

Cooperators $\hat{\alpha} \geq 25$ and $\hat{\beta} \geq 0$, i.e., a cooperator's estimated contribution is non-decreasing in the average contribution of others and is always at least

given run ending after a player's contribution decision. Since this bias applied to both students and water managers, it is ignored.

${ }^{15}$ When the number of rounds divided by the number of players is not an integer, the number of observations is not equal; e.g., four subjects playing seven rounds would mean that three subjects played two rounds each and one played a single round.

${ }^{16}$ Why use 25/50 tokens (50 percent) as a cut-off for cooperators? Half is an obvious focal point for humans. In ultimatum games (one player decides how to split an endowment and his partner decides to 
25 (of 50) tokens. ${ }^{16}$

Free-riders $\hat{\beta} \geq 0$ and $\hat{\alpha}+\hat{\beta}(50)<25$, i.e., a free-rider's estimated contribution is non-decreasing in the average contribution of others but stays below 25 tokens.

Reciprocators $\hat{\alpha}<25, \hat{\beta} \geq 0$ and $\hat{\alpha}+$ $\hat{\beta}(50) \geq 25$, i.e., a reciprocator's estimated contribution is increasing in the average contribution of others, below 25 tokens when the average contribution of others is zero, and at least 25 tokens when the average contribution of others is 50 .

No Type $\hat{\beta}_{i}<0$. Players who give less when others give more are classified as "no type" and ignored in further analysis.

See Figure 5.2 for examples of subjects classified as cooperators and free-riders and Figure 5.3 for examples of reciprocators. Each panel shows all data for one player in one session; the fitted line matches regression output, i.e., $\hat{x}_{i}=\hat{\alpha}_{i}+\hat{\beta}_{i} \hat{\bar{x}}_{i}$. Note that each dot is a $\left(\bar{x}_{i g t}, x_{i g t}\right)$ pair that records the average contributions of others to the public account (independent variable on $\mathrm{x}$-axis) and how much a subject put in the public account (dependent variable on y-axis).

The OLS estimates and linear results from this classification scheme are easy to use - one can type players with a few observations - and understand - but some critics see this simplicity as an unrealistic depiction of "real types". This issue and estimation techniques are discussed in Section 5.4.

\subsubsection{Group Cooperation}

Group cooperation is quantified as the ratio of actual to maximum potential contributions to the public account. ${ }^{17}$ In PGGs, both surplus and profit are maximized when players put all tokens into the group account. With an MCR of 0.5 , a group of four and endowments of 50 tokens each, each player receives $0.5(4 * 50)=100$ tokens, i.e., double his endowment. ${ }^{18}$ Efficiency is 100 percent in this case and 0 percent if no players contribute to the public account.

Because sessions had between 13 and 20 players, and groups had four or five players, session efficiency is not a simple average of player or group efficiency but the efficiency of the average player in the average group. ${ }^{19}$

Note the connection between types and efficiency: If cooperators dominate, group contributions and efficiency are higher; if free-riders dominate, they are lower. (Reciprocators react to others.) The order of play by types (e.g., cooperator in round one, free-rider in round two, etc.) will not affect efficiency if there are enough rounds

reject-leaving both with nothing - or accept the split), the modal offer is fifty/fifty. For a discussion of this result and the possible reasons behind it, see Camerer and Thaler (1995).

${ }^{17}$ See Footnote 6 for a comparison of this efficiency to the more common definition of efficiency as the ratio of actual to maximum attainable surplus (Plott, 1982).

${ }^{18}$ Players in group of five had the same MCR, which meant their maximum possible payoff was 125 tokens, and the calculation of efficiency takes that effect into account.

${ }^{19}$ For example, player 12 is in group three (five players) for run one, group two (four players) for run two, etc. and experiences an individual efficiency that averages efficiency across his five groups. Session efficiency is the average of players' individual efficiencies.

${ }^{20}$ Say we have three reciprocators and one free-rider. If all donate 50 in (non-binding, simultaneous) round zero, the total is 200 . If the free-rider gives zero in round one, the total drops to 150 . The next reciprocator will see an average of 33 (i.e., (150-50)/3 since the average excludes own contribution) and give 33 in round two; the next one will see an average of 28 and give 28. Total contributions will continue to deteriorate until the run ends or they hit zero. Now imagine that a reciprocator goes in round one and a free-rider in round two: The same deterioration will occur with a one-round lag. With enough rounds, therefore, final efficiency will be the same. Typing (based on reactions to others' contributions) does not change with ordering. 

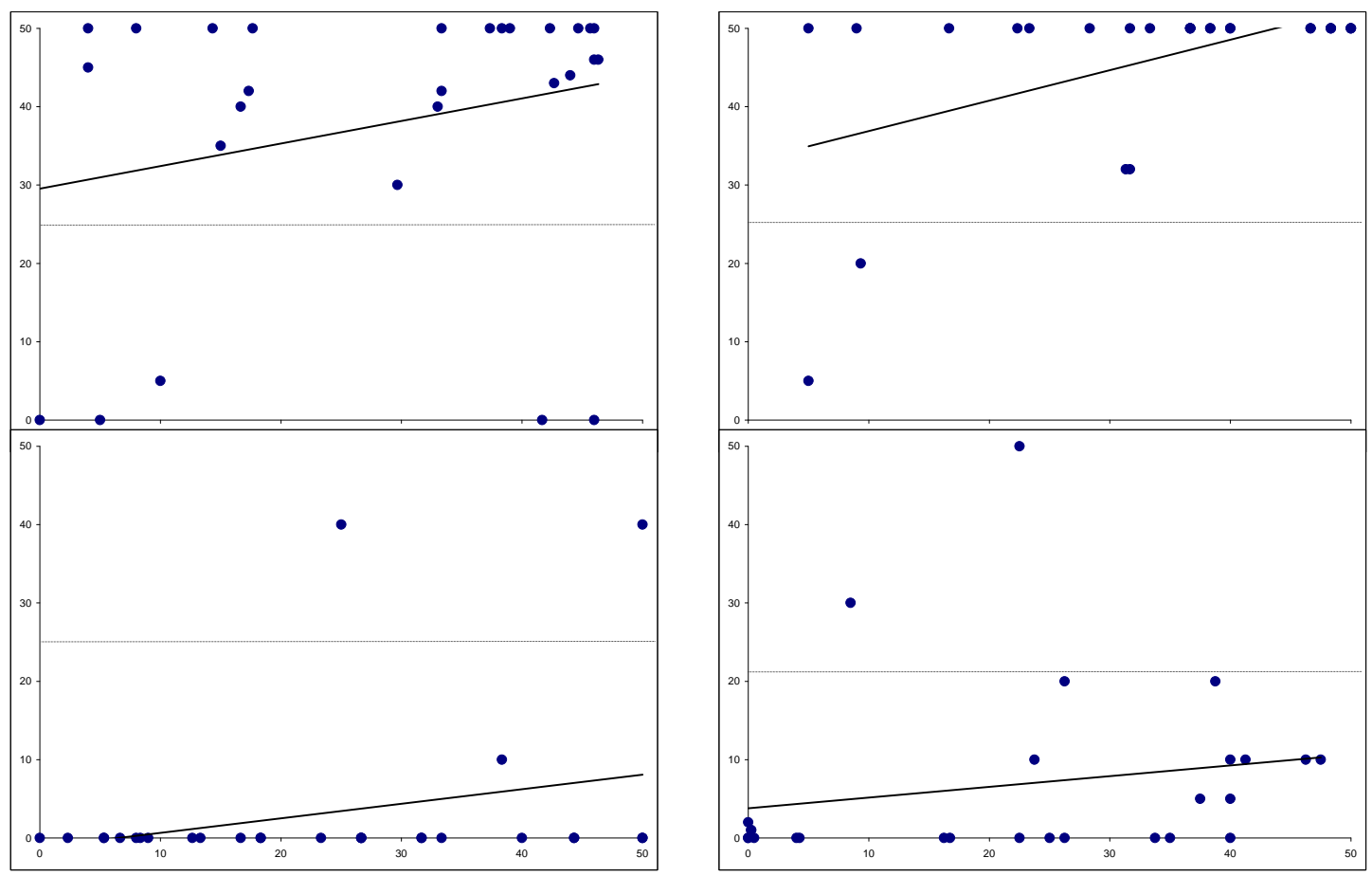

Figure 5.2: Subjects typed as cooperators (top) and free-riders (bottom). Contributions (y-axis) are in response to observed average contribution of others (x-axis).
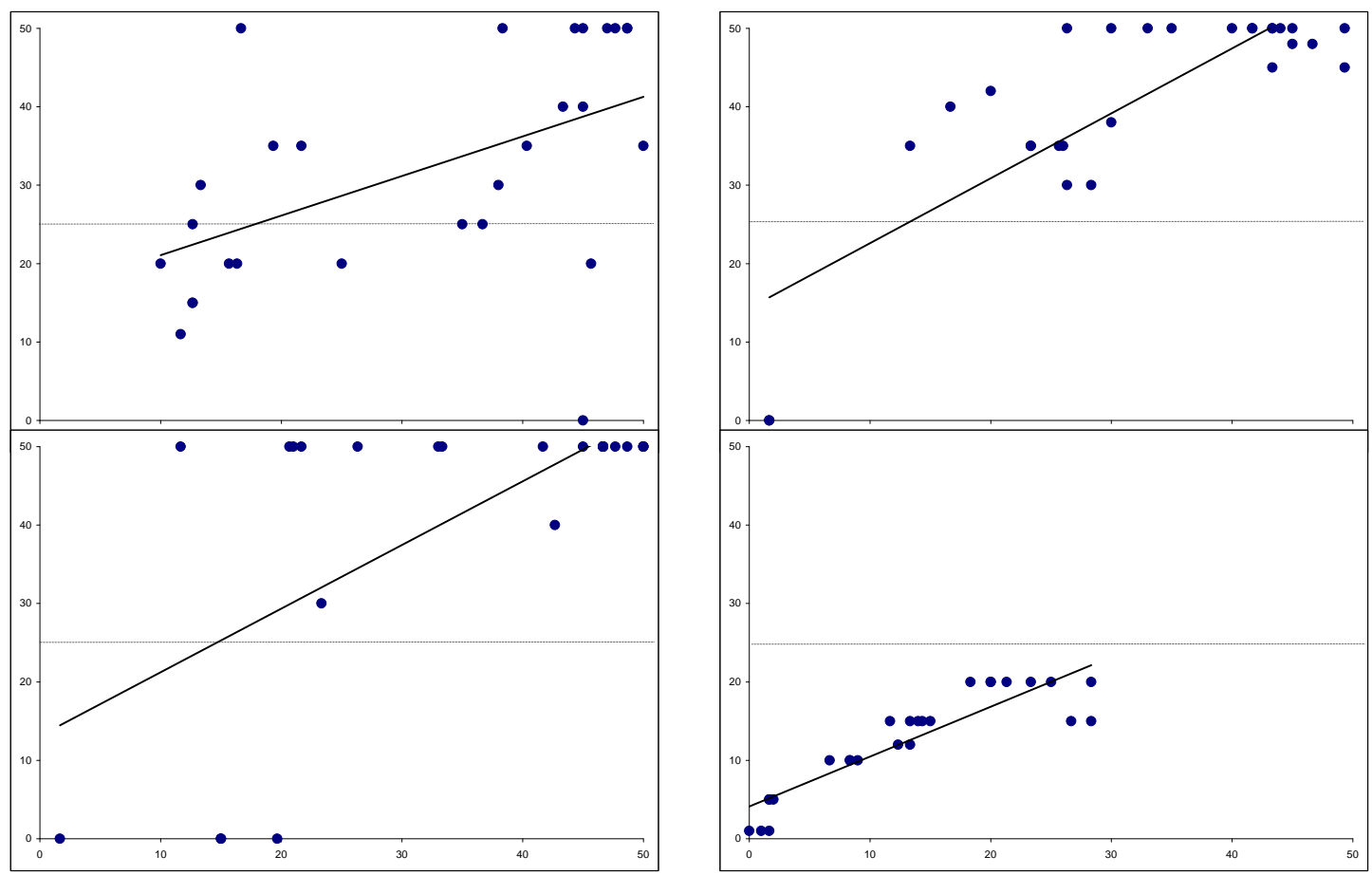

Figure 5.3: Subjects typed as reciprocators 
or if randomization provides sufficient variation. ${ }^{20}$

\subsubsection{Hypotheses}

The PGG is meant to test relative and absolute cooperation of member agency managers, and session efficiency allows us to test the following hypotheses:

$\mathbf{H}_{0}^{1}$ (Relative Cooperation) MAMs and students are equally cooperative, i.e., group efficiencies are statistically identical.

$\mathbf{H}_{0}^{2}$ (Absolute Cooperation) MAMs achieve cooperation at a level greater than or equal to seventy percent.

The threshold for absolute cooperation is calculated using an "out-of-sample" method, i.e., the reaction functions of average student cooperators and reciprocators. (These functions are $\hat{x}_{c}=28.9+0.34 \hat{\bar{x}}$ for cooperators and $\hat{x}_{r}=6.1+0.79 \hat{\bar{x}}$ for reciprocators, and they are depicted in Figure 5.5 on page 77.) A group of one cooperator and three reciprocators would achieve an equilibrium efficiency of 75 percent. $^{21}$ It seems reasonable to say that such a group would be cooperative, and the level of absolute cooperation is conservatively set at 70 percent. If any group - no matter its mix of types - should achieve the same or better cooperation, it also seems reasonable to call it "absolutely cooperative."

\subsubsection{Session Details}

Nine sessions with UC Davis students (UG1-UG9) established a baseline for comparison to three water manager sessions. Student sessions took place at a computer lab at UC Davis; water manager sessions took place at several locations; see Table 5.1. All sessions took place in late 2006 .
Each session began after subjects signed legal consent/disclosure forms and received their anonymous participant number. Participants heard directions for G1 (see Appendix A) and played five runs of G1. After each run, they were reshuffled into new groups of $4-5$ participants. After G1 was complete, half the players were randomly assigned to play G2 and half to G3auction games described in Chapter 7. After completing these games, subjects answered questions that provided demographic information and values for the Trust Index (see below); Appendix A.4 has the questionnaire. Finally, each player received an anonymous cash payment in proportion to his performance. The average payment to students was about $\$ 15$; for water managers, the figure was tripled. Total session length was less than 1.5 hours.

Table 5.2 gives summary descriptive statistics for each session. "Experience" refers to the share of participants with experience of eBay or economic experiments. I create a Trust Index (TI) from the answers to four yes/no questions: "People generally do the right thing," "I find it better to accept others for what they say and appear to be," "I am doubtful of others until I know they can be trusted," and "I almost always believe what people tell me." 22 The yes answers to these questions are added $(+1,+1$,$1,+1)$ to get individual TI values $\in[-1,3]$. If stated preferences match revealed preferences, the TI should be higher for cooperators and lower for free-riders. That proposition is partially true; see Table 5.4.

\section{$5.3 \quad$ Results}

This section has results from all experimental sessions except UG1, which was in-

\footnotetext{
${ }^{21} \mathrm{~A}$ group of five with one cooperator and four reciprocators reaches 73 percent. A group of four cooperators and one reciprocator reaches 86 percent efficiency.

${ }^{22}$ Pre-testing included 20 questions from sources exploring Machiavellianism (see Gunnthorsdottir et al. (2002)), and the top four in variance were retained.
} 
Table 5.1: Details of water manager sessions

\begin{tabular}{llll} 
Group & Subjects & Participants & Location \\
\hline CWAs & $\begin{array}{l}\text { Executives, consultants and staff attending the an- } \\
\text { nual meeting of the investor-owned utilities' Califor- } \\
\text { nia Water Association }\end{array}$ & San Francisco \\
\hline MAMs & $\begin{array}{l}\text { Member Agency Managers attending their monthly } \\
\text { meeting }\end{array}$ & 15 & Los Angeles \\
\hline METs & MET executives and senior staff & 14 & Los Angeles \\
\hline
\end{tabular}

Table 5.2: Descriptive statistics of experimental subjects

\begin{tabular}{lrcrrrrrrr}
\multicolumn{2}{c}{ Session } & Num. & Median & \multicolumn{2}{c}{ Share } & \multicolumn{2}{c}{ Education (\%) } & \multicolumn{2}{c}{ Experience (\%) } \\
Name & Date & Subj. & Age & Male & Engnr & Econ & eBay & Expmt & TI \\
\hline UG1 & Oct 19 & 18 & 20 & 56 & 17 & 39 & 50 & 17 & 0.67 \\
UG2 & Oct 23 & 20 & 20 & 50 & 0 & 35 & 55 & 10 & 0.90 \\
UG3 & Oct 24 & 16 & 20 & 56 & 0 & 81 & 63 & 25 & 0.69 \\
UG4 & Oct 26am & 13 & 21 & 69 & 0 & 62 & 69 & 31 & 0.54 \\
UG5 & Oct 26pm & 20 & 21 & 45 & 10 & 65 & 55 & 20 & 0.80 \\
UG6 & Oct 31am & 20 & 21 & 60 & 5 & 35 & 75 & 15 & 0.65 \\
UG7 & Oct 31pm & 16 & 21 & 44 & 13 & 31 & 75 & 25 & 1.31 \\
UG8 & Nov 2 & 19 & 20 & 58 & 11 & 63 & 68 & 32 & 0.84 \\
UG9 & Nov 7 & 20 & 21 & 60 & 20 & 45 & 60 & 15 & 0.60 \\
\hline CWAs & Nov 16 & 13 & 55 & 85 & 31 & 46 & 38 & 0 & 1.46 \\
MAMs & Nov 17am & 15 & 49 & 87 & 73 & 7 & 33 & 0 & 2.47 \\
METs & Nov 17pm & 14 & 51 & 54 & 14 & 14 & 21 & 0 & 2.07 \\
\hline
\end{tabular}

terrupted by a computer crash. Besides the main results on group efficiency and player type, I present an analysis of the correlation between TI values from the questionnaire and types from the experiments.

Figure 5.4 shows group efficiency (cooperation). Students averaged 34.9 percent of maximum possible efficiency, which is indicated by a horizontal line (error bars of \pm 5.8 percent represent the $95 \%$ confidence interval). The difference between student efficiency and MAMs efficiency $(46 \%)$ is statistically significant, but there is no statistical difference among CWAs, METs and student efficiencies. ${ }^{23}$ These results reject the null hypotheses, i.e.,

$\mathbf{H}_{0}^{1}$ (Relative Cooperation): MAMs and students are equally cooperative, i.e., group efficiency is statistically identical. Reject.

$\mathbf{H}_{0}^{2}$ (Absolute Cooperation): MAMs achieve cooperation at a level greater than or equal to seventy percent. Reject.

Although the result for $\mathrm{H}_{0}^{1}$ is encouraging for those who hope that MAM might have sufficiently social preferences to achieve efficiency at MET, the result for $\mathrm{H}_{0}^{2}$ is not: MAM cooperation (at 46 percent) is substantially lower than the minimum level

\footnotetext{
${ }^{23}$ The ordering of the results for different groups of water managers matches our intuition of cooperation rising with familiarity, i.e., MAMs have "explicitly" cooperative relations; METs work together but may be competitive; and CWAs know each other and meet annually. That said, the differences between these single observations of the target populations are not statistically-robust.
} 


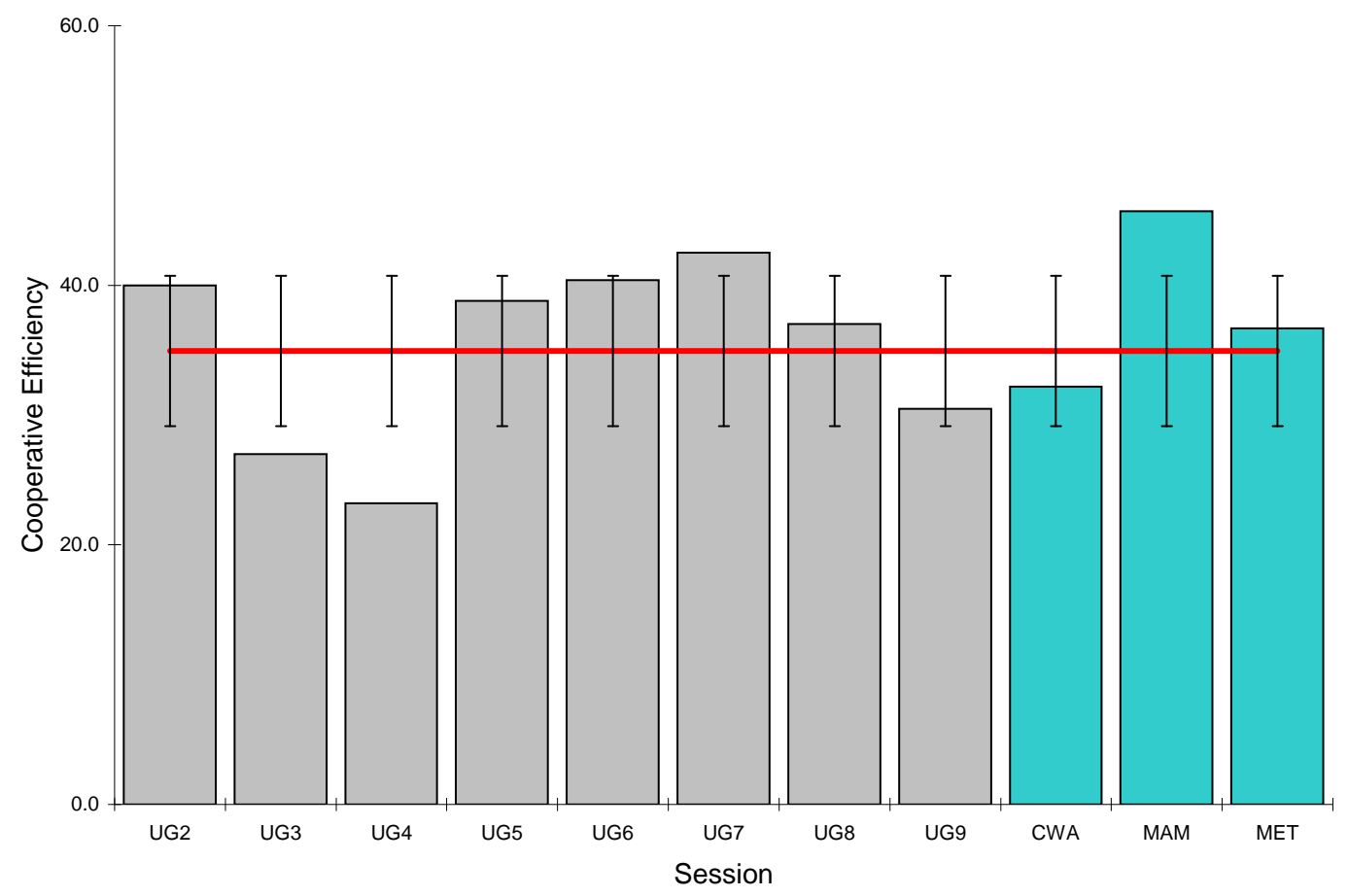

Figure 5.4: Only MAM cooperation was higher than average student cooperation

of cooperation (70 percent) we would get from any group of reciprocators and one or more cooperators. From this result, we can conclude that MAMs do not have the absolute level of cooperation necessary to solve collective-action problems - in the lab. Applicability outside the lab is discussed in Section 5.4.4.

To understand our efficiency results, it helps to look at the shares of cooperators, free-riders and reciprocators. ${ }^{24}$ Table 5.3 shows the share of each type and average group efficiencies, and Figure 5.5 shows the average estimated contribution profile for types among students.

An alternative measure of "propensity to cooperate" is the TI (see page 74) from the questionnaire. Table 5.4 shows the relation between values for stated preference and values for revealed preference: For students, average TI scores for each type are significantly different at the 5 percent level; for managers, they overlap even at the 10 percent level.

\subsection{Discussion}

MAMs cooperation is higher than the benchmark but not high enough to call MAMs "cooperative." In this section, we discuss the method of typing and application of these results to everyday (outside the lab) activities of water managers. Table 5.5 sets the stage for the discussion of typing subjects. It shows the share of types calculated by the OLS method described above (top lines in the student and water manager subsections) and share of types resulting from other OLS methods, which are discussed next.

\subsubsection{Statistical Significance}

OLS regressions give estimates of $\hat{\alpha}_{i}$ and $\hat{\beta}_{i}$, and these coefficients are statistically in-

\footnotetext{
${ }^{24} 136$ of 144 students and 34 of 42 water managers are classified within these three types.
} 
Table 5.3: Subject types and group efficiency

\begin{tabular}{|c|c|c|c|c|}
\hline & \multicolumn{3}{|c|}{ Shares of Type (Percent) } & \multirow{2}{*}{$\begin{array}{l}\text { Efficiency } \\
\text { (Percent) }\end{array}$} \\
\hline & Cooperator & Free-Rider & Reciprocator & \\
\hline CWAs & 10 & 40 & 50 & 32 \\
\hline MAMs & 14 & 21 & 64 & 46 \\
\hline METs & 10 & 20 & 70 & 37 \\
\hline UG (average) & 4 & 12 & 84 & 35 \\
\hline
\end{tabular}

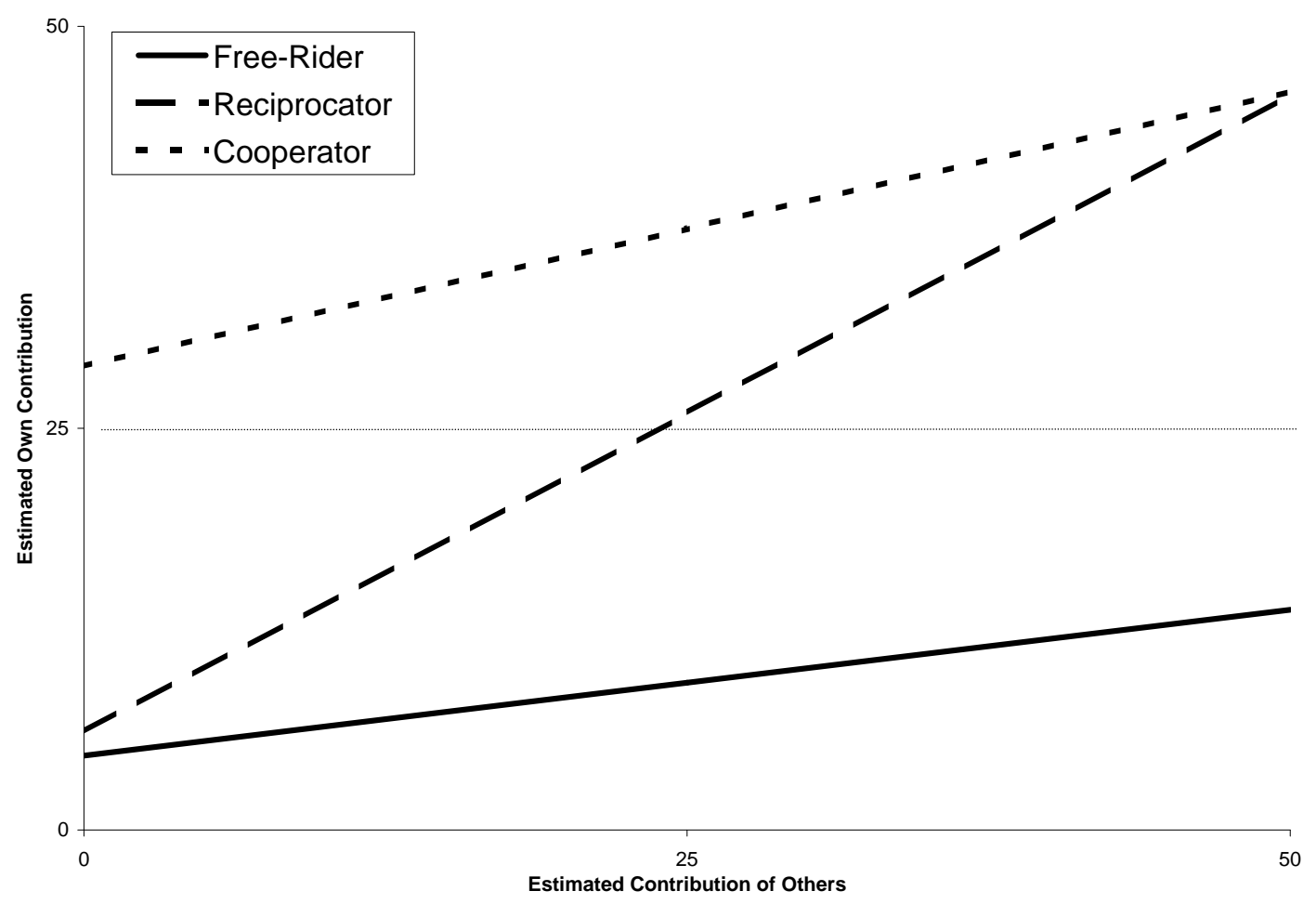

Figure 5.5: Average types from linear characterization of students.

Table 5.4: Average Trust Index values

\begin{tabular}{lcc} 
& Water Managers & Students \\
\hline Cooperators & 2.25 & 1.83 \\
Free-riders & 1.89 & 0.31 \\
Reciprocators & 2.05 & 0.82 \\
\hline Group average & 2.03 & 0.81 \\
\hline
\end{tabular}


Table 5.5: Subject types by estimation method

\begin{tabular}{|c|c|c|c|c|c|}
\hline \multirow[b]{2}{*}{ OLS Regression } & \multicolumn{4}{|c|}{ Shares of Type (Percent) } & \multirow{2}{*}{$\begin{array}{c}\text { No Type } \\
\text { (count) }\end{array}$} \\
\hline & Coop. & Free-Rider & Recip. & Hump & \\
\hline Students & & & & & \\
\hline all coefficients & 4 & 12 & 84 & & 8 \\
\hline signif. coeff. only & 3 & 27 & 69 & & 1 \\
\hline quadratic (all coeff.) & 4 & 10 & 72 & 14 & 6 \\
\hline Water Managers & & & & & \\
\hline all coefficients & 12 & 26 & 62 & & 8 \\
\hline signif. coeff. only & 13 & 45 & 43 & & 2 \\
\hline quadratic (all coeff.) & & not estin & ated & & \\
\hline
\end{tabular}

significant for some individuals. KH use all point estimates in their typing - regardless of statistical significance - and that method is used here. Using all estimates means ignoring error structure, but this cost to accuracy is more than compensated by avoiding an even greater problem-bias in typing.

Bias is introduced when insignificant estimates are set to zero because zero values of $\hat{\beta}$ are associated with free-riders. Put differently, assigning individuals with coefficients that are not significantly different from zero to the free-rider group would overstate the importance of free-riders. We can see this effect in Table 5.5, where the share of free-riders among students rises from 12 percent with all coefficients to 27 percent with significant coefficients only. (The shares among water managers take a similar jump-from 26 to 45 percent.)

\subsubsection{Quadratic Form}

KH's typing method forces each player's actions to fit a linear form, and it is not hard to imagine that some players may play a different strategy, e.g., increasing contributions up to a certain point and then decreasing them. Fischbacher et al. (2001) find that 14 percent of subjects have such a "humpshaped" contribution profile.

Allowing for quadratic variation in
Equation (5.1) gives us:

$$
x_{i g t}=\alpha_{i}+\beta_{i} \bar{x}_{i g t}+\gamma_{i}\left(\bar{x}_{i g t}-\bar{x}_{i}\right)^{2}+\epsilon_{i g t},
$$

where $\bar{x}_{i}$ is the average contribution of others for all rounds and $\gamma_{i}$ is an additional parameter to be estimated. $\bar{x}_{i}$ is used in $\left(\bar{x}_{i g t}-\bar{x}_{i}\right)^{2}$ to increase variation in the quadratic relationship and reduce problems with collinearity.

The estimating of Equation 5.2 with data from 144 students results in the classification of six students as "no type" (meaningful negative $\beta$ and $\gamma$ coefficients). Of the 138 remaining students, 19 (14 percent-as in Fischbacher et al. (2001)) are humped types (positive $\beta$ and negative $\gamma$ coefficients); six (4 percent) are cooperators; 14 (10 percent) are free-riders; and 100 (72 percent) are reciprocators. Figure 5.6 shows the average types found using the quadratic form.

How do we interpret these results? The main shift (compared to the linear-only method) is from reciprocators to humpshaped. In Table 5.5, we see that the share of reciprocators in OLS falls from 84 percent to 72 percent in OLS-quadratic, which has 14 percent hump-shaped types. This result implies that some subjects typed as reciprocators with a linear approximation are really 


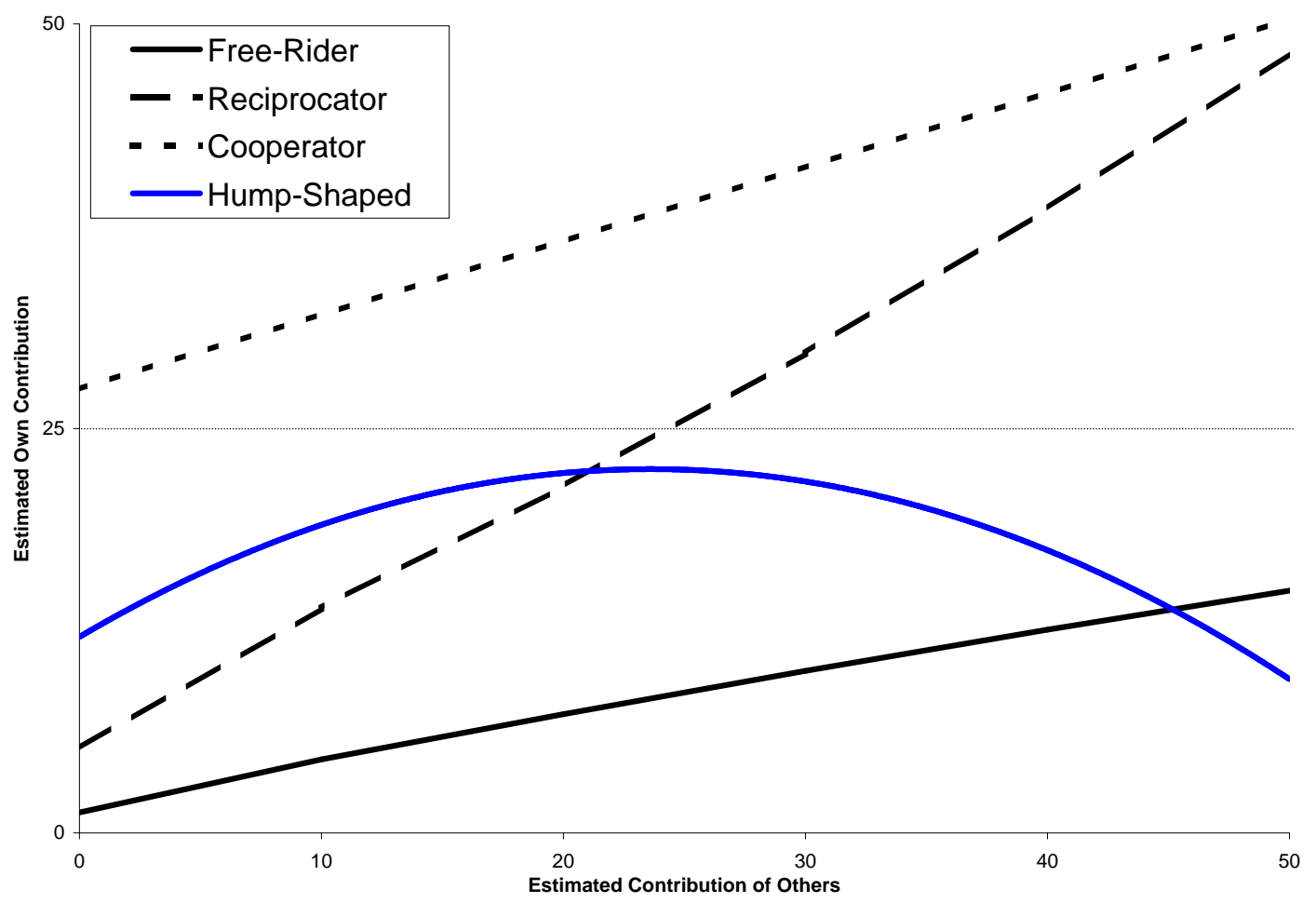

Figure 5.6: Average types from quadratic characterization of subjects

contributing fewer tokens when the average contribution to the public account is above 28-30 tokens.

I do not use quadratic estimates because classification of types is more arbitrary (without statistical significance as a filter, most subjects have some value for $\gamma$, which introduces confusion as to who is a free-rider, reciprocator, etc.), and the only difference appears to be a transfer from reciprocators to hump-shaped types.

\subsubsection{Tobit Model}

Finally, there is the much larger issue of contributions that are censored at upper and lower boundaries in the estimation model. ${ }^{25}$ Since an OLS estimate of the relationship between censored values of $x_{i g t}$ and $\bar{x}_{i g t}$ will produce inconsistent estimates, a Tobit model would probably be more accurate. Tobit is not used because it would require new definitions of types, and types defined under such a scheme would not be compatible with types defined with KH's scheme. Since a Tobit typing scheme is beyond the scope of this work, it is left for future efforts.

\subsubsection{Application to MET}

MAMs are relatively more cooperative than MET managers, CWA executives and students but do not reach absolute levels of cooperation that would support claims that MAMs are "cooperative enough" to make MET efficient as a cooperative. The implication of this result is that MET should design institutions and incentive structures under the assumption that managers (of all

\footnotetext{
${ }^{25}$ For water managers, 43 percent of contribution decisions ( $x_{i g t}$ values) are 0 or 50 ; for students, 46 percent are.
} 
types, acting for their employers) are more likely to act in the interest of self than the interest of the entire group.

On a more basic level are three questions: Can the actions of an individual in an experiment be used to "type" that individual's organization? If we wanted to do that, which individuals would we choose to represent member agencies - their MAMs or do these results apply outside the lab?

The first answer is no: The "behavior" of an organization is the outcome of a complex negotiation among all its members, and every member agency is subject to the opinion and action of many parties (see Footnote 1). The basic conclusion is that no person is an accurate representative of his organization.

Given this caveat, we come to the second best option: If we had to choose one person to represent each member agency, who should we choose? While directors are the formal representatives of member agencies on the Board, and their votes determine the policies that MET implements, I am confident that MAMs are more accurate representatives of member agencies and that interactions among MAMs more accurately capture the relations among member agencies and how "cooperative" MET is. First, directors no longer dominate MET or run it to maximize regional benefits - insiders, Hundley Jr. (1992), and O'Connor (1998b) all agree that the introduction of term limits in 1974 reduced directors' institutional knowledge and increased politicization in the appointment of directors. These effects reinforce each other: Many directors represent their agencies instead of the region and directors? If we measure actions in the lab,

treat their position as an intermediate step on the way to higher office. Second, this effect increases the relative power of member agency staff - and the general manager (McDermott, 1998). Finally, MAMs work with each other to design and implement policies. Thus, if we want to choose any group of people whose relations were going to affect cooperation between member agencies, it would be MAMs. ${ }^{26}$

Do these results apply outside the lab? Do they apply to everyday coordination, cooperation and conflict at MET? Consider the free-rider strategy in a PGG: Contribute nothing and benefit from the contributions of others. Perhaps the closest match to the PGG is the decision to invest in capital projects: Frequent water buyers pay (via sales revenue) for storage projects that irregular water buyers use in drought conditions. ${ }^{27}$ Because storage is a public good (all member agencies benefit from it), "freeriding" agencies get the benefit without the cost. Water managers call this strategy "cost shifting," and the battles over who pays and who benefits are prominent in MET's history (Section 3.11). These quotations characterize a problem that has existed for over fifty years:

Since all members [of MET] are not of equal size and since all do not use District water equally, there is a strong tendency for the cities with a strong demand for water, but with little assessed property value, to pursue policies in making water prices as low as possible and to let the bulk of the costs be carried by taxes.

\footnotetext{
${ }^{26}$ These concerns do not mean that it would not be a good idea to run cooperation experiments with directors, only that the results of those sessions would have been less important than the MAMs results reported here.

${ }^{27}$ This case occurs in 1987-1991 drought: In 1990, LADWP takes over six-times its 1986 delivery while SDCWA - closer to its "base allocation" - takes only 27 percent more water.
} 
—Milliman (1956a, p. 491)

[Some] agencies appear to want MET to develop costly backup capacity - or insurance - for their local supply strategies, while seeking to shift the cost from these benefits on to Metropolitan and other agencies and consumers.

-Blue Ribbon Task Force (1994, p. 23)

Although infrastructure spending and PGGs have similarities, their decision processes differ. Experiments use a noncooperative structure (no communication or binding agreements), but member agencies talk and make agreements - actions that characterize a cooperative game. Are managers really playing a cooperative game? According to Ostrom et al. (1994), communication and contracts mean little without external enforcement or trust. MET is a self-regulated cooperative with rules and agreements (e.g., preferential rights, water rates, or the Laguna Declaration) that are "enforced" through internal administrative codes. As far as trust is concerned, both insiders and outsiders (PriceWaterhouseCoopers, 1998; O'Connor, 1998a,b; Erie, 2006) observe low trust among member agencies and their representatives. Although MAMs did not participate in explicit trust experiments, they had the opportunity to express their level of trust when answering questions behind the Trust Index. Unfortunately, the absence of any correlation between what managers said and did (no difference across types in Table 5.4) leads one to conclude that their answers were cheap talk.

Even if we assume the situation at MET is non-cooperative, perhaps MAMs can talk their way to a more efficient outcome? ${ }^{28}$ Communication will increase cooperation. But how high will it get? Could managers achieve an absolute level of cooperation that is efficient enough? Perhaps, but results from lab experiments should temper our optimism.

\subsection{Summary}

This chapter described a cooperation experiment in which member agency managers (MAMs) and several comparison groups (students, other managers) decided how much of a public good they wanted to produce. The results from the experiments reject the hypothesis that MAMs are just as cooperative as students (they are more cooperative) but also reject the hypothesis that MAM are "cooperative enough" to maximize group welfare. These results are subject to critiques (i.e., external validity, individuals representing organizations, and the most-appropriate representative), which are addressed.

Although MET is a cooperative, its executives and managers from its member agencies do not behave in ways consistent with cooperative attitudes and preferences. Although a significant share of water managers behaved in ways consistent with being cooperative types, twice as many behaved as free-riders. Even cautious observers should be willing to support institutional rules based on the assumption that water managers' preferences are more selfinterested than social.

\footnotetext{
${ }^{28}$ Ostrom et al. (1994) find that communication - without binding agreements - in PGGs increases efficiency by 42-80 percent. Other mechanisms (punishment, incremental commitments or voting) can also increase efficiency; see examples in Fehr and Schmidt (1999), Kurzban et al. (2001) and Kroll et al. (2007).
} 
5.5. SUMMARY 


\section{Chapter 6}

\section{Testing for Impacts of Water Misallocation}

How do we know if MET's waterallocation policies are inefficient? If they are (as predicted by theory - see Chapter 4), can the inefficiency be measured? This chapter tests the theory by running an econometric estimation of the impact of water on property values using 60 years of panel data. The intuition behind this examination is that water is a necessary-but not sufficient-production input; its presence attracts people (in general) and waterintensive industries (in particular). Since land near reliable water is in greater demand, it will have greater value. ${ }^{1}$

So the first hypothesis to test is whether quantity has any impact on value. After this basic question come follow-up questions: Does the source of water (local or MET) or ratio between these two quantities (dependency; see Section 4.2.4) matter? ${ }^{2}$ Finally, there is the question of how well MET fulfills its role as a regional water provider. Did MET, for example, smooth water-supply disruptions during the 1987-
1991 drought such that members all experienced the same damage to their property values?

Answering these questions will take the rest of the chapter, but the quick answers are these: Water has a positive impact on land value; the source and share of water (local versus MET) can matter; and the drought had asymmetric effects on member agencies. Although these results come with many caveats, we cannot reject inefficient water allocation.

The next section reviews prior work in this area, explains the simple relation being tested, and states hypotheses. Section 6.2 discussed limitations and problems with the model. Section 6.3 describes data used in the estimation. Section 6.4 gives the econometric model. Section 6.5 has results, and Section 6.6 on page 91 summarizes.

\subsection{Theoretical Model}

The impact of water on agricultural land value is well known. Veeman et al. (1997)

\footnotetext{
${ }^{1}$ Water is used not just in production (landscaping, processing foods, agriculture) but also as a direct consumption good (swimming pools, drinking water) that contributes to overall "quality of life" that increases land value.

${ }^{2}$ Water managers say their local water (from the ground, LAA, desalination, or recycling) is "more reliable"; if true, local water should have a stronger positive impact on land values.
} 
find, for example, that water rights add 35 percent to the value of non-irrigated land. Schlenker et al. (2007) estimate that the permanent supply of one AF/year of surface water increases the net value of California agricultural land by $\$ 656$ /acre.

The impact of water on urban land values is less clear. Although water is necessary for economic growth, it is not sufficient (Hanemann, 2005). Urban land value is mainly a function of population, location and income; water will have a weak impact, if any. The economic rationale for ignoring (i.e., not measuring) the influence of water on urban land values is reinforced by a public policy that-according to Tarlock and van de Wetering (2008) - water should not limit urban growth in the western US. This policy explains common phenomena such as average cost pricing and "building ahead" of demand described in Section 3.3 and criticized (as leading to unsustainable growth) in Section 4.4.2.

A literature review uncovered only one article that discusses the influence of water on urban growth. Beeson et al. (2001) find that precipitation has a significant positive effect on population density in the United States of 1840. By 1990, this significance disappears. In fact, precipitation has a negative correlation with population growth in the 150 years after 1840 . These results correspond to what we know about water in the western US: As infrastructure has brought water to arid regions, people have moved from wet, colder areas to dry, warmer areas.

Thus, this estimation represents a first attempt to measure the impact of water supply on urban land values. The measurement uses this model:

$$
\begin{aligned}
A V_{i t}= & \beta_{0} A V L_{i, t-1}+\beta_{1} \text { local }_{i t}+\beta_{2} \text { met }_{i t}+\beta_{3} \text { metsh }_{i t} \\
& +\beta_{4} \text { shmet }_{i t}+\delta_{1 \ldots n} \text { Drought }_{i}+\mathbf{X}_{i t}+\epsilon_{i t}
\end{aligned}
$$

where $A V$ is assessed land value; $A V L$ is the lagged dependent variable; local is the quantity of local water, met is the quantity of MET water; metsh is the share of met in a member's total supply (local plus met), and shmet represents the member's share of total MET sales; and Drought dummies for each member agency allow for post-drought shifts in valuation. $\mathbf{X}_{i t}$ is a matrix of control variables for member-agency fixed effects (before the drought), pooled drought effects, population, and land use. All variables are indexed by member agency $(i)$ and year $(t)$.

The panel is split lengthwise to run separate city and MWD regressions-allowing for more coefficient variation than would be possible with a single "form" dummy. ${ }^{3}$
Results from estimating the two sub-panels will allow us to test five pairs of hypotheses on the correlation of $\mathrm{AV}$ with right-hand side (RHS) variables:

$H_{0}^{1 C}$ Quantity of water, regardless of source, is insignificant for cities.

$H_{0}^{1 M}$ Quantity of water, regardless of source, is insignificant for MWDs.

$H_{0}^{2 C}$ Water sources (local and met) have equal coefficients for cities.

$H_{0}^{2 M}$ Water sources (local and met) have equal coefficients for MWDs.

$H_{0}^{3 C}$ The share of MET water (metsh) is insignificant for cities.

$H_{0}^{3 M}$ The share of MET water (metsh) is insignificant for MWDs.

\footnotetext{
${ }^{3}$ The most obvious reason for this is that cities sell water at retail, and MWDs sell at wholesale.
} 
$H_{0}^{4 C}$ The share of MET's total sales (shmet)is insignificant for cities.

$H_{0}^{4 M}$ The share of MET's total sales (shmet) is insignificant for MWDs.

$H_{0}^{5 C}$ Post-1994 dummies have equal coefficients for cities.

$H_{0}^{5 M}$ Post-1994 dummies have equal coefficients for MWDs.

\subsection{Potential Problems}

First, this reduced-form model may be misspecified. In theory, it would be better to use a structural model to connect water via a production function to income and thence to demand for real estate with market values - leading to assessed values after a slight lag. ${ }^{4}$

Without historical data and parameters to specify a structural-form model, the only choice is to use a reduced-form model that puts causal relations in a black-box. This model is misspecified to the extent that it assumes homogeneity in the way RHS variables (water in Burbank versus water in Pasadena) and functional parameters (e.g., decreasing versus constant returns to scale) affect AV.

Second, AV and water supply may affect each other, creating endogeneity problems. We know, for instance, that land with water is more valuable than land without water, all else equal. We can say that water from local sources (e.g., rivers and aquifers) causes an increase in land value through an endowment effect. But it is also clear that land value can be used to increase water supplies through a wealth effect. (Only a city with the wealth of Los Angeles could afford to build the LAA and import water from Owens Valley; recall Section 3.1.) Thus, it is possible that a regression of land value on water supply will suffer from endogeneity, i.e., that water supply (especially imported water) and land value are jointly determined.

Bjornlund and O'Callaghan (2005) discusses water's two-fold impact on farm values - through the water and the infrastructure, which is non-tradable and worthless without water. ${ }^{5}$ They-along with Schlenker et al. (2007) — state that the value of farm land is a function of water and not vice versa. For example, both papers discuss how land prices fluctuate in response to drought and flood - and the changing value of water rights.

In the case of MET, endogeneity is even less important because member agencies received unlimited access to MET's water, below the cost of local water production and without regard for their land values. Put another way, land values never did and still do not affect how much water member agencies got from MET. ${ }^{6}$ Because MET's biggest expense (the Colorado River Aqueduct, or CRA) was mostly financed by Los Angeles, most member agencies experienced MET water as an exogenous shock to their supplies. Since all members pay the same postage stamp price (Section 4.4.2), and price is not used as a rationing mechanism, member agency wealth does not matter. ${ }^{7}$ Since MET water does not flow towards

\footnotetext{
${ }^{4}$ See Poterba et al. (1991) and Guan and Hubacek (2007) for examples relating income to real estate demand and water to production functions, respectively.

${ }^{5}$ The regression here does not control for infrastructure, which is an unobserved variable.

${ }^{6}$ See Section 3.3 for MET's early pricing and annexation policies. Voting at MET is in proportion to assessed value (Section 2.1), but access to water is unlimited.

${ }^{7} \mathrm{MET}$ has rationed water with pro-rata formulas, not in proportion to purchasing power or price. Los Angeles could have used its wealth (hence votes) to award itself more water but did the opposite. Section 3.3.2 describes how Los Angeles voted to subsidize the water supply of poorer member agencies and took little water for itself.
} 
money, we can ignore endogeneity.

Third, we must worry about omitted RHS variables that influence $\mathrm{AV}$ at the same time that the drought occurred. Although "post-drought" dummies for each water agency may capture changes in value from post-drought changes in perceived reliability, they may reflect the end of the Cold War or impact of the S\&L crisis. ${ }^{8}$ The upshot is that significant coefficients may result from omitted variables - not postdrought shocks related to water.

Although endogeneity is not a problem, potential problems with the reduced form and member agency dummies mean that we should interpret results with caution. Although significant results can mean many things, the most humble interpretation would be "a failure to find no evidence of misallocation."

\subsection{Data}

Most data come from annual reports (ARs) that MET issues after the fiscal year ends on June 30. (The year from July 11989 to June 301990 is called FYE90, and the Annual Report for FYE90 is called AR90.) MET does not have historic data on land use, but the decennial surveys of the California Department of Water Resources (DWR) fill the void. The main challenge is aggregating, interpolating and homogenizing the data into a useable form. ${ }^{9}$

\subsubsection{Assessed Value}

To measure the impact of water on land value, we need reliable data on the Market Value (MV) of land for all of MET's member agencies. Unfortunately, those data do not exist. MET only kept records of Assessed Value (AV) for purposes of voting rights and tax assessments. AV was highly correlated with MV until 1977 (Smith, 1970), but the 1978 enactment of Proposition 13 destroyed the connection between MV and AV (Garmaise and Moskowitz, 1999)-introducing many biases into both measures (Kindahl, 1983). ${ }^{10}$ Although Proposition 13 is disruptive, the CA State Association of Counties (2004, p. 16) concludes that "a county's relative amount of property tax revenue received in 1978 and 2002 remains relatively unchanged." Put differently, the AVs of Southern California counties did not change in different ways. Unfortunately, this result does not tell us if AV is a good predictor of $\mathrm{MV}$. The bottom line is that AV is an imperfect proxy for MV. AV values are stated in 2004 dollars.

\subsubsection{Area}

Member agency area comes from 19421993 ARs. After AR93, MET stopped reporting area data by member agency. Unfortunately, member agencies' versions of their own area data cannot be used because they do not match MET's numbers. The 1993-2005 gap is filled by interpolating between MET's member-agency figures for 1993 and 2005. Given a total change of less than 0.5 percent, the potential harm for assuming a linear interpolation is slight.

\subsubsection{Population}

Member agency population, in thousands, comes from 1942-1993 ARs. MET stopped reporting population data after the 1993 AR but provided a different data se-

\footnotetext{
${ }^{8}$ Edelstein and Kroll (1997) say the 1991-93 recession's impact on jobs disappears by 1995, but the impact on real estate is still evident in 1996.

${ }^{9}$ See Appendix D for data sources. Data are aggregated to reflect the current set of member agencies, i.e., Pomona Valley MWD became Three Valleys MWD, Chino MWD became Inland Empire MWD, and Coastal MWD merged into MWDOC.

${ }^{10}$ Since 1978, Proposition 13 limits property taxes to one percent of the 1975 AV - or the post-1978 sale price if the property is sold - plus a two percent annual increase unless inflation is significant.
} 
ries from 1980 to 2004. Unfortunately, the overlapping years of these data sets do not match, and they are integrated by interpolation, i.e., adding the difference between AR and MET data in 1980 to AR figures in 10 percent steps (beginning in 1970) so that the "adjusted" AR data for 1980 equals MET data for 1980. The 1980-2004 series is used after 1980.

\subsubsection{Water}

Member agencies get water from local sources (i.e., the LAA, groundwater, reclaimed water and/or IID-SDCWA transfers) and MET. MET has different definitions for different types of water delivery over the years, which are merged into one category (MET delivery).

MET's treatment of "groundwater recharge" merits a brief explanation: MET counts year $t$ groundwater recharge as delivered but not used in year $t$, but then counts use (in year $t+1$, say) against local supply, which inflates local supply and reduces the supply of imported MET water. I correct this "slip" by treating groundwater recharge in year $t$ as MET delivery in year $t+1$ and removing it from local supply in year $t+1$. Table 6.1 shows an example of this correction.

Unfortunately, AR water-delivery data only run from 1942 to 1997, and MET's delivery data from 1979-2006 do not match the earlier set during their 18-year overlap. ${ }^{11}$ Luckily, the choice between the $\mathbf{A R}$ (switching from ARs in 1997) and MET (switching in 1979) datasets does not seem to matter: Both local and MET deliveries are lower in the AR dataset, so neither set introduces bias. ${ }^{12}$ The AR dataset is used because it reflects adjustments for miscalculated groundwater deliveries.

\subsubsection{Land Use}

DWR has three major categories of land use: urban, agricultural and non-water/native vegetation. Urban land is classified as residential, commercial, industrial or other use (ures, ucom, uind, uotr); agricultural land is used for annual, perennial and other crops (aannual, aperennial, aother). Shares of different land uses add to 1.00, and the remaining category (Nonwater/native vegetation) is the omitted variable.

The DWR's land surveys began in the 1950s and repeat every 8-10 years until the 1990s. ${ }^{13}$ The surveys cover fifteen member agencies between three and five times. Unfortunately, there are no surveys for the other 11 member agencies.

MET's 1990 and 2000 surveys provide the only data for missing member agencies and data for the period after the last tabulated DWR survey. These two sets are merged with a combination of category matching and mergers, linear interpolation, and subjective reconciliation into one dataset that is still missing 722 (or 49 percent) of 1,475 potential observations.

There are two different ways to generate those 722 datapoints: The manual method uses data from similar member agencies in the same year and own data in earlier or later years (i.e., copy the earliest observation back to 1942 and the latest observation

\footnotetext{
${ }^{11}$ Annual delivery totals differ by $\mathrm{min} / \mathrm{max} /$ average of $0.2 / 5.1 / 1.5$ percent, and individual member agencies have greater variation.

${ }^{12}$ Two-sided t-tests comparing local and MET supplies to all member agencies in the overlapping years 1979-1997 reject null hypotheses that annual mean deliveries are the same in both sets. The test fails to reject the alternate hypothesis that the mean for local-MET $(67,297 \mathrm{AFY})$ is greater than local-AR $(65,822 \mathrm{AFY})$, a difference of 2.2 percent. The test fails to reject the alternate hypothesis that the mean for MET-MET $(66,609 \mathrm{AFY})$ is greater than MET-AR $(66,141 \mathrm{AFY})$, a difference of 0.7 percent.

${ }^{13}$ After 1990, DWR reports raw GIS data, which is too unwieldy to aggregate to the member agency level.
} 
Table 6.1: Correcting MET's accounting for groundwater delivery

\begin{tabular}{cccccc} 
Year & G/W & \multicolumn{2}{c}{ DET Supply } & Local & MA \\
Sirect & Total & Supply & Use \\
\hline \multicolumn{7}{c}{ MET's method } \\
2 & $\mathbf{2}$ & 10 & $\mathbf{2}+10=12$ & 3 & $10+3=13$ \\
\hline Total & 0 & 8 & $0+8=8$ & 5 & 13 \\
\hline \hline \multicolumn{7}{c}{ Correct method } \\
1 & $\mathbf{2}$ & 10 & 10 & 3 & 26 \\
2 & 0 & $8+\mathbf{2}=10$ & 10 & $5-\mathbf{2}=3$ & 13 \\
\hline Total & 20 & 6 & 26 \\
\hline \multicolumn{7}{c}{}
\end{tabular}

forward to 2004). The imputed method uses the ice package in STATA to create estimated values (Wayman, 2003; Carlin et al., 2007; Royston, 2007).

Table 6.2 reports goodness of fit results from regressions using data from these two methods and a baseline case without landuse data. Values closer to zero indicate better fit (for background on AIC and BIC, see Akaike (1974) and Schwarz (1978), respectively). Fit is similar for all three models, and residuals cluster around zero. ${ }^{14}$ The nouse model has the worst fit. Although the manual and imputed models have similar fit, the manual model is easier to explain and understand, so it is used from here.

\subsection{Econometric Model}

This section describes the exact regression variables and model. Because member agencies joined MET over the years, the panel data from 1942-2004 are unbalanced. Although cities and MWDs are in separate panels, remaining heterogeneity among member agencies implies heteroscedastic errors, so Generalized Least Squares is used. All data are indexed by year and member agency.

The dependent variable is deflated assessed value per acre (a_avd), stated in thousands of 2004 dollars. Assessed value, population and water delivery are divided by area to get per acre values. ${ }^{15}$ RHS variables are:

- lagged assessed value (a_avd_lag) — to control for auto-correlation. ${ }^{16}$

- population (a_pop) and population squared (a_pop2) - to allow for quadratic relations

- water deliveries by AF (a_local and a_met), MET's percentage share of the MA's total (metsh, with localsh omitted), and each MA's percentage share of total MET deliveries (shmet) - to control for different measures of water supply

- variables for land use, expressed in

\footnotetext{
${ }^{14}$ Robust OLS of the dependent variable $\left(a_{-} a v d\right)$ on residuals from the manual models results in insignificant coefficients and $\mathrm{R}^{2}$ values just above zero.

${ }^{15}$ Area is the number of acres in that member agency in that period; lagged AV is divided by lagged area. Area-deflated variables are marked with "a_" prefixes in the regressions.

${ }^{16}$ The per-acre ratio of $a_{-} a v d / a_{-} a v d \_l a g$ averaged across all data is 1.120 for cities and 1.138 for MWDs. Extremely-significant (z-values over 200) regression coefficients on the RHS value for a_avd_lag are 1.141 and 1.149 , respectively. The difference suggests the net impact of other RHS variables on $a \_a v d$ is negative.
} 
Table 6.2: Comparing econometric models for goodness-of-fit

\begin{tabular}{llrrrrr} 
Form & Model & obs. & log likelihood & df & AIC & BIC \\
\hline \multirow{3}{*}{ Cities } & No Use & 851 & $-3,483$ & 37 & 7,040 & 7,216 \\
& Manual & 851 & $-3,441$ & 44 & 6,970 & 7,179 \\
& Imputed & 851 & $-3,459$ & 44 & 7,006 & 7,215 \\
\hline \multirow{3}{*}{ MWDs } & No Use & 607 & $-1,840$ & 31 & 3,742 & 3,879 \\
& Manual & 607 & $-1,826$ & 38 & 3,728 & 3,896 \\
& Imputed & 607 & $-1,792$ & 38 & 3,659 & 3,827 \\
\hline
\end{tabular}

shares (e.g., percent urban residential) that sum to 1.00; "non-water" is the omitted variable.

- Member agency dummies (MA1 $M A 26)$ - to allow for MA-level fixed effects, with $M A 1$ and $M A 26$ dropped in the city and MWD panels, respectively.

- a post-drought dummy $($ postd $=1$ for FYE94-FYE04) to capture any change in values after the 1987-1991 drought. Figure 6.1 shows that 1994 was the year in which total assessed values broke from their upward trends.

- post-drought dummies for each member agency (postdma[1 - 26]) — to explore differential post-drought effects, with postma 1 and postma 26 dropped.

- two dummies for the cities of Santa Ana and Anaheim in 1986-to control for an administrative change in assessed value at MET

\subsection{Results}

See Appendix Tables B.1 and B.2 for complete regression output. Table 6.3 shows that each AF of MET water has a positive, significant impact on AV for both cities and MWDs. ${ }^{17}$ For MWDs, the positive impact of local water is statistically indistinguishable from MET water. The impact of local water is small, weakly significant, and robust to the exclusion of Los Angeles. The share of MET water in total supply (metsh) is significantly negative for cities. Although this result appears to contradict the positive coefficient on MET water, it makes sense in a scenario where a city is buying some MET water, but MET is not the city's primary source of supply. These results allow us to evaluate previously-stated hypotheses:

$H_{0}^{1 C}$ Quantity of water, regardless of source, is insignificant for cities. Reject. MET water has a significant positive impact on AV.

$H_{0}^{1 M}$ Quantity of water, regardless of source, is insignificant for MWDs. Reject. MET and local water have significant, positive impacts on $\mathrm{AV}$.

$H_{0}^{2 C}$ Water sources (local and met) have equal coefficients for cities. Reject. MET water is associated with higher AV than local water.

$H_{0}^{2 M}$ Water sources (local and met) have equal coefficients for MWDs. Fail to Reject. Confidence intervals for coefficients overlap (at the 95 percent level).

$H_{0}^{3 C}$ The share of MET water (metsh) is insignificant for cities. Reject. The coefficient is negative and significant.

\footnotetext{
${ }^{17}$ Schlenker et al. (2007) estimate - using a different method - that an additional AF of water is associated with an additional value of $\$ 656 /$ acre for agricultural land.
} 

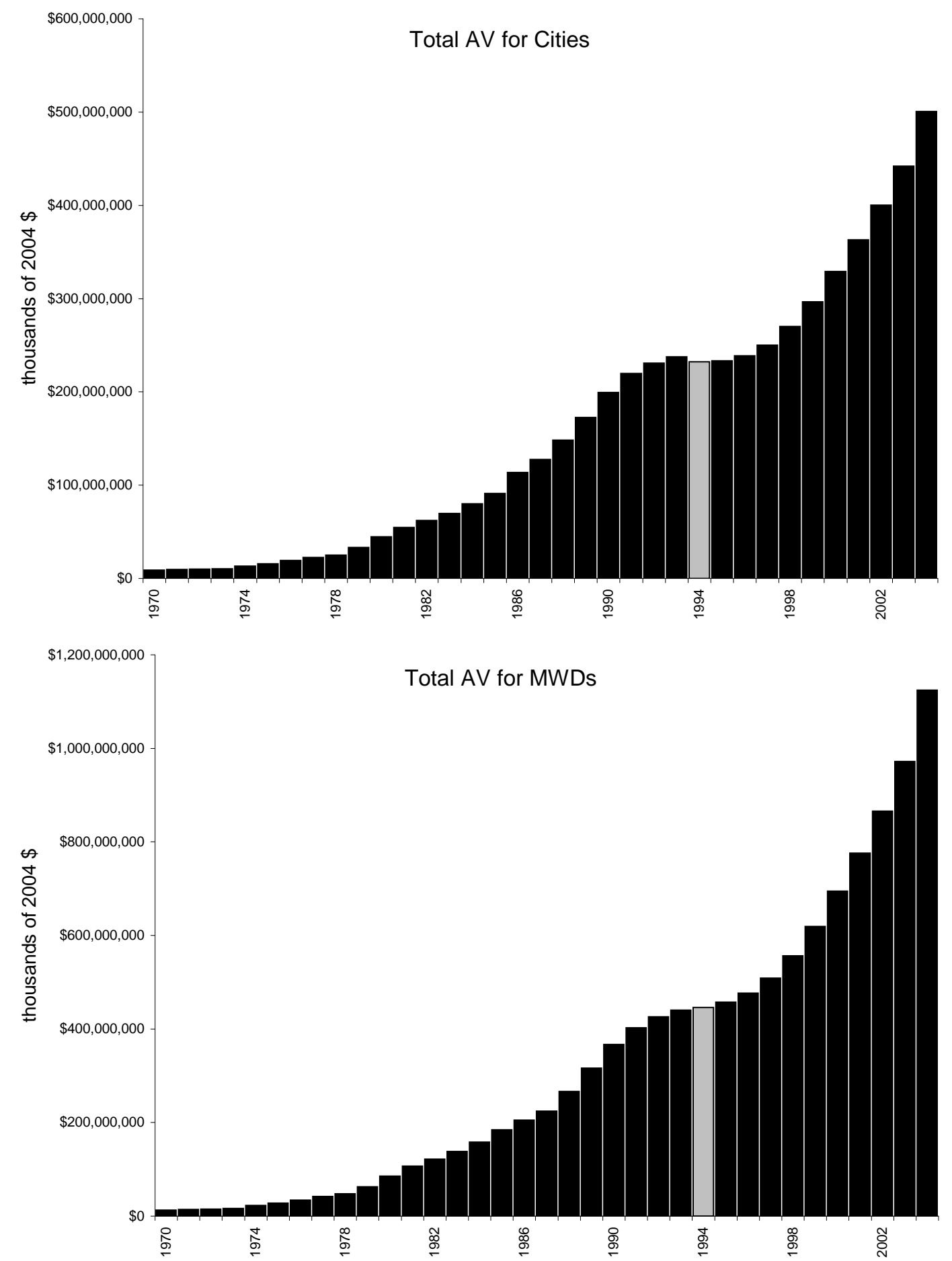

Figure 6.1: Assessed values broke from their trends in 1994 
Table 6.3: The effects of water supply on assessed value

\begin{tabular}{clrrr} 
Dep Var: a_avd & coefficient & & p-value \\
\hline \multirow{4}{*}{ Cities } & a_local & 2.3 & & 0.11 \\
& a_met & 16.7 & $* * *$ & 0.00 \\
& metsh & -23.0 & $* * *$ & 0.00 \\
& shmet & 4.0 & & 0.82 \\
\hline \multirow{3}{*}{ MWDs } & a_local & 7.2 & $* * *$ & 0.00 \\
& a_met & 8.1 & $* * *$ & 0.00 \\
& metsh & 1.2 & & 0.43 \\
& shmet & -3.89 & & 0.66 \\
\hline \multicolumn{3}{c}{ *** Significant at the $1 \%$ level }
\end{tabular}

$H_{0}^{3 M}$ The share of MET water (metsh) is insignificant for MWDs. Fail to Reject.

$H_{0}^{4 C}$ The share of MET's total sales (shmet)is insignificant for cities. Fail to Reject.

$H_{0}^{4 M}$ The share of MET's total sales (shmet) is insignificant for MWDs. Fail to Reject.

$H_{0}^{5 C}$ Post-1994 dummies have equal coefficients for cities. Reject. Many postdrought coefficients for city dummies are significantly negative. Table 6.4 shows the shift/acre from coefficient estimates and size of that shift relative to baseline, 1994 assessed values. (All numbers are in 2004 dollars). Anaheim, Compton and Santa Ana experience no drop; Beverly Hills and Santa Monica experience the largest drops in value/acre; and all other cities experience drops between these two groups. In percentage terms, decreases average six percent. A look at the cities and their AVs suggests that measured changes in AV could easily reflect depreciating real estate in wealthier areas - not the effects of drought. (The correlation between base value/acre and percentage shift is -0.48 .)

$H_{0}^{5 M}$ Post-1994 dummies have equal coefficients for MWDs. Reject. Twothirds of MWDs post-drought coefficients are significantly negative. Table 6.5 shows the shift/acre from coefficient estimates and size of that shift relative to baseline, 1994 assessed values. These results are similar to results from cities - the correlation between value/acre and percentage shift is -0.63 . Across both cities and MWDs, the sum of all shifters is - $\$ 33.4$ billion, or five percent of total 1994 AV (in 2004\$). This figure represents a significant and persistent reduction in post-1994 assessed values that may be related to the drought.

\subsection{Summary}

This chapter presents a regression analysis of factors affecting urban land values. Controlling for many variables in a 60-year panel of data divided into city and MWD sub-panels, the results reject three of four hypotheses stating that the quantity of water per acre has no impact on assessed value per acre. More interesting perhaps is the estimate that an additional acre-foot of annual water supply increases MWDs' assessed land values by $\$ 7,000-\$ 8,000$ per 
Table 6.4: Post-drought shifts in AV for cities (000s of 2004\$)

\begin{tabular}{rlrrrrr} 
MA & $\begin{array}{r}1994 \mathrm{AV} \\
\text { num }\end{array}$ & $\begin{array}{r}1994 \mathrm{Area} \\
(\$)\end{array}$ & $\begin{array}{r}\text { AV/acre } \\
\left(\$ \mathrm{mi}^{2}\right)\end{array}$ & $\begin{array}{c}\text { Post-1994 shift } \\
(\$ / \text { acre })\end{array}$ & $\begin{array}{r}\text { (\$acre }) \\
(\% \text { change })\end{array}$ \\
\hline 1 & Anaheim (omitted) & $12,081,208$ & 49 & 387 & 0 & 0 \\
2 & Burbank & $6,459,630$ & 17 & 590 & -27 & -5 \\
3 & Beverly Hills & $6,602,209$ & 6 & 1,810 & -138 & -8 \\
5 & Compton & $1,226,402$ & 10 & 188 & 0 & 0 \\
8 & Fullerton & $4,857,777$ & 22 & 343 & -20 & -6 \\
10 & Glendale & $8,511,969$ & 31 & 435 & -25 & -6 \\
12 & Los Angeles & $144,603,074$ & 469 & 482 & -30 & -6 \\
13 & Long Beach & $14,422,825$ & 50 & 452 & -30 & -7 \\
16 & Pasadena & $7,060,336$ & 23 & 476 & -19 & -4 \\
17 & Santa Ana & $8,204,457$ & 27 & 468 & 0 & 0 \\
19 & San Fernando & 560,689 & 2 & 365 & -18 & -5 \\
20 & Santa Monica & $7,273,331$ & 8 & 1,403 & -81 & -6 \\
21 & San Marino & $1,446,927$ & 4 & 595 & -33 & -6 \\
22 & Torrance & $8,950,581$ & 22 & 650 & -43 & -7 \\
\hline total/weighted average: & $232,261,415$ & 740 & 491 & -27 & -6
\end{tabular}

Table 6.5: Post-drought shifts in AV for MWDs (000s of 2004\$)

\begin{tabular}{rlrrrrr} 
MA & & $\begin{array}{r}1994 \mathrm{AV} \\
\text { num }\end{array}$ & $\begin{array}{r}1994 \mathrm{Area} \\
(\$)\end{array}$ & $\begin{array}{r}\text { AV } / \text { acre } \\
(\$ / \text { acre })\end{array}$ & $\begin{array}{r}\text { Post-1994 shift } \\
(\$ / \text { acre })\end{array}$ \\
\hline 4 & Central Basin & $44,107,538$ & 177 & 390 & -28 & -7 \\
6 & Calleguas & $24,417,729$ & 350 & 109 & -6 & -6 \\
7 & Eastern & $14,489,434$ & 540 & 42 & 0 & 0 \\
9 & Foothill & $4,068,782$ & 21 & 303 & -21 & -7 \\
11 & Inland Empire & $24,001,312$ & 242 & 155 & 0 & 0 \\
14 & Las Virgenes & $6,563,078$ & 119 & 86 & -7 & -8 \\
15 & MWDOC & $106,429,941$ & 600 & 277 & -19 & -7 \\
18 & SDCWA & $105,226,937$ & 1,421 & 116 & 0 & 0 \\
23 & Three Valleys & $19,436,148$ & 133 & 228 & -20 & -9 \\
24 & Upper San Gabriel & $27,476,322$ & 144 & 299 & -24 & -8 \\
25 & West Basin & $49,037,903$ & 159 & 483 & -39 & -8 \\
26 & Western (omitted) & $20,806,079$ & 510 & 64 & 0 & 0 \\
\hline total/weighted average: & $446,061,203$ & 4,415 & 158 & -7 & -5
\end{tabular}


acre, i.e., the persistent increase in value of an acre of land from the persistent presence of a marginal AF of water is $\$ 7,000$ $\$ 8,000$ per acre. For cities, the origin of water is significant: An AF of MET water is "worth" an additional $\$ 16,000 /$ acre, but local water supply has no impact. (Compare both of these estimates to 1994 average values of $\$ 158,000 /$ acre at MWDs and $\$ 491,000$ at cities.) If we assume that water supply is constrained, we can interpret these results to mean that MWDs are getting equal value from scarce supplies of local and MET water; cities, on the other hand, have adequate local water but much more constrained access to MET water. The high value of additional MET water suggests that cities are not getting as much as they want, ceteris paribus - a result consistent with the fact that cities control their local water but share control over MET water. These results are also interesting because they appear to be the first estimates of the impact of water on urban land values, i.e., that dependency on MET has a negative impact on AV over time. ${ }^{18}$

Three of four hypotheses on dependency fail to be rejected; one rejected hypothesis indicates that cities that get more of their water from MET may have lower assessed values. In a final result, we see that post1994 coefficients for some member agencies are significant and negative; those of other member agencies are insignificant. This result rejects null hypotheses that member agencies experienced the same drop in assessed values in and after 1994. Although other factors (the S\&L collapse and end of the Cold War) may be responsible for these results, and the effects are observed in richer areas (perhaps because they experienced the effects of a deflating real estate bubble), the results do not allow us to dismiss the possibility that inefficiency or changing perceptions of water security had (and continue to have) asymmetric effects on members.

\footnotetext{
${ }^{18}$ The unique structure of these data may be responsible for this innovation. It is rare to find real estate and water data that extend so far into the past in a diverse region with strong variations in water supply.
} 


\section{Chapter 7}

\section{Experiments with Auctions}

Planners will need to adopt a behavioral approach to the analysis and projection of urban demand, as opposed to the engineering/public health approach... The behavioral approach focuses not on how much water people need but rather on how much water they are willing to pay for.

- Hanemann (2005, p. 80)

This chapter describes how MET could use auctions to allocate water supply and conveyance capacity among member agencies. Since auctions are fast, fair and transparent, they can be used to allocate water more efficiently - reducing misallocation resulting from MET's current policies of postage stamp pricing (PSP) (Section 4.4.2) and pro-rata rationing in shortage (Section 2.4). The rebate of money from auctions can (after repaying costs) reward conservation, improve equity and/or end contention over outdated policies (e.g., preferential rights) that interfere with MET's present operations. As Hanemann suggests above, a market system with prices can improve water allocation, and auctions are the fastest way to discover what people are willing to pay for it.

The main objection to auctions - that the poor cannot compete with the richis answered by setting aside a significant portion of inframarginal water for distribution on a per-capita basis. Setting aside such "lifeline" water improves equity without lowering efficiency since remaining sup- plies are allocated on the margin. Note also that auctions increase efficiency (through the use of a profit-maximizing market mechanism) without requiring that MET change its form as a non-profit, public cooperative.

The next section gives a brief overview of markets and auctions for non-economists. Section 7.2 describes the features that auctions at MET should have, and Section 7.3 describes two different experimental auctions run with water managers and undergraduate students. The results of those auctions are in Section 7.4, and the discussion is in Section 7.5. Section 7.6 concludes.

\subsection{Markets and Auctions}

Markets aggregate desires to supply and demand goods and bring them into equilibrium via price. Because markets aggregate information from many sources, they are faster, accurate, innovative and make fewer mistakes than bureaucratic allocation (Scott, 1998). Economists have made the same points about water markets: trades negotiated only on price maximize efficiency (without centralized intervention), 
and prices smooth shocks in supply and demand across sectors and regions (Milliman, 1956a; Howitt, 1997).

Markets for goods with few substitutes (e.g., water) are particularly valuable (relative to bureaucratic allocation) because they guarantee supply - at the right price. They would be attractive to member agencies because they are more flexible than formulaic rationing, which reduces the need for investment in expensive, alternative supplies (e.g., desalination) to ensure against sudden loss of supply. Also note that markets - as institutions - reduce conflict and increase trust (Henrich et al., 2001; Benz, 2004). Less conflict and more trust among member agencies would facilitate cooperation on other projects at MET.

Markets also have advantages at the household level: Mansur and Olmstead (2007) calculate that increasing prices in drought (instead of rationing) can increase average household welfare by the equivalent of four-months expenditure on water.

MET would need to have two marketsone for conveyance and another for water. MET's current system of PSP combines the price of conveyance with that of water, but these goods are not perfect complementsHowitt (1997) points out that conveyance can be scarcer than water. With PSP, it is not hard to see how the price could be "right" for water but low for conveyanceleading to excess demand for conveyance. If PSP are too high for conveyance, excess supply would exist and water would not go to where it has a higher economic value. ${ }^{1}$ Flexible conveyance prices would equalize supply and demand as well as signal bottlenecks that need expansion.

\subsubsection{Auctions}

Since supplies of water and conveyance capacity are fixed in the short-run, any market allocation will take some form of "cap and trade" with prices balancing supply and demand. Auctions are a good way to discover the price that equates supply and demand. Although two auctions may seem complicated, they can be run interdependently: Murphy et al. (2000), for example, run "smart" auction markets for water that integrate conveyance constraints.

Most auction literature (Kagel and Levin, 2001; Klemperer, 2002; Hailu and Thoyer, 2006; Porter and Vragov, 2006) concentrates on incentive-compatible bidding, i.e., designing a mechanism that leads bidders to reveal their true demand functions through their bids. If bids reflect true willingness to pay, both efficiency and auction revenue are maximized. Although the auction mechanism proposed here is meant to accomplish these same goals, MET's form as a cooperative (i.e., consumers as owners) means that efficiency is more important that revenue maximization. And perhaps more important than maximum efficiency is relative efficiency (compared to rationing by formula), flexibility and simplicity. For these reasons, it seems that best auction design for MET would have a single-price and an endogenous ending (i.e., an ending that is always extended after a bid - ensuring that bidders always have the chance to respond to the most-recent bid.)

\subsubsection{Equity}

Over forty years ago, Folz (1965) noted that markets for water would not be accepted if they increased inequality. To address this concern, water could be divided

\footnotetext{
${ }^{1}$ This problem is most obvious when member agencies face the choice of paying a wheeling charge to move non-MET water or paying the PSP for both water and conveyance. MET's "high" wheeling prices have reduced water trades, imports and transshipment than would be economically attractive at prices closer to marginal cost.
} 
into two quantities: inframarginal "lifeline" water allocated on a per-capita basis, and the marginal remainder sold by competitive auction. ${ }^{2}$ Lifeline water would be similar to MET's cheap Tier 1 water (see Section 2.3.1). How would lifeline and auction water interact? Would auction efficiency fall? Are they substitutes? How would conveyance auctions be affected? First, DiSegni Eshel (2002) shows that diversions for inframarginal water would not reduce the efficiency of auctions for marginal water. Second, storage of lifeline water (or banking lifeline credits) could interfere with the price or allocation of market water, so lifeline water will probably need to be used in the current period. Finally, lifeline water should be bundled with "lifeline conveyance" to assure delivery. Also note that auctions within MET would not result in any third party impacts - effects on those who do not participate or benefit from water reallocationsince no water would leave the MET service area. These impacts complicate and/or prevent trades among service areas (Gardner, 2003; Hanak, 2003). ${ }^{3}$

\subsection{Auctions at MET}

An auction mechanism could work in the following way:

1. Every day, member agencies bid for a known quantity of water and conveyance. ${ }^{4}$ (Since these auctions are similar, further details on the conveyance auction are omitted. ${ }^{5}$ )

2. Bids are ordered from highest to lowest price to form a demand schedule.

3. The auction design will determine if buyers pay the highest rejected bidà la Vickrey (1961) — or their actual bid. ${ }^{6}$ Although the former is more efficient and raises more money, Cummings et al. (2004) note that political reality may be more important than economic efficiency: First-price auctions suffer from bid-shading, but common-price auctions appear to give bidders windfall profits - the difference between their bid and the price paid-which is politically unpopular.

Conveniently, Ausubel (2004) develops a multi-unit auction where each buyer pays close to his bid price but

\footnotetext{
${ }^{2}$ According to Gleick (1996), a worldwide basic human right is 50 liters/capita/day (LCD). Back in the US, Glennon (2005) recommends 5,000 gallons/household/month; using 2.95 people/household, this is about 210 LCD. Water use of MET's city members (in 2004) varies from 383 LCD in Compton to 1,239 LCD in Beverly Hills; among MWDs, use ranges from 557 LCD at Inland Empire to 1,436 LCD in Las Virgenes. Since the average for all of MET is 811 LCD, an entitlement to half this amount-400 LCD or $105 \mathrm{Gal} / \mathrm{Capita} /$ Day or $0.12 \mathrm{AF}$ per year - may be a reasonable allocation, but member agencies will decide this number.

${ }^{3}$ Murphy et al. (2003) test the effects of third-party participation on water trades in an experimental setting. They find that third parties reduce/eliminate efficiency gains; they recommend that third parties receive compensation in exchange for giving up their right to affect trade.

${ }^{4}$ According to Brian Thomas (MET's CFO), "While the administrative rules governing demand changes state that changes can be made only twice a day, in reality we make changes more frequently - as demands require" (Thomas, 2006a).

${ }^{5}$ Although the auction formats may be similar, their interdependencies mean that MET would be conducting a combinatorial auction. Optimal behavior and/or strategies in combinatorial auctions are difficult to describe but not difficult to implement in experimental or real-world scenarios; see, e.g., (Rassenti et al., 1982). Those strategies can be simplified by bundling conveyance with lifeline water and/or running "smart" auctions that integrate conveyance constraints - as discussed in Section 7.1.1.

${ }^{6}$ Hailu and Thoyer (2006) conclude that Vickrey-style auctions (as here) are more efficient than discriminatory price auctions when there is high competition, as is the case in auctions for marginal units.
} 
does not reduce his bid. Ausubel's design delivers efficiency in a politicallyacceptable way: Buyers state how many units they want at a given price. As the auction price ascends and quantity demanded at each price falls, incremental allocation of units to buyers reduces supply to keep pace with the quantity demanded at same or higher prices. Because buyers "clinch" units at a price equal to the bid of those who drop out, they bid their willingness to pay, which is efficient.

Note that prices in either case (uniform or discriminatory) will be more efficient than MET's current PSP prices because they will allocate water to those who value it. It is not clear if auction prices (or total revenue) will be higher or lower than PSP in normal conditions: Tier 1 PSP are based on total baseline usage (including many low value uses) and Tier 2 PSP are based on marginal cost of new water. If lifeline water is based on per-capita allocations (and has a low price similar to Tier 1 prices today), then marginal water at auction will be sought by low population, high consumption areas. MET's decision on lifeline allocations and rates will determine how competitive auctions are - and how high prices go.

Since auctions for water (or conveyance) would be a form of marginal revenue to MET, and this revenue would be matched with marginal costs, it might be wise to set a price floor at marginal cost. Although the floor could be set at average cost, such a system of covering fixed costs in- troduces the inefficiency of PSP. If auction prices started above marginal cost and rose above average cost, fixed costs could be paid from auction revenues. If the price fell below average cost, other revenue sources (e.g., property taxes) would have to cover remaining fixed costs.

4. To ensure reliability, the auction duration is endogenous: Every new bid extends the auction duration by long enough for new bids to arrive; the auction ends if no new bids are received within the fixed "last chance" period. Because member agencies are guaranteed access to as much water as they are willing to pay for, auctions guarantee reliability.

5. These auctions need not be expensive to run. MET already allocates water on a daily basis (see Footnote 4), so additional costs - given engineering constraints - would be limited to additional accounting.

Section 7.3 reports experimental results from a simplified version of this mechanism (Game 3, or G3) along with results from an auction with initial endowments (Game 2, or G2). The following sections describe how auctions might change prices and profits at MET.

\subsubsection{Price Volatility}

Auction prices will change every daya lot more often than the current system of negotiating annual changes over several months. Price changes would not require bargaining and equilibrium would be "spontaneous." Ironically, frequent price changes would make water managers' jobs easier because they would solve problems of rationing and reliability. ${ }^{7}$ Instead of the cur-

\footnotetext{
${ }^{7}$ Recall from Footnote 16 on page 20 that we are using an economic definition of reliability (supply is available for the demand that exists at a given price) — not a physical definition (turning on the tap makes water come out).
} 
rent case where a reduction in MET supplies leads to difficult negotiations among member agencies insisting their demand has not changed, increases in auction prices would gradually squeeze demand until it matched reduced supplies. No member agencies would face reliability problems: Members could buy reliability (additional supply) on a daily basis - saving years of delay and large amounts of money now spent on supply-enhancing infrastructure. Prices would also give a clear indicator for costbenefit analyses of capital expenditures.

But-what if prices fell to zero (or the marginal cost floor)? What if they rose above regulated rates? Can member agencies pass prices through to their (retail/wholesale) customers? Wholesale and retail price fluctuations happen all the time (think of oil and gasoline), but water managers are certainly not used to it. 8 Several transitional steps are possible:

- Guarantee prices for inframarginal lifeline water allocated on a per capita basis outside the auction.

- Charge final customers "too much" for water bought at auction and rebate any savings. ${ }^{9}$ Alternatively, smooth market prices over several months, e.g., a March bill comprised of onethird of the customer's water cost from each of January, February and March. Note that municipalities can already increase prices via surcharges, e.g., like the energy surcharges the Los Angeles City Council adds to water bills.

- Borrowing from Lach et al. (2005a), who observe consumers are only willing to pay more if they get better reliability or quality, charge consumers a higher "option" rate to guarantee their supply.

- Educate customers about value (not cost) pricing. Given "the price of water in the United States is ridiculously low" because it is based on cost of service, not the cost of water, this can make price fluctuations more palatable - or facilitate an overcharge/rebate scheme (Glennon, 2005).

- Allow customers to choose flexible prices or fixed (and expensive) increasing block rates.

- Transition to auctions (and fluctuating prices) gradually, allowing customers to get used to a fixed and variable (auction) component in price. Move more water from the current allocation system to the auction system until only the lifeline component is left under fixed pricing.

These steps may be overcautious since most consumers understand price fluctuations.

\subsubsection{Profits from Auctions}

If auction revenue exceeds the variable cost of auctioned water, "profits" would be allocated to fixed costs. Remaining funds, if any, could be rebated to members in proportion to:

Past Taxes: Until the early 1970s, a majority of MET's revenue came from taxes; see Section 3.3.2. Los Angeles

\footnotetext{
${ }^{8}$ Managers at power utilities were certainly surprised by fluctuations in wholesale prices during 2001 that resulted from California's botched energy deregulation. Those problems resulted from the continuation of retail price caps as well as market manipulation by firms such as Enron (Economist Staff, 2001). A wholesale water market within MET - especially if a bid-only market — would not have market power issues, but buyers would need to pass prices through to downstream customers.

${ }^{9}$ Hall (2000) reports that LADWP managers keep rates high so increasing costs can be absorbed without triggering public hearings for rate increases.
} 
paid about 70 percent of all property taxes - just under $\$ 3$ billion in 2004 dollars.

Preferential Rights: Member agencies hold PRs in proportion to their past payments towards fixed costs; see Section 2.4.2. Repayment would allow the retirement of PRs. Although LADWP is the largest holder of PRsat 21 percent-SDCWA owns 16 percent of PRs; see Table 2.1. (Tax repayments would reduce PRs.)

Population: Per capita rebates are progressive and reward efficiency.

Assessed Value: Rebates in proportion to land value are regressive.

Purchases: Rebates in proportion to purchases (i.e., revenue - not profits) would lower the actual cost of water (increasing the incentive to bid more) but also increase the incentive to bid less to receive a larger per unit rebate. $^{10}$

The last two rebates create perverse outcomes. Rebates in proportion to assessedvalues would give the largest rebates to the wealthiest areas (regardless of past tax payments), and that outcome is politically unacceptable. Purchase rebates create incentives to lower bids, which is not incentivecompatible. I prefer the first three rebate schemes, and they could be sequentially or simultaneously implemented - depending on the importance of past payments/PRs or conservation/equity.
Auctions will also put downward pressure on costs by giving more price information: Observable margins between wholesale and retail prices will create yardstick competition among agencies (Shleifer, 1985), and frequent price updates will help managers manage operating and investment decisions. If customers have access to "profit" rebates, the pressure to shave margins (raise local efficiency) will intensify.

\subsection{Experimental Design}

This section outlines the auction experiments that ran directly after the public goods game (G1) described in Chapter 5. Participants-Member Agency Managers (MAMs), MET executives (METs), private-industry water executives (CWAs) and undergraduate students (UGs) - were randomly allocated to play one of two auction games (G2 and G3) for the remainder of the experimental session. (See Table 5.2 for a description of the subjects and Appendix $\mathrm{C}$ for a copy of the instructions.)

In both auctions, subjects redistributed units of "water" among themselves. Endowments and redistribution method (buy-sell or bidding) were different in each auction. In both auctions, subjects received different induced-demand functions, which would facilitate Pareto-improving trades. In both auctions, the supply of water was fixed in proportion to the number of participants.

Induced demands for the auction good ("water") were Low, Medium or High. In a group of ten, for example, four players would have Low induced demands, four

\footnotetext{
${ }^{10}$ Say Buyer A bids $a$ for a unit and Buyer B bids $b$ for a second unit. The price that A pays will be $P_{A}=a-\frac{a}{a+b}(a+b-2 c)$, where $c$ is the cost per unit, and $\{a, b, c\}>0$. From the first order condition of $\frac{\partial P_{A}}{\partial a}=\frac{2 b c}{(a+b)^{2}}>0$, we see that $P_{A}$ is rising in $a$. Since Buyer A (and other buyers) want to pay less, they will lower their bids (to maximize their share of the revenue rebate), which is not the way to structure an auction. (Competition over units will increase prices, but this incentive will dampen that competition.)

${ }^{11}$ Valuations from first unit to unit $n$ are $93 / 85 / 74 / 61 / 49 / 44 / 32 / 23 / 19$ for Low types, 135/113/91/76/55/36/9 for Medium types and 163/129/81/47 for High types. In the ten-player session described, total demand at prices above zero would be 72 units, i.e., nine units for each of four L types, seven units for each of four $\mathrm{M}$ types, and four units for each of two $\mathrm{H}$ types.
} 
would have Medium demand, and two would have a High demand schedule. ${ }^{11}$ Variation in demand schedules and the mix of $\mathrm{H} / \mathrm{M} / \mathrm{L}$ types created opportunities to trade. Figure 7.1 (truncated at 51 units) shows how the induced values of these ten players aggregate into a demand curve. Since each auction has a known demand function and fixed quantity of units, the Pareto optimal price ( 55 in all auctions) is known but not disclosed to subjects.

Each auction had a different source of supply: In G2, Low demand subjects shared the total endowment evenly. ${ }^{12}$ In G3, subjects received no endowment, and all units were in a common-pool. For both games, supply was four units/subject, so a group of ten competed for a supply of 40 units. Note that demand is positive for the first 72 units, but supply is limited to 40 units. The next sections detail the auction designs, state hypotheses, and describe auction logistics.

\subsubsection{G2-Buy-Sell Auction}

Figure 7.2 is a screenshot from the endowment auction (Game 2, or G2) in which some subjects begin with endowments and others have nothing (Box A). In Box B, players see their demand schedules. (The player in the screenshot is a Low demand type who has sold three units from his eight unit endowment.) All subjects buy and sell units in a double-auction in which they can submit bids as buyers (Box C), asks as sellers (Box D), and accept others' bids and asks (Boxes E and F). The number of trades and trade prices are endogenous.

\subsubsection{G3-Bid-Only Auction}

Figure 7.3 is a screenshot from the bidonly auction (G3) in which subjects have no endowments. In Box B, players see their demand schedules. (The player in the screenshot is a Low demand type.) Subjects bid for $Q$ units from a common pool (Box C). When a player's bid is at or above the $Q^{t h}$ highest bid (the price to beat or PtBcalled "current price" in Box D), that player has "claim" on the item. ${ }^{13}$ When the auction ends, all $Q$ claims are finalized as purchases at the $\mathrm{PtB}$, i.e., realtime profit estimates in Box A are finalized. ${ }^{14}$

Subjects can only claim units for which they have positive valuation. (Thus, a subject with High induced value can claim up to four units. If $\mathrm{PtB}$ rises above his lowest bid for a claimed unit, his claim is lost and he can submit another bid.) Bidders know their claim count and PtB throughout the auction. The number of bids and PtB are endogenous.

\subsubsection{Hypotheses}

For each auction, efficiency is the total value of units held at the end of the auction divided by the maximum value feasible. ${ }^{15}$ Put differently, efficiency is the area under the demand curve for those who end up with units divided by the area if units went to those with the highest valuation.

\footnotetext{
${ }^{12}$ According to Plott (1982), market power is not a problem with at least three sellers. Since all sessions had at least three sellers, there should not have been (and did not appear to be) any problems with market power.

${ }^{13}$ Ties among bids are broken by random allocation. If supply is three units and bids are $2,3,6,1,4$, subjects who bid 3, 6 and 4 win units at a price of 3. This design draws from Cummings et al. (2004)—where sellers compete by offering to sell at lower prices.

${ }^{14}$ One defect in this design is the use of a common price in a multiple-unit auction; players have an incentive to bid less than WTP for units $2 \ldots n$ because their lowest accepted bid may determine the price on all units. One way around this is to have a second buy-sell auction to squeeze out any misallocation; another is to use a better multi-unit auction design — such as that of Ausubel (2004). I thank Charles Noussair for this point.

${ }^{15}$ Tokens traded for units of water affect individual surplus (and payoffs) but not total surplus.
} 


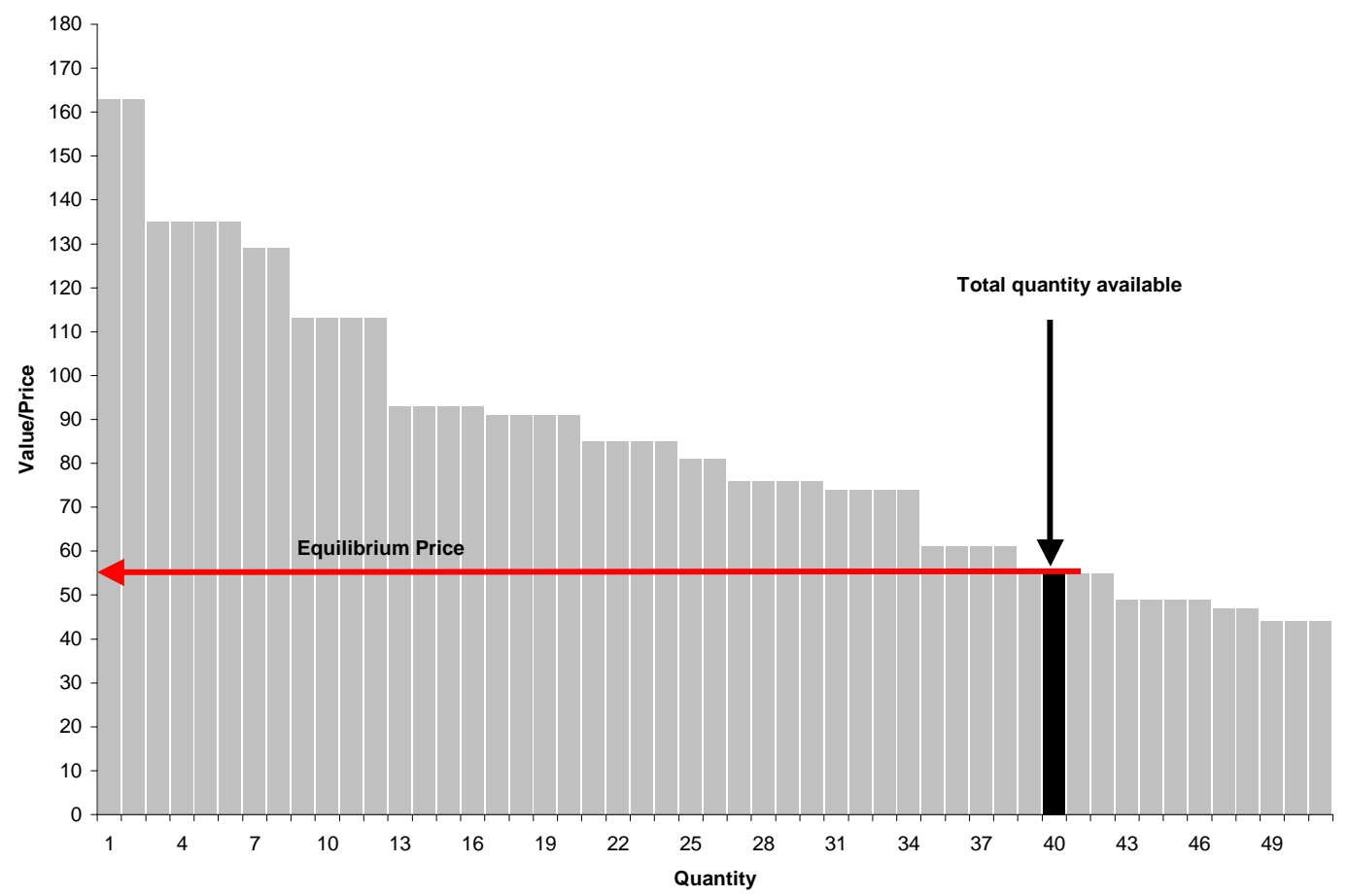

Figure 7.1: Induced value demand curve for a ten-person auction

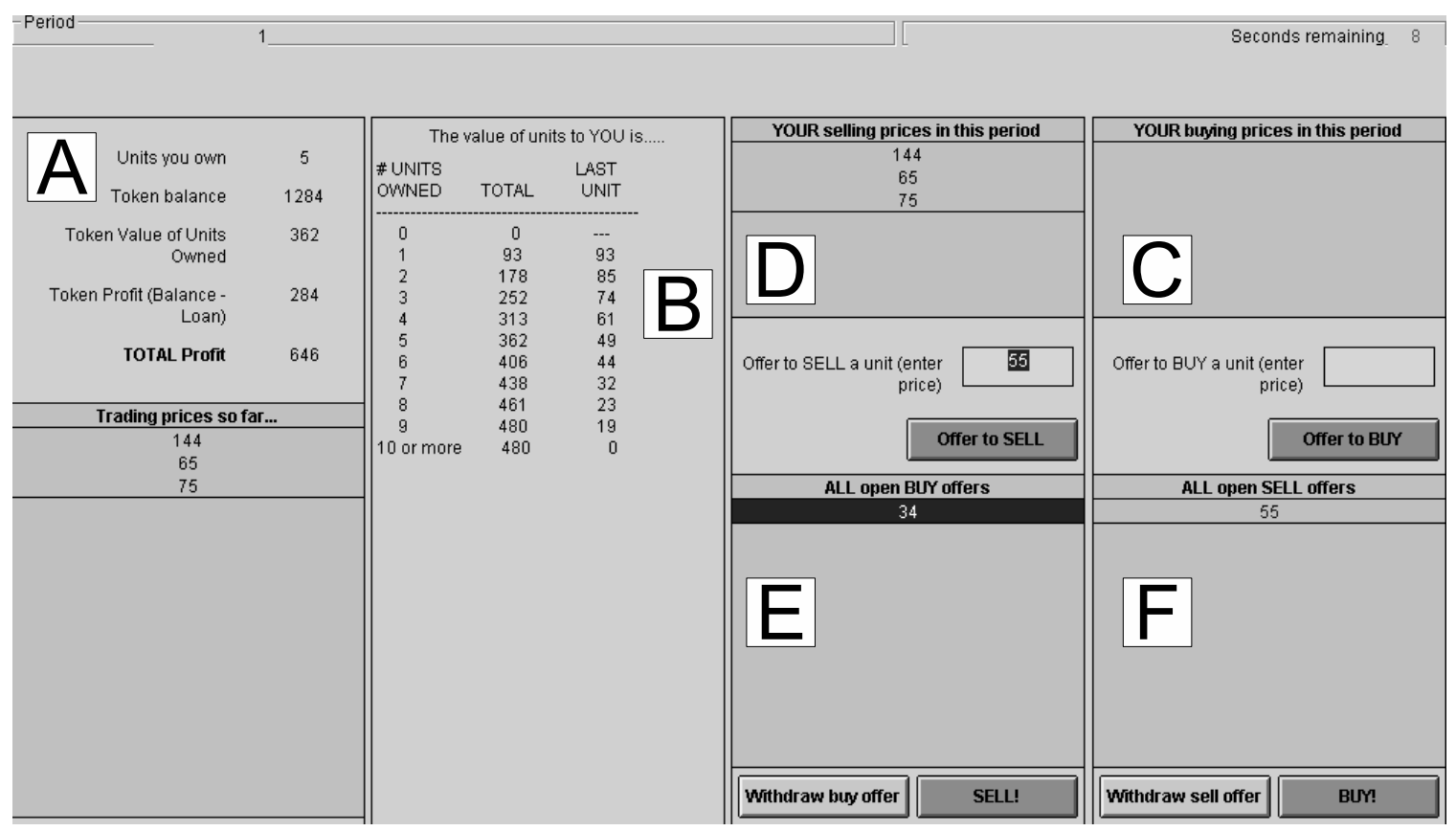

Figure 7.2: Screenshot from G2 (buy-sell auction) 


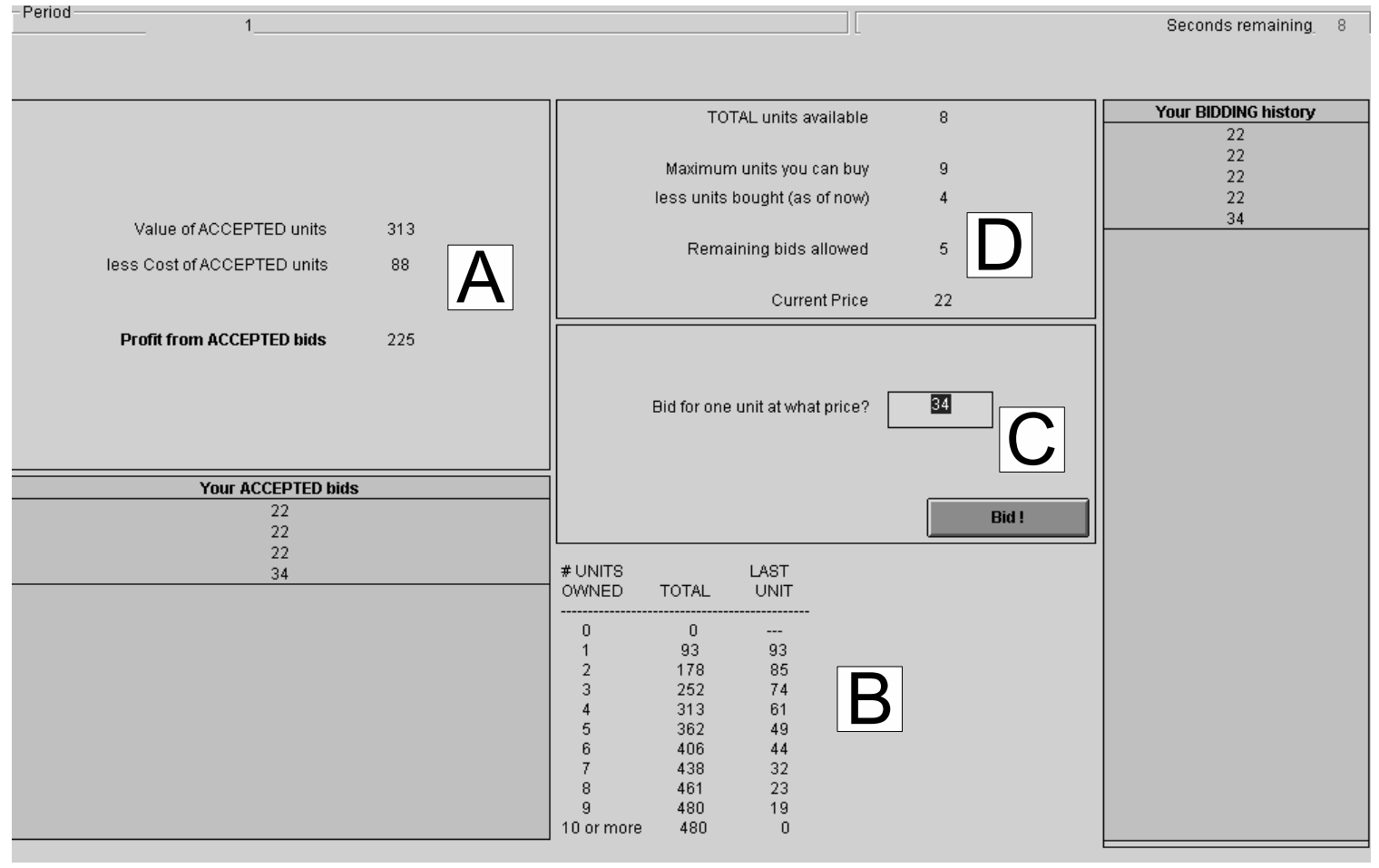

Figure 7.3: Screenshot from G3 (bid-only auction)

Although these auctions have similar efficiency in theory, subject pool (students versus water managers) and auction design (G2 versus G3) can have important effects. The following hypotheses test for pool and/or design effects on experimental results:

$\mathbf{H}_{0}^{G 2}$ Water managers and students play G2 with equal efficiency.

$\mathbf{H}_{0}^{G 3}$ Water managers and students play G3 with equal efficiency.

$\mathbf{H}_{0}^{W M}$ Water managers play G2 and G3 with equal efficiency.

$\mathbf{H}_{0}^{S T}$ Students play G2 and G3 with equal efficiency.

Managers and students might play differently because of context, i.e., auctions for "water." Although context in experiments was frowned upon in the past (see, e.g., Smith (1976) and Plott (1982)), it is con- sidered more acceptable today, especially when using non-student subjects or trying to connect experiments to the world outside the lab - what Harrison and List (2004) call "framed field experiments." Tisdell and Ward (2001) suggest that familiarity helps non-students follow directions, and Cooper (2006) finds that professional managers are quicker to choose optimal paths in a familiar environment. Context is especially important when it has qualitative effects: Ward et al. (2006) find that context changes the efficiency ranking of treatments when students and farmers trade in experimental water markets.

Context makes sense because water managers competing for a scarce good will probably think of water; second, an explicit label creates a consensus over what is being allocated; and third, results will be more accurate if managers behave as water 
managers. Context supports the claim that these results have external validity (see Section 5.1.2), i.e., that water managers subjected to similar constraints, information, etc. outside the lab would act in substantially the same way. The most obvious impact of context is that managers' familiarity with buying and selling water would affect their trading.

Between-treatment efficiency may vary due to endowment effects, i.e., putting an additional value on an object merely because you possess it (Kahneman et al., 1990). If subjects in G2 experience endowment effects, they may ask for higher selling prices - reducing efficiency. If water managers import the risk-aversion they are known to have (Lach et al., 2005a), they may experience even stronger endowment effects. Students, in contrast, experience weaker endowment effects than the general public (Horowitz and McConnell, 2002). Overall, we might expect that manager efficiency in G2 will be lower than student efficiency.

\subsubsection{Session Details}

Table 7.1 shows descriptive statistics of participants in each auction. (Percentage shares are the average of shares from individual sessions; G1 types are from Chapter 5.) Table 7.2 shows the number of players, count of players with $\mathrm{L} / \mathrm{M} / \mathrm{H}$ induced demands, and supply of units available for each auction type for all sessions. ${ }^{16}$ All sessions had a market-clearing price of 55 tokens.

After a trial period of experimenter- determined length, both groups played nine auction periods of 90 seconds each. ${ }^{17}$ After each period, subjects had 30 seconds to review their results and see their profits. Subjects' induced demands and endowments are the same in the trial and all nine periods. All subjects receive a loan of auction currency for buying or bidding to remove liquidity problems. (None went bankrupt.)

In a pre-test with a fourth group of water managers, some G3 subjects bid above their imputed values and/or bid for units with zero value. ${ }^{18}$ Because the contagion of this behavior spread to other players faster than irrational bidders went bankrupt, it drastically reduced efficiency. Two paternalistic controls were introduced: Subjects could not buy units that had a zero value to them in G3, and bids were capped at 175 tokens in both games. ${ }^{19}$

\subsection{Results}

In general (across sessions and subject groups), efficiency improved with experience, via higher trade volumes and prices closer to the clearing price of 55 . Note that MAMs and METs paid higher-than-average prices for water in both auction designs while CWAs - in three of four segmentspaid less than average. Table 7.3 gives descriptive statistics from sessions, and Figure 7.4 shows average auction efficiency (with error bars for $95 \%$ confidence intervals) for water managers and students.

Unpaired t-tests of mean efficiency within auction type indicate that water managers have lower efficiency than students in G2 (t-stat 2.174). Water managers

\footnotetext{
${ }^{16}$ Supply was not 4 units/player in some G2 sessions where three players had low demand because the supply had to be evenly divided among three players. (METs G3 mistakenly restricted supply to 27 units total.) Efficiency statistics take actual supply into account.

${ }^{17}$ In pre-tests, this length seemed to be long enough to allow trades but short enough to keep session length down. It turned out that 90 seconds was not enough time for trading efficiency; see Section 7.5.

${ }^{18}$ For example, the High demand function hits the horizontal axis on the fifth unit (value=0).

${ }^{19}$ Although the highest valuation is 163 tokens, players in G3 bid 175 tokens; in G2, the single highest trade was at 160 tokens.
} 
Table 7.1: Descriptive statistics of participants (percent shares)

\begin{tabular}{lrrrr} 
& \multicolumn{2}{c}{ Managers } & \multicolumn{2}{c}{ Students } \\
& G2 & G3 & G2 & G3 \\
\hline males & 72 & 79 & 62 & 51 \\
economists & 18 & 17 & 54 & 48 \\
eBay experience & 40 & 21 & 60 & 67 \\
experimental experience & 0 & 0 & 24 & 17 \\
\hline cooperators (G1) & 9 & 17 & 4 & 4 \\
free-riders (G1) & 36 & 8 & 10 & 13 \\
reciprocators (G1) & 55 & 75 & 86 & 82 \\
\hline
\end{tabular}

Table 7.2: Player counts, induced demands and unit supplies

\begin{tabular}{lrrrrr|rrrrr} 
& \multicolumn{5}{c|}{ G2 } & \multicolumn{5}{c}{ G3 } \\
Session & Players & L & M & H & Units & Players & L & M & H & Units \\
\hline UG1 & 9 & 4 & 3 & 2 & 36 & 9 & 4 & 3 & 2 & 36 \\
UG2 & 10 & 4 & 4 & 2 & 40 & 10 & 4 & 4 & 2 & 40 \\
UG3 & 8 & 3 & 3 & 2 & 32 & 8 & 3 & 3 & 2 & 32 \\
UG4 & 7 & 3 & 2 & 2 & 27 & 6 & 2 & 2 & 2 & 24 \\
UG5 & 10 & 4 & 4 & 2 & 40 & 10 & 4 & 4 & 2 & 40 \\
UG6 & 10 & 4 & 4 & 2 & 40 & 10 & 4 & 4 & 2 & 40 \\
UG7 & 8 & 3 & 3 & 2 & 32 & 8 & 3 & 3 & 2 & 32 \\
UG8 & 10 & 4 & 4 & 2 & 40 & 9 & 3 & 4 & 2 & 36 \\
UG9 & 10 & 4 & 4 & 2 & 40 & 10 & 4 & 4 & 2 & 40 \\
\hline CWAs & 7 & 3 & 2 & 2 & 27 & 6 & 2 & 2 & 2 & 24 \\
MAMs & 8 & 3 & 3 & 2 & 30 & 7 & 2 & 3 & 2 & 28 \\
METs & 7 & 3 & 2 & 2 & 27 & 7 & 3 & 2 & 2 & 27 \\
\hline
\end{tabular}

have higher efficiency than students in G3 (t-stat 2.89). Unpaired t-tests of mean efficiency within group indicate that water managers have a higher efficiency in G3 than in G2 (t-stat 2.51). The result for students is reversed: They have a lower efficiency in G3 than in G2 (t-stat 2.68). These results reject all hypotheses, i.e.,

$\mathbf{H}_{0}^{G 2}$ Water managers and students play G2 with equal efficiency. RejectWater managers' G2 efficiency is lower. They may experience stronger endowment effects.

$\mathbf{H}_{0}^{G 3}$ Water managers and students play
G3 with equal efficiency. RejectWater managers' G3 efficiency is higher. Their efficiency may be linked to more bidding and higher $\mathrm{PtB}$, i.e., more aggressive competition.

$\mathbf{H}_{0}^{W M}$ Water managers play G2 and G3 with equal efficiency. RejectWater managers' G2 efficiency is lower. Endowment effects may lower G2 efficiency while competition may raise G3 efficiency.

$\mathbf{H}_{0}^{S T}$ Students play G2 and G3 with equal efficiency. Reject-Students' G2 
Table 7.3: Auction efficiency improved with experience

\begin{tabular}{|c|c|c|c|c|c|c|c|c|c|c|c|c|}
\hline \multirow{3}{*}{$\begin{array}{l}\text { Session } \downarrow \\
\text { Periods } \rightarrow\end{array}$} & \multicolumn{6}{|c|}{ G2 Averages } & \multicolumn{6}{|c|}{ G3 Averages } \\
\hline & \multicolumn{2}{|c|}{ Trades/Unit } & \multicolumn{2}{|c|}{ Trade Price } & \multicolumn{2}{|c|}{ Efficiency } & \multicolumn{2}{|c|}{ Bids/Unit } & \multicolumn{2}{|c|}{ Final PtB } & \multicolumn{2}{|c|}{ Efficiency } \\
\hline & $1-5$ & $6-9$ & $1-5$ & $6-9$ & $1-5$ & $6-9$ & $1-5$ & $6-9$ & $1-5$ & $6-9$ & $1-5$ & $6-9$ \\
\hline UG1 & 0.8 & 0.9 & 69 & 66 & 87 & 93 & 2.3 & 2.3 & 21 & 33 & 89 & 91 \\
\hline UG2 & 0.9 & 1.1 & 71 & 72 & 84 & 88 & 3.2 & 5.2 & 21 & 36 & 84 & 88 \\
\hline UG3 & 0.7 & 0.7 & 73 & 70 & 96 & 94 & 4.0 & 3.8 & 47 & 53 & 93 & 94 \\
\hline UG4 & 0.6 & 0.7 & 71 & 67 & 84 & 96 & 2.3 & 2.5 & 21 & 33 & 78 & 87 \\
\hline UG5 & 1.0 & 1.1 & 71 & 63 & 85 & 91 & 4.1 & 4.1 & 30 & 46 & 86 & 90 \\
\hline UG6 & 0.8 & 0.9 & 78 & 65 & 87 & 85 & 4.6 & 3.9 & 26 & 41 & 87 & 82 \\
\hline UG7 & 1.0 & 1.1 & 69 & 56 & 95 & 92 & 2.3 & 1.8 & 27 & 41 & 88 & 86 \\
\hline UG8 & 1.0 & 1.4 & 52 & 55 & 84 & 92 & 3.0 & 2.7 & 15 & 34 & 84 & 81 \\
\hline UG9 & 0.6 & 0.8 & 67 & 38 & 84 & 85 & 2.3 & 1.8 & 18 & 34 & 81 & 84 \\
\hline CWAs & 0.5 & 0.6 & 36 & 43 & 78 & 83 & 2.6 & 3.4 & 18 & 58 & 86 & 91 \\
\hline MAMs & 0.9 & 1.0 & 102 & 88 & 87 & 84 & 2.5 & 2.6 & 30 & 46 & 87 & 93 \\
\hline METs & 0.7 & 0.7 & 73 & 84 & 94 & 86 & 3.8 & 3.8 & 37 & 48 & 92 & 90 \\
\hline ALL & 0.8 & 0.9 & 69 & 64 & 87 & 89 & 3.1 & 3.2 & 24 & 42 & 86 & 88 \\
\hline
\end{tabular}

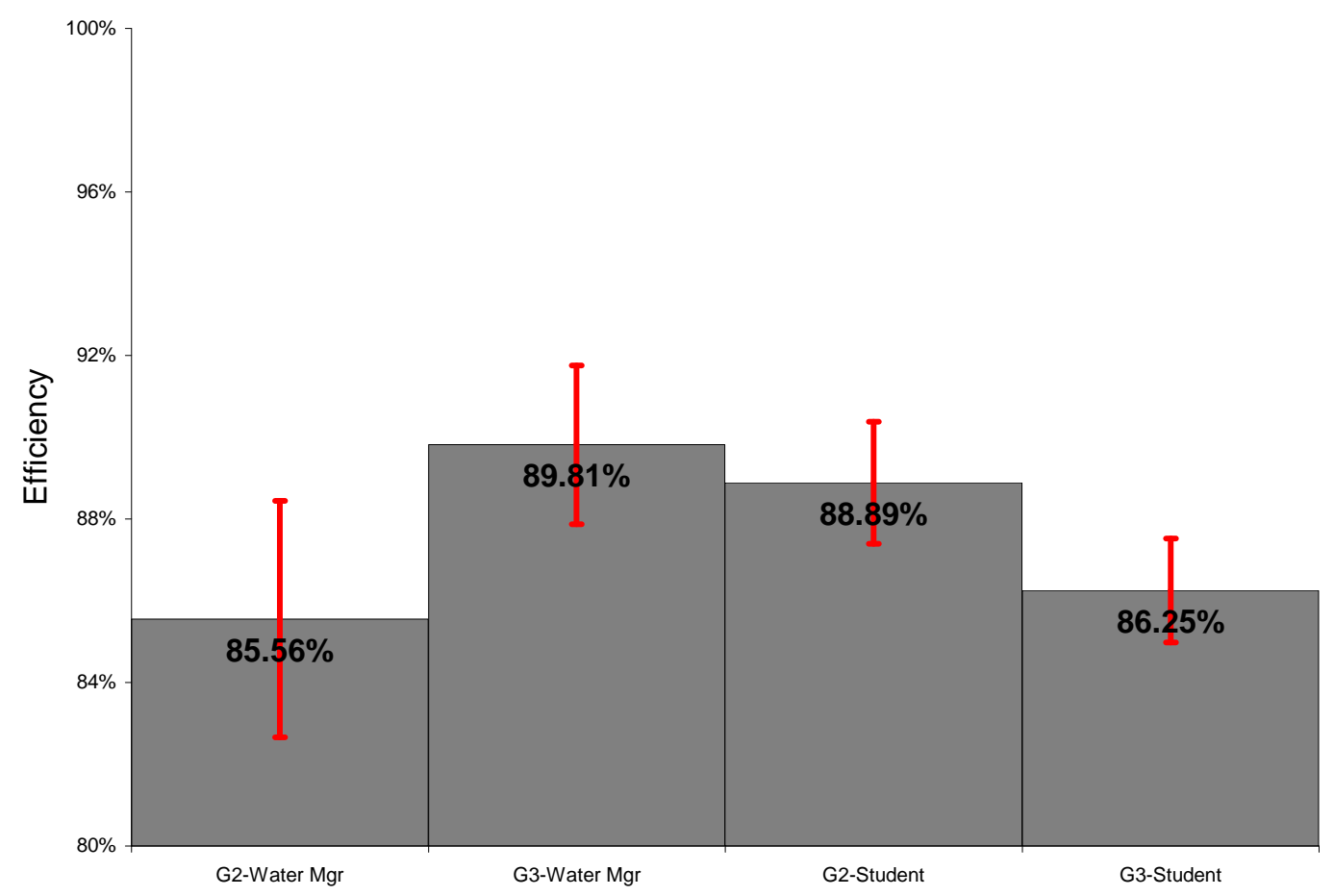

Figure 7.4: Water manager and student auction efficiencies 
efficiency is higher. They seemed to learn faster in G2 than in G3: In G2, average efficiency increased from 87 percent (periods $1-5$ ) to 91 percent (periods 6-9); in G3, the increase was from 85 to 87 percent.

\subsection{Discussion}

Experimental results were skewed by the limited duration of the auctions (90 seconds each), which facilitated out-of equilibrium strategies and lower efficiency. At 8690 percent, efficiency was lower than that found (95 percent or more) in typical double or uniform price auctions (Kagel and Roth, 1995; Kagel and Levin, 2001). Longer auctions or auctions that ended when players stopped trading/bidding (endogenous duration or soft ending) would improve allocation and increase efficiency. On the other hand, the small range of efficiency values indicates that the different groups had similar success with the two designs.

G2 efficiency suffered from low trading volumes, skewed trading prices (too low or high) and confusion (buy high, sell low). G3 efficiency fell because players pursued a tacit strategy of non-competition to minimize PtB - a problem explored in Porter and Vragov (2006). This strategy increased profits but misallocated units to players with lower values. ${ }^{20}$ This out-of-equilibrium strategy can always be beaten by players bidding their demand schedules, but players rarely behaved that way. Because players shaded their bids below their willingness to pay (keeping PtB down), other players were able to snipe (submit last-second bids) with success. Snipees could not respond before the end of the auction, and snipers ended up with units - as explored in Roth and Ockenfels (2002). ${ }^{21}$ Although players eventually began bidding more, $\mathrm{PtB}$ did not rise fast enough to make sniping and overbidding unprofitable.

A careful look at trading data helps us see another reason for lower G3 efficiency: Players were overbidding and winning units that other players with higher values "should have" won in the auction. The overbidders ended up with units because the auctions ended before PtB rose high enough to make their bids unprofitable, i.e., before they were forced to pay a price close to a bid that was higher than their induced value for the unit. Because prices did not rise fast enough, strategic (or mistaken) overbidding was profitable for individual players but lowered efficiency through misallocation. Figure 7.5 gives an example of overbidding - something that happened in three student sessions but not other sessions; see Figure 7.6. Kagel and Levin (2001) suggest longer auction periods to halt this behavior.

After underbidding and overbidding comes multiple bidding, and subjects did that too. Whether subjects were bidding average value or just submitting multiple bids at some focal number, the result was always inefficient. ${ }^{22}$ Of 3,591 successful bids for units in G3, 44 percent match bids by the

\footnotetext{
${ }^{20}$ If subjects bid the same fraction of their valuations, it would be efficient. Because they did not, the final distribution of units was skewed and inefficient. Minimum bids would not fix this problem without being linked to demand schedules - an action that would make players redundant.

${ }^{21}$ Cummings et al. (2004) avoid sniping by using an endogenous auction duration.

${ }^{22}$ For example, a subject with medium demand has values of $\{135113917655369$ \} for seven units. If he bids the average value $(515 / 7=74)$ —or slightly less, say 70 , to "protect profits" — efficiency falls if PtB rises over 9 , which it often does.

${ }^{23}$ That is, 1,586 (44\%) bids match 626 earlier bids for a total of 2,212 (62\%) multiple bids. Some subjects submitted nine duplicate bids. Of 7,765 unsuccessful bids, the share of duplicate bids is higher: 53 percent match other bids, 73 percent are multiple bids.
} 


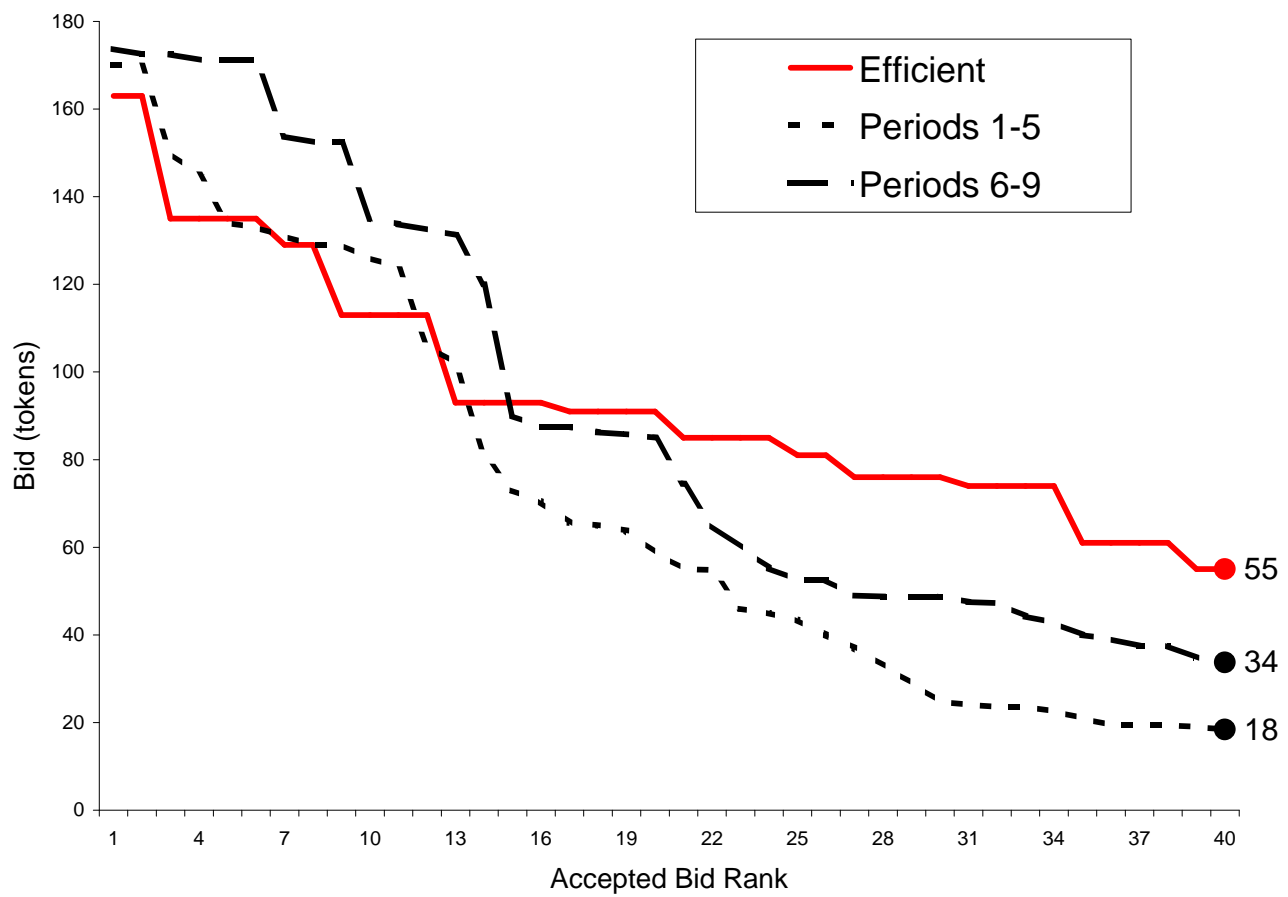

Figure 7.5: Students sometimes overbid (from Nov 7 session)

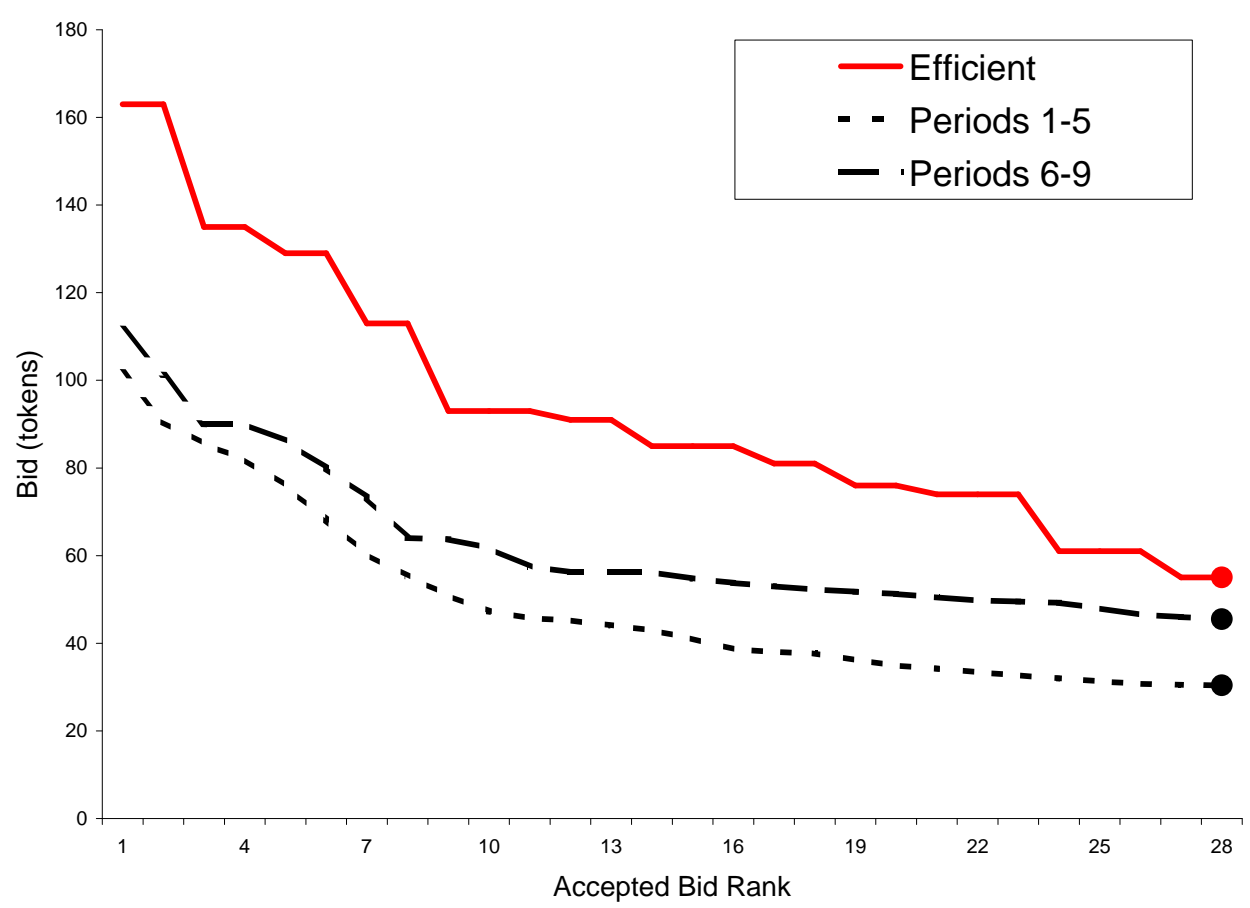

Figure 7.6: Most students (and all water managers) did not overbid 
same subject in the same period. ${ }^{23}$ Even if the initial bid was on the margin, the fact that demand schedules slope down (one unit of demand at each price) means that at least 44 percent of successful bids were not on the margin.

\subsection{Summary}

This chapter presents theoretical arguments and experimental results on how MET might use auctions to allocate water and conveyance. The theoretical virtues of auctions are straightforward: they are simple to understand, explain and implement; they increase "procedural utility" from participating in a transparent and "fair" mechanism (Benz, 2004; Frey, 2005); they are flexible and robust; they respond to changing conditions; and they allocate with price - not political, bureaucratic or engineering methods - thereby reducing conflict.

In practice, MET could allocate inframarginal lifeline water (for equity) and auction remaining marginal water (for efficiency). Revenues in excess of fixed and variable costs could be rebated on a per capita basis (rewarding efficiency and en- hancing equity) or could repay member agencies' previous payments towards MET's fixed costs. Note that internal auctions do not require that MET change its structure as a public cooperative of member agencies to achieve the efficiency of a private market of competitors.

The results from the two designs (buysell, double auction and bid-only, uniformprice auction) and two subject groups (students and water managers) show statistical differences in performance efficiency, but these results were probably affected by the limited duration of the auctions. Despite this weakness, results are still useful: They do not reject the possibility that water managers suffer endowment effects but do reject the possibility that water managers cannot do as well as a students in auctions.

If MET wanted to explore its options with respect to auctions, it could use pilot auctions to compare different auction structures and institutional arrangements, e.g., who can buy and sell, what is being bought and sold, etc. ${ }^{24}$ Although initial rights (endowment, mechanism, rebates, etc.) will reflect political reality, auctions could efficiently allocate those rights.

\footnotetext{
${ }^{24}$ Groundwater issues will occupy center stage. Without clear rights, some member agencies may overdraft groundwater, as happened in the 1987-1991 drought; see Section 3.12. Although long-term use of auctions should lead to zero net overdrafting (pump when price is high, recharge when it is low), Gardner et al. (1997) report that experimental subjects extract more groundwater than is optimal. Auctions must be implemented with caution.
} 
7.6. SUMMARY 


\section{Chapter 8}

\section{Conclusion}

This dissertation began with the following question: Why did MET members vote $25-1$ to impose a high wheeling charge on the San Diego County Water Authority (SDCWA)? SDCWA wanted to buy water from farmers but needed MET's pipes to move the water. Since SDCWA was a member agency of MET, a cooperative of water agencies, it seemed reasonable that SDCWA would pay the marginal cost of moving that water. But it was not reasonable to MET's other members, and they voted 25-1 (against SDCWA) to charge a price that reflected the (higher) average cost of moving water anywhere in MET's system (Chapter 1). This postage-stamp pricing (PSP) charging members the same price for water no matter where it is delivered - did not discriminate against SDCWA; MET uses it everywhere (Chapter 2).

Why would MET use PSP? As a type of average cost pricing, it subsidizes higher cost, marginal users, which is inefficient. ${ }^{1}$ The answer to that question predated MET's foundation: Los Angeles created MET to increase its supply of cheap electrical power (Chapter 3). When MET ended up with "too much" water, LADWP subsidized water prices (using PSP) until
MET grew large enough for demand to absorb supply. The implicit subsidy to high cost (marginal) buyers was not a problem while water was a club good - a non-rival good that need not be rationed-because there was no need to dampen demand. In the 1960s, lawsuits reduced water supplies and LADWP's removal of subsidies increased costs, but MET's institutions did not change to reflect water's changing nature from club to private (i.e., rival) good.

MET managed to muddle through until the 1987-1991 drought hit, and members' access to water had to be rationed, and MET's "all for one and one for all" culture collapsed. Some members wanted to strengthen MET, but others sought water independence. It is from this period that MET's inefficiency started to surface in the form of conflict among members and policies that misallocated water and costs (Chapter $4)$.

But how do we know that MET was inefficient? According to Hart and Moore (1996), cooperatives are efficient (relative to firms) when members have reasonably homogenous preferences. Assuming preferences are a function of characteristics, it seems obvious that members that differ in

\footnotetext{
${ }^{1}$ When SDCWA paid the PSP to move water, it was higher than the marginal cost of moving the water it wanted - contrary to the usual case where marginal cost is higher than the average, or PSP, cost.
} 
size, form (city, MWD), etc. will have heterogeneous preferences. I quantify heterogeneity through a measure of dependency that rises when members get more water from MET and/or members buy more of MET's water.

Although members were heterogeneous in dependency, this fact alone did not seem to explain MET's inefficiency: Member dependency had been heterogeneous long before the drought without appearing to affect MET's efficiency. This fact-and the surprising strength of feelings over the fairness of the wheeling charge - indicates that some other forces had perhaps smoothed MET's operations until the drought revealed MET's weaknesses.

A study of MET's past revealed that MET had cheap, abundant water for many years. So perhaps abundance had been sufficient for MET to operate smoothly? If member agencies could get as much water as they pleased - and Los Angeles was going to subsidize that water - then members would have little reason for conflict and policies would not misallocate water, since there was "too much" of it. ${ }^{2}$ It was clear that MET was indeed operating in an era of abundance until the early 1960s, when legal actions reduced water supplies and Los Angeles ended its subsidies. In subsequent years, the "end of abundance" only became more obvious.

Or perhaps managers and directors of member agencies were so cooperative that they could ignore dependency and allocate water to maximize group welfare? Testimonials of Los Angeles' exemplary leadership, the shared culture of engineers and the 25year domination of Joseph Jensen as Chairman of the Board all pointed to this possibility. Water managers' popular image (and self image) as public servants working for the general good supported this idea.
Cooperation, social preferences and maximization of group welfare are trickier to measure. While there was abundant evidence that water managers considered themselves to be cooperative (and perhaps they had been), there was also increasing evidence (lawsuits, etc.) contradicting that notion. I conducted cooperation experiments with member agency managers (MAMs) and several comparison groups (undergraduate students, other managers) to find how much they would contribute towards a public good (Chapter 5). The results from the experiments reject the hypothesis that MAMs are just as cooperative as students (they are slightly more cooperative) but also reject the hypothesis that their level of absolute cooperation is sufficient to maximize group welfare.

So, MET may have been efficient until the 1960s - when the end of abundance made heterogeneity relevant and managers could not cooperate "enough" to ignore differences and maximize group welfare by sharing of water resources. With the existence of relevant, heterogeneous preferences, theory indicates that MET is inefficient as a cooperative.

In Chapter 6, I try to detect inefficiency using 60 years of panel data - looking at the various ways in which water supply might affect member agencies' land values. The impact of water is positive and significant for MWDs - an additional acre-foot (AF) of annual water supply (local or MET) increases assessed land values by $\$ 7,000$ $\$ 8,000$ per acre. For cities, the impact varies by origin: An AF of MET water is "worth" an additional $\$ 16,000 /$ acre, but local water supply has no impact. We can interpret these results to mean that MWDs are getting equal value from local and MET water; cities, on the other hand, have adequate lo-

\footnotetext{
${ }^{2}$ This explanation ignores the inefficiency of Los Angeles' subsidies, which is not relevant if we are only interested in MET's efficiency as a cooperative.
} 
cal water but much more constrained access to MET water. The high value of additional MET water suggests that cities are not getting as much as they want, ceteris paribus. Other results show that dependency (buying more water from MET) has a negative impact on cities' land values and that member agencies' land values fell by different percentages after 1994 (post-drought). This last result has many caveats, but it does not reject the possibility that MET's water allocation policies did not benefit all member agencies evenly.

Chapter 7 outlines how MET can efficiently allocate water within non-profit, equity, logistical and engineering constraints using internal auctions. The chapter begins with a theoretical discussion and reports results from two experimental auctions. MET could replace its current water allocation system with internal auctions for marginal water (after an initial inframarginal per capita allocation that assures equity). If these auctions generated revenue in excess of variable and fixed costs, rebates of "profits" could contribute to conservation, equity, or repaying members' past contributions to MET. Although auctions would be more efficient in shortage - allocating with willingness to pay instead of formulas - their benefit in "normal" times would also be significant: Constant price updates would signal changing supply and demand. Although the monetary value of efficiency from each transaction might be small, aggregate benefits would be great. More importantly, the qualitative difference in the way water and costs are allocated in auctions would transform patterns of water use. In the current system, one builds storage to maintain reliability in shortage. In an auction market, prices would rise in shortage (reducing demand), and supply would be more elastic: Instead of hitting the hard constraint of their own storage facilities, members could "buy reliability" at MET's auctions. The auction experiments suffered from technical problems (auction periods were too short), the results indicate that water managers have stronger endowment effects than students in the buy-sell auction and managers are more aggressive in the bid-only auction.

The biggest obstacle to implementing auctions is that additional effort and risk does not come with greater benefits: If water management improves or agencies save money, those benefits go to customers. Since water managers face no competition, they can continue with business as usual until a shortage occurs, and they implement their usual policies of steeply higher prices and/or mandatory rationingavoiding long-term solutions yet again.

In sum, MET needs to react to changes that began 40 years ago, and this need grows stronger as climate change, legal restrictions, and growing demand strain MET's supplies. In 2008, amid widespread discussion of drought, MET announced that it would use its typical solution-formulasto allocate a shrinking water supply among member agencies, and some agencies have reacted with (typical) lawsuits challenging the equity and efficiency of these formulas (Schoch, 2008a). MET needs to replace formulas, lawsuits and misallocation with a mechanism that rations in scarcity-prices. 
Appendices 



\section{Appendix A}

\section{Instructions for Cooperation Game}

G1, G2 and G3 refer to the cooperation game, buy-sell auction, and bid-only auction, respectively.

\section{A.1 Experimenter Procedures}

\section{Set-up}

1. Print sign-up list from CASSELLWEB to track no-shows.

2. Folders are numbered with "random" 2 digit numbers: 30313439414247485052 55565760636569717477798183868790919397

3. Folders contain (ordered top-to-bottom):

(a) G1 on pink

(b) G2 on light green

(c) G3 on light blue

(d) Questionnaire on yellow [backup - reuse]

4. Place folders next to the computers with a pen, (1 copy) Bill of Rights (2 copies) Consent Forms on top.

5. We have

- Payment envelopes with numbers matching those on folders (in pen or labels).

- $\$ 15 * \mathrm{~N}$ (or $\$ 50 * \mathrm{~N}$ for MET) in cash for payouts. $[2 * \$ 20+20 * \$ 10+16 * \$ 5$ $+80 * \$ 1=\$ 400$.]

6. Turn off firewall on server.

7. Start zTree.

\section{Starting}

1. Subjects enter and choose a computer.

2. Subjects read/review the Bill of rights/Consent form while waiting.

3. When everyone has arrived, subjects start zLeaves.

4. Close the door. Reject latecomers (who signed up - check list) with $\$ 5$ show-up fee. 
5. Set G1 for number of subjects in background. Make sure there is at least one subject in each group under parameters.

6. Run|Clientstable* to confirm all subjects are connected.

7. Read General Instructions.

\section{G1}

Run five times (this is a secret!)

Pre Read G1 instructions (5ms)

Run Press F5 to start.

Run 2 Change SubNumInput $=0$; before second run.

Run 2-5 Change Countmax $=16 / 7 / 23 / 32 / 32$

During Countersign consent form and collect our copies.

During Prep for G2/3. Set number of subjects in background and parameter table*. Put odd subject into G3. For G2, adjust EndM and/or EndH in subjects.do (allocate Supply/4 to four LD G2 subjects). For G3, change Supply to $N * 0.5 * 4$ in globals.do.

\section{Finishing}

1. FilelOpen Questionnaire and choose questionnaire.ztq.

2. Adjust Group size (N-1) to match actual group size. Press F5 to start questionnaire.

3. After subjects enter Folder Number and goto screen 2 of questionnaire (with questions), . pay file exists.

4. Open . pay in Excel, subtract 250 from points (to remove 1,000 token endowment added to profit. Since profit was multiplied by 0.25 to get payout, remove 250 points), divide by 100, and round for USD payout [x3 for water managers].

5. Save . pay file

6. Put cash in envelopes by Folder Number.

7. Trade envelopes for folders.

8. Ctrl+F4 all open zLeaves and log-off subjects.

\section{A.2 Instructions for Session}

1. Welcome. We are starting now.

2. Please turn off your cell phones.

3. Does anyone have questions about the Bill of Rights or Consent Form? [WAIT]

4. Please sign the bill of rights and both copies of the consent form. (The extra copy is for you to keep.)

5. Please put all forms where I can co-sign and collect them during the experiment.

6. Today you will play two games - each more than once.

7. Your earnings depend on how well you play the games. 
8. Your decisions and earnings will be anonymous. You will be identified by the number on the front of your folder. When we begin, you will enter the folder number into the computer.

9. In all games, we use "tokens" for game money. The value of a token in real money is different in each game. You will learn the value before you begin each game.

10. After the games, we will calculate and distribute earnings, in cash, in envelopes marked with your folder number. A research foundation has provided the funds for this study.

11. Please stay silent throughout this experimental session and keep your attention on your own computer.

12. Please raise your hand if you have a question. I will answer questions individually.

13. Please take out the pink sheet, marked "Game 1" and close your folder until I tell you to open it again.

14. Please read along with me.

\section{A.3 Instructions for G1}

This is a game of group and individual investment behavior.

- You are in a group of 4 with 3 others, chosen at random. (If you are in a GROUP OF FIVE, you will find out during the game.)

- You have an endowment of 50 tokens to invest. Others have the same endowment.

- You invest your tokens in the Individual Exchange and the Group Exchange.

- Your earnings depend on how you and your group invest tokens.

- 50 tokens $=\$ 0.75$ [for students; $\$ 3.00$ for Water managers]

Every token you invest in the Individual Exchange returns one token in earnings to you only.

Every token you invest in the Group Exchange returns 0.5 tokens in earnings to every member of your group, including yourself. It does not matter who invests in the Group Exchange - everyone gets a return from every token invested in the Group Exchange, whether or not they invested.

Your task is to maximize your earnings by choosing how many of your tokens to invest in the Group Exchange. (Remaining tokens go to the Individual Exchange.) Examples:

\begin{tabular}{lccc} 
& 1 & 2 & 3 \\
\hline Your Group Exchange investment & 0 & 50 & 30 \\
Your Individual Exchange investment & $\mathbf{5 0}$ & $\mathbf{0}$ & $\mathbf{2 0}$ \\
\hline If others' Group Exchange investments total & 90 & 110 & 0 \\
$\ldots$. total Group Exchange investment is ... & $0+90=90$ & $50+110=160$ & $30+0=30$ \\
\cline { 2 - 4 } ... and everyone's Group Exchange return is & $90 / 2=\mathbf{4 5}$ & $160 / 2=\mathbf{8 0}$ & $30 / 2=\mathbf{1 5}$ \\
\hline Your total earnings (in tokens) are & $50+45=95$ & $0+80=80$ & $20+15=35$
\end{tabular}

\section{Game Timing}

1. All members of your group start with a simultaneous investment in the Group Exchange (Round 1). Click "Continue" after you enter your choice. You only have 20 seconds to click. A countdown clock is in the top-right corner of your screen. 
2. In Round $\mathbf{2}$ and thereafter, you will (one person at a time) see the number of people in your group (either 4 or 5), the TOTAL investment in the Group Exchange and the average investment of others in your group. You will change or confirm your Group Exchange investment and click "Continue." You only have 10 seconds to click. If you take too long, your choice does not change.

3. The opportunity to see the total and change/confirm passes from person to person in your group for an unknown, random number of rounds until the run ends, and all investments are final. You will have at least one opportunity to change/confirm your investment. Although you must wait while the decision passes around your group, try to pay attention so as to not to miss your turn.

4. When each run ends, you will see your investment, the total investment in the Group Exchange, your earnings from the current run, and your cumulative earnings.

5. When the game repeats, players are randomly reshuffled into new groups and the final round changes to a new, random number.

6. We will begin now. The first thing you will do is enter your Folder Number.

\section{A.4 Questionnaire}

[Note that auction games (G2/G3) take place before the questionnaire is given; see Appendix C.]

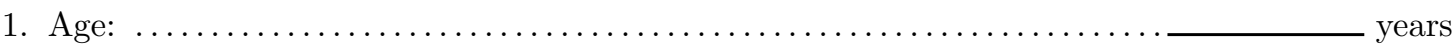

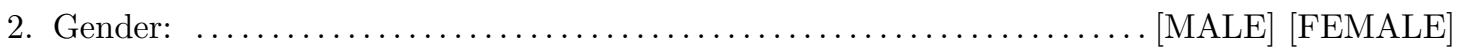

3. Your educational or professional field (circle one)

(a) Anthropology

(b) Economics

(c) Engineering

(d) Law

(e) MBA/finance

(f) Political Science

(g) Sociology

(h) Other Liberal Arts (English, Communications, etc.)

(i) Other Science (Biology, Chemistry, Math, etc.)

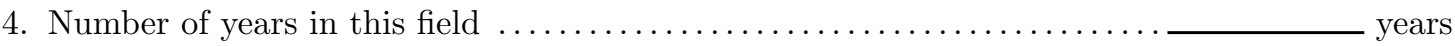

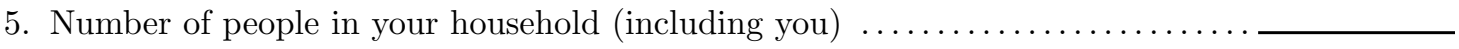

6. Have you used an internet auction (e.g., eBay) to buy /sell something? . . ....... [Y] $[\mathrm{N}]$

7. Have you participated in an experiment similar to this one? ................ $[\mathrm{Y}][\mathrm{N}]$

8. Number of people here who...

(a) ... you know and work with?

(b) ... you know but do NOT work with?

(c) ... you do NOT know but DO work with?

(d) ... you do NOT know and do NOT work with?

(e) The total (group minus 1 for you) should be

9. Some questions to answer using your own interpretation:

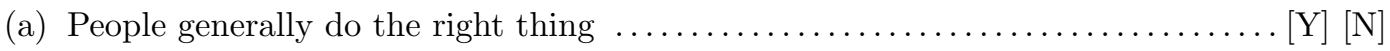

(b) I find it better to accept others for what they say and appear to be $\ldots \ldots \ldots \ldots[\mathrm{Y}][\mathrm{N}]$

(c) I am doubtful of others until I know they can be trusted ................ $[\mathrm{Y}][\mathrm{N}]$

(d) I almost always believe what people tell me ........................ 


\section{Appendix B}

\section{Regression Output}

Tables B.1 and B.2 have manual model output for cities and MWDs, respectively. Section 6.3 describes the data, Section 6.4 describes the model, and Section 6.5 interprets these results. Notes:

- "a_" prefixes to variables denote normalization by the number of acres in that member agency in that period.

- ma1 and postdma1 (City of Anaheim) are omitted from the city regression.

- ma26 and postdma26 (Western MWD) are omitted from the MWD regression.

- Numbers for cities or MWDs are:

\begin{tabular}{rlrl}
\multicolumn{1}{c}{ Cities } & \multicolumn{2}{c}{ MWDs } \\
\hline 1 & Anaheim (omitted) & 4 & Central Basin \\
2 & Burbank & 6 & Calleguas \\
3 & Beverly Hills & 7 & Eastern \\
5 & Compton & 9 & Foothill \\
8 & Fullerton & 11 & Inland Empire \\
10 & Glendale & 14 & Las Virgenes \\
12 & Los Angeles & 15 & MWDOC \\
13 & Long Beach & 18 & SDCWA \\
16 & Pasadena & 23 & Three Valleys \\
17 & Santa Ana & 24 & Upper San Gabriel \\
19 & San Fernando & 25 & West Basin \\
20 & Santa Monica & 26 & Western (omitted) \\
21 & San Marino & & \\
22 & Torrance & &
\end{tabular}


Table B.1: Cross-sectional time-series FGLS regression results for Cities

\begin{tabular}{|c|c|c|}
\hline Dep Var: a_avd & coefficient & $\mathrm{p}$-value \\
\hline a_avd_lag & $1.14^{* * *}$ & 0.00 \\
\hline a_pop & $-1751.54^{* *}$ & 0.04 \\
\hline a_pop2 & 53630.94 & 0.19 \\
\hline a_local & 2.34 & 0.11 \\
\hline a_met & $16.68^{* * *}$ & 0.00 \\
\hline metsh & $-22.97^{* * *}$ & 0.00 \\
\hline shmet & 3.95 & 0.82 \\
\hline ures & $163.82^{* * *}$ & 0.00 \\
\hline ucom & -186.20 & 0.18 \\
\hline uind & $-425.86^{* * *}$ & 0.00 \\
\hline uotr & $176.31^{* * *}$ & 0.00 \\
\hline aannual & $1658.73^{* * *}$ & 0.00 \\
\hline aperennial & $147.40^{* * *}$ & 0.01 \\
\hline aother & $103.12^{*}$ & 0.06 \\
\hline ma2 & 0.08 & 0.99 \\
\hline ma3 & $-65.45^{* * *}$ & 0.00 \\
\hline ma5 & $28.89^{* * *}$ & 0.00 \\
\hline ma8 & $26.98^{* * *}$ & 0.00 \\
\hline ma10 & 4.31 & 0.71 \\
\hline ma12 & -8.51 & 0.25 \\
\hline ma13 & $-21.95^{* * *}$ & 0.01 \\
\hline ma16 & $-34.28^{* * *}$ & 0.00 \\
\hline ma17 & 10.34 & 0.20 \\
\hline ma19 & $47.36^{* * *}$ & 0.00 \\
\hline $\operatorname{ma} 20$ & -17.40 & 0.16 \\
\hline $\operatorname{ma} 21$ & $-85.30^{* * *}$ & 0.00 \\
\hline $\operatorname{ma} 22$ & $29.56^{* * *}$ & 0.00 \\
\hline postd & -7.24 & 0.25 \\
\hline postdma2 & $-26.61^{* * *}$ & 0.00 \\
\hline postdma3 & $-137.56^{* * *}$ & 0.00 \\
\hline postdma5 & -5.55 & 0.39 \\
\hline postdma8 & $-19.65^{* *}$ & 0.03 \\
\hline postdma10 & $-25.27^{* * *}$ & 0.00 \\
\hline postdma12 & $-30.27^{* * *}$ & 0.00 \\
\hline postdma13 & $-29.91^{* * *}$ & 0.00 \\
\hline postdma16 & $-18.52^{* * *}$ & 0.01 \\
\hline postdma17 & -9.17 & 0.26 \\
\hline postdma19 & $-17.70^{* *}$ & 0.03 \\
\hline postdma20 & $-81.20^{* * *}$ & 0.00 \\
\hline postdma21 & $-33.24^{* * *}$ & 0.00 \\
\hline postdma22 & $-42.95^{* * *}$ & 0.00 \\
\hline d_sac & $162.56^{* * *}$ & 0.00 \\
\hline d_ac & $182.86^{* * *}$ & 0.00 \\
\hline Intercept & $-56.17^{*}$ & 0.07 \\
\hline
\end{tabular}


Table B.2: Cross-sectional time-series FGLS regression results for MWDs

\begin{tabular}{|c|c|c|}
\hline Dep Var: a_avd & coefficient & $\mathrm{p}$-value \\
\hline a_avd_lag & $1.15^{* * *}$ & 0.00 \\
\hline a_pop & -1185.10 & 0.21 \\
\hline a_pop2 & 30284.43 & 0.72 \\
\hline a_local & $7.20^{* * *}$ & 0.00 \\
\hline a_met & $8.09^{* * *}$ & 0.00 \\
\hline metsh & 1.21 & 0.43 \\
\hline shmet & -3.89 & 0.66 \\
\hline ures & -16.95 & 0.17 \\
\hline ucom & -21.22 & 0.47 \\
\hline uind & $-43.95^{*}$ & 0.08 \\
\hline uotr & $31.38^{* * *}$ & 0.00 \\
\hline aannual & 3.28 & 0.87 \\
\hline aperennial & $-33.26^{* *}$ & 0.03 \\
\hline aother & 6.64 & 0.56 \\
\hline ma4 & 1.83 & 0.78 \\
\hline ma6 & $4.27^{* * *}$ & 0.00 \\
\hline $\operatorname{ma7}$ & -2.76 & 0.41 \\
\hline ma9 & 6.89 & 0.23 \\
\hline ma11 & -3.04 & 0.24 \\
\hline ma14 & 1.08 & 0.71 \\
\hline ma15 & 2.86 & 0.13 \\
\hline ma18 & 2.04 & 0.36 \\
\hline ma23 & 2.38 & 0.14 \\
\hline $\operatorname{ma} 24$ & 0.96 & 0.81 \\
\hline ma25 & -0.13 & 0.96 \\
\hline postd & 0.56 & 0.66 \\
\hline postdma4 & $-28.24^{* * *}$ & 0.00 \\
\hline postdma6 & $-6.08^{* * *}$ & 0.00 \\
\hline postdma7 & 1.89 & 0.35 \\
\hline postdma9 & $-21.29^{* * *}$ & 0.00 \\
\hline postdma11 & -3.45 & 0.18 \\
\hline postdma14 & $-7.33^{* * *}$ & 0.00 \\
\hline postdma15 & $-18.70^{* * *}$ & 0.00 \\
\hline postdma18 & -2.60 & 0.50 \\
\hline postdma23 & $-20.03^{* * *}$ & 0.00 \\
\hline postdma24 & $-24.38^{* * *}$ & 0.00 \\
\hline postdma 25 & $-38.64^{* * *}$ & 0.00 \\
\hline Intercept & -2.53 & 0.40 \\
\hline
\end{tabular}




\section{Appendix $\mathrm{C}$}

\section{Instructions for Auction Games}

G1, G2 and G3 refer to the games of cooperation, auction with endowment and auction without endowment, respectively.

\section{C.1 Experimenter Procedure}

Run once (1 Trial plus 9 periods) (this is a secret!)

1. Press F5 to start so subjects know which auction they are in.

2. Read instructions.

3. Press continue button to see demand schedule and then play Trial 1.

4. Press F12 to stop clock to answer questions.

5. Restart the clock (Shift + F12) and then stop it again during profits so they can ask further questions.

\section{C.2 Instructions for G2/G3}

1. Everyone has been randomly assigned to one of two groups in the room. Both groups will play an auction game that lasts 90 seconds. You will repeat the game many times.

2. Please look on your screen to see which auction game you are playing and remove either the blue or green sheet from your folder. Do not press the button until I tell you.

3. Your goal is to maximize profits. You get profits from owning units of water and tokens. Your running profits are shown in [Box A]. In the GREEN, there is a loan of 1,000 tokens. Your "token profit" (second to last line) excludes that loan.

4. Players' values for units differ but DO NOT CHANGE in later auctions. See [Box B] for a sample. The value of an additional unit is less than the value of units you already have. In Box B, for example, the first unit of water is worth 93 tokens. The second unit is worth 85 tokens. Together they are worth 178 tokens. The value of additional units is positive but keeps falling until the 9 th unit is worth 19 tokens and the 10th unit is worth NOTHING. 
5. In Box C, you offer to buy units of water (GREEN) or bid for units of water (BLUE). You are not allowed to bid more than 175 tokens for a unit. Since nobody values a unit that high, you are sure to lose money buying at that price. (This is to limit your ability to lose money through a mistake or misunderstanding.)

6. The supply of units is fixed at $4 N_{i}$ units for each group $i$.

7. In the GREEN, the number of units you OWN are in the top line of Box A. In the BLUE, the number you own as of any give moment is shown in the middle line of Box D

8. In the GREEN auction, some of you own units of water and some of you own ZERO units of water. Those of you who own can sell water $[$ Box D and E] to those who do not [Box C and F]. Nobody owns units at the start of the BLUE auction.

9. If you buy a unit for less than its value to you, you make a profit. If you pay more than its value, you make a loss.

10. Please read the rest of the directions on your sheet. If you have a question, raise your hand.

11. When you are finished, press the "Done Reading Instructions" button. When everyone has done so, you will see your actual values for units.

After that, we will play one "Trial" period so you can get familiar with the auction layout. Note that your TOTAL profits will say "-1000" in the Trial period only. Ignore it.

\section{C.3 Instructions for G2}

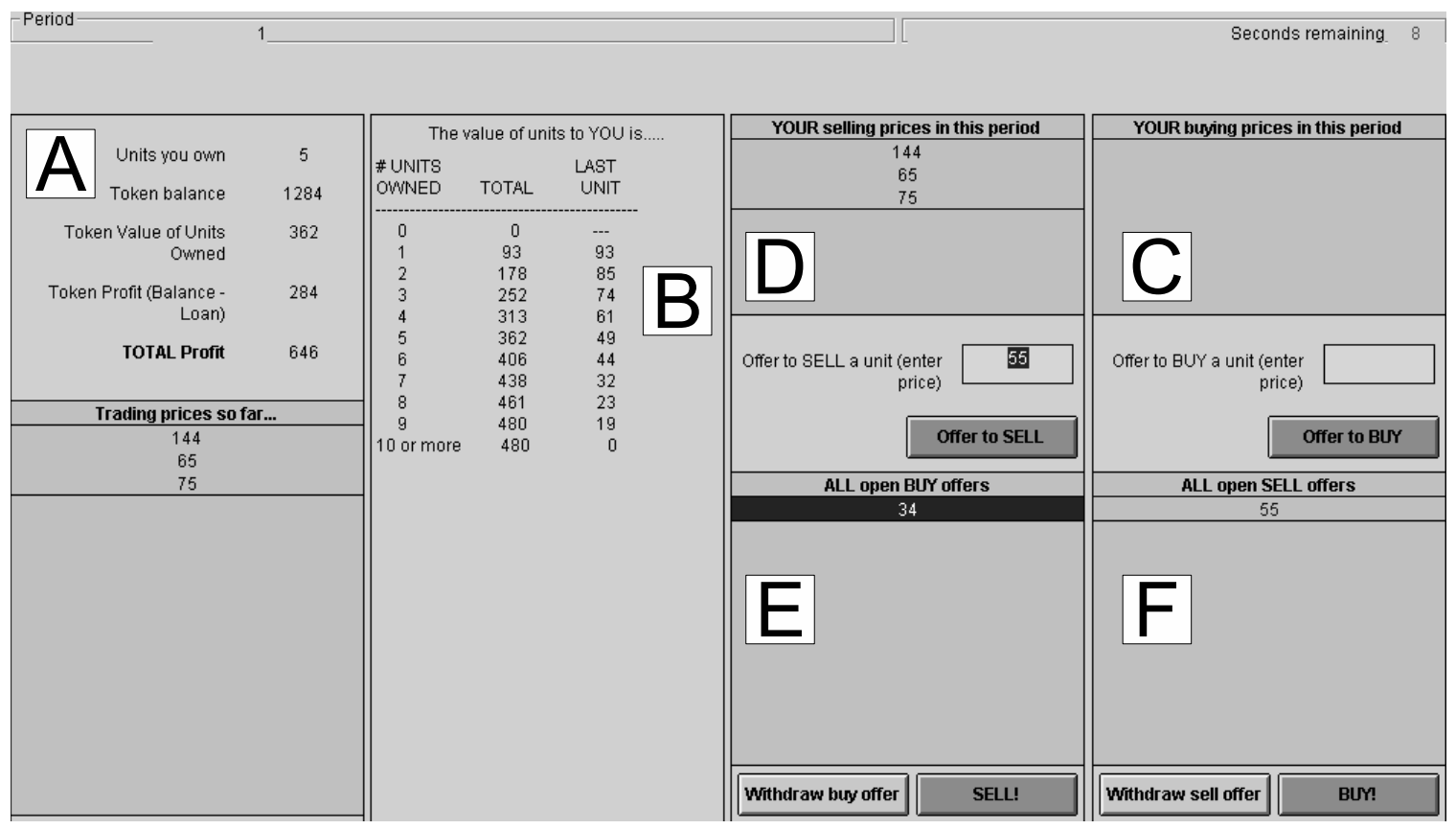

Your task is to maximize earnings, which equals the value of units of water you have at the end of the auction plus the net number of tokens you earn selling or spend buying 
water. (You have a 1,000 token loan that will be deducted.) These numbers and your current profit are in Box A. Given that 100 tokens $=\$ 0.25$ [for students; $\$ 0.75$ for Water managers], you would have earned $\$ 1.62[\$ 4.85]$ in this sample auction.

Box A also shows the units you own and your token balance. Players begin with different endowments of units. Your endowment and valuation do not change in later auctions.

[OFFER TO BUY] In Box C, you offer tokens to buy units. Your must offer more tokens than the highest offer in Box E. Your successful purchases are in Box C.

[OFFER TO SELL] In Box D, you offer to sell units for tokens. Your price must be less than the lowest offer in Box F. The number of units you own (and can therefore sell) is shown in Box A. Your successful sales are in Box D.

[SELL!] In Box E are all offers to buy. Your offers are in BLUE (none shown here). To accept the highest, highlighted buy offer (example: 34), press "SELL!." To withdraw your offer to buy, highlight one of your BLUE lines and press "Withdraw buy offer."

[BUY!] In Box F are all offers to sell. Your offers are in BLUE (example: 55). To accept the lowest, highlighted sell offer (none shown here), press "BUY!." To withdraw your offer to sell, highlight one of your BLUE lines and press "Withdraw sell offer."

\section{C.4 Instructions for G3}

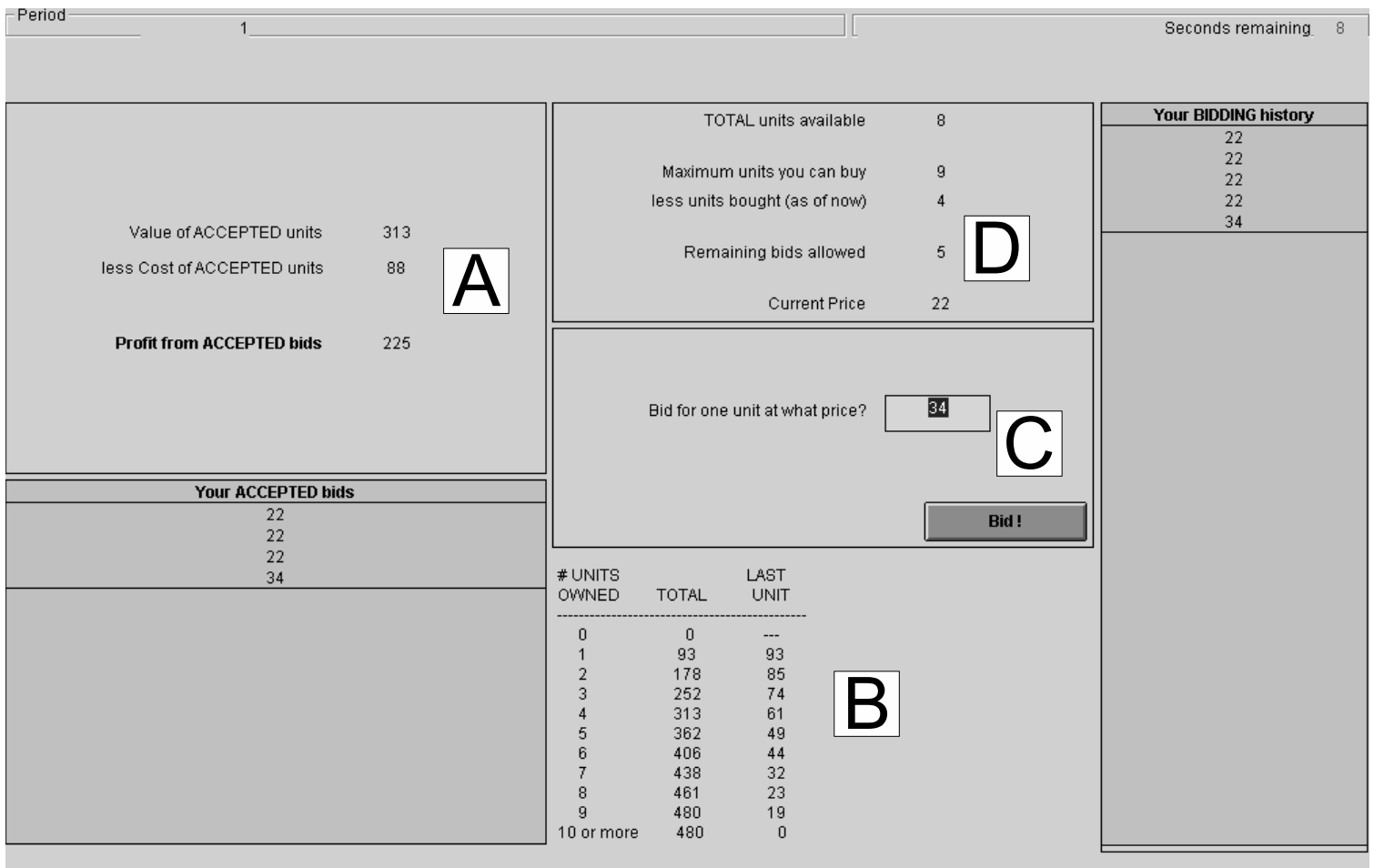

- Your current profit (the value of units less the current price times number of units) is in Box A.

- Given that 100 tokens $=\$ 0.50$ [for students; $\$ 1.50$ for Water managers], you would have earned $\$ 1.13[\$ 3.38]$ in this sample auction.

- Nobody has units at the start of the auction. 
- To get units, you bid in [Box $\mathbf{C}]$.

- Although bids are accepted (units are bought) according to the amount of the bid, the actual price you pay for the is the "current price" [Box D]. This price is the same as the lowest, accepted bid (of ALL bids).

- For example, if there are 3 units and 5 bids (1,2,5,6 and 9), the top bids (5,6 and 9) get the units, but the price is the lowest-accepted bid (5).

- Current price is zero until the total number of bids exceeds total units available. After that, you must bid more tokens than the current price to buy another unit.

- You are not allowed to bid for units that have no value to you, i.e., unit 10 has a zero value. You will see your "maximum units you can buy" and the "remaining bids allowed" throughout the auction.

- If your remaining bids allowed is zero, you cannot bid and must wait for the current price to rise high enough for one of your accepted bids to be rejected.

- Bids cannot be withdrawn. You cannot see others' bids. 


\section{Appendix D}

\section{Notes on Data Sources}

This appendix explains how various sources of data are combined to create the tables and figures in the text (called a Final Data or FD objects). FD objects are listed in Sections D.1 and D.2. They are based on Raw Data (RD) files and/or Processed Data (PD) files. RD files are marked "RD," but PD files are not. I list the details of PD files in Section D.3. Each PD file's description includes its sources (S:), processing methods (P:), and destinations (D:).

Starting with any FD object, the reader can find the RD or PD files that it is based on. If it is based on a PD file, the reader can then trace the origin of that PD file to other $\mathrm{PD}$ or RD files. $\mathrm{PD}$ files are available from the author. RD files are available from public locations or the author. ("AR" RD files are MET's annual reports.)

File Types: .dta (STATA data), .do (STATA do), .mdb (Microsoft Access), .log (STATA output log), .xls (Microsoft Excel), and .ztt (z-tree treatment).

\section{D.1 Final Data-Tables}

2.1 area (area hack tab in area.xls), population (Pop80-04 tab in Population.xls), year joined (RD: http://www.mwdh2o.com/mwdh2o/pages/memberag/member02.html), board seats (RD: http://www.mwdh2o.com/mwdh2o/pages/board/bio01.html), votes (2006 stats from AV95-06 tab in AssessedValues.xls), share of sales (METalt tab in WaterDelivery.xls), water uses (2004 stats from Localalt and METalt tabs in WaterDelivery.xls), water sources (2004 stats from Localalt and METalt tabs in WaterDelivery.xls), preferential rights (RD: Preferential Rights -- FY2006 Final.pdf - dated 4 Oct 2005 - from Stathis Kostopoulos (MET) via email of 8 May 2006).

2.2 RD: MET (2004a,c); Thomas (2007b)

2.3 RD: http://www.mwdh2o.com/mwdh2o/pages/finance/finance_03.html

3.1 RD: Milliman (1956a, pp. 154-158)

3.2 RD: Milliman (1957, p. 281)

3.3 RD: Dawn Chin (MET) via email of 27 Feb 2008

3.4 RD: Dawn Chin (MET) via email of 2 Mar 2006 
3.5 water table in met.mdb

4.1 dependency tab in WaterDelivery.xls

5.1 RD: author data

5.2 G1 types table from met_exp.mdb

5.3 coop tab in $\mathrm{G} 1$. $\mathrm{xls}$

5.4 G1 Types TI query in met_exp.mdb

5.5 UG stata out, mgr stata out and quadratic tabs in G1.xls

6.1 RD: hypothetical data

6.2 C6Stata080329.log

6.3 C6Stata080329.log

6.4 C6Regression.xls

6.5 C6Regression.xls

7.1 G23 desc query from met_exp.mdb

7.3 G23 stats query from met_exp.mdb

B.1 C6Stata080329.log

B.2 C6Stata080329.log

\section{D.2 Final Data-Figures}

1.1 RD: http://tinyurl.com/3ql4hp

2.1 export tab in WaterDelivery.xls

2.2 cost tab in WaterSupply.xls

2.3 RD: hypothetical figure

2.4 water prices tab in WaterPrices.xls

3.1 data tab in Power. $x 1$ s

3.2 AreaOnly tab in area.xls

3.3 data tab in WaterSupply.xls

3.4 data tab in WaterSupply.xls

3.5 data tab in WaterSupply.xls

3.6 demand tab in WaterDelivery.xls

3.7 AV tab in assessedvalue.xls

3.8 data tab in METRevenue.xls

3.9 LocalMET tab in WaterDelivery.xls

3.10 LocalMET tab in WaterDelivery.xls

5.1 screenshot from G1PG20p5g.ztt

5.2 ug stata in tab in G1.xls 
5.3 ug stata in tab in G1.xls

5.4 coop tab in G1.xls

5.5 quadratic tab in $\mathrm{G} 1 . \mathrm{x}$ ls

5.6 quadratic tab in G1.xls

6.1 av figs tab in assessedvalue.xls

7.1 induced tab in G23.xls

7.2 screenshot from G2-3Auction20p2g.ztt

7.3 screenshot from G2-3Auction20p2g.ztt

7.4 G2G3Eff tab in G23.xls

7.5 g23bidsug tab in G23.xls

7.6 g23bidswm tab in G23.xls

\section{D.3 Processed Data Files}

Area.xls has five tabs:

Area40-88 S: 1940-1988 ARs (RD). D: Area0nly tab.

Area89-93 S: 1989-1993 ARs (RD). D: AreaOnly tab.

Area0nly S: Area40-88 and Area89-93 tabs. D: export tab and Figure 3.2.

area hack S: 2005 data from http://www.mwdh2o.com/mwdh2o/pages/memberag/ member02.html (RD). P: Interpolation from 1993 to 2005 as described in Section 6.3.2 on page 86. D: export tab and Table 2.1.

export S: AreaOnly and area hack tabs. P: Merged. D: area table in met.mdb.

AssessedValues.xls has five tabs:

AV S: 1940-1997 ARs (RD). D: export tab.

AV95-06 S: AV_GovnceModl.xls from Stathis Kostopoulos (MET) via email of 5 May 2006 (RD). D: export tab and Table 2.1.

export S: AV and AV95-06 tabs. P: Cleaned. D: Figure 3.7 and AV table in met.mdb. deflator S: (Bureau of Labor Statistics, 2007) (RD). D: deflate table in met.mdb. av figs S: AV table in met.mdb. P: Aggregated for cities and MWDs. D: Figure 6.1. C6data.dta S: out table of met.mdb. D: "no use" and "ICE" models in C6Regression.do. C6data_imputed.dta S: out-imputed table of met.mdb. D: "manual" in C6Regression.do. C6Regression.do S: C6data.dta and C6data_imputed.dta. P: described in Sections 6.3.5 and 6.4 .

C6Regression.xls S: C6Stata080329.log and AV table in met.mdb. P: Combine and estimate relative AV shifts for cities and MWDs. D: Tables 6.4 and 6.5.

C6Stata080329.log S: C6Regression.do. D: C6Regression.xls and Tables 6.2, 6.3, B.1 \& B.2.

G1.dta S: mgr stata in tabs in g1.xls. D: G1mgr.log. 
g1.xls has nine tabs:

ug data S: G1 source files (RD). D: ug stata in tab, G1 Efficiency in met_exp.mdb. ug stata in S: ug data tab. P: Cleaned. D: G1 UG data and Figures 5.2 \& 5.3.

ug stata out S: G1UG.log. P: type as described in Section 5.2.1. D: Table 5.5 and G1 types table in met_exp.mdb.

mgr data S: G1 source files (RD). D: mgr stata in tab.

mgr stata in S: mgr data tab. P: cleaned. D: G1.dta.

mgr stata out S: G1mgr.log. P: type as described in Section 5.2.1. D: Table 5.5 and G1 types table in met_exp.mdb.

coop S: G1 session query in met_exp.mdb. P: aggregated. D: Table 5.3 and Figure 5.4 .

robustness S: ug stata in and mgr stata in. P: checks for changes in behavior over rounds. D: None.

quadratic S: G1ug.log. P: described in Section 5.4.2. D: Table 5.5 and Figures 5.5 and 5.6.

G1mgr.log S: G1.dta. P: "bys sub: reg give seeavg if ug==0, cluster(run) nohe". D: mgr stata out tab in G1.xls.

G1PG20p5g.ztt S: Author-inspired by (Kurzban and Houser, 2005). P: 20 players in 5 groups described in Section 5.2. D: Figure 5.1 and G1 Source files.

G1ug.log S: G1 quad UG STATA query in met_exp.mdb. P: "bys sub: reg give seeavg if $\mathrm{ug}==0$, cluster(run) nohe" (linear typing) and "bys sub: reg give seeavg seeavg2 if $\mathrm{ug}==0$, cluster(run) nohe" (quadratic typing) described in Section 5.4.2. D: ug stata out and quadratic tabs in G1.xls.

G23.dta S: G23 Results table in met_exp.mdb. D: G23_eff.do.

g23.xls has four tabs:

G2G3Eff S: G23 source files (RD). D: Figure 7.4.

induced S: L/M/H players described in Section 7.3. P: Aggregates. D: Figure 7.1.

g23bidsug S: Nov 7 UG session (RD). D: Figure 7.5.

g23bidswm S: MAM session (RD). D: Figure 7.6.

G23_eff.do S: G23.dta. P: described in Section 5.2.2. D: G23_eff.log.

G23_eff.log S: G23_eff.do. D: Section 5.3.

G23Auction20p2g.ztt S: Author-inspired by (Cummings et al., 2004) and Hansen, Kaplan and Kroll's experiments at UCDavis and SacState. P: 20 players in 2 groups (G2 and G3) described in Section 7.3. D: G23 source files and Figures 7.2 \& 7.3.

GAll.xls S: G1 source files (RD). D: G1 types table in met_exp.mdb.

LandUse.xls S: DWR data from http://www.dpla.water.ca.gov/sd/land_use/landuse. html (RD) and MET data from 1990 and 2000 Land Use by Agency.xls from Gary Tilkian (MET) via email of 2 Feb 2007 (RD). P: 14 tabs that impute and merge data in many steps. D: LandUse table in met.mdb.

met.mdb has 11 tables: 
Area S: export tab in area.xls. D: All1 query.

AV S: export tab in AssessedValues.xls. D: All1 query.

deflate S: deflator tab in AssessedValues.xls. D: AV table.

LandUse S: export tab in LandUse.xls. D: All2 query.

LandUse-Imputed S: LandUse table. P: Covers missing years (e.g., pre-1964 and post2000 for Anaheim) by copying earliest survey observation (e.g., 1964) to earlier years (1942-1963) and latest survey observation (2000) to later years (20012004); results marked "imputed.". D: All2-imputed query.

MA S: Descriptive data on member agencies (RD). D: All1 query.

out S: All2 query. D: data.dta.

out-imputed S: All2-imputed query. D: data_imputed.dta.

Pop S: export tab in population.xls. D: All1 query and demand tab in WaterDelivery.xls.

Water S: export tab in WaterDelivery.xls. D: All1 query, demand tab in WaterDelivery.xls and Table 3.5.

and seven queries:

All1 S: Area, AV, MA, Pop and Water tables. D: All2 queries.

Al12 S: LandUse table and All1 query. D: out table.

All2-imputed S: LandUse-imputed table and All1 query. D: out-imputed table.

Dependency S: Water table. P: aggregates over different year ranges. D: dependency tab in WaterDelivery.xls.

LCD S: Pop and Water tables. D: Footnote 2 in Chapter 7.

METLocal S: Water table. P: Aggregated by year. D: export tab in WaterDelivery.xls. met_exp.mdb has eight tables:

G1 Efficiency S: ug data tab of G1.xls. P: efficiency for every player in every run. D: G1 session query.

G1 types S: GAll.xls and mgr stata out \& ug stata out tabs of G1.xls. D: G1 Types TI query and Table 5.2.

G1 UG data S: ug stata in tab in g1.xls. D: G1 quad UG STATA query.

G1 UG seeavgavg S: G1 UG data. P: average of seeavg. D: G1 quad UG STATA query.

G23 Contracts S: G23 source files. D: G3 repeat bids query.

G23 Profits S: G23 source files. D: not used.

G23 Results S: G2G3Eff tab in G23.xls. D: G23 stats query.

and six queries:

G1 quad UG STATA S: G1 UG data and G1 UG seeavgavg tables. D: G1ug.log.

G1 session S: G1 Efficiency and G1 types tables. D: coop tab in G1.xls

G1 Types TI S: G1 Efficiency and G1 types tables. D: Table 5.4.

G23 desc S: G1 types table. D: Table 7.1.

G23 stats S: G23results table. D: Table 7.3.

G3 repeat bids S: G23 Contracts table. D: Section 7.5. 
METRevenue.xls S: Reven001.PDF from Brian Thomas (MET) via email of 21 Aug 2007 (RD). P: aggregates; also has cost-benefit calculations for CRA power and taxes. D: Figure 3.8 and Section 3.5.

Population.xls has four tabs:

Pop40-93 S: 1940-1988 ARs (RD). D: merge tab.

Pop80-04 from UC Davis Request (10-06).xls from Warren Teitz (MET) via email of 23 Oct 2006 (RD). D: merge tab and Table 2.1.

merge S: Pop40-93 and Pop80-04 tabs. P: Described in Section 6.3.3 on page 86. D: export tab.

export S: merge. D: Population table in met.mdb.

Power.xls S: pp. 17-23 of AR60 (RD). D: Figure 3.1.

WaterDelivery.xls describes water delivered to MAs and has seven tabs:

LocalMET S: 1945-1997 ARs (RD). D: merge tab and Figures $3.9 \& 3.10$.

Localalt S: Production\&Sales_info.xls from Gary Tilkian (MET) via email of 20 Oct 2006 (RD). D: merge tab and Table 2.1.

METalt S: same as Localalt. D: merge tab and Table 2.1.

merge S: LocalMET, Localalt and METalt tabs. P: Reconciles and merges. D: export tab.

export S: merge tab and METLocal query in met.mdb. D: water table in met.mdb and Figure 2.1.

dependency S: dependency query from met.mdb. D: Table 4.1.

demand S: Water and Pop tables from met.mdb. D: Figure 3.6.

WaterPrices.xls has two tabs:

Water Rates S: Water Rates_LIBfiles.xls from Stathis Kostopoulos (MET) via email of 5 May 2006 (RD). D: WaterPrices tab.

WaterPrices S: Water Rates tab and deflator tab in AssessedValues.xls. P: deflated values (2004 dollars) for untreated M\&I water. D: Figure 2.4.

WaterSupply.xls describes water delivered to MET and has two tabs:

data S: CRA data from "Historical Net Diversions Into the Colorado River Aqueduct" from John Scott (MET) via email of 2 Mar 06 (RD). SWP data from Table B-5B p B-288 Bulletin 132-04 Management of SWP (RD). Entitlements from http://www.publicaffairs. water.ca.gov/swp/pdf/contractors.pdf (RD). D: Figures 3.3, 3.4 and 3.5.

cost S: Table 2.2. P: Combines and extrapolates. D: Figure 2.2. 


\section{References}

Akaike, H. (1974). A New Look at the Statistical Model Identification. IEEE Transactions on Automatic Control, 19(6):716-723.

Alatas, V., Cameron, L., Chaudhuri, A., Erkal, N., and Gangadharan, L. (2006). Subject Pool Effects in a Corruption Experiment: A Comparison of Indonesian Public Servants and Indonesian Students. University of Melborne Research Paper 975.

Alchian, A. A. and Demsetz, H. (1972). Production, Information Costs, and Economic Organization. American Economic Review, 62(5):777-795.

Allison, G. T. (1969). Conceptual Models and the Cuban Missile Crisis. American Political Science Review, 63:689-718.

Arrow, K. J. (1963). Social Choice and Individual Values. Number Monograph 12 in Cowles Foundation for Research in Economics at Yale University. Yale University Press, New Haven CT, second edition.

Atwater, R. and Blomquist, W. (2002). Rates, Rights, and Regional Planning in the Metropolitan Water District of Southern California. Journal of the American Water Resources Association, 38(5):1195-1205.

Ausubel, L. M. (2004). An Efficient Ascending-Bid Auction for Multiple Objects. American Economic Review, 94(5):1452-1475.

Axelrod, R. (1984). The Evolution of Cooperation. Basic Books, New York.

Bardhan, P. K. and Singh, N. (2004). Inequality, Coalitions and Collective Action. Institute of Business and Economic Research Working Paper E04-339.

Barnett, T. P. and Pierce, D. W. (2008). When Will Lake Mead Go Dry? Journal of Water Resources Research, 44(W03201).

Baumol, W. J. and Bradford, D. F. (1970). Optimal Departures From Marginal Cost Pricing. American Economic Review, 60(3):265-283.

Beeson, P. E., DeJong, D. N., and Troesken, W. (2001). Population Growth in US Counties, 1840-1990. Regional Science and Urban Economics, 31(6):669-699.

Benz, M. (2004). Introducing Procedural Utility: Not only What, but also How Matters. Journal of Institutional and Theoretical Economics, 160(3):377-401. 
Bergstrom, T. C. and Stark, O. (1993). How Altruism Can Prevail in an Evolutionary Environment. American Economic Review, 83(2):149-55.

Berkman, M. P. and David, J. (2000). Water Subsidies in Southern California: Do They Exist and Have They Contributed to Urban Sprawl? A Comment on an Article by Stephen P. Erie and Pascale Joassary-Marcelli Titled 'Unraveling Southern California's Water/Growth Nexus: Metropolitan Water District Policies and Subsidies for Suburban Development, 1928-1996'. California Western Law Review, 37:121-146.

Bertrand, M. and Mullainathan, S. (2003). Enjoying the Quiet Life? Corporate Governance and Managerial Preferences. Journal of Political Economy, 111(5):1043-1075.

Bjornlund, H. and O'Callaghan, B. (2005). A Comparison of Implicit Values and Explicit Prices of Water. Pacific Rim Property Research Journal, 11(3):316-331.

Black, D. (1948). On the Rationale of Group Decision-making. Journal of Political Economy, $56(1): 23-34$.

Blue Ribbon Task Force (1994). Final Report, Metropolitan Water District of Southern California.

Borenstein, S., Busse, M., and Kellogg, R. (2008). Principal-agent Incentives, Excess Caution, and Market Inefficiency: Evidence from Utility Regulation. NBER Working Paper 13679 .

Boronkay, C. (1990). Incremental Interruption and Conservation Plan. Letter from GM to Board of Directors, Metropolitan Water District of Southern California. 20 Nov.

Bowles, J. (2008). Colorado River farmers skip crops, send water to Southern California instead. Press-Enterprise, 30 Mar.

Boxall, B. (2007). Water-supply cuts would hit Ariz. first: Drought could trigger reductions in Colorado River deliveries, but California would be spared unless shortages worsen, US report says. Los Angeles Times, 1 Mar.

Brewer, M. F. (1964). Economics of Public Water Pricing: The California Case. In Smith, S. C. and Castle, E. N., editors, Economics and Public Policy in Water Resource Development, chapter 14, pages 222-247. Iowa State University Press, Ames.

Brick, T. (2003). The Metropolitan at 75: With Renewed Commitment to Cooperation, Water Stewardship, The Future Is Bright. Aqueduct, 4(1):23.

Brooks, D. C. (1964). Pricing and Marketing of Imported Water in Southern California. Metropolitan Water District of Southern California, Los Angeles.

Buchanan, J. M. (1965). An Economic Theory of Clubs. Economica, 32(125):1-14.

Bureau of Labor Statistics (2007). Los Angeles-Anaheim-Riverside-All Urban Consumers. Consumer Price Index Historical Data Series, US Department of Labor. http://www . dir.ca.gov/DLSR/CPI/CPIHistDataSeries.xls. 
Bureau of Reclamation (2004). Law of the River. http://www.usbr.gov/lc/region/ g1000/lawofrvr.html.

CA Dept. of Water Resources (1930). Report to the Legislature of 1931 on the State Water Plan. Bulletin no. 25, California Department of Public Works, Division of Water Resources.

CA Dept. of Water Resources (2007). Climate Change in California. Fact sheet, California Department of Water Resources. June.

CA Legislature (1879). State of California Constitution, Sacramento.

CA Legislature (1927). Metropolitan Water District Act. In General Laws, Amendments to Codes, Resolutions, Constitutional Amendments Passed at the Regular Session of the Forty-Seventh Legislature, chapter 429, pages 694-714. California State Printing Office, Sacramento. Approved by the Governor 10 May 1927. Enacted 29 Jul 1927.

CA State Association of Counties (2004). The Property Tax Roller Coaster: Explanations for Variations in County Property Tax Revenues. Technical report.

CA State Auditor (1996). Metropolitan Water District of Southern California: A Review of Evaluations and Audits Conducted by Other Entities. Report 1995-105, Bureau of State Audits, Sacramento.

CA State Auditor (2004). Metropolitan Water District of Southern California: Its Administrative Controls Need to Be Improved to Ensure an Appropriate Level of Checks and Balances over Public Resources. Report 2003-136, Bureau of State Audits, Sacramento.

Cadsby, C. B. and Maynes, E. (1998). Choosing Between a Socially Efficient and Free-Riding Equilibrium: Nurses versus Economics and Business Students. Journal of Economic Behavior \& Organization, 37(2):183-192.

Camerer, C. and Thaler, R. H. (1995). Anomalies: Ultimatums, Dictators and Manners. Journal of Economic Perspectives, 9(2):209-219.

Cardenas, J.-C. (2000). How Do Groups Solve Local Commons Dilemmas? Lessons from Experimental Economics in the Field. Environment, Development and Sustainability, $2: 303-322$.

Cardenas, J.-C. (2003). Real Wealth and Experimental Cooperation: Experiments in the Field Lab. Journal of Development Economics, 70:263-289.

Cardenas, J.-C. (2004). Bringing the Lab to the Field: More than Changing Subjects. Working Paper. www. aeaweb.org/annual_mtg_papers/2005/0107_0800_0304.pdf.

Carlin, J. B., Galati, J. C., and Royston, P. (2007). A New Framework for Managing and Analysing Multiply Imputed Data in STATA. Stata Journal, forthcoming.

Chakravorty, U., Hochman, E., Umetsu, C., and Zilberman, D. (2004). Privitizing Water Distribution. Emory Economics Working Paper 0403. 
Ciriacy-Wantrup, S. and Bishop, R. (1975). "Common Property" as a Concept in Natural Resources Policy. Natural Resources Journal, 15:713-727.

Colorado River Board of CA (1992). Report to the California Legislature on the Current Condition of the Salton Sea and the Potential Impacts of Water Transfers. Legislative report.

Commonwealth Club of CA (1931). Commonwealth Club of California on the State Water Plan. The Commonwealth-Part Two, 7(22):51-132.

Conaughton, G. (2006). Water project costs soar. North County Times, 1 Dec.

Cooper, D. J. (2006). Are Experienced Managers Experts at Overcoming Coordination Failure? Advances in Economic Analysis 8 Policy, 6(2).

Cooper, D. J., Kagel, J. H., Lo, W., and Gu, Q. L. (1999). Gaming against Managers in Incentive Systems: Experimental Results with Chinese Students and Chinese Managers. American Economic Review, 89(4):781-804.

Cummings, R. C., Holt, C. A., and Laury, S. (2004). Using Laboratory Experiments for Policy Making: An Example from the Georgia Irrigation Reduction Auction. Journal of Policy Analysis and Management, 23(2):341-363.

Cyert, R. M. and March, J. G. (1992/1963). A Behavioral Theory of the Firm. Blackwell Business, Cambridge, MA, second edition.

Czech, B. (2000). Shoveling Fuel for a Runaway Train. University of California Press, Berkeley, CA.

DeHaven, J. C. and Hirshleifer, J. (1957). Feather River Water for Southern California. Land Economics, 33(3):198-209.

Dietz, T., Ostrom, E., and Stern, P. C. (2003). The Struggle to Govern the Commons. Science, 302(5652):1907-1912.

DiSegni Eshel, D. (2002). The Microstructure of Water Markets: Bargaining vs. Auctioning Approaches. Selected Paper, Workshop on Water and Agriculture at Hebrew University, 8 Dec. http://departments.agri.huji.ac.il/economics/kenes-dafna.pdf.

Dixon, L., Dewar, J., Pint, E., Reichardt, R., and Edelman, E. (1998). Building a New Vision for the Metropolitan Water District of Southern California: Options for Key Policy Decisions. Draft DRU-1931-MWD, RAND, Santa Monica, CA.

Economist Staff (2001). A state of gloom. Economist, 18 Jan.

Economist Staff (2003). Frozen taps. Economist, 29 May.

Edelstein, R. and Kroll, C. (1997). California Real Estate Recovery Begins as Economy Expands. Fisher Center Research Reports 0397. 
Ely, M. (1995). Interview with former Executive Assistant to Secretary of Interior Ray Lyman Wilbur (1929-1933), conducted by Steve Erie. 9 Mar.

Erie, S. P. (2000). Mulholland's Gifts: Further Reflections upon Southern California Water Subsidies and Growth. California Western Law Review, 37(1):147-60.

Erie, S. P. (2006). Beyond Chinatown: The Metropolitan Water District, Growth, and the Environment in Southern California. Stanford University Press, Stanford, CA.

Erie, S. P. and Joassart-Marcelli, P. (2000). Unraveling Southern California's Water/Growth Nexus: Metropolitan Water District Policies and Subsidies for Suburban Development, 1928-1996. California Western Law Review, 36(2):267-290.

Falk, A. and Fehr, E. (2003). Why Labour Market Experiments? Labour Economics, 10(4):399-406.

Faulhaber, G. R. (1975). Cross-Subsidization: Pricing in Public Enterprises. American Economic Review, 65(5):966-77.

Fehr, E. and List, J. A. (2004). The Hidden Costs and Returns of Incentives: Trust and Trustworthiness Among CEOs. Journal of the European Economic Association, 2(5):743771.

Fehr, E. and Schmidt, K. M. (1999). A Theory of Fairness, Competition, and Cooperation. Quarterly Journal of Economics, 114(3):817-868.

Fehr, Ernst; Tyran, J.-R. (2005). Individual Irrationality and Aggregate Outcomes. Journal of Economic Perspectives, 19(4):43-66.

Fetbrandt, S. (2007a). Water museum funds run dry. Press-Enterprise, 3 Apr.

Fetbrandt, S. (2007b). State says grants to water district may have to be refunded. PressEnterprise, 27 Apr.

Fischbacher, U. (2007). z-Tree: Zurich Toolbox for Ready-made Economic Experiments. Experimental Economics, 10(2):171-178.

Fischbacher, U., Gachter, S., and Fehr, E. (2001). Are People Conditionally Cooperative? Evidence from a Public Goods Experiment. Economics Letters, 71(3):397-404.

Flaxman, B. E. (1976). The Price of Water: Who Pays and Who Benefits? A Policy Study of the Metropolitan Water District of Southern California. Masters Thesis, Claremont Graduate School (Public Policy Studies).

Folz, W. E. (1965). Political and Social Barriers to Western Water Development. In Engelbert, E. A., editor, Strategies for Western Regional Water Development: Proceedings of the Western Interstate Water Conference, pages 72-95. University of California Printing Department.

Frey, Bruno S.and Stutzer, A. (2005). Beyond Outcomes: Measuring Procedural Utility. Oxford Economic Papers, 57:90-111. 
Gächter, S., Herrmann, B., and Thonï, C. (2004). Trust, Voluntary Cooperation, and Socio-Economic Background: Survey and Experimental Evidence. Journal of Economic Behavior \& Organization, 55(4):505-531.

Gächter, S. and Riedl, A. (2002). Moral Property Rights in Bargaining. Institute for Empirical Research in Economics Working Paper 113.

Gächter, S. and Thöni, C. (2005). Social Learning and Voluntary Cooperation among Like-Minded People. Journal of the European Economic Association, 3:303-14.

Gardner, B. D. (2003). Weakening Water Rights and Efficient Transfers. Water Resources Development, 19:7-19.

Gardner, R., Moore, M. R., and Walker, J. M. (1997). Governing a Groundwater Commons: A Strategic and Laboratory Analysis of Western Water Law. Economic Inquiry, $35(2): 218-234$.

Garmaise, M. J. and Moskowitz, T. J. (1999). Confronting Information Asymmetries: Evidence from Real Estate Markets. Center for Research in Security Prices Working Paper 507.

Gleick, P. H. (1996). Basic Water Requirements for Human Activities: Meeting Basic Needs. Water International, 21:83-92.

Gleick, P. H., Wolff, G., Chalecki, E. L., and Reyes, R. (2002). The New Economy of Water: The Risks and Benefits of Globalization and Privatization of Fresh Water. Technical report, Pacific Institute for Studies in Development, Environment, and Security, Oakland, CA.

Glennon, R. (2005). Water Scarcity, Marketing, and Privatization. Texas Law Review, $83(7): 1873-1902$.

Gottlieb, R. and FitzSimmons, M. (1991). Thirst for Growth: Water Agencies as Hidden Government in California. University of Arizona Press, Tucson.

Graff, T. J. (1985). Public Information, Accountability and Myth Regarding the Long-Term Availability of Colorado River Water to the Metropolitan Water District of Southern California. Position paper, Environmental Defense Fund. 28 Jan.

Guala, F. (2003). Experimental Localism and External Validity. Philosophy of Science, 70:1195-1205.

Guan, D. and Hubacek, K. (2007). A New and Integrated Hydro-economic Accounting and Analytical Framework for Water Resources: A Case Study for North China. Journal of Environmental Management, forthcoming.

Gunnthorsdottir, A., McCabe, K., and Smith, V. (2002). Using the Machiavellianism Instrument to Predict Trustworthiness in a Bargaining Game. Journal of Economic Psychology, 23(1):49-66. 
Haan, M., Kooreman, P., and Riemersma, T. (2006). Friendship in a Public Good Experiment. Working Paper. http://www.eco.rug.nl/ haanma/drop.pdf.

Hailu, A. and Thoyer, S. (2006). Multi-unit Auction Format Design. Journal of Economic Interaction and Coordination, 1(2):129-146.

Hall, D. C. (2000). Public Choice and Water Rate Design. In Dinar, A., editor, The Political Economy of Water Pricing Reforms, chapter 9, pages 189-212. Oxford University Press, New York.

Hanak, E. (2003). Who Should Be Allowed to Sell Water in California? Third-Party Issues and the Water Market. Monograph, Public Policy Institute of California, San Francisco.

Hanemann, W. M. (2005). The Economic Conception of Water. In Rogers, P. P., Ramon Llamas, M., and Martinez Cortina, L., editors, Water Crisis: Myth or Reality?, pages 61-92. Taylor \& Francis, Oxford.

Hansmann, H. (1996). The Ownership of Enterprise. Belknap Press, Cambridge, MA.

Hansmann, H. B. (1980). The Role of Nonprofit Enterprise. Yale Law Journal, 89(5):835901.

Harris, R. W. (1990). Southern California's Water Resources: An Assessment of Supply and Demand with Projected Drought Effects. Masters Thesis, University of California, Los Angeles (Civil Engineering).

Harrison, G. W. and List, J. A. (2004). Field Experiments. Journal of Economic Literature, 42.

Hart, O. and Moore, J. (1996). The Governance of Exchanges: Members' Cooperatives versus Outside Ownership. Oxford Review of Economic Policy, 12(4):53-69.

Hart, O. and Moore, J. (1998). Cooperatives vs. Outside Ownership. NBER Working Paper 6421.

Henrich, J. et al. (2001). In Search of Homo Economicus: Behavioral Experiments in 15 Small-Scale Societies. American Economic Review, 91(2):73-78.

Herbst, P. and Prüfer, J. (2007). Firms, Nonprofits, and Cooperatives: A Theory of Organizational Choice. CentER Discussion Paper 2007-7.

Herdt, T. (2007). Changes in climate tied to water supply. Ventura County Star, 24 Aug.

Herrmann, B., Thoni, C., and Gachter, S. (2008). Antisocial Punishment Across Societies. Science, 319(5868):1362-1367.

Hildebrand, C. E. (1984). The Relationship between Urban Water Demand and the Price of Water. Consultant Report, Metropolitan Water District of Southern California, Los Angeles. 
Hirshleifer, J. and Milliman, J. W. (1967). Urban Water Supply: A Second Look. American Economic Review, 57(2):169-178.

Hodgson, S. (2003). Legislation on Water Users Organizations. Legislative Study, Food and Agriculture Organization of the United Nations, Rome.

Horowitz, J. K. and McConnell, K. E. (2002). A Review of WTA/WTP Studies. Journal of Environmental Economics and Management, 44(3):426-447.

Howitt, R. E. (1997). Water Market-Based Conflict Resolution. In Sanchez, R., Woled, J., and Tilly, D., editors, Proceedings of the First Biennial Rosenberg International Forum on Water Policy: Resolving Conflict in the Management of Water Resources, number 93 in Water Resources Center Report. University of California Centers for Water and Wildlife Resources.

Hundley Jr., N. (1992). The Great Thirst: Californians and Water, 1770s-1990s. University of California Press, Berkeley.

IID et al. (2003). Quantification Settlement Agreement, Imperial Irrigation District, Metropolitan Water District of Southern California and Coachella Valley Water District. Master contract for 21 legal agreements.

Kagel, J. H. and Levin, D. (2001). Behavior in Multi-Unit Demand Auctions: Experiments with Uniform Price and Dynamic Vickrey Auctions. Econometrica, 69(2):413-454.

Kagel, J. H. and Roth, A. E. (1995). The Handbook of Experimental Economics. Princeton University Press, Princeton, NJ.

Kahneman, D., Knetsch, J. L., and Thaler, R. H. (1990). Experimental Tests of the Endowment Effect and the Coase Theorem. Journal of Political Economy, 98(6):1325-48.

Kahrl, W. L. (1979). The California Water Atlas. State of California, Sacramento.

Kindahl, J. K. (1983). Tax Limits and Property Values. Land Economics, 59(3):315-323.

Klemperer, P. (2002). What Really Matters in Auction Design. Journal of Economic Perspectives, 16(1):169-189.

Kovalchika, S., Camerer, C. F., Gretherb, D. M., Plott, C. R., and Allmanc, J. M. (2005). Aging and Decision Making: A Comparison between Neurologically Healthy Elderly and Young Individuals. Journal of Economic Behavior \&3 Organization, 58(1):79-94.

Kroll, S., Cherry, T. L., and Shogren, J. F. (2007). Voting, Punishment, and Public Goods. Economic Inquiry, 45(3):557-570.

Kurzban, R. and Houser, D. (2005). An Experimental Investigation of Cooperative Types in Human Groups: A Complement to Evolutionary Theory and Simulations. Proceedings of the National Academy of Sciences, 102(5):1803-1807. 
Kurzban, R., McCabe, K., Smith, V., and Wilson, B. (2001). Incremental Commitment and Reciprocity in a Real Time Public Goods Game. Personality and Social Psychology Bulletin, 27:1662-1673.

Kwoka, Jr., J. E. (2005). The Comparative Advantage of Public Ownership: Experience from US Electric Utilities. Canadian Journal of Economics, 38(2):622-40.

Lach, D., Rayner, S., and Ingram, H. (2005a). Maintaining the Status Quo: How Institutional Norms and Practices Create Conservative Water Organizations. Texas Law Review, 83(7):2027-2053.

Lach, D., Rayner, S., and Ingram, H. (2005b). Taming the Waters: Strategies to Domesticate the Wicked Problems of Water Resource Management. International Journal of Water, 3(1):1-17.

LADWP (2006). LADWP, State sign agreement allowing water transfers from California Aqueduct to Los Angeles Aqueduct. Press Release, Los Angeles Department of Water and Power. 9 Jun.

LADWP (n.d.). Ezra Scattergood. http://www . ladwp.com/ladwp/cms/ladwp001011.jsp.

Lait, M. (2007). MWD approves bailout of troubled water museum. Los Angeles Times, 14 Feb.

Ledyard, J. O. (1995). Public Goods: A Survey of Experimental Research. In Kagel, J. H. and Roth, A. E., editors, Handbook of Experimental Economics. Princeton University Press, Princeton, NJ.

Levitt, S. D. and List, J. A. (2007). What Do Laboratory Experiments Measuring Social Preferences Reveal about the Real World? Journal of Economic Perspectives, 21(2):153174.

Levitt, S. D., List, J. A., and Reiley, D. H. (2007). What Happens in the Field Stays in the Field: Professionals Do Not Play Minimax in Laboratory Experiments. Working Paper. http://www.u.arizona.edu/ dreiley/papers/ProfessionalsMinimax.pdf.

Libecap, G. D. (2004). Transaction Costs: Valuation Disputes, Bi-Lateral Monopoly Bargaining and Third-Party Effects in Water Rights Exchanges. The Owens Valley Transfer to Los Angeles. NBER Working Paper 10801.

Machiavelli, N. (1998/1532). The Prince. University of Chicago Press, Chicago, IL.

Mansur, E. T. and Olmstead, S. M. (2007). The Value of Scarce Water: Measuring the Inefficiency of Municipal Regulations. Working Paper. http://www.som.yale.edu/faculty/ etm7/papers/mansur_olmstead_water.pdf.

McCann, R. J. and Zilberman, D. (2000). Governance Rules and Management Decisions in California's Agricultural Water Districts. In Dinar, A., editor, The Political Economy of Water Pricing Reforms, chapter 4, pages 79-104. Oxford University Press, New York. 
McCubbins, M. D., Noll, R. G., and Weingast, B. R. (1989). Structure and Process, Politics and Policy: Administrative Arrangements and the Political Control of Agencies. Virginia Law Review, 75(2, Symposium on the Law and Economics of Bargaining):431-482.

McDermott, R. (2002). Experimental Methods in Political Science. Annual Review of Political Science, 5(1):31-61.

McDermott, T. (1998). Knee-Deep disputes for "water buffaloes;" the power of the Metropolitan Water District long went unquestioned. Now it is mired in inertia, ineptitude. Los Angeles Times, 1 Nov.

McFadden, D. (1975). The Revealed Preferences of a Government Bureaucracy: Theory. Bell Journal of Economics, 6(2):401-416.

Meade, R. (2005). Ownership vs. Regulation in Electricity Reform: The Role of Governance. SSRN Working Paper 807144.

Mehlum, H. and Moene, K. (2002). Battlefields and Marketplaces. Defence and Peace Economics, 13(6):485-496.

Mestelman, S. and Feeny, D. (1988). Does Ideology Matter?: Anecdotal Experimental Evidence on the Voluntary Provision of Public Goods. Public Choice, 57:281-286.

MET (1939). History and First Annual Report, Metropolitan Water District of Southern California, Los Angeles.

MET (1990). Water Conservation Pricing Approaches of the Metropolitan Water District. Staff Report, Metropolitan Water District of Southern California, Los Angeles.

MET (1992). Annexation Charge Study, Right of Way \& Land Division, Metropolitan Water District of Southern California, Los Angeles.

MET (1997a). January 14 Regular Meeting of the Board of Directors. Minutes, Metropolitan Water District of Southern California, Los Angeles.

MET (1997b). Resolution to Adopt Wheeling Rates Effective January 15, 1997. Board of Directors Resolution, Metropolitan Water District of Southern California, Los Angeles. Approved 14 Jan 1997.

MET (2001). Annexation Policy and Procedure. Briefing, Subcommittee on Rules and Ethics, Metropolitan Water District of Southern California, Los Angeles.

MET (2003). Purchase Order for Imported Water Supply to Be Provided by the Metropolitan Water District of Southern California. Legal contract, Metropolitan Water District of Southern California, Los Angeles. Effective 1 Jan 2003.

MET (2004a). Comprehensive Annual Financial Report, Metropolitan Water District of Southern California, Los Angeles.

MET (2004b). 2004-5 Long Range Finance Plan, Metropolitan Water District of Southern California, Los Angeles. 
MET (2004c). Integrated Water Resources Plan-2003 Update, Metropolitan Water District of Southern California, Los Angeles. Approved Jul 2004.

MET (2005). Metropolitan to begin negotiations with developer for Diamond Valley Lake recreation improvements. Press Release, Metropolitan Water District of Southern California, Los Angeles. 8 Nov.

MET (2006). Diamond Valley Lake at a Glance. Fact Sheet, Metropolitan Water District of Southern California, Los Angeles.

MET (2007a). Expanded Central Valley Groundwater Banking Program Offers Southern California Additional Drought Insurance. Press Release, Metropolitan Water District of Southern California, Los Angeles. 8 May.

MET (2007b). Water Rates and Charges. Metropolitan Water District of Southern California. http://www.mwdh2o.com/mwdh2o/pages/finance/finance_03.html.

MET-RAND (1998). MWD Strategic Visioning Project, Metropolitan Water District of Southern California. Presented to the MWD Board of Directors Dec 8.

Milliman, J. W. (1956a). The History, Organization and Economic Problems of the Metropolitan Water District of Southern California. PhD Dissertation, University of California, Los Angeles (Economics).

Milliman, J. W. (1956b). Commonality, the Price System, and Use of Water Supplies. Southern Economic Journal, 22(4):426-437.

Milliman, J. W. (1957). Economic Problems of the Metropolitan Water District of Southern California. Proceedings of the 32nd Annual Conference of the Western Economic Association, pages 42-45.

Moe, T. M. (1984). The New Economics of Organization. American Journal of Political Science, 28(4):739-777.

Murphy, J., Dinar, A., Howitt, R., Mastrangelo, E., Rassenti, S. J., and Smith, V. L. (2003). Mechanisms for Addressing Third Party Impacts Resulting from Voluntary Water Transfers. SSRN Working Paper 437600.

Murphy, J. J., Dinar, A., Howitt, R. E., Rassenti, S. J., and Smith, V. L. (2000). The Design of "Smart" Water Market Institutions Using Laboratory Experiments. Environmental and Resource Economics, 17(4):375-394.

Newlin, B. D., Jenkins, M. W., Lund, J. R., and Howitt, R. E. (2002). Southern California Water Markets: Potential and Limitations. Journal of Water Resources Planning and Management, 128(1):21-32.

O'Connor, D. E. (1998a). Governance of the Metropolitan Water District of Southern California: An Overview of the Issues. Legislative Analysis CRB-98-013, California State Library. 
O'Connor, D. E. (1998b). Governance of the Metropolitan Water District of Southern California: Options for Change. Legislative Analysis CRB-98-018, California State Library.

Oliver, P. E., Marwell, G., and Teixeira, R. (1985). A Theory of the Critical Mass I: Interdependence, Group Heterogeneity, and the Production of Collective Action. American Journal of Sociology, 91(3):522-556.

Olson, M. (1971). The Logic of Collective Action. Harvard University Press, Cambridge, MA.

Oshio, K. (1992). Urban Water Diplomacy: A Policy History of the Metropolitan Water Supply in the Twentieth Century Southern California. PhD Dissertation, University of California, Santa Barbara (History). Page numbers from Technical Completion Report UCAL-WRC-W-762.

Ostrom, E., Gardner, R., and Walker, J. (1994). Rules, Games, and Common-Pool Resources. Ann Arbor Books, Ann Arbor, MI.

Ostrom, V. (1953). Water Supply, volume VIII of Metropolitan Los Angeles: a Study in Integration. Haynes Foundation, Los Angeles.

Pace, P. (2003). Met's Philosophy: Installation Speech. Aqueduct, 75th anniversary special issue:13-17.

Palacios-Huerta, I. and Volij, O. (2008). Experientia Docet: Professionals Play Minimax in Laboratory Experiments. Econometrica, 76(1):71-115.

Parsons, W. W. (1990). The Politics of Water in the Southwest: Policy Patterns of Water Elites in Southern California and Arizona. PhD Dissertation, University of Arizona (Political Science).

Peters, H. E., Unur, A. S., Clark, J., and Schulze, W. D. (2004). Free-Riding and the Provision of Public Goods in the Family: A Laboratory Experiment. International Economic Review, 45(1):283-299.

Philip, T. (2003). The water barons. Sacramento Bee. Editorials published between 26 Jan and 23 Nov.

Plott, C. R. (1982). Industrial Organization Theory and Experimental Economics. Journal of Economic Literature, 20(4):1485-1527.

Polanyi, K. (2001/1944). The Great Transformation: The Political and Economic Origins of Our Time. Beacon Press, Boston.

Porter, D. and Vragov, R. (2006). An Experimental Examination of Demand Reduction in Multi-Unit Versions of the Uniform-Price, Vickrey, and English Auctions. Managerial and Decision Economics, 27(6):445-458.

Poterba, J. M., Weil, D. N., and Shiller, R. (1991). House Price Dynamics: The Role of Tax Policy and Demography. Brookings Papers on Economic Activity, (2):143-203. 
PriceWaterhouseCoopers (1998). Situational Analysis of the Metropolitan Water District of Southern California, Metropolitan Water District of Southern California. Presented to the MWD Board of Directors 17 Sep.

Public Policy Institute of California (2006). Water Supply and Quality. Fact Sheet.

Quinn, T. H. (1983). Groundwater Management in California: An Economist's View of the Political Pickle. In Proceedings of the 14th Biennial Conference on Groundwater, Davis, California. California Water Resources Center.

Quinn, T. H. (2006a). Personal Communication. 28 Apr.

Quinn, T. H. (2006b). Personal Communication. 14 May.

Quinn, T. H. (2006c). Personal Communication. 7 June.

Rake, L. (2006). LV's growth will stop in 2013 without White Pine water, Mulroy says. Las Vegas Sun, 16 Aug.

Rassenti, S., Smith, V., and Bulfin, R. (1982). A Combinatorial Auction Mechanism for Airport Time Slot Allocation. Bell Journal of Economics, 13(2):402-417.

Reisner, M. (1993). Cadillac Desert. Penguin Books, New York.

Rosen, M. D. and Sexton, R. J. (1993). Irrigation Districts and Water Markets: An Application of Cooperative Decision-Making Theory. Land Economics, 69(1):39-53.

Rossman, A. (2005). Can California Make Peace with Its Neighbors and Itself? Working Paper. http://tinyurl.com/2xh7uj.

Roth, A. E. and Ockenfels, A. (2002). Last-Minute Bidding and the Rules for Ending Second-Price Auctions: Evidence from eBay and Amazon Auctions on the Internet. American Economic Review, 92(4):1093-1103.

Royston, P. (2007). Multiple Imputation of Missing Values: Further Update of ICE, with an Emphasis on Interval Censoring. Stata Journal, forthcoming.

Saltzgaver, H. (2008). Water allocations leave city thirsty. Gazette Newspapers, 24 Jan.

Schelling, T. C. (1960). The Strategy of Conflict. Harvard University Press, Cambridge, MA.

Schlenker, W., Hanemann, W., and Fisher, A. (2007). Water Availability, Degree Days, and the Potential Impact of Climate Change on Irrigated Agriculture in California. Climatic Change, 81(1):19-38.

Schoch, D. (2008a). Southeast L.A. County water agency sues over MWD drought plan. Los Angeles Times, 18 Apr.

Schoch, D. (2008b). Water board approves drought plan. Los Angeles Times, 13 Feb. 
Schwarz, G. (1978). Estimating the Dimension of a Model. Annals of Statistics, 6(2):461464.

Scott, J. C. (1998). Seeing like a State: How Certain Schemes to Improve the Human Condition Have Failed. Yale University press, New Haven, CT.

SDCWA (2001). SDCWA vs. MWD, BoD of MWD, Los Angeles, and Does 1-100. Complaint for Declaratory Relief, Superior Court of the State of California for the County of San Diego. Case GIC 761526. 30 Jan.

SDCWA (2002). Regional Water Facilities Master Plan: Chapter 4-Water Supply Analysis. Engineering Department Draft Report, San Diego County Water Authority.

SDCWA (2004). Key Milestones in the Water Authority's History. http://www.sdcwa. org/news/pdf/WaterAuthorityTimeline.pdf.

SDCWA (2006a). Drought Management Plan Report. Draft, San Diego County Water Authority. 23 Mar.

SDCWA (2006b). How Much Does the Water Cost? FAQ, San Diego County Water Authority. http://www.sdcwa.org/news/revenue.phtml.

Sexton, R. J. (1986). The Formation of Cooperatives: A Game-Theoretic Approach with Implications for Cooperative Finance, Decision Making, and Stability. American Journal of Agricultural Economics, 68(2):214-225.

Shleifer, A. (1985). A Theory of Yardstick Competition. Rand Journal of Economics, $16(3): 319-327$.

Shleifer, A. (1998). State versus Private Ownership. Journal of Economic Perspectives, $12(4): 133-150$.

Skaperdas, S. (2003). Restraining the Genuine Homo Economicus: Why the Economy Cannot Be Divorced from Its Governance. Economics and Politics, 15(2):135-162.

Smith, A. (1909/1776). An Inquiry into the Nature and Causes of the Wealth of Nations. P. F. Collier \& Son, New York.

Smith, T. R. (1970). Land value versus real property taxation: A case study comparison. Land Economics, 46(3):305-313.

Smith, V. L. (1976). Experimental Economics: Induced Value Theory. American Economic Review, 66(2):274-79.

Sofaer, A. D. (1997). California and Colorado River Water: Seize the Opportunity. In Sanchez, R., Woled, J., and Tilly, D., editors, Proceedings of the First Biennial Rosenberg International Forum on Water Policy: Resolving Conflict in the Management of Water Resources, number 93 in Water Resources Center Report. University of California Centers for Water and Wildlife Resources. 
Staatz, J. M. (1983). The Cooperative as a Coalition: A Game-Theoretic Approach. American Journal of Agricultural Economics, 65(5):1084-1089.

State Water Resources Control Board (1984). In The Matter of Alleged Waste and Unreasonable Use of Water by Imperial Irrigation District. Decision 1600: Regarding Misuse of Water by Imperial Irrigation District.

Tagliabue, J. (2002). As multinationals run the taps, anger rises over water for profit. New York Times, 22 Aug.

Tarlock, A. D. and van de Wetering, S. B. (2008). Growth Management and Western Water Law: From Oases to Archipelagos. Hastings West-Northwest Journal of Environmental Law and Policy, Winter:983.

Thomas, B. G. (2006a). Personal Communication. 22 May.

Thomas, B. G. (2006b). Personal Communication. 5 Dec.

Thomas, B. G. (2007a). Personal Communication. 4 Sep.

Thomas, B. G. (2007b). Personal Communication. 21 Nov.

Thompson, J. G., Parker, M., Templin, W., and Reynolds Jr, R. R. (1993). A Review of Application Issues of the Metropolitan Water District-MAIN Water Forecasting System. Water Resources Bulletin, 29(3):425-433.

Timmins, C. (2002). Measuring the Dynamic Efficiency Costs of Regulators' Preferences: Municipal Water Utilities in the Arid West. Econometrica, 70(2):603-629.

Tisdell, J. and Ward, J. (2001). An Experimental Evaluation of Water Markets in Australia. Presented at the 8th International Water and Resource Economics Consortium.

Tooby, J. and Cosmides, L. (1992). The Psychological Foundations of Culture. In The Adopted Mind: Evolutionary Psychology and the Generation of Culture. Oxford University Press, Oxford.

Union of Concerned Scientists (2006). Global Warming and California's Water Supply. Fact Sheet. http://www.ucsusa.org/assets/documents/global_warming/ucs-ca-water. pdf.

USWNO Staff (1998). San Diego Water Authority approves seeking Metropolitan Water District litigation cost-recovery legislation. US Water News Online, March. http://www . uswaternews. com/archives/arcrights/8sandie3.html.

Veeman, T., Veeman, M., Adamowicz, W., Royer, S., Viney, B., Freeman, R., and Baggs, J. (1997). Conserving Water in Irrigated Agriculture: The Economics and Valuation of Water Rights. Rural Economy Project Report 97-01, University of Alberta Faculty of Agriculture, Forestry and Home Economics, Edmonton.

Vickrey, W. (1961). Counterspeculation, Auctions, and Competitive Sealed Tenders. Journal of Finance, 16:8-37. 
Vining, A. R. and Boardman, A. E. (1992). Ownership Versus Competition: Efficiency in Public Enterprise. Public Choice, 73:205-239.

Wahl, R. W. and Davis, R. K. (1986). Satisfying Southern California's Thirst for Water: Efficient Alternatives, Scarce Water and Institutional Change. Resources for the Future, Washington, DC.

Wallsten, S. J. and Kosec, K. (2005). Public or Private Drinking Water? The Effects of Ownership and Benchmark Competition on US Water System Regulatory Compliance and Household Water Expenditures. AEI-Brookings Joint Center Working Paper 05-05.

Ward, J. R., Tisdell, J. G., Straton, A., and Capon, T. (2006). An Empirical Comparison of Behavioural Responses from Field and Laboratory Trials to Institutions to Manage Water as a Common-Pool Resource. Working Paper. http://www.iascp.org/bali/papers/ Ward_John_Empirical.pdf.

Wayman, J. C. (2003). Multiple Imputation for Missing Data: What Is It and How Can I Use It?

Weiser, M. (2007). Delta water exports halved. Sacramento Bee, 29 Dec.

Weiser, M. and Ellis, J. (2007). Smelt ruling could spell scarcer and pricier water. Sacramento Bee, 15 Dec.

Wilson, J. Q. (1989). Bureaucracy: What Government Agencies Do and Why They Do It. Basic Books, New York.

Young, M. B. (1998). Draft Paper on Events Leading up to and Chronology of the 1990-92 Drought Years and Supply Reliability Improvements Achieved as a Result of the Drought. Memo to member agency managers, Metropolitan Water District of Southern California. 25 Aug.

Zelmer, J. (2003). Linear Public Goods Experiments: A Meta-Analysis. Experimental Economics, 6(3):299-310.

Zetland, D. (2008). Focal Points in Public Goods Games: Explicit Information Increases Reciprocation. SSRN Working Paper 1122144. 


\section{Author and Subject Indices}

Akaike (1974), 88

Alatas et al. (2006), 69

Alchian and Demsetz (1972), 63

Allison (1969), 65

Arrow (1963), 66

Atwater and Blomquist (2002), 14, 21, 43, 47

Ausubel (2004), 97, 101

Axelrod (1984), 67

Bardhan and Singh (2004), 57

Barnett and Pierce (2008), 7

Baumol and Bradford (1970), 59

Beeson et al. (2001), 84

Benz (2004), 96, 109

Bergstrom and Stark (1993), 67

Berkman and David (2000), 34, 57

Bertrand and Mullainathan (2003), 63

Bjornlund and O'Callaghan (2005), 62, 85

Black (1948), 66

Borenstein et al. (2008), 63

Boronkay (1990), 44

Bowles (2008), 37

Boxall (2007), 7

Brewer (1964), 61, 62

Brick (2003), 35

Brooks (1964), 61

Buchanan (1965), 25, 54, 55

Cadsby and Maynes (1998), 68

Camerer and Thaler (1995), 72

Cardenas (2000), 69

Cardenas (2003), 56

Cardenas (2004), 69

Carlin et al. (2007), 88

Chakravorty et al. (2004), 3

Ciriacy-Wantrup and Bishop (1975), 2, 55

Conaughton (2006), 45

Cooper et al. (1999), 68
Cooper (2006), 103

Cummings et al. (2004), 97, 101, 107, 132

Cyert and March (1963), 63

Czech (2000), 3

DeHaven and Hirshleifer (1957), 4

DiSegni Eshel (2002), 97

Dietz et al. (2003), 2

Dixon et al. (1998), 47, 62, 63

Edelstein and Kroll (1997), 86

Ely (1995), 27

Erie and Joassart-Marcelli (2000), 34

Erie (2000), 6, 57

Erie (2006), 22, 23, 31, 32, 35, 38, 45, 49, 81

Falk and Fehr (2003), 67

Faulhaber (1975), 62

Fehr and List (2004), 68

Fehr and Schmidt (1999), 81

Fehr (2005), 65

Fetbrandt (2007a), 63

Fetbrandt (2007b), 63

Fischbacher et al. (2001), 78

Fischbacher (2007), 70

Flaxman (1976), 16, 22, 42, 43

Folz (1965), 3, 96

Frey (2005), 109

Gächter and Riedl (2002), 22

Gächter and Thöni (2005), 51, 52

Gächter et al. (2004), 68

Gardner et al. (1997), 109

Gardner (2003), 97

Garmaise and Moskowitz (1999), 86

Gleick et al. (2002), 3

Gleick (1996), 97

Glennon (2005), 97, 99

Gottlieb and FitzSimmons (1991), 3, 35

Graff (1985), 3

Guala (2003), 67 
Guan and Hubacek (2007), 85

Gunnthorsdottir et al. (2002), 74

Haan et al. (2006), 69

Hailu and Thoyer (2006), 96, 97

Hall (2000), 99

Hanak (2003), 97

Hanemann (2005), 13, 84, 95

Hansmann (1980), 63

Hansmann (1996), 56

Harrison and List (2004), 66, 68, 103

Harris (1990), 21, 48

Hart and Moore (1996), i, 49, 52, 53, 63,

111

Hart and Moore (1998), 52

Henrich et al. (2001), 69, 96

Herbst and Prüfer (2007), 52

Herdt (2007), 7

Herrmann et al. (2008), 69

Hildebrand (1984), 20

Hirshleifer and Milliman (1967), 3

Hodgson (2003), 56

Horowitz and McConnell (2002), 104

Howitt (1997), 96

Hundley Jr. (1992), 27, 35, 38, 45, 80

Kagel and Levin (2001), 96, 107

Kagel and Roth (1995), 107

Kahneman et al. (1990), 104

Kahrl (1979), 30

Kindahl (1983), 86

Klemperer (2002), 96

Kovalchika et al. (2005), 68

Kroll et al. (2007), 81

Kurzban and Houser (2005), 70, 132

Kurzban et al. (2001), 81

Kwoka (2005), 3

Lach et al. (2005a), 47, 55, 63, 99, 104

Lach et al. (2005b), 63

Lait (2007), 63

Ledyard (1995), 67

Levitt and List (2007), 67

Levitt et al. (2007), 69

Libecap (2004), 26

Machiavelli (1532), xv

Mansur and Olmstead (2007), 21, 96

McCann and Zilberman (2000), 58
McCubbins et al. (1989), 13

McDermott (1998), 38, 40-42, 80

McDermott (2002), 67, 68

McFadden (1975), 65

Meade (2005), 52

Mehlum and Moene (2002), 58

Mestelman and Feeny (1988), 68

Milliman (1956a), 14, 17, 26-32, 34-36, 41, $42,61,81,96,129$

Milliman (1956b), 45

Milliman (1957), 29-31, 36, 38, 45, 129

Moe (1984), 47

Murphy et al. (2000), 96

Murphy et al. (2003), 97

Newlin et al. (2002), 47

O'Connor (1998a), 13, 31, 47, 81

O'Connor (1998b), 13, 43, 47, 80, 81

Oliver et al. (1985), 35

Olson (1971), 13, 51

Oshio (1992), 17, 31, 32, 39, 61

Ostrom et al. (1994), 2, 41, 42, 81

Ostrom (1953), 26, 27, 30-32, 34-36, 42, 45, 54

Pace (2003), 11

Palacios-Huerta and Volij (2008), 69

Parsons (1990), 27, 35

Peters et al. (2004), 69

Philip (2003), 13

Plott (1982), 68, 72, 101, 103

Polanyi (1944), 2

Porter and Vragov (2006), 96, 107

Poterba et al. (1991), 85

Quinn (1983), 48

Quinn (2006a), 62

Quinn (2006b), 19

Quinn (2006c), 4, 6, 39

Rake (2006), 3

Rassenti et al. (1982), 97

Reisner (1993), 26

Rosen and Sexton (1993), 58

Rossman (2005), 36, 38, 40

Roth and Ockenfels (2002), 107

Royston (2007), 88

Saltzgaver (2008), 60

Schelling (1960), 65 
Schlenker et al. (2007), 84, 85, 89

Schoch (2008a), 113

Schoch (2008b), 7

Schwarz (1978), 88

Scott (1998), 95

Sexton (1986), 61

Shleifer (1985), 100

Shleifer (1998), 3

Skaperdas (2003), 35

Smith (1970), 86

Smith (1976), 68, 103

Sofaer (1997), 4, 61

Staatz (1983), 61

Tagliabue (2002), 1

Tarlock and van de Wetering (2008), 62, 84

Thomas (2006a), 20, 97

Thomas (2006b), 59

Thomas (2007a), 4

Thomas (2007b), 15, 129

Thompson et al. (1993), 18

Timmins (2002), 63

Tisdell and Ward (2001), 103

Tooby and Cosmides (1992), 67

Veeman et al. (1997), 83

Vickrey (1961), 97

Vining and Boardman (1992), 3

Wahl and Davis (1986), 39, 47

Wallsten and Kosec (2005), 3

Ward et al. (2006), 103

Wayman (2003), 88

Weiser and Ellis (2007), 7

Weiser (2007), 38

Wilson (1989), 3, 42

Young (1998), 44, 45

Zelmer (2003), 69

Zetland (2008), 70

\section{Corporate Authors}

Blue Ribbon Task Force (1994), 22, 47, 63, 81

Bureau of Labor Statistics (2007), 131

Bureau of Reclamation (2004), 36

CA Dept. of Water Resources (1930), 36

CA Dept. of Water Resources (2007), 7

CA Legislature (1927), 27
CA State Association of Counties (2004), 86

CA State Auditor (1996), 13

CA State Auditor (2004), 13

Colorado River Board of CA (1992), 4

Commonwealth Club of CA (1931), 36

Economist Staff (2001), 99

Economist Staff (2003), 3

IID et al. (2003), 6

LADWP (2006), 14

LADWP (nd), 26, 27

MET-RAND (1998), 43

MET (1939), 13

MET (1990), 21, 39

MET (1992), 30, 40

MET (1997a), 5

MET (1997b), 5, 6

MET (2001), 40

MET (2003), 23

MET (2004a), 5, 16, 18, 20, 30, 37, 43, 129

MET (2004b), 13, 63

MET (2004c), 37, 38, 129

MET (2005), 14

$\operatorname{MET}(2006), 14$

MET (2007a), 14

MET (2007b), 17

PriceWaterhouseCoopers (1998), 47, 81

Public Policy Institute of California (2006), 47

SDCWA (2001), 43, 45, 58

SDCWA (2002), 22, 37, 38, 43

SDCWA (2004), 32, 45

SDCWA (2006a), 21, 41, 63

SDCWA (2006b), 17, 20

State Water Resources Control Board (1984), 4

USWNO Staff (1998), 6, 63

Union of Concerned Scientists (2006), 7 


\section{Subject Index}

abundance, 50, 53-55, 103

conveyance, 96

end, 43

growth, 26, 31, 54

assessed value

annexation charge, 30

LA share, 35, 54, 58

market value, $85-86$

MET revenue, 29, 34, 80

post-drought, 89

regression, $84,88,91$

votes, $13,34,40,43,85$

auction, 96-100

at MET, 48, 95, 97

efficiency, 97, 101-107

equity, 97

experiment, see experiments

rebates, 99

average cost, 4

auction prices, 98

control, 62-64

pricing, 5, 8, 20, 30, 60

subsidies, 3, 35, 42, 61, 84

BCP, see Boulder Canyon Project

Boulder Canyon Project, 26-28

Hoover Dam, see Hoover Dam

Boulder Dam, see Hoover Dam

Bureau of Reclamation, 47

California Legislature

MET Act, 3, 11, 27

monitoring MET, 13, 32

wheeling settlement, 6

Center for Water Education, 63

club good, 2, 6, 55

collective action, 11

free-riding, 47, 51

SDCWA defects, 45

Colorado River

drought, 7

water rights, 26-32, 36, 47

Colorado River Aqueduct, 4, 36-37

bond issue, 28, 54 capacity, 30

costs, 15, 61, 85

expansion tool, 31,55

proposed, 27

water source, 14, 43

wheeling, see wheeling

Colorado River Compact, 36

common-pool good, 2

conflict, 53

costs, 41-45, 58, 80

emergence, 49, 58

future, 7

inefficiency, 56

lawsuits, see lawsuits

reducing, 63, 96, 109

consumer

choice, see MET

cooperative, $3,11,51$

willingness to pay, 59, 99

conveyance

auction, 96-97

necessity, 4, 96

postage stamp pricing, 60

pricing, 4, 17, 20, 23, 59

wheeling, see wheeling

cooperation, 50

absolute, 74, 75, 79

contributing factors, $42,56,69,81,96$

efficiency, 53-54, 67

MET, 49, 65, 80

public goods game, see experiments

relative or absolute, 66

cooperative, see cooperators, MET

efficiency, 49, 52, 53

game, 51

heterogeneity, 49, $5 \mathbf{5}$

outcome, 52

profits, 5

cooperators, 51,66

MET, 76, 79

preferences, see preferences

core, 7,54

cost, see average, fixed and marginal cost

CRA, see Colorado River Aqueduct

culture 
engineers, 30, 41, 109

lawyers, $\mathbf{4 1}, 48$

customer

collective action, 47

demand, 44

dependency, 55

pricing, 99-100

principal-agent, 49, 63

demand

elasticity, 59

estimation, 18, 62

excess, 2, 96

growth, 7,55

hardening, 3, 61

inaccurate projections, 29

induced, 100

management, 8, 17, 20, 37-39, 43, 99, 100

price, see price

SDCWA, 31

dependency, 55

regression, 89, 93

reliability, 53

SDCWA, 45

desalination, see supply

Diamond Valley Lake, 14

drought

1987-91, 43

agriculture, 38

allocation efficiency, 86-91

Incremental Interruption and Conservation Plan, 43

LADWP purchases, 45, 80

policies, 48

SDCWA reaction, $4, \mathbf{4 5}$

1977, 39

demand reduction, 43

global warming, 7

no allocation plan, 21

policies, 7, 21-23, 60, 96

efficiency, 49, $\mathbf{5 9}$

abundance, 50, $\mathbf{5 5}$

auction experiments, 101, 104-109

auctions, 97 caveats, 50

collective action, 47

cooperation, 49-50, 54

cooperative, 52

cooperative outcome, 52

equity, 95, 96

markets, 95

MET, 56

allocation, 59

conflict, 57

monopoly, 47

public goods game, $\mathbf{6 7}, 72-81$

water allocation, $\mathbf{5 9}, 83,89$

elasticity, 20, 21

agricultural, 30

Ramsey pricing, 59

electricity

deregulation, 47

utilities, 3

value to $\mathrm{LA}, 26,34,54$

equity

efficiency, 95, 96

per capita rebates, 100

third-party impacts, 97

Tier prices, 60

water, 2

water managers, 21

excludable good, 2

expansion, see growth

experiments, 66

auction, 100, 125

efficiency, 101, 107

sniping, 107

context, 103

cooperation, see public goods game

field, 66, 103

public goods game, 51, 67, 65-71

efficiency, 67, 72-74

types, $71,76,80$

validity

external, 67, 104

internal, 67

fixed cost, see average cost

auctions, 99 
bond debt, 29

control, 62

efficient, 20, 59-61

preferential rights, 43, 100

subsidies, 22, 55

good, see club, common pool, private and public goods

groundwater, see supply

growth

policy, 31, 32, 35

heterogeneity, 52

cooperative members, see cooperative member agency, see MET

homogeneity, see heterogeneity

Hoover Dam, 14, 26-28

benefits, 34

IID, see Imperial Irrigation District

Imperial Dam, 26

Imperial Irrigation District, 26, 58

MET, 26

sell water to MET, 37

sell water to SDCWA, 45, 87

water rights, 36,47

wheeling, see wheeling

incentives, $7,52,79$

costs, 62

experiments, 67, 96, 101, 107

perverse, 61, 100

postage stamp pricing, 64

principal-agent, 47, 63

Incremental Interruption and Conservation Plan, 43

inefficiency, see efficiency

institutions, see cooperative, MET

efficient, 2, 8, 50, 55, 79, 96, 109

evolution, 48, 55, 59, 80

Jensen, Joseph, 32

expansionist, 32, 49, 53

reign, $34,40,58$

Kightlinger, Jeffrey

election, 40, 58
LAA, see Los Angeles Aqueduct

LADWP

conservation, 39

history, 26

Hoover power, 28

LAA, see Los Angeles Aqueduct

preferential rights, 21, 100

pro-growth, 32

subsidies, 34-35, 53

votes, $40,54,58$

Laguna Declaration, 32, 36

lawsuit, 45

land, 83

agricultural, 32, 62, 83-85

assessed value, see assessed value

fallowing, 37

urban, 84

use, 87

lawsuits

Arizona vs. California, 36

Planning and Conservation League vs. DWR, 38

postage stamp pricing, 6

preferential rights, 45

Quantification Settlement Agreement, 6

wheeling, 45

Lerner Index, 6

location, see postage stamp pricing

Los Angeles Aqueduct, 26, 28, 35, 85

bargaining chip, 14, 26, 35, 45, 57

electricity, 26-27

marginal cost

CRA water, 31

efficient, 20, 59-61, 96

subsidies, 3, 62

Tier 2 pricing, 19, 60, 98

member agency, see MET

MET

Board of Directors, 13, 56

Jensen, Joseph, 32, 53

power shift, 40

conflict, see conflict or lawsuits

cooperative, 3, 6, 8, 11, 50-51, 55, 75, 80, 95-96, 109 
foundation, 11, 27

governance, 13

groundwater accounting, 87

growth, 32

import monopoly, 4, 34, 45

importance, 4

member agency heterogeneity, 1, 6, 11,

$17,23,32,42-44,52,55-57,60,63$,

$80,89,93,97,99$

revenue, $\mathbf{1 5}, 18,31,34,60$

$\operatorname{mix}, 42,58$

taxes, see assessed value

self-regulating, 13, 81

service area, 30, 31, 86

voting, 13, 52, 56

water and money buffers, 62

water supplies, see supply

Monterey Agreement, 38

Mulholland, William, 25

proposes MET, 27

Owens Valley, see Los Angeles Aqueduct

PGG, see experiments

postage stamp pricing, 16, 23

efficiency, 60

lawsuit, 6

wheeling charge, 5

preferences, see principal-agent, reliability, types

merged, 47, 49, 66-80

selfish, 6, 51-54, 65, 66, 80

social, $6,50-51, \mathbf{5 3}, 54-56,65,75$

preferential rights, 21, 43

challenged, 45

option, 100

price, see demand, postage stamp pricing

Board sets, 16, 39, 48

seasonal, 17

signals, 21-23, 61, 96

principal-agent

ignored, 13, 47, 49

private good, 2,6

Proposition 13, 39, 86

PSP, see postage stamp pricing

public good, 2 public goods game, see experiments

purchase orders, 23,60

Quantification Settlement Agreement, 6

Ramsey pricing, 59

reliability, 20, 47, 53

auctions, 98

growth, 3, 32, 61

Laguna Declaration, 32

perception, 86

preferences, 49-63, 99

rival good, 2

scarce, see abundance, drought, reliability

Scattergood, Ezra F., 26

SDCWA, see dependency, drought, wheeling

joins MET, 31-32

Seven Party Agreement, 28, 36

slack, 63

State Water Project, 4, 37-38

costs, 14,61

water source, $7,14,43$

storage, 14,55

charges, 17

Diamond Valley Lake, 14

excessive, 62-63

free-riding, 80

Lake Mead, 7

preferential rights, 22

reliability, see reliability

subsidies, see average cost, efficiency, fixed cost, LADWP, marginal cost, postage stamp pricing, wheeling

supply

allocation, 18

CRA, see Colorado River Aqueduct

desalination, 14, 45, 96

excess, 2, 17, 96

groundwater, 29, 109

depleted, 27, 31, 44

local vs. MET, 61, 93

SWP, see State Water Project

surplus, see efficiency

SWP, see State Water Project 
third-party impacts, 97

types, see cooperators, free-riders, reciprocators

water, see abundance, club good, Colorado

River, drought, land, MET, storage

allocation, $7,41,50,59-62,83$

auctions, 95, 107

base, $8,21, \mathbf{4 3}, 59$

lifeline, 97

no plan, 21

conservation, see demand

cost, 14

demand, see demand, elasticity, price

water managers, see cooperation, culture, preferences

experiments, 66-69, 75-76, 101-104

pro-growth, 3

rationing, 20-21

reliability, 20, 83

shirking, 47, 63

welfare, see efficiency

group, 53-54

markets, 52

Progressive ideals, 35

water in California, 13

Weymouth, F. E., 41

wheeling, see postage stamp pricing

barrier to trade, 96

cost calculation, 6,61

dispute, see lawsuits

MET-SDCWA, 4-6, 31, 41, 47, 58, 63 